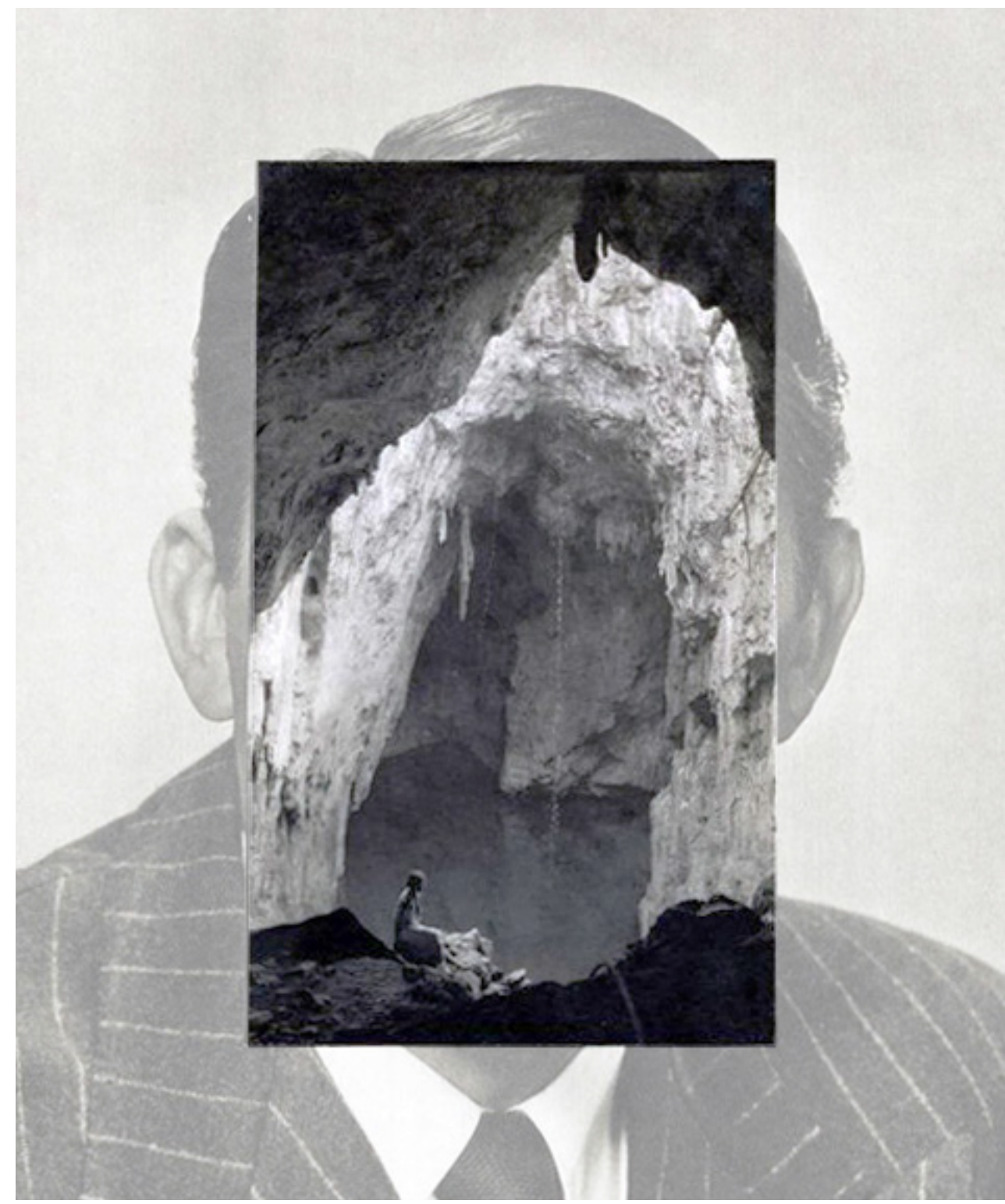

an architecture of imagery

anna f. pavia 



\section{Cover: Mask IV, 2005}

\section{John Stezaker}

The work of John Stezaker is preoccupied with the found image. Stezaker's images are decontextualized and exhibited as an infringement into the uncanny and sublime. The collage style illuminates and exaggerates unconscious elements of the contemporary world. The subjectivity of the imagery encourages a seeing into the beyond.

In early October of 2015, Mask IV was presented as an encapsulation of the initial ideas of this thesis - it has inspired the direction of the following work. 



\title{
AN ARCHITECTURE OF IMAGERY
}

\author{
by Anna F. Pavia \\ Bachelor of Architectural Science, Ryerson University, \\ 2014 \\ A thesis \\ presented to Ryerson University \\ in partial fulfillment of the \\ requirements for the degree of \\ Master of Architecture \\ in the Program of \\ Architecture \\ Toronto, Ontario, Canada, 2016 \\ (C) Anna F. Pavia, 2016
}





\section{AUTHOR'S DECLARATION FOR ELECTRONIC SUBMISSION OF A THESIS}

I hereby declare that I am the sole author of this thesis. This is a true copy of the thesis, including any required final revisions, as accepted by my examiners.

I authorize Ryerson University to lend this thesis to other institutions or individuals for the purpose of scholarly research.

I further authorize Ryerson University to reproduce this thesis by photocopying or by other means, in total or in part, at the request of other institutions or individuals for the purpose of scholarly research.

I understand that my thesis may be made electronically available to the public. 
An Architecture of Imagery

Anna F. Pavia

Master of Architecture 2016

Architecture Program, Ryerson University

\section{Abstract}

The development of ocularcentric culture can be traced through the modes and history of representation. The omnipotence of form and a visual aesthetic within contemporary architecture parallels this notion of visual primacy. The role of imagery within contemporary design practice is twofold: it is both a tool for investigating spatial realities and the product of a systematic design process. Emotive spaces are created when perceptual phenomena are in the vanguard rather than the aftermath of constructed objects. Through the reconsideration of image, as a multi-dimensional design tool, the spatial realities of the built context are investigated. Within film and contemporary media, architectural imagery combines with the temporal realm to enrich user perceptions of the built environment. The restoration of architecture as a communicative medium is facilitated by restructuring its current model from a formal object generated by a system of abstract geometries into a perceptual model. 


\section{Acknowledgments}

The completion of this thesis is owed to a distinguished few:

John Cirka,

who has encouraged and challenged this work with unwavering enthusiasm.

Our conversations are my most valuable token of this experience.

Arthur Wrigglesworth,

whose passion for design is contagious and inspiring.

Cheryl Atkinson,

for posing the difficult and necessary questions.

Lisa, David, Bianca and Eric,

for eagerly participating in all of the drafts that have amounted to this.

Filomena and Alberto,

for their warm company.

Joseph, Andrew, Julia and Jessica,

for their brazen honesty.

And finally, my MArch cohort,

for their unfailing support and friendship. 
To Rosanna and Mauro 


\section{table of contents}

Author's Declaration iii

Abstract $\mathrm{V}$

Acknowledgments vii

Dedication ix

List of Figures xiii

Introduction 1

1 | Communicating Culture 4

1.1 Evolving Perceptions 5

1.2 Modes of Communication 8

$\begin{array}{ll}1.3 \text { Through the Looking Glass } & 11\end{array}$

2 | Models of Perception 14

2.1 Modern Reception 15

2.2 Practising Habit $\quad 17$

2.2.1 Quotidian: Routine and Ritual 21

2.3 Design Research Proposal 23

2.3.1 Ritual Imagery $\quad 26$

3 | Reel Imagery 30

3.1 Cinema and the City 31

3.2 Utopian Cinema 33

3.3 A Day in the Life $\quad 39$

3.3.1 Thresholds of Juxtapositions 41

3.3.2 Quotidian Revisited 41 
4| Image as Communication $\quad 46$

4.1 Pictorial Monuments $\quad 47$

4.2 Architecture as Spectacle $\quad 48$

5 | Mediums of Imagery $\quad 54$

5.1 Lived Imagery $\quad 55$

5.2 Associative Imagery $\quad 59$

5.3 Investigative Imagery $\quad 61$

6 | An Architecture of Imagery 64

6.1 A Perceptual Design Model 65

6.2 House 1

6.2.1 Temporal Imagery $\quad 72$

6.3 House 2

6.4 Conclusion 85

$\begin{array}{ll}\text { Appendix A } & 88\end{array}$

Film Review + Analysis; Quotidian

Appendix B

94

Ritual Imagery; Quotidian

Appendix C

98

Schematic Design; House 1

Appendix D

118

Schematic Design; House 2

Bibliography

129 
Cover: Mask IV, 2005, John Stezaker

Source: Poynor, Rick and Essays. "John Stezaker's Collages: Maximum Resonance with Limited Means." 2003. Accessed August 29, 2016. http://designobserver.com/article.php?id=35958.

Editted by: Anna F. Pavia

Figure 1: House without Rooms, 1974, Raimund Abraham

Source: "Voyeurism \& Other Deviances Act II." Liem Than. Accessed July 29, 2016.

http://liemthan.com/voyeurism-1/.

Figure 2: Diagram of the Field of Vision, 1930, Herbert Bayer

Source: "Small.observations." Small.observations. Accessed July 29, 2016. http://smallobservations.tumblr.com/.

Figure 3: Le champ de l'oeil, 1950, James Gibson

Source: "From the Corner of Your Eye?...," April 7, 2013, accessed September 2, 2016. https://drjamesmcardle.com/2013/04/07/from-the-corner-of-your-eye/.

Edited by: Anna F. Pavia

Figure 4: Evolution of Representation

a. Notre-Dame de Paris, 1345

Source: "North and South Rose Windows, Notre Dame, Paris." May 3, 2013. Accessed July 29, 2016. https://enthusiastical.wordpress.com/2013/05/03/southern-rosewindow-notre-dame-paris/.

b. Rescue of St. Placidus, 1450, Fra Filippo

Source: Art, National Gallery of. "Saint Benedict Orders Saint Maurus to the Rescue of Saint Placidus." 2016. Accessed July 29, 2016. http://www.nga.gov/content/ngaweb/Collection/art-object-page.41620. html.

c. School of Athens, 1511, Raphael

Source: Gallery of can architecture make us more creative? - 4 (no date) Available at: http://www.archdaily.com/353496/can-architecture-make-us-more- cr eative/51598a80b3fc4b39b500005a-can-architecture-make-us-morecreative-image(Accessed: 29 July 2016).

d. The Ambassadors, 1533, Hans Holbein

Source: "The Ambassadors - Hans Holbein the Younger - Google Arts \& Culture." Accessed July 29, 2016. https://www.google.com/culturalinstitute/beta/u/0/asset/ bQEWbLB26MG1LA. 
e. Anamorphic Skull Detail

Source: “The Ambassadors by Hans Holbein." Accessed July 29, 2016. http://www.dodedans.com/Eholbein-ambassador.htm.

f. Self-Portrait, 1695, Rembrandt

Source: Accessed August 5, 2016.

https://i.ytimg.com/vi/rFMFH8Nf0Zw/maxresdefault.jpg.

g. Le goûter, 1911, Jean Metzingerf.

Source: Esaak, Shelley. "Picasso and the Avant-Garde in Paris." July 11, 2010. Accessed July 29, 2016.

http://arthistory.about.com/od/from_exhibitions/ig/Picasso-andthe-Avant-Garde/Tea-Time--1911.htm.

Figure 5: Printing Press, 1436, Johannes Gutenberg

Source: "Renaissance and Reformation." Accessed July 29, 2016.

https://jhalonimmuseum.wikispaces.com/

Renaissance+and+Reformation.

Figure 6: Views from the Train, 2015

Source: Anna F. Pavia

Figure 7: Charles-Édouard Jeanneret at the Acropolis, 1911

Source: “From Paris with Love." December 2015. Accessed July 29, 2016. http://frompariswithlove-becky.blogspot.ca/2015/11/le-corbusierat-pompidou-center-april.html.

Figure 8: Flaneur, Ceasefire Magazine

Source: Robinson, Andrew. Walter Benjamin: Politics of Everyday Life.

(Ceasefire Magazine), February 18, 2014.

https://ceasefiremagazine.co.uk/walter-benjamin-politics-everydaylife/.

Figure 9: Lonely Metropolitan, 1932 / 1969, Herbert Bayer

Source: "Archives." July 1, 2012. Accessed July 29, 2016.

http://catalog.org.uk/we-interrupt-this-transmission/.

Figure 10: Layers of Attention

Source: Anna F. Pavia

Figure 11: Therme Vals, 1996, Peter Zumthor

Source: Bridger, Jessica. Back to the Magic Mountain. (uncube magazine),

December 11, 2013.

http://www.uncubemagazine.com/blog/11664073.

Figure 12: The Practice of Everyday Life, 1984, Michel de Certeau

Source: Everyday Life. Accessed July 29, 2016.

https://i.warosu.org/data/tg/img/0209/93/1349398782286.jpg.

Figure 13: Transcriptions of Quotidian

Source: Subject X. Morning Routine. (2015). 
Figure 14: Conditions of Routine and Ritual

Source: "The Emotion Machine." The Emotion Machine. Accessed May 08, 2016.

http://www.theemotionmachine.com/routines-vs-rituals.

Figure 15: Extracted Rituals

Source: Anna F. Pavia

Figure 16: Ritual Acts Sequence

Source: Anna F. Pavia

Figure 17: Study Models; Movement Representation

Source: Anna F. Pavia

Figure 18: Agoraphobia, 2011, Franck Vervial

Source: "Agoraphobia, Par Franck Vervial." August 1, 2016. Accessed August 1, 2016.

https://www.flickr.com/photos/vervial/6326823480.

Figure 19: Man with a Movie Camera, 1929, Dziga Vertov

a. Still 1

Source: Dziga Vertov's Man with a Movie Camera (1929)liquid Architecture." Accessed July 29, 2016.

http://www.liquidarchitecture.org.au/program/dziga-vertovs-manwith-a-movie-camera-1929/.

b. Still 2

Source: "Man with a Movie Camera Review: Montage Spinning out of Control." July 23, 2015. Accessed July 29, 2016. https://silentlondon.co.uk/2015/07/23/man-with-a-movie-camerareview-montage-spinning-out-of-control/.

Figure 20: Andre De Toth, Phyllis Kirk and Vincent Price watching House of Wax in 3D, 1953

Source: "House of Wax Blu-Ray 3D Review." September 29, 2013. Accessed July 29, 2016. http://www.dvdizzy.com/houseofwax.html.

Figure 21: Tativille, Playtime, 1967, Jacques Tati + Eugene Roman

Source: "Rewriting the Statement ...." November 22, 2012. Accessed July 29, 2016

http://dip9.aaschool.ac.uk/rewriting-the-statement/.

Figure 22: Stills; Metropolis

a. Constructed Sets; Gothic Cathedral

Source: "Boiteaoutils: \# Film Architecture. From Metropolis to Blade Runner." Boiteaoutils: \# Film Architecture. From Metropolis to Blade Runner. Accessed November 27, 2015. http://boiteaoutils.blogspot.ca/2010/09/film-architecture-frommetropolis-to.html.

b. Opening Scene; The Heart Machine

Source: Covering Media. Accessed November 27, 2015. http://www.coveringmedia.com/movie/1927/03/metropolis.html. 
c. Subterranean Workers

Source: "Boiteaoutils: \# Film Architecture. From Metropolis to Blade Runner." Accessed November 27, 2015. http://boiteaoutils.blogspot.ca/2010/09/film-architecture-frommetropolis-to.html.

d. City Model; multi-leveled urban scheme

Source: "On the Set of Fritz Lang's Metropolis (1927)." 2016. Accessed July 29, 2016.

http://prettycleverfilms.com/galleries/on-the-set-of-fritz-langsmetropolis-1927/\#V5u4tLgrLIU.

Figure 23: Stills; Mon Oncle

a. Villa Arpel

Source: "Houselife." May 9, 2012. Accessed November 27, 2015. https://hotcharchipotch.wordpress.com/2012/05/09/houselife/.

b. Monsieur Hulot's apartment

Source: "Houselife." May 9, 2012. Accessed November 27, 2015. https://hotcharchipotch.wordpress.com/2012/05/09/houselife/.

c. Crumbling, "old Paris"/ new housing

Source: "Playtime - Jacques Tati - Paris Orly Airport." December 9, 2012. Accessed November 27, 2015. https://plazalondon.wordpress.com/2012/12/09/playtime-byjacques-tati/large_play_time_blu-ray2/.

Figure 24: Stills; Playtime

a. Bland ambiguity of "new Paris"

Source: "Playtime - Jacques Tati - Paris Orly Airport." December 9, 2012. Accessed November 27, 2015. https://plazalondon.wordpress.com/2012/12/09/playtime-byjacques-tati/large_play_time_blu-ray2/.

b. "Old Paris" is only seen in reflections of "new Paris"

Source: "Playtime - Jacques Tati - Paris Orly Airport." December 9, 2012. Accessed November 27, 2015. https://plazalondon.wordpress.com/2012/12/09/playtime-byjacques-tati/large_play_time_blu-ray2/.

c. Sterile environment of "new Paris"

Source: "Playtime - Jacques Tati - Paris Orly Airport." December 9, 2012. Accessed November 27, 2015. https://plazalondon.wordpress.com/2012/12/09/playtime-byjacques-tati/large_play_time_blu-ray2/.

Figure 25: Stills; Brazil

a. Sam's Workplace; Information Retrieval

Source: FilmGrabber. "Brazil." October 4, 2010. Accessed July 29, 2016. https://film-grab.com/2010/10/04/brazil/.

b. Urban landscape of Brazil

Source: FilmGrabber. "Brazil." October 4, 2010. Accessed July 29, 2016. https://film-grab.com/2010/10/04/brazil/. 
c. Sam's Escape; Les Espaces d'Abraxas

Source: FilmGrabber. "Brazil." October 4, 2010. Accessed July 29, 2016. https://film-grab.com/2010/10/04/brazil/.

d. Ms. Ida Lowry's apartment

Source: FilmGrabber. "Brazil." October 4, 2010. Accessed July 29, 2016. https://film-grab.com/2010/10/04/brazil/.

Figure 26: Manhattan Transcripts, 1981, Bernard Tschumi

Source: "Gallery of Bernard Tschumi on His Education, Work and Writings 6." Accessed July 29, 2016.

http://www.archdaily.com/548021/bernard-tschumi-on-hiseducation-work-and-writings/541468b2c07a80712f000063_ bernard-tschumi-on-his-education-work-and-writings_636_ manhattan_transcripts_3-jpg/.

Figure 27: Porta Vittoria, 1986, Steven Holl

Source: Holl, Steven. "Steven Holl. Porta Vittoria, Project, Milan, Italy, Passage Below Water Basin, Perspective and Plan. 1986." 2016. Accessed July 29, 2016. http://www.moma.org/collection/works/187.

Figure 28: Layers of Quotidian Revisited

a. Toronto, Venice, Marrakech, Paris, Barcelona, Madrid and Porto

Source: "Maps." Accessed July 29, 2016. https://www.bing.com/mapspreview.

b. Stills; Environments for Acts

Source: Anna F. Pavia

c. Stills; Threshold Documentation

Source: Anna F. Pavia

d. Acts of Rituals

Source: Anna F. Pavia

e. Stills; Morning, Midday, Evening

Source: Anna F. Pavia

f. Film; Quotidian Revisited

Source: Anna F. Pavia

Figure 29: Sydney Opera House, 1973, Jørn Utzon

Source: Photography, Matt Lauder. "B\&W View Sydney Opera House Sails Overseas Terminal View Landscape." September 12, 2015. Accessed July 29, 2016. https://mattlauder.com.au/main-photo-gallery/landscape-gallery/ sydney-city-nsw/sydney-opera-house-8/.

Figure 30: World Trade Centre, 1966, Minoru Yamasaki

Source: "9/11 Remembered: The Iconic Twin Towers Through the Years." April 4, 2013. Accessed July 29, 2016. http://www.nydailynews.com/new-york/world-trade-center-40thanniversary-gallery-1.1307674. 
Figure 31: Brazilian National Congress, 1964, Oscar Niemeyer

Source: Congress, Brazilian National. "Brazilian National Congress." Accessed November 21, 2015.

http://openbuildings.com/buildings/rid?keyword=brazilian+national+congress.

Figure 32: Guggenheim Museum, Bilbao, 1997, Frank Gehry

Source: "GUGGENHEIM'S MUSEUMS." July 14, 2015. Accessed July 29, 2016.

https://www.visionaireworld.com/blog/guggenheims-museums/.

Figure 33: Church of St. Peter, 1966, Sigurd Lewerentz

Source: Balters, Sofia. "AD Classics: St. Mark's Church in Bjorkhagen / Sigurd

Lewerentz." September 7, 2011. Accessed November 21, 2015.

http://www.archdaily.com/157478/ad-classics-st-marks-church-in-bjorkhagensigurd-lewerentz.

Figure 34: Explored Precedents

a. Jewish Museum, 1999, Daniel Libeskind

Source: Anna F. Pavia

b. Seona Reid Building, 2014, Steven Holl, Chris McVoy

Source: “Doublespace_architecture_steven_holl_glasgow_reid_school_of_arts-0038." Accessed July 30, 2016.

http://www.doublespacephoto.com/featured-projects/Glasgow-Schoof-ofArt/1/.

c. Bruder Klaus Chapel, 2007, Peter Zumthor

Source: Sveiven, Megan. "Bruder Klaus Field Chapel / Peter Zumthor." January 26, 2011. Accessed November 21, 2015. http://www.archdaily.com/106352/bruder-klaus-field-chapel-peter-zumthor/.

d. The High Line, 2014, James Corner Field Operations and Diller Scofidio + Renfro

Source: Anna F. Pavia

Figure 35: Images of Matter

a. Villa Savoye, 1929, Le Corbusier

Source: "La Villa Savoye - Ville de POISSY." July 8, 2016. Accessed November 21, 2015. http://www.ville-poissy.fr/index.php/cadre-de-vie/decouvrir-poissy/sites-etmonuments/la-villa-savoye.html.

b. Still; Nostalghia, 1983, Andrei Trakovsky

Source: Accessed August 6, 2016.

https://1.bp.blogspot.com/-XeAOXM- 4lko/V1Nb8Jo2cjl/AAAAAAAAG9g/ Cq3dbKRGZJgvbABXIKEUMCSGsHgvp1 kyACLcB/s1600/tumblr_ mstlqxNSat1rOwsxq03_1280.png.

Figure 36: Carceri d'invezione, 1749, Giovanni Battista Piranesi

Source: "Piranesi's 'Imaginary Prisons."” December 14, 2013. Accessed November 21, 2015.

http://www.italianways.com/piranesis-imaginary-prisons/. 
Figure 37: Exodus, or the Voluntary Prisoners of Architecture, 1972, Rem Koolhaas

Source: "Visual Atlas," March 19, 2011, accessed November 21, 2015. http://socks-studio.com/2011/03/19/exodus-or-the-voluntaryprisoners-of-architecture/.

Figure 38: Prairie House, 1961, Herb Greene

Source: Greene, Herb. "PRAIRIE HOUSE." Accessed July 29, 2016. http://www.herbgreene.org/GREENE\%20IMAGES/Architecture/ BUILT\%20WORK/ Prairie\%20House/PRAIRIE\%20HOUSE.html.

Figure 39: Para-Site, 1989, Diller + Scofidio

Source: "Diller Scofidio + Renfro." 1981. Accessed July 30, 2016. http://www.dsrny.com/projects/para-site.

Figure 40: Slow House, 1991, Diller + Scofidio

a. Constructed Slow House Model

Source: "Diller Scofidio + Renfro." 1981. Accessed July 30, 2016. http://www.dsrny.com/projects/slow-house.

b. Final Film Model

Source: "Slow House Final Film Model." July 30, 2016. Accessed July 30, 2016. https://www.flickr.com/photos/peterhess/2687299926.

Figure 41: Experimental Drawing; House 1

Source: Anna F. Pavia

Figure 42: Elements of Design Research

Source: Anna F. Pavia

Figure 43: Parti Models; House 1

Source: Anna F. Pavia

Figure 44: Framed Landscapes Study

a. Longitudinal Section

Source: Anna F. Pavia

b. Cross Section

Source: Anna F. Pavia

Figure 45: Layered Spaces Study

Source: Anna F. Pavia

Figure 46: Axes Intersection Study

Source: Anna F. Pavia

Figure 47: Framed Intersections Study

a. Stills

Source: Anna F. Pavia Northern Exterior View

b. Film

Source: Anna F. Pavia 
Figure 48: Northern Exterior View

Source: Anna F. Pavia

Figure 49: Spatial Sequence; House 2

a. Scenes

Source: Anna F. Pavia

b. Stills

Source: Anna F. Pavia

c. Film

Source: Anna F. Pavia

Figure 50: Void Axis Series; House 2

Source: Anna F. Pavia

Figure 51: Experimental Drawing; House 2

Source: Anna F. Pavia

Figure 52: Reviews of Lived Imagery

Source: Anna F. Pavia

Figure 53: Study Models; Movement Representation Source: Anna F. Pavia

Figure 54: Arrangement of Experiential Section Source: Anna F. Pavia

Figure 55: Parti Models; Component Exploration Source: Anna F. Pavia

Figure 56: Experimental Drawings Source: Anna F. Pavia

Figure 57: Scenes; Threshold Study Source: Anna F. Pavia

Figure 58: Parti Model; House 1 Source: Anna F. Pavia

Figure 59: Project Context, Idaho Springs, Colorado Source: Anna F. Pavia

Figure 60: Eastern Exterior View Source: Anna F. Pavia

Figure 61: Level 01

a. Entrance

Source: Anna F. Pavia

b. Interior

Source: Anna F. Pavia 
Figure 62: Axis Overview Study

a. Film

Source: Anna F. Pavia

b. Stills

Source: Anna F. Pavia

Figure 63: Orthographic Drawings; House 1 Source: Anna F. Pavia

Figure 64: Level 03 Source: Anna F. Pavia

Figure 65: Western Exterior View Source: Anna F. Pavia

Figure 66: Cross Section Study Source: Anna F. Pavia

Figure 67: Project Context

a. Project Site

Source: Anna F. Pavia

b. View; House 2

Source: Anna F. Pavia

c. Playter Estates, TO

Source: "Maps." Accessed August 1, 2016. https://www.bing.com/mapspreview.

Figure 68: Voided Axis Study; House 2 Source: Anna F. Pavia

Figure 69: Orthographic Drawings; House 2 Source: Source: Anna F. Pavia

Figure 70: Planar Sections; Physical Model Source: Anna F. Pavia 

an architecture of imagery 


\section{introduction}

Communication and information characterize contemporary culture.

The privileging of vision in Western culture has led to a surplus of visual imagery that serves as a platform for communication. Imagery is a collective medium of expression, propelled by the mass distribution of pictures and diagrams; it supports and advances an ocularcentric culture. Optics is the most prevalent mode of a user's perception of space - vision is the most influential of the senses in the formation of judgement.

The perception of the everyday environment poses a challenge for contemporary architectural practice. Within contemporary design, the esteem of form and aestheticism support ocularcentric culture but this design model only accounts for a small portion of the visual field. In this model, architecture is conceived as a transitory moment of a user's focal layer of attention. Architecture, however, is experienced through the peripheral sphere of consciousness. In contrast, a design model that foregrounds the perception of the user is more akin to how space is experienced and interpreted.

The development of transportation and camera technologies has played a critical role in the representation and distortion of the visual world. In particular, the optics of film has changed typical perceptions of space. As a tool with the ability to focus, deepen and reveal elements not caught by vision, film and camera technologies allow for a more thorough understanding of the built environment. Like cinema, architecture reconciles images of everyday life; both art forms define, focus and frame human interaction. The spectator experiences both cinema and architecture through the muscles and skin as much as the eyes. Investigating architecture through film gives way to a more comprehensive understanding of imagery's reception within familiar contexts. Camera technologies extend vision and give way to heightened levels of perception, awareness and understanding of space. Images are no longer used merely to document buildings, but rather to also explore visual and spatial realities. A perceptual design process is enabled when film is used as an investigative tool rather than a medium used solely to represent space. 


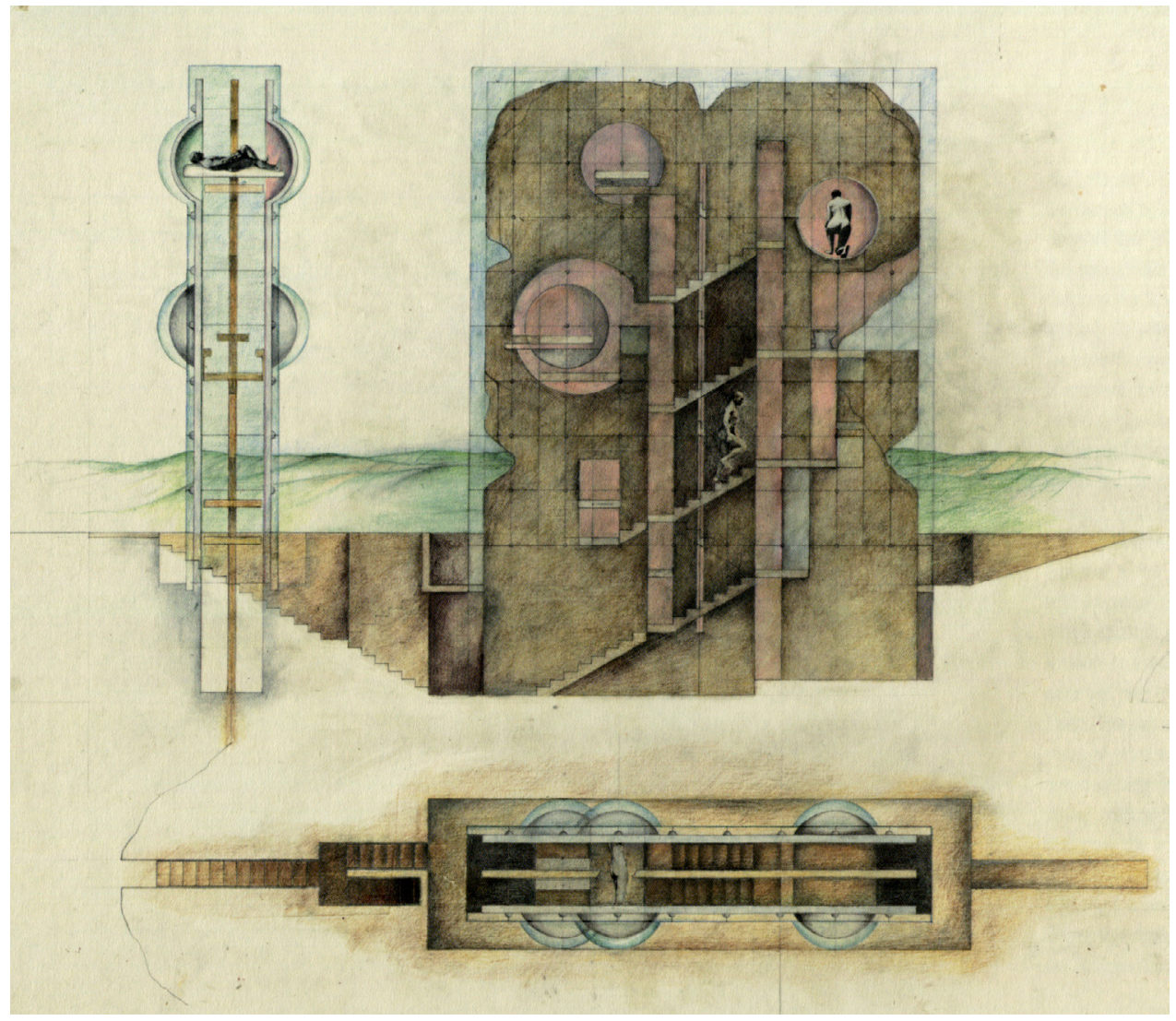

F.1 
Figure 1: House without Rooms,

1974

Raimund Abraham

Abraham explores the nature of dwelling by considering the emotive conditions within the archetypal house. The spaces of the house are carved out of a cliff; the drawing describes a space of solidity and seclusion. His other works communicate space through this consistent form of atmospheric imagery.
Imagery is a critical tool for representing and disseminating ideas and is the most universal tool for communication. This thesis reconsiders the image as a tool for exploring and representing the temporal qualities of space. Image is used as an optical, or other, still, of a moment in time. Furthermore, imagery is defined as a perceptual composition, a system of representational images.

This research considers the dwelling as a vehicle for exploring architectural imagery as it is the user's most familiar context. Given that the routine motions of the user within the dwelling are idealized through ritual activity, this research also examines and tests user routines and habits. Ritual is a multisensorial act that generates meaning but this thesis strips ritual of its religious connotations and instead represents the haptic component of the spatial experience. Ritual, in the context of this design research, is a meaningful moment that arises from convention or habit. By redefining imagery and ritual to explore the perceptual dimensions of form and function in contemporary architecture, this thesis restores architecture as a communicative medium through a design model that foregrounds the perceptual experience of its users. This work idealizes the textures of ordinary landscapes by reconsidering the use of imagery, peripheral vision and the pictorial plane in the development and visualization of space. 


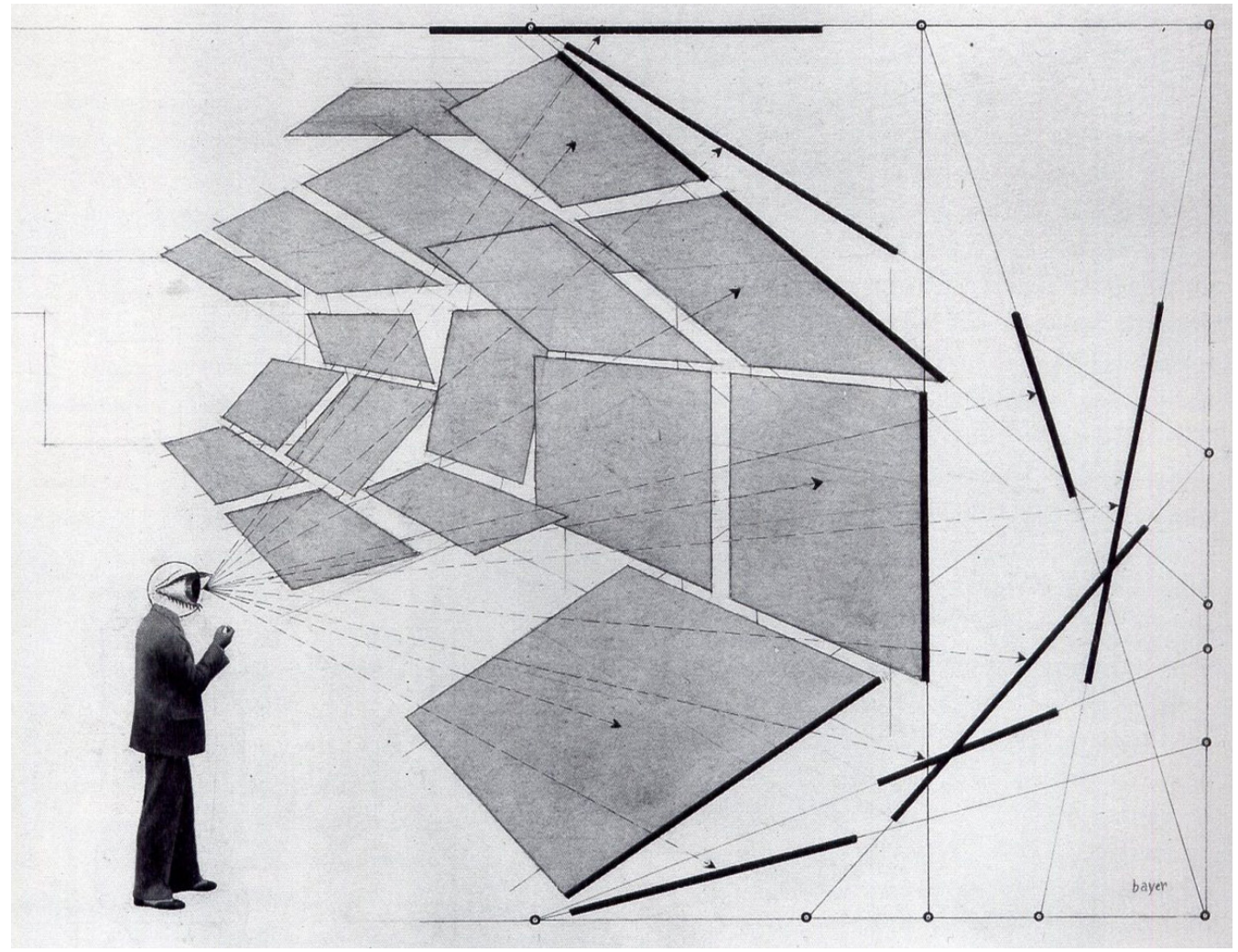

Figure 2: Diagram of the Field of Vision, 1930 Herbert Bayer 


\title{
1 | communicating culture
}

\author{
1.1 Evolving Perceptions
}

Perception is an interpretation of the sensory data screening processes, and a user's perception of space is an expression of this filtering process. Sensory data informs and communicates the culture of an environment. As the last of the senses to evolve, vision is the primary medium that data is fed through - it is the most principal means of gathering information. According to anthropologist Edward Hall:

Man's ability to plan has been made possible because the eye takes in a larger sweep; it codes vastly more complex data and thus encourages thinking in the abstract. . Man's evolution has been marked by the development of the 'distance receptors' sight and hearing. Thus he has been able to develop arts which employ these two senses to the virtual exclusion of the others. Poetry, painting, music, architecture and dance depend primarily though not exclusively on eyes and ears. ${ }^{1}$

Scholars of optical physiology and psychology determined how the perceptual faculties (eyes, brains, nerves and muscles) participate in informing the perception of an object. Vision is associated with nerve and muscle movements and these movements produce aesthetic and mental sensations. ${ }^{2}$ Maurice Merleau-Ponty, an early $20^{\text {th }}$ century phenomenologist and philosopher, describes perception as the inherent relationship between the optical image and the physical body. He quotes French poet Paul Valéry, "the painter takes his body with him,"3 to describe the intertwining of vision and movement that is needed to illustrate that which is embodied by the artist. The perception of the visual is impacted by the artist's physical presence in the world.

James Gibson, psychologist and visual perception specialist, discerned that learning occurs through interpreting meanings from various places: "A keystone in the arch of human understanding is the recognition that man at certain points synthesizes experience." ${ }^{4}$ Gibson was the first to distinguish between the visual field and the visual world; the retinal image is the former and that which a person perceives is the latter. The visual world is a composition of perceptions, memories and images conceived from both real and imagined places of respective experiences. ${ }^{5}$ Therefore, according to Gibson, all that is seen does not correspond to an actual reality, as there are infinitely subjective views on the appearance of the environment. 


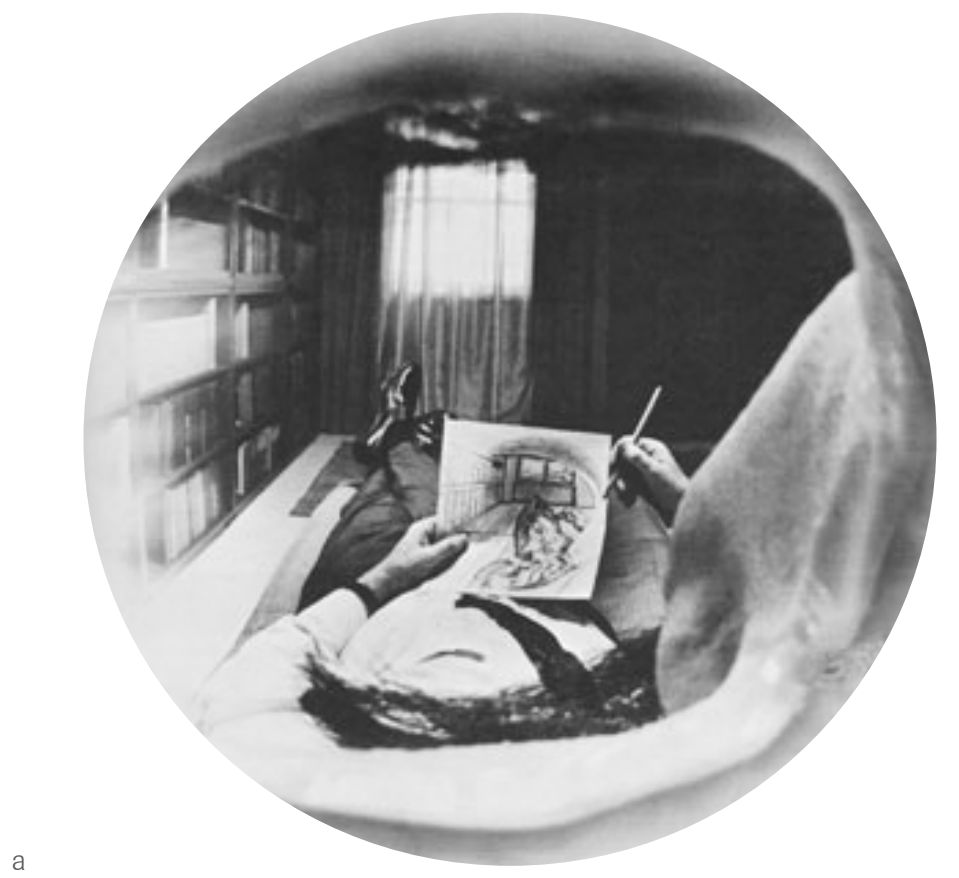

For Gibson, the selectiveness of the viewing process is based on the previous experiences of the viewer: "[The] image that we make for ourselves is different than the projection that is displayed to the retina." ${ }^{6}$ Additionally, the sensual engagement of the body is necessary to gain an understanding of space, as messages received through the body's nervous system stabilize the user's visual world. Perceptions of space exist within a continuous background that is dependent on a user's interpretation of the visual field. ${ }^{7}$ As a function of sight, vision is closely linked with understanding. Intellect, as a result of thought, is intertwined with vision and an integral part of perception.

Viewing spaces through interfaces condenses the full range of visual experiences. Projections through windows, paper or screens focus on objects and details. Architectural representation creates a platform for its users to participate in, interact with and reflect on. ${ }^{8}$ Peripheral vision, which focuses on spatial orientation, is imperceptible in conventional modes of architectural representation. It is not always possible to physically engage with distinguished architectural projects scattered around the globe, and conventional modes of representation in photographs and drawings address 


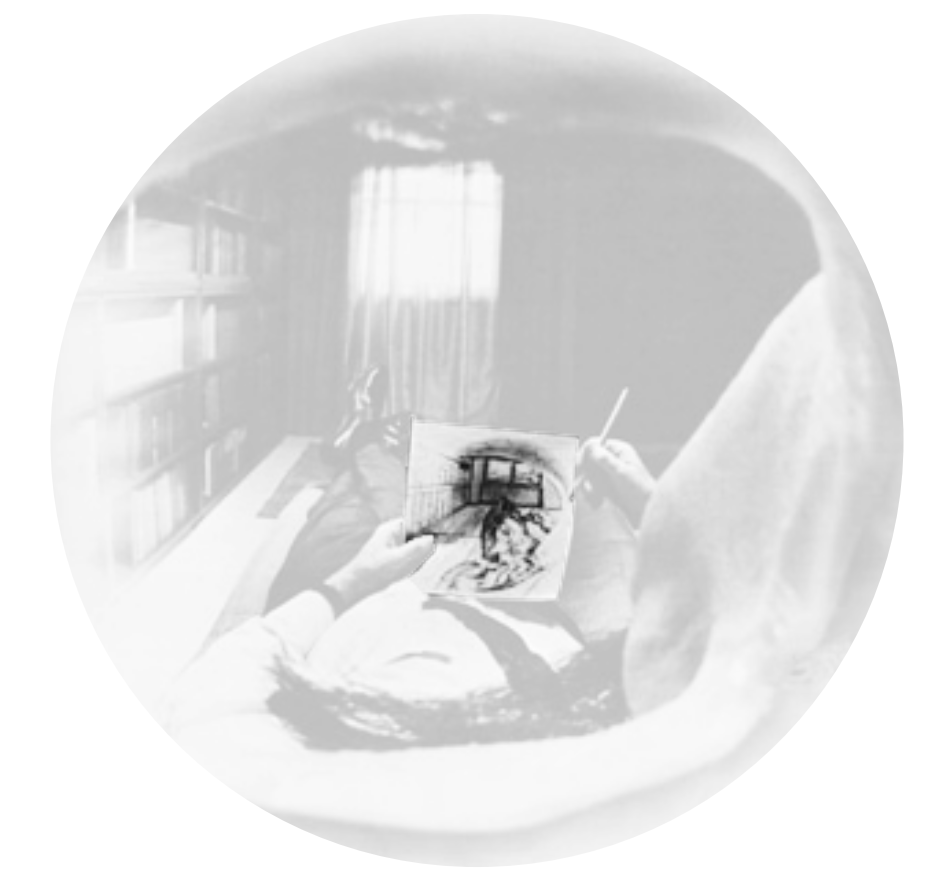

Figure 3: Le champ de l'oeil, 1950 James Gibson

a. Visual Field: retinal image

b. Visual World: interpretation of retinal image

only a small portion of the visual field. The medium through which space is viewed creates an additional layer of information about the space in question. ${ }^{9}$ Therefore, the judgements made of architectural space are a result of their manner of representation. This thesis considers the role of imagery as a tool to both visualize and embody the complexities of architectural space. Mediums of communication are critical to architects and designers as they dictate how a design will be received by its users. In order to advance conversations about architecture, virtual and other three-dimensional modes of visualization must be explored and utilized to disseminate design ideas. Typical modes of representation are focused on the foveal vision - the design approach of this thesis demands more engagement from the observer. As such, perception informs this design research. Using experimental imagery, this thesis has a focus on the peripheral awareness of the user. 

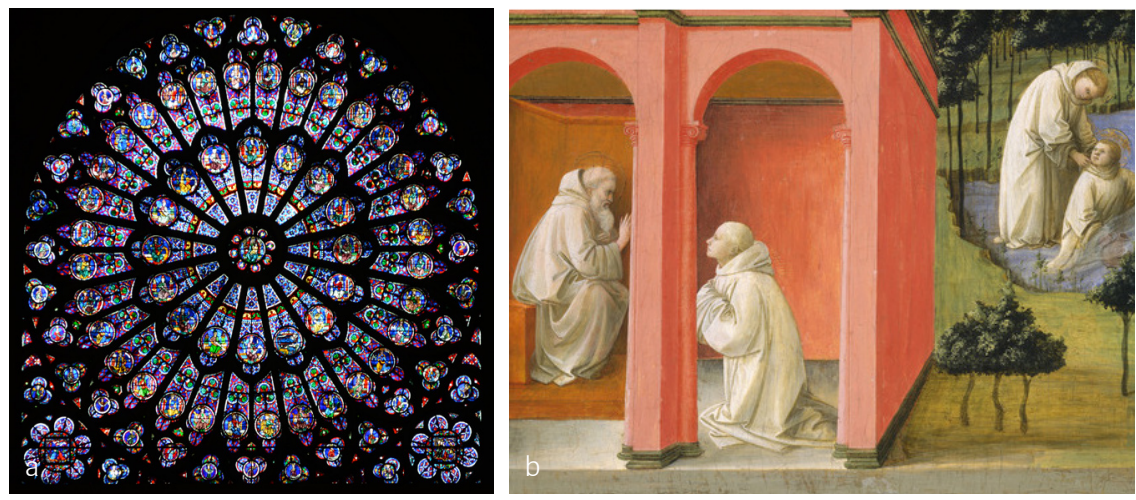

\subsection{Modes of Communication}

Early Greek culture illustrates the biases of the visual world. The Allegory of the Cave, in which Plato advises society to beware the tricks of imperfect eyes, demonstrates the illusions of sense perception. Painting, as a mode of imitation, was banned from the Republic as there was suspicion surrounding representation in ancient Greek culture. ${ }^{10}$ Within the Medieval Ages, a theological emphasis was placed on vision, especially within religious practice. Imagery was a way to educate the faithful: biblical stories were illuminated through the stained glass and carvings of Gothic cathedrals, and iconography informed the medieval Christendom. An analysis of paintings from the Middle Ages shows how artisans perceived the world. For instance, in Fra Filippo Lippi's Rescue of St. Placidus, the characters in the foreground are the same height as those in the background. ${ }^{11}$ This work reveals that medieval artisans did not distinguish between the visual world and the actual retina image.

Art and literature have always been rich mediums for exploring and understanding the perceptual world. The work of the Renaissance era was rapidly received because of its geometric order. According to historian Martin Jay, "Linear perspective with its dependence on optical principles seemed to symbolize a harmonious relationship between mathematical tidiness and God's will." ${ }^{2}$ The vantage point of the work was from the eye of the beholder and the spectator was the centre of the visual world. Linear perspective demonstrated the mastery of spatial representation and distinguished artisans' comprehension of the visual process through the accurate representation of the visual field. Renaissance artists explored linear perspective through several vanishing points, representing space with greater detail and complexity than their predecessors. The replication of pictures and diagrams using Johannes Gutenberg's Printing Press prompted the distribution of scientific knowledge across linguistic boundaries, and the replication of pictoral statements was considered to be as revolutionary as the replication of text. ${ }^{13}$ The technical improvements in representation continued into the $16^{\text {th }}$ century. Further, aided by the industrial revolution, vision quickly became the most dominant sense within the modern world. ${ }^{14}$

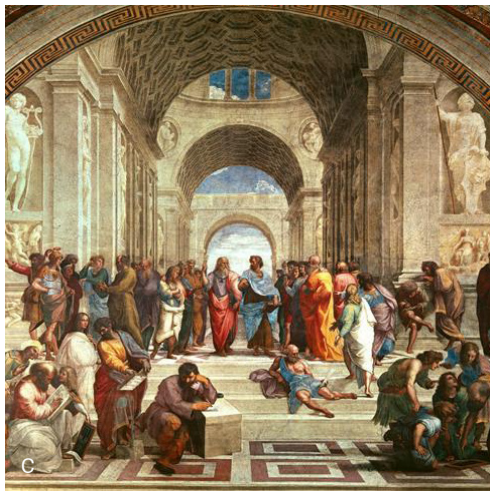

Figure 4: Evolution of Representation

a. Notre-Dame de Paris, 1345

b. Rescue of St. Placidus, 1450 Fra Filippo

c. School of Athens, 1511 Raphael

d. The Ambassadors, 1533 Hans Holbein

e. Anamorphic Skull Detail;

The painting demonstrates one of the first instances of anamorphic projections The blur of white in the lower portion of the frame, when viewed at an angle almost parallel to the pictorial plane, is actually the image of a skull. The work demonstrates an awareness and understanding of visual process.

\section{f. Self-Portrait, 1695 \\ Rembrandt}

g. Le goûter, 1911 Jean Metzinger 

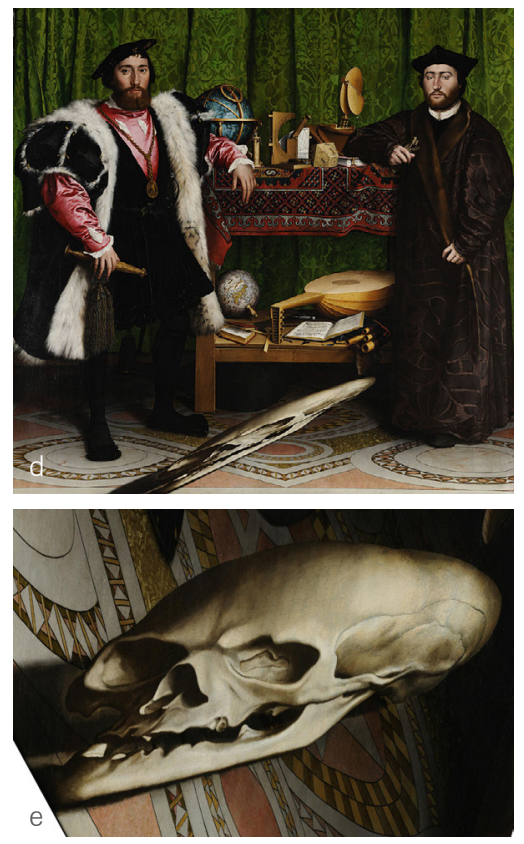
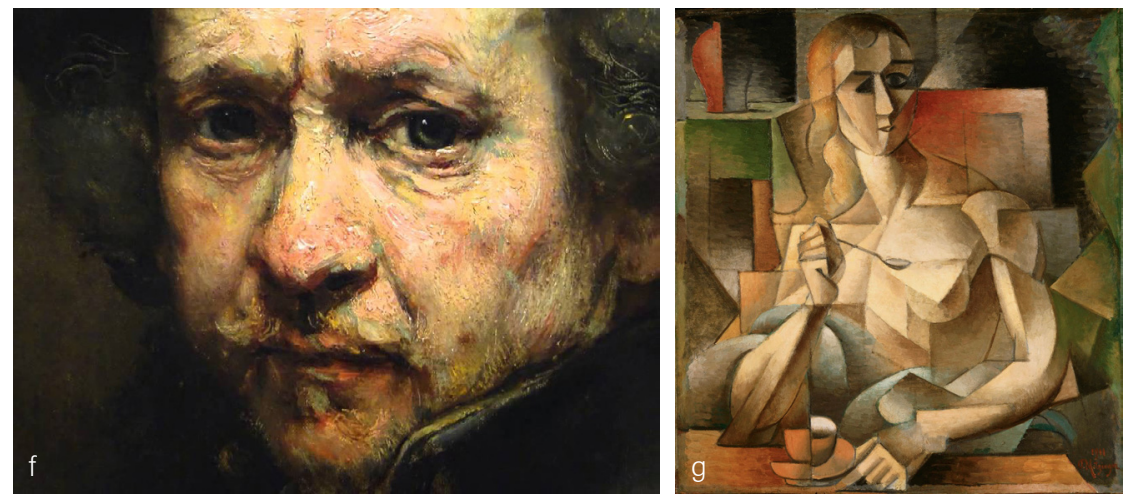

The Baroque era explored the sublime and object's changing representation in space. Artisans explored spatial planes by overloading visual apparatuses with images. The distorted, abstract character of Baroque art signalled an abandonment of realistic representations of the external world. The intentional distortion of images, through non-planar mirrors, was especially notable within anamorphic projections. ${ }^{15}$ Hans Holbein's The Ambassadors is one of the first anamorphic paintings to initiate an anti-ocularcentric discourse. Similarly, the paintings by Rembrandt Harmenszoon van Rijn used dramatic drawing techniques to emphasise the dimensionality of objects. His visually intense paintings were designed to trap viewers in a series of paradoxes. If the viewer's eye is held constant, the details appear sharp but then dissolve as one moves closer to the work.

The modern art movements of the $20^{\text {th }}$ century signal an evolving awareness and understanding of visual process. As an avant-garde movement, Cubism explored the whole through fragments. One of the primary aims of the movement was to demonstrate its capabilities as a medium. ${ }^{16}$ By depicting multiple viewpoints, Cubism evades the boundaries of perspective and creates an instant awareness of the entire composition of the object or setting. In addition to Cubism, other modern art movements, such as Impressionism, Surrealism and Expressionism considered the human visual process to produce distorted representations of reality. 

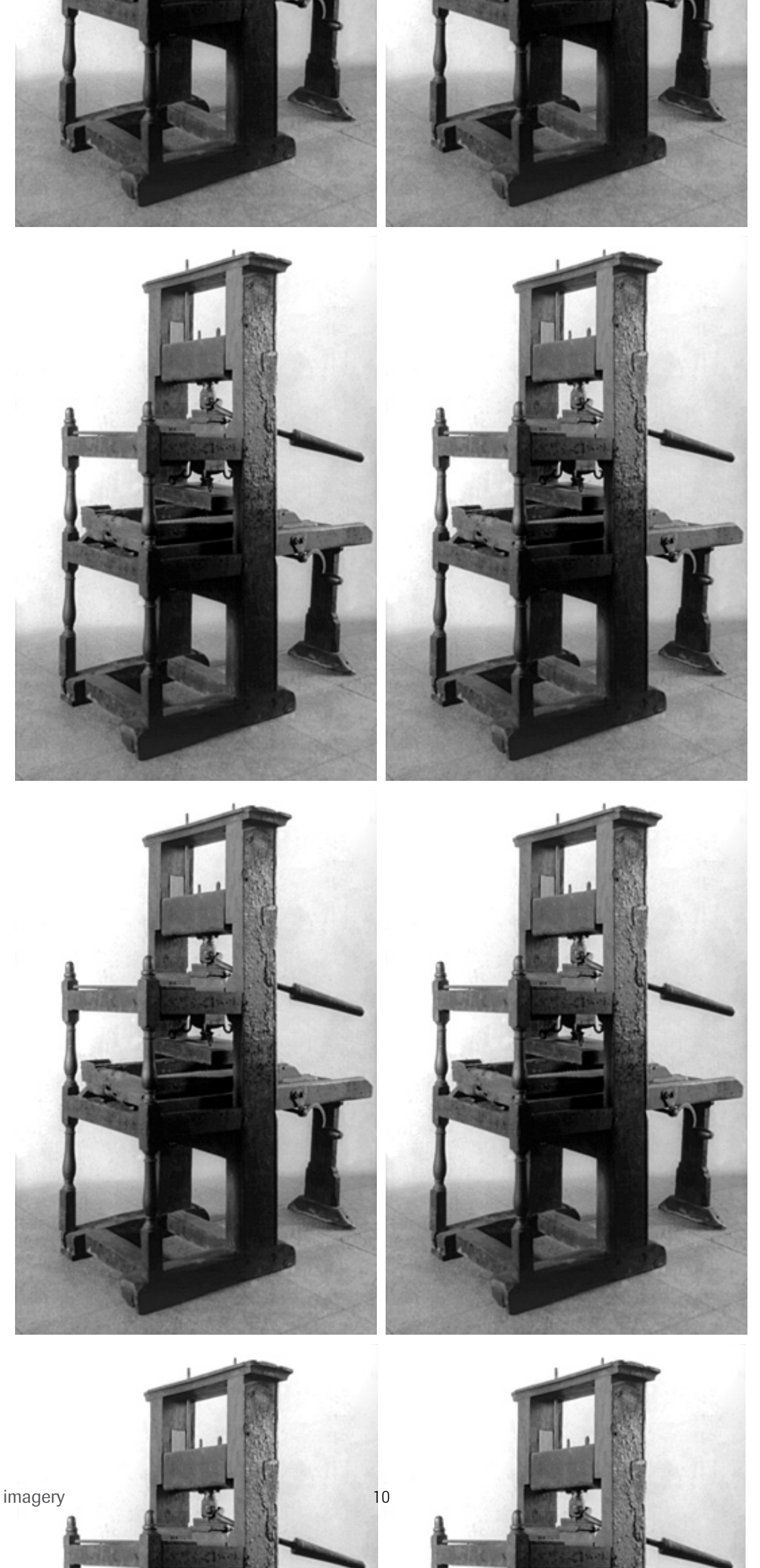


\subsection{Through the Looking Glass}

The modern visual paradigm considers representation to be that which the mind 'sees.' Rene Descartes highly regarded the invention of seeing-devices; to him, anything that heightened the power of sight, the most significant sense, was invaluable. Cartesian philosophy's exploration of ocularcentrism, ${ }^{17}$ which both privileges vision over the other senses and associates it with logical reasoning, considers the affiliation between speculation and observation. Speculation is the rational perception of clear, distinct forms of the unclouded mind. Observation, however, is based purely on sensory perception; the interaction of the senses results in knowledge through the interpretation of the environment. ${ }^{18}$

Figure 5: Printing Press, 1436 Johannes Gutenberg
The most common way of observing abstracted, architectural space, is through locomotion. Mitchell Schwarzer's Zoomscape, explores the illusion of distorted space, within an urban context, through the lenses of transportation and camera technologies. These mediums are criticized for flattening the perception of architectural aesthetics and altering the manner in which the built environment is viewed and interpreted. When experienced in motion, houses and entire cities are broken into fragments, pieces seen in succession as images that superimpose onto one another. ${ }^{19}$ The built environment is seen within frames and becomes committed to memory as the outline of a graphic, pictorial still. Architecture is experienced in this technologically-expanded visual field. Only upon arrival in new cities, on the roadside or on television are buildings seen as assemblages of intermittent spaces. ${ }^{20}$ By framing mediums, the observer watches through the machine, muddling constructions of space and time. Advanced visual tools, transportation and camera technologies encourage the dissemination of two-dimensional images of architecture.

The amount of accessible digital imagery provides an optical inhabitation of built settings within both a physical and temporally boundless setting. Digital images have changed how the user experiences and communicates about space. As discussed above, Medieval and Renaissance painters represented the city in ways that were visually and geometrically pleasing, whereas the contemporary representation depicts the city in motion. Standardized building practices catalyze a paradoxical repetition of scenery and experience. The machine-velocity of transport and framing technologies has changed both the representation and ways in which the viewer understands space. The feeling of traveling paired with going "nowhere new" 21 is a paradox that characterized modernism and prevails within contemporary consumer culture. The familiarity and sameness of perception anesthetizes the user. ${ }^{22}$

The city viewed through locomotion is remembered as an abstract composition of imagistic fragments. The medium through which information is transferred controls the scale and form of human association and action. ${ }^{23}$ Therefore, human senses, which all media are extensions of, ${ }^{24}$ configure perceptions of awareness and understanding. The new image that results 

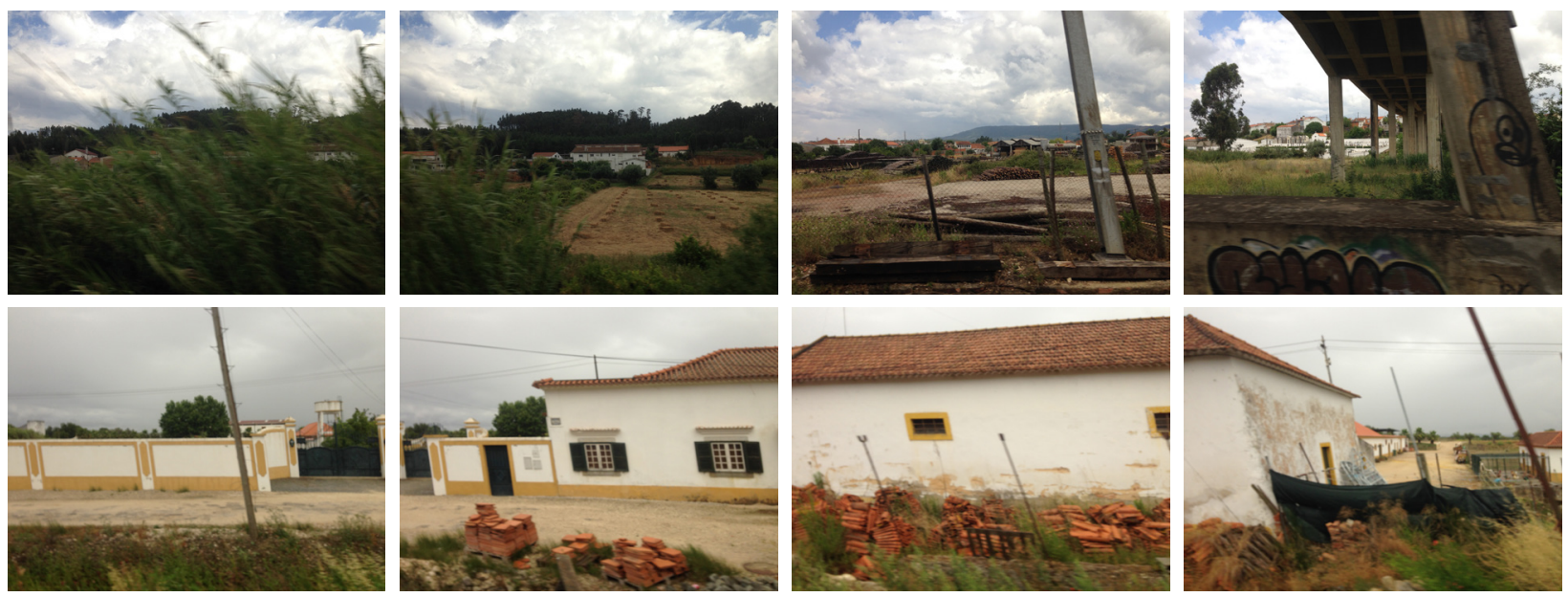

from breaking down and rearranging the city is similar to Bernard Tschumi's exploration in the Manhattan Transcripts. This alternative way of reading architecture - which rearranges the same elements - considers space, events and movement as independent of each other. ${ }^{25}$ Tschumi's design strategy is considered to be recombinatory architecture; space that is dispersed, rearranged in time and redefined.

Contemporary life is largely interpreted through vision, and its realities are masked by representation. Space is viewed through a variety of interfaces and is mediated back to the user through images. Serving political, commercial or artistic purposes, the image informs the user's understanding of the world. Tschumi pursues a perceptual design model and his work isolates and considers the experience of the user through a set of discontinuous scenarios in light of a formal composition or form. An architecture that heightens the user's awareness of space is the result. Tschumi's work addresses moments of action and highlights the viewpoints of the user while negating conventional modes of architectural representation. A modified perceptual model facilitates the development of this proposed design project by exploring how the user views, understands and communicates architectural space.

Notes

1 Edward T. Hall, The Hidden Dimension. (Garden City: Doubleday, 1966), 40.

2 Mitchell Schwarzer, Zoomscape: Architecture in Motion and Media. (New York: Princeton Architectural Press, 2004), 15.

3 Maurice Merleau-Ponty et al., The Primacy of Perception: And Other Essays on Phenomenological Psychology, the Philosophy of Art, History, and Politics, 8th ed. (Evanston: Northwestern University Press, 1964), 162.

4 Edward T. Hall, The Hidden Dimension. (Garden City: Doubleday, 1966), 66. 
5 Juhani Pallasmaa, The Eyes of the Skin: Architecture and the Senses. (Chichester: Wiley-Academy, 2005)

6 Jörg Kurt Grütter, Architektur Wahrnehmung = Architecture Perception. (Sulgen: Niggli, 2012), 10.

7 Edward T. Hall, The Hidden Dimension. (Garden City: Doubleday, 1966), 92.

8 Dalibor Vesely, Architecture in the Age of Divided Representation: The Question of Creativity in the Shadow of Production. (Cambridge: MIT Press, 2004), 4.

9 Marshall McLuhan, Understanding Media: The Extensions of Man (New York: McGraw-Hill, 1964), 24.

10 Martin Jay, Downcast Eyes: The Denigration of Vision in Twentieth-century French Thought. (Berkeley: University of California Press, 1993), 27.

11 Edward T. Hall, The Hidden Dimension. (Garden City: Doubleday, 1966), 87.

12 Martin Jay, Downcast Eyes: The Denigration of Vision in Twentieth-century French Thought. (Berkeley: University of California Press, 1993), 57.

13 Ibid.

14 Ibid., 45.

15 Ibid., 47.

16 Marshall McLuhan, Understanding Media: The Extensions of Man (New York: McGraw-Hill, 1964), 34.

17 "Ocularcentrism," July 23, 2016, accessed September 2, 2016, http://www. oxfordreference.com/view/10.1093/oi/authority.20110803100245338.

18 Martin Jay, Downcast Eyes: The Denigration of Vision in Twentieth-century French Thought. (Berkeley: University of California Press, 1993), 33.

19 Mitchell Schwarzer, Zoomscape: Architecture in Motion and Media. (New York: Princeton Architectural Press, 2004), 13.

20 lbid., 21

21 Ibid., 25.

22 Ibid.

23 Marshall McLuhan, Understanding Media: The Extensions of Man (New York: McGraw-Hill, 1964), 24.

24 Ibid., 23.

25 Mitchell Schwarzer, Zoomscape: Architecture in Motion and Media. (New York: Princeton Architectural Press, 2004), 26. 


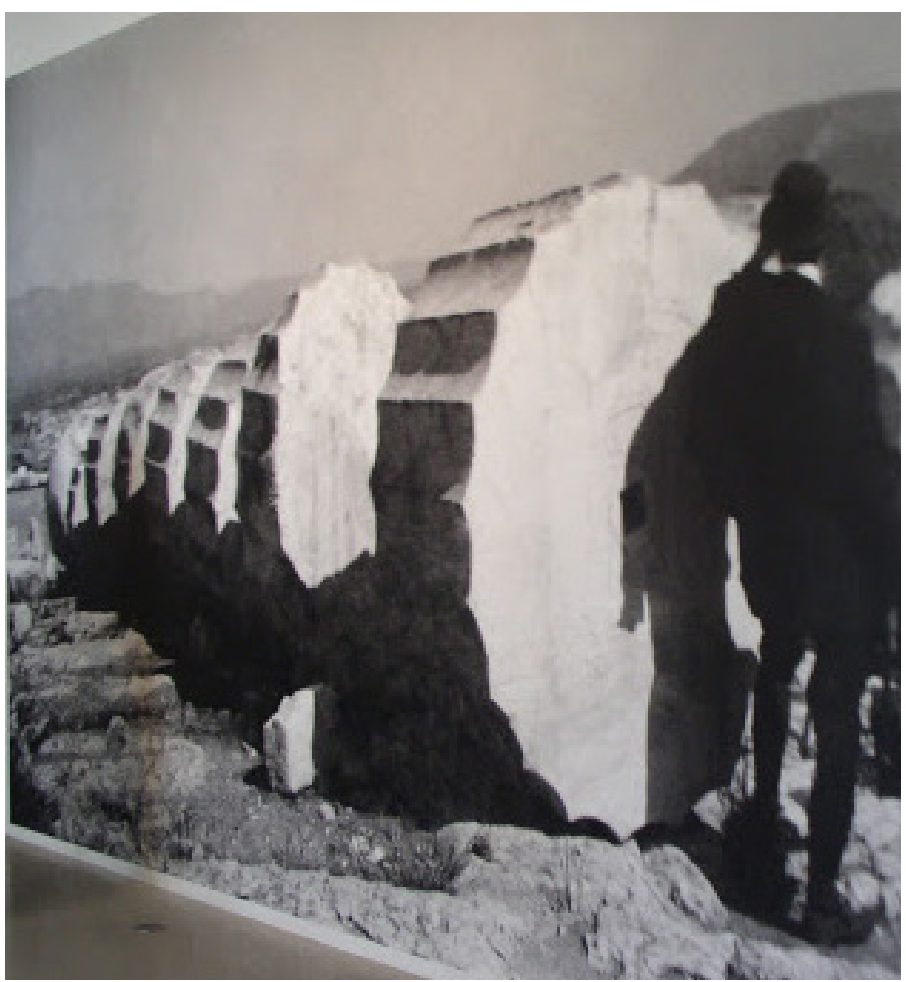

Figure 7: Charles-Édouard Jeanneret at the Acropolis, 1911 


\section{2 | models of perception}

\subsection{Modern Reception}

At the end of the $19^{\text {th }}$ century, the rapid growth of European cities led to the development of the modern metropolis. Modernist culture aimed to interpret and explain the phenomena of the new urban context. The city became the subject of analysis in the developing fields of sociology, psychoanalysis, psychology and political geography. The city's spatial conditions were blamed for the emergence of a series of diseases. George Miller Beard identified neurasthenia, weakness of the nerves, as the most common mental disease of modern life. 'The physical state of the new cities rendered modern life a harsh contrast to life in traditional European cities. Another disease, Agoraphobia, discovered by Henri Legrand du Saulle, was considered to be a unique nervous disorder having to do with anxiety or discomfort in vast empty places. Viennese architect, Camillo Sitte states, "the universal trend of the time was the fear of open spaces."2 Modern scholars saw the lack of boundaries within the visual fields of New Urbanism as the cause of mental distress.

Le Corbusier, a pioneer of modern architecture, considered the effect of the modern context on the individual. His concept of ineffable space was a transcendent space that prompted an emotional response from the user, ${ }^{3}$ and was developed on his travels to the Acropolis in 1933. Le Corbusier's journey evoked fear, awe and terror that contributed to his appreciation of spatial experience. He detached the Parthenon as an object within space and instead classified it as part of the sublime. For Le Corbusier, the creation of ineffable space was necessary to eradicate the phobias of the metropolis. Ineffable space can be penetrated by light and air. ${ }^{4}$ Adopting themes of transparency from $18^{\text {th }}$ century building, modernists assumed that a glass city would be visually and socially open and therefore free of mental disturbance.

Within the critique of modern architecture, the urban street was also considered by modernist thinkers. The modern street is a mere passage that the body moves through in its daily routine. In The Work of Art in the Age of Mechanical Reproduction, modern cultural critic Walter Benjamin criticizes the reception of the built environment: "Architecture has always represented the prototype of a work of art that is received in a state of distraction and by the collective." ${ }^{5}$ According to Benjamin, the urban dweller is made bored by the excessive visual stimuli within the city and seeks relief from the conditions of routine. As such, within modern life, there is an obvious need for entertainment as well as distraction. 

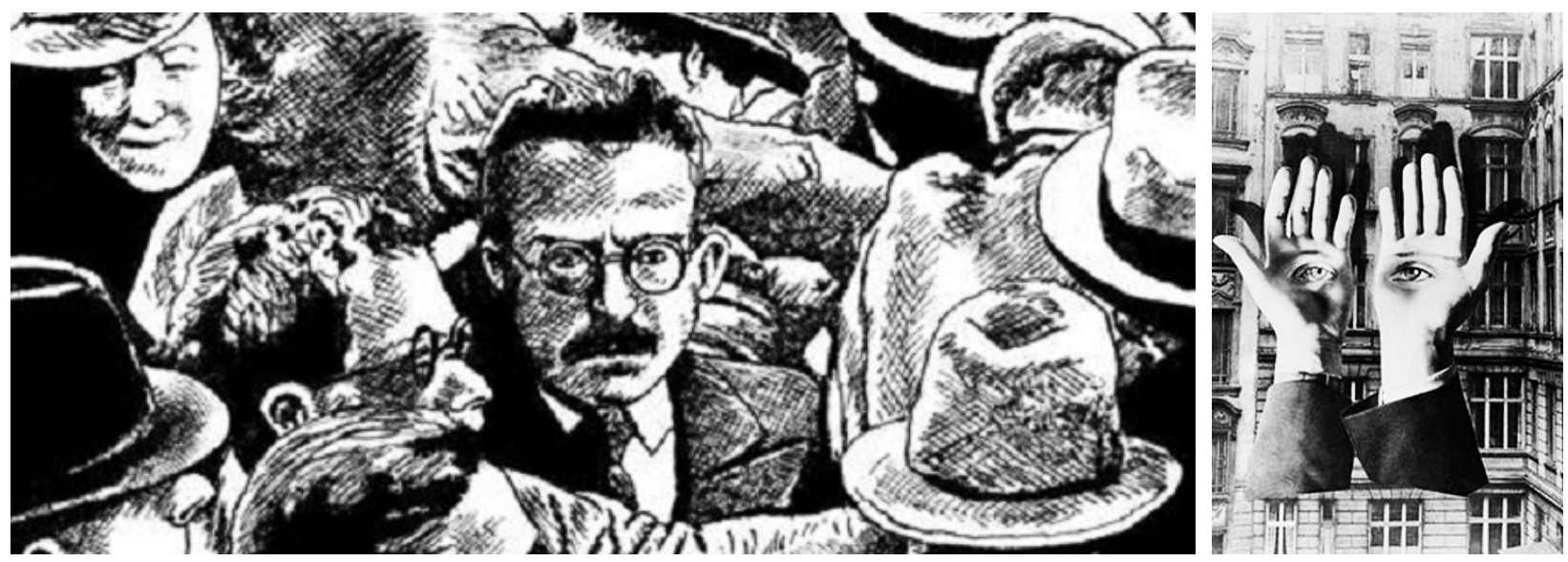
F.8

F.9

Klaus Reigel, a mid-19th century psychologist, suggests through a historical analysis of visual cultures, that the solution to distraction within the Metropolis is developed through both the tactile and optical senses:

Buildings are received twofold: through how they are used and how they are perceived. Or to put it in a better way: in a tactile and an optical fashion. No idea of such reception is conveyed by imagining it as it takes place collectedly - as in the case amoung tourists, for example, ogling famous buildings. The fact is, there is not, on the tactile side, any counterpart to what on the optical side constitutes contemplation. Tactile reception does not occur both through the medium of attentiveness and at the same time through that of habit. As regards to architecture, the latter largely determines even optical reception. The truth of the matter is that this also tends to occur very much in a state of close attention than in one of casual observation. ${ }^{6}$

Individuals perceive architecture in perceptual states of distraction; therefore, the perception of the everyday environment presents a challenge to contemporary architectural practice. Distraction constitutes the absentmindedness of users within a state of habitual activity. Within contemporary society, excessive media distracts and depletes the well-being of the psyche and vitality of space. The contemporary architectural design model must be reconsidered - the phenomenal experience of the user should be foregrounded throughout the design process.

Figure 8: Flaneur, Ceasefire Magazine

Figure 9: Lonely Metropolitan, 1932 / 1969 Herbert Bayer 

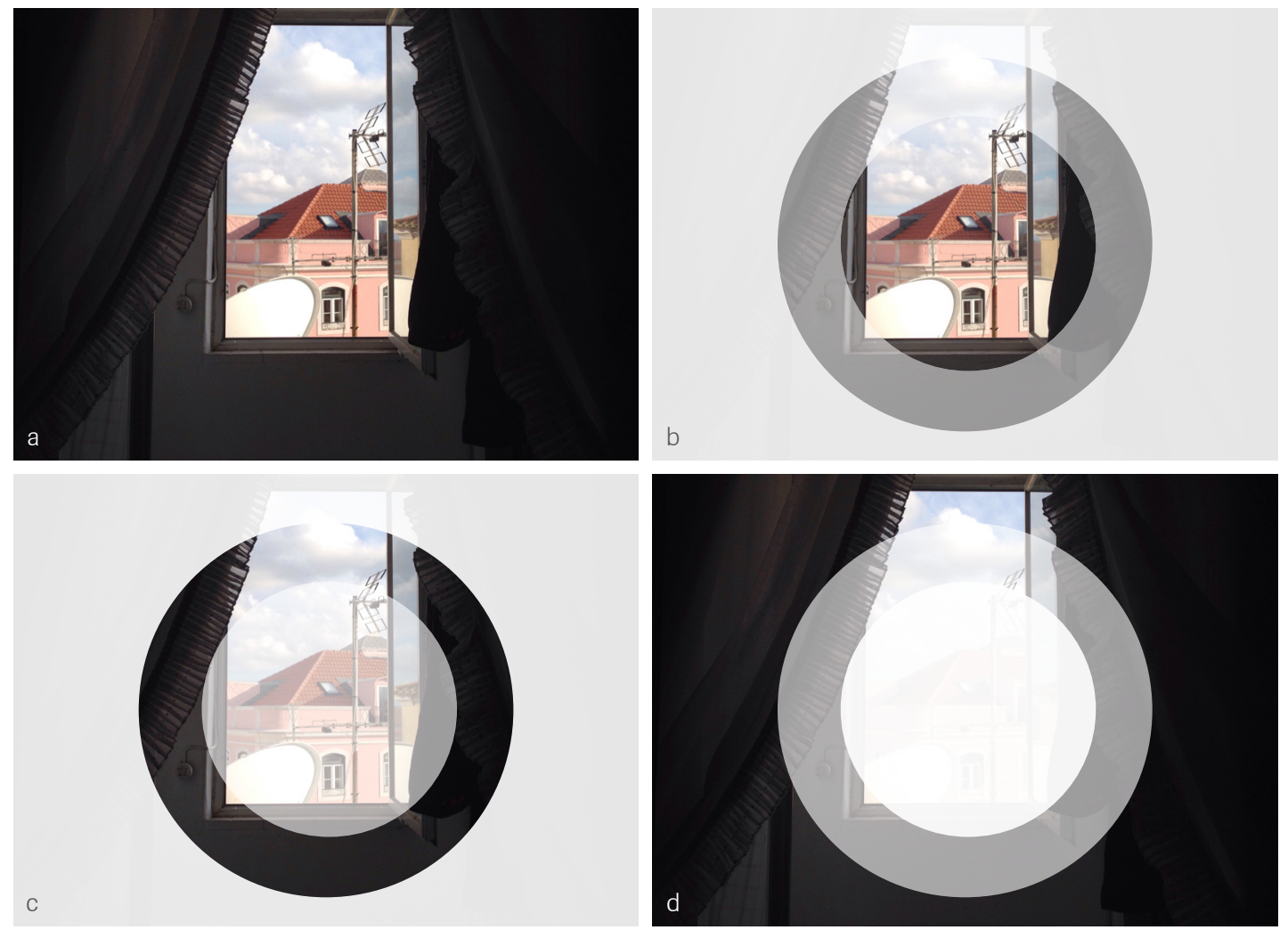

Figure 10: Layers of Attention

a. Lisboa, 2015

b. Theme

Focal attention: House

(focus of foveal vision)

c. Thematic field

Context for focus: Window frame

d. Marginal awareness

Peripherals: Room/ Curtains

\subsection{Practising Habit}

Architectural objects are not central to or the focus of everyday life. Architecture exists at the margins of the everyday, in the peripheral sphere of consciousness. Phenomenology examines the structures of consciousness as experienced from a first-person point of view. Within the phenomenological framework, there is not a single kind of attention; rather, attention shifts within the ever-changing environments of everyday life. According to phenomenologist Aron Gurwitsch's tripartite model of attention, ${ }^{7}$ focal attention is the first layer of attention; this layer hosts the foveal vision where visual acuity is highest. The thematic field is the second layer and is the context of the focal attention. The third and final layer is a state of marginal awareness; this periphery is the most relevant to the discussion of the experience of architecture. The experience of architectural space is an active interplay between the perceiver and their surroundings. The contents of the three fields of attention are constantly interchanging - a change in environment triggers a shift in attention. The discussed layers deliver information about the conditions of the environment to the perceiver.

Atmosphere, the primary constituent of daily experience, is the mood and ambiance of space. The relationships between architectural juxtapositions, such as light, shadow, material, scale, users' emotions and recollections all encompass atmosphere. According to Gurwitsch, the marginal layer of 


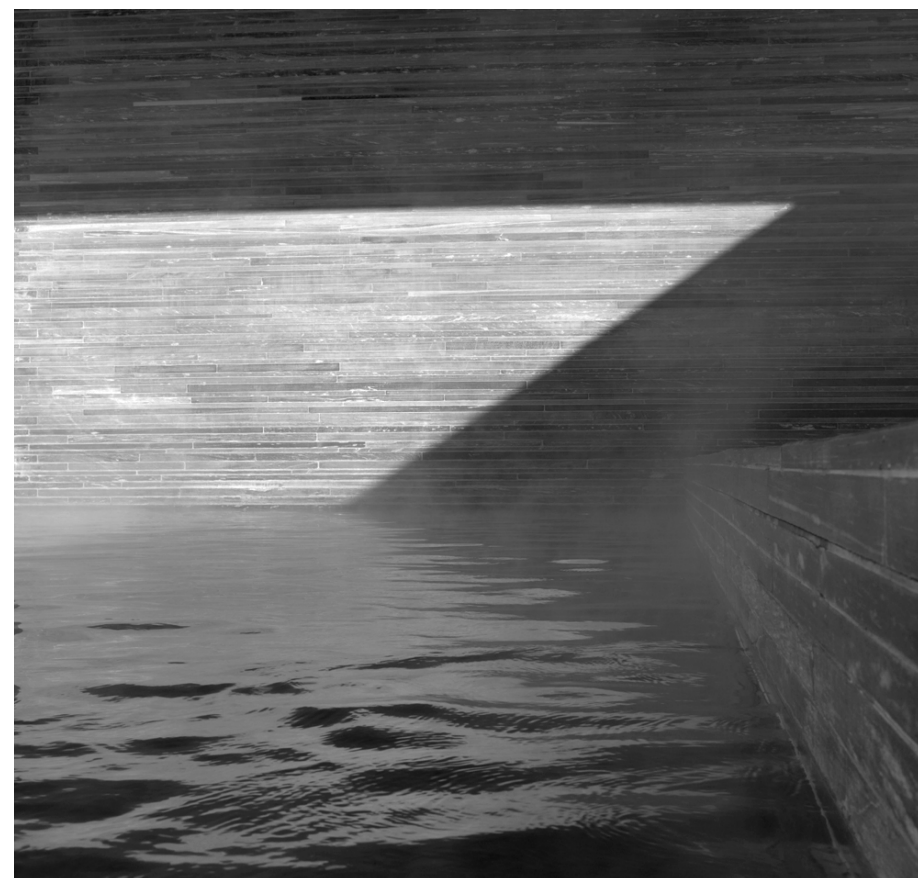

perception recognizes atmosphere. Finnish architect and phenomenologist Juhani Pallasmaa, describes atmosphere as the sensorial and emotive impression of a setting, and that which provides the character of a place: "Indeed, the immediate judgement of the character of space calls for our entire embodied sense, and it is perceived in a diffuse and peripheral manner rather than through precise and conscious observation." ${ }^{8}$ Atmosphere is perceived before conscious identification, intellectual understanding or reflection. When it provokes emotions and memories, atmosphere can be consciously recognized and acknowledged. In Swiss architect Peter Zumthor's discussion of the design of the Therme Vals, the location of the site and the purpose of the building are described in primordial terms. He refers to the mountains, rock and water but comments very little on the visual content of the space or the arrangement of volumes ${ }^{9}$ - the language used merely refers to the atmospheric conditions of space.

The dwelling hosts the most familiar and common atmosphere. The events that occur within the dwelling consist of a cycle of ordinary acts and humble rituals. These ritualistic spaces host primitive activities; for example, the kitchen is a space to prepare and share meals. ${ }^{10}$ The experience of entering or being at home evokes various kinds of environmental awareness, but there is no objective recognition or appreciation of the larger built surrounding. As the most familiar place, a sense of orientation in the dwelling is not necessary; the built space is ignored and only the textures and senses of personal belongings 


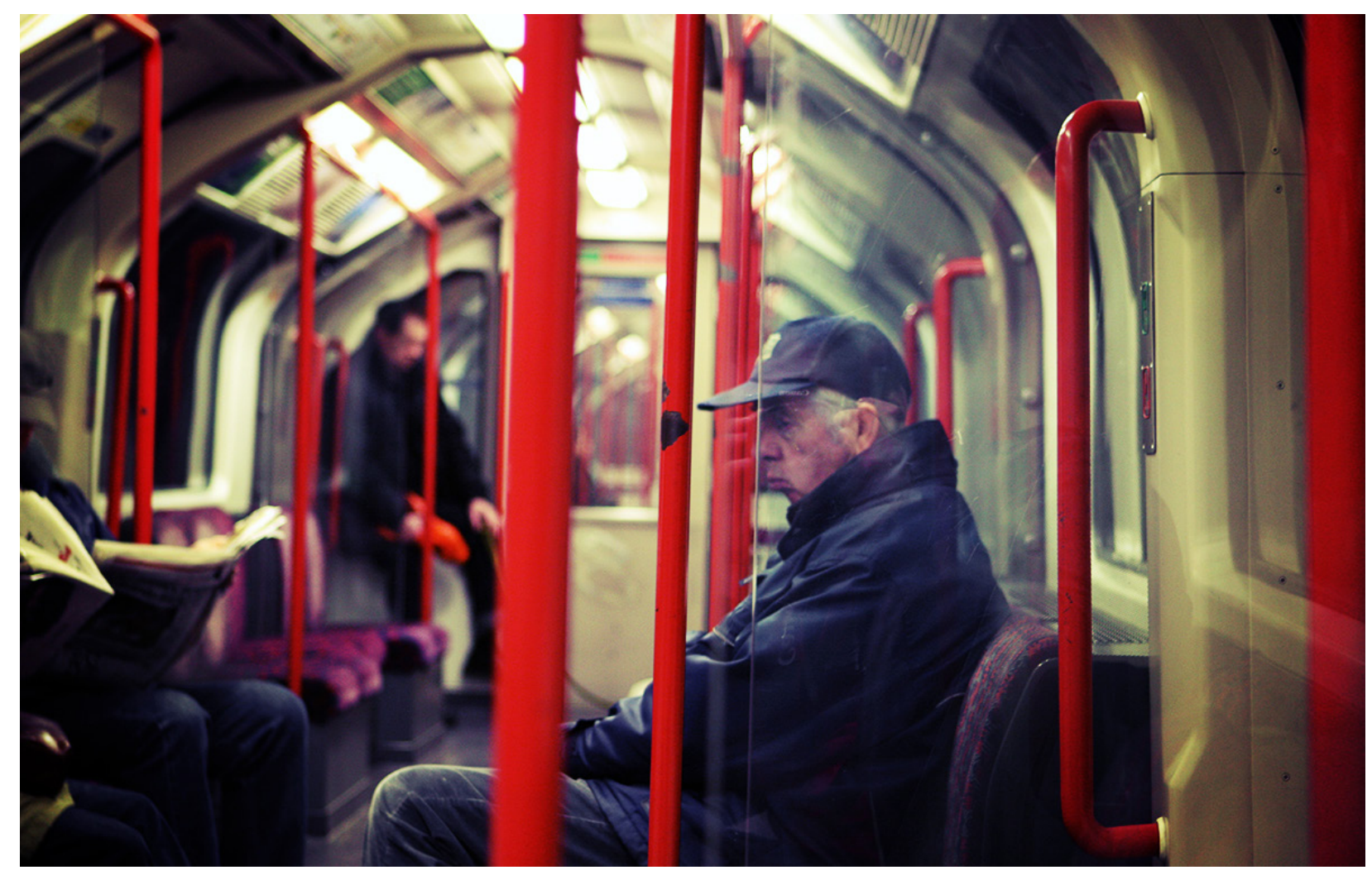

Figure 12: The Practice of Everyday Life, 1984

Michel de Certeau exist. As Pallasmaa states, "the experience of the home is structured by distinct activities ... not by visual elements." ${ }^{11}$ Similarly, Alvar Alto constitutes the experience of place as an action; he places more value on the act of entering a space than the visual elements of a doorway. Distinct contrasts between light and shadow, enclosure and view, solitude and participation, quietude and sound, and intimacy and openness characterize architectural spaces that respond to the dweller's dynamic mental and emotive states. The dwelling's seasonal changes and environment illustrate its temporal qualities. A perceptual exploration of space uses verbs rather than nouns to describe authentic architectural experiences. An architecture that engages its users as active participants within the public realm of cities is necessary to be investigated as it is the environment in which the routines of everyday life are conducted.

The repetitive and unconscious character of everyday life distinguishes it from other aspects of daily existence. In The Practice of Everyday Life, Michel de Certeau explores the appropriation of everyday situations and considers the ways in which people individualize mass culture. For de Certeau, ordinary people demonstrate creative resistance in the conventional acts of doing, walking, talking, reading, dwelling and cooking. His work focuses on the everyday practises and characteristics of consumers and his bottom-up approach enables him to explore consumer interpretations of products, rituals, representations, laws and cultural images. In de Certeau's investigation of the 


\section{Attempt 1: Routine}

"I woke up at 7:00 a.m., feeling annoyed because my alarm was buzzing in my ear and I didn't want to get up because I was tired. I got dressed and was feeling confused because I didn't know what the temperature outside was, short sleeve or long sleeve?

Because I was cleaning my room yesterday, I felt clean making my bed. Walked to the washroom to do my hair, I was hoping to do my hair well to impress the girls at school. I rushed it because I was tired. I pulled out my toothbrush, brushing my teeth, feeling fresh and awake. When I washed my face, I was feeling no longer tired but wide awake.

I walked downstairs to eat my breakfast. All-Bran is the worst cereal I've ever had but it's all I had. I then watched Life with Derek. That's my favourite show to watch in the morning and felt so happy that there was a new episode.

Then I got my bag and that depressed me because all I was thinking is 6 hours of hell that was awaiting for me in under 20 minutes.

Before I left, I mouth-washed to still have that fresh feeling and put on some deodorant to seem manly. As I walked out the door, I felt the cool breezy feeling that fall was coming."
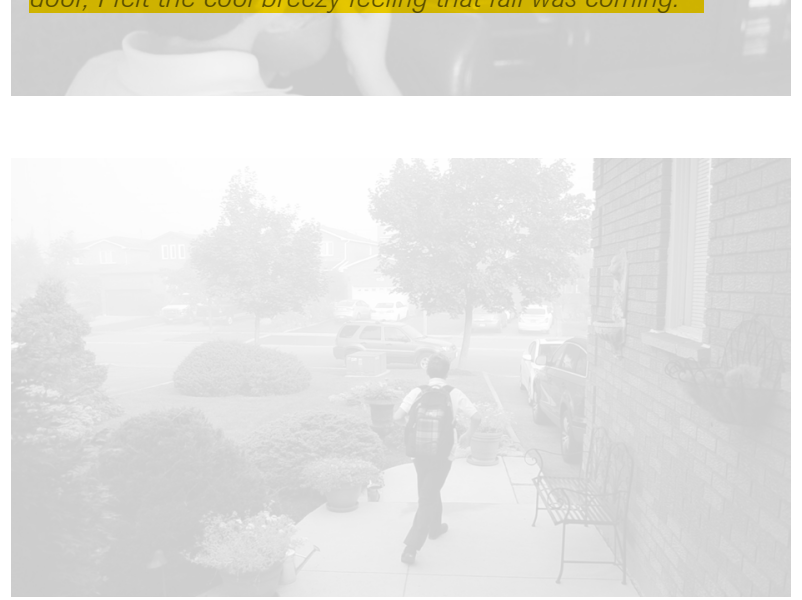

Attempt 2: "Backwards"

"It felt weird that I was walking backwards. It felt so different, I was scared if I was going to run into something-it's not normally what I do every day.

I got dressed facing the opposite side of the mirror. It was hard to see how I looked in my uniform. I double- checked my collar because I couldn't see myself. I needed to check to see if I looked ok. And then I made my bed and it was weird because I'm walking backwards. I would touch everything and keep aware of my surroundings by touching the walls and doors to make sure I was going in the right direction.

After I made my bed, I went to freshen up, do my hair. I wasn't looking in the mirror, which affected how my hair looked. I took shorter to do my hair, because if I had been looking at my hair I would have noticed all the defects and try to fix it.

Then I brushed my teeth, it was harder because I wasn't looking and the toothpaste dripped down. Then I washed my face. I went downstairs after that. It was difficult; I had to take each step with caution. I was holding onto the railing in case I fell.

Then when I got downstairs, I went to have a yogurt and then I got my lunch ready. I guess it was harder to find what I was looking for. Then I prepared my bag, I couldn't see what I was doing. I was touching the baseboards- making sure I was going in the right direction.

Then I went back upstairs to freshen up, which was difficult, it was easier going up, so if I was to fall, it'd be safer.

Then I directed myself to the bathroom, it was weird because I was mouth-washing and putting on my deodorant all backwards and I couldn't see what I was looking at. Then I walked downstairs backwards, I was making sure that I didn't fall.

Then when I got to the bottom, I put on my shoes which was normal, because I was looking at my shoes. Then I walked outside and it was hard and dangerous. When I was walking on the driveway, I had a slim path to walk on between the curb and the parked car, so I chose to walk on the grass instead, because if I was to fall, I wouldn't damage anything. Then I walked on the curb and I couldn't really see what was going on behind me. I couldn't really see if cars were coming." 
Figure 13: Transcriptions of Quotidian

Subject: 15 year old male

Act: Morning Routine, preparing for school

Hypothesis 1: Subject will likely report on the emotional aspects of livedexperience:

_attentive/ inattentive, reflective/ pre-reflective, thematic/ peripheral perception

Hypothesis 2: Subject will likely describe physical contrasts in spatial experience: _enclosure/ openness, exposure/ revelation, concealment/ obfuscation, in/ out, borders/ limits, paths/ intersections, proximity/ distance, narrowness/ breadth

Figure 14: Conditions of:

\section{Routine}

Focus on completion of tasks

Minimal Engagement

Tedious and Meaningless

Externally Motivated

Dull Awareness

Disconnected Series of Events

\section{Ritual}

Focus on performance of tasks

Full Engagement

Symbolic and Meaningful

Internally Motivated

Bright Awareness

Tells a Story practices of everyday rituals, he considers the re-use and function of memory to be the tool that allows consumers to read and invent what appears to be their realities. Vision characterizes consumption in contemporary society. Reading is an activity that, for most people, depends on vision. De Certeau claims that, "Reading seems to constitute the maximum development of the passivity assumed to characterize the consumer - the consumer as a voyeur in a show of big society."12 De Certeau points out that the consumer's lived experience is contingent on associations given to symbols and images.

In The Production of Space, Henri Lefebvre describes imagery in the built environment as an "ensemble of images, signs, symbols unlimited because it is empty - yet at the same time it is full of juxtapositions and proximities of emotional distances and limits. ${ }^{13}$ The thresholds of these juxtapositions within architectural space are transitional and enjoyed because of the ritual significance that the user associates with them. These juxtapositions are used as a platform in this investigation of familiar imagery within a dwelling.

\subsubsection{Quotidian: Routine and Ritual}

The experiment outlined below explores which elements of daily architectural experiences a dweller perceives. By considering routine actions within the dwelling, this research identifies how a place acquires visibility for its users. This design experiment manipulates the representative imagery, narrative, awareness and the temporal nature of routine in order to affect the user's perception of space.

Attempt 1: Subject is asked to walk through his daily routine and describe his impressions of it.

Attempt 2: Subject is asked to repeat all instances of the routine but backwards and describe his impressions of it.

After each attempt, Subject is shown imagery that represents his past livedexperience and given the opportunity to discuss what he remembers.

Purpose: Within this design research, ritual has been rendered as a multi-sensorial act (Figure 14). The proposed experiment discerns if heightening the perception of the user within a habitual environment is a viable method for turning routine into ritual.

Observations: As hypothesized, following Attempt 1, when asked to describe his typical routine, the Subject produced an emotional and subjective description. Contrarily, the Attempt 2 description centres on the physical aspects of the Subject's spatial experience and on the proper completion of tasks. The experiment demonstrates that by disorienting the user within the space (Attempt 2), the routine (Attempt 7) turned into a ritual. The description of Attempt 2 points to the Subject's heightened awareness of his physical surroundings, suggesting that the proposed strategies contribute to enhancing perception of a habitual environment (Figure 13). 


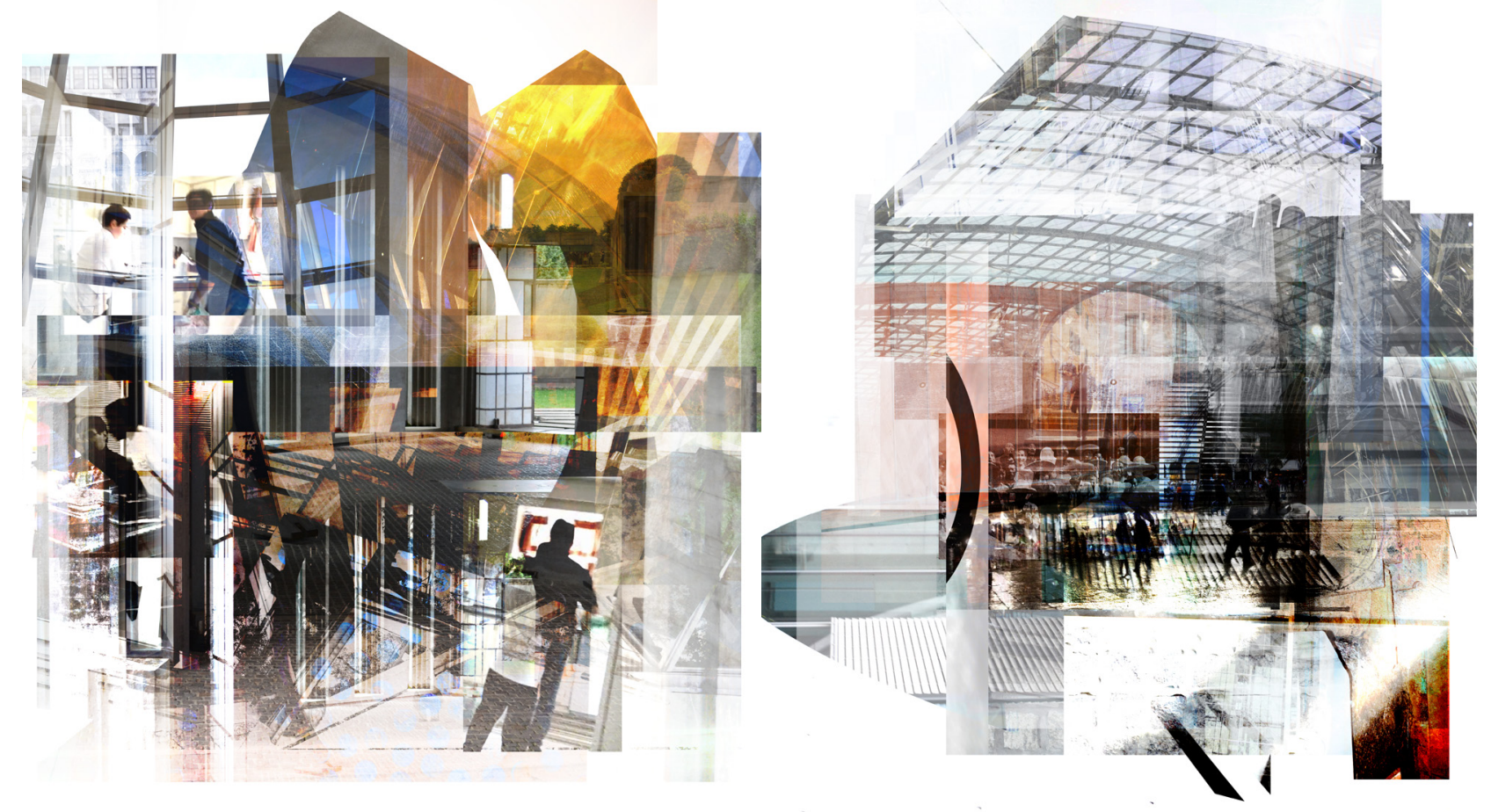

a
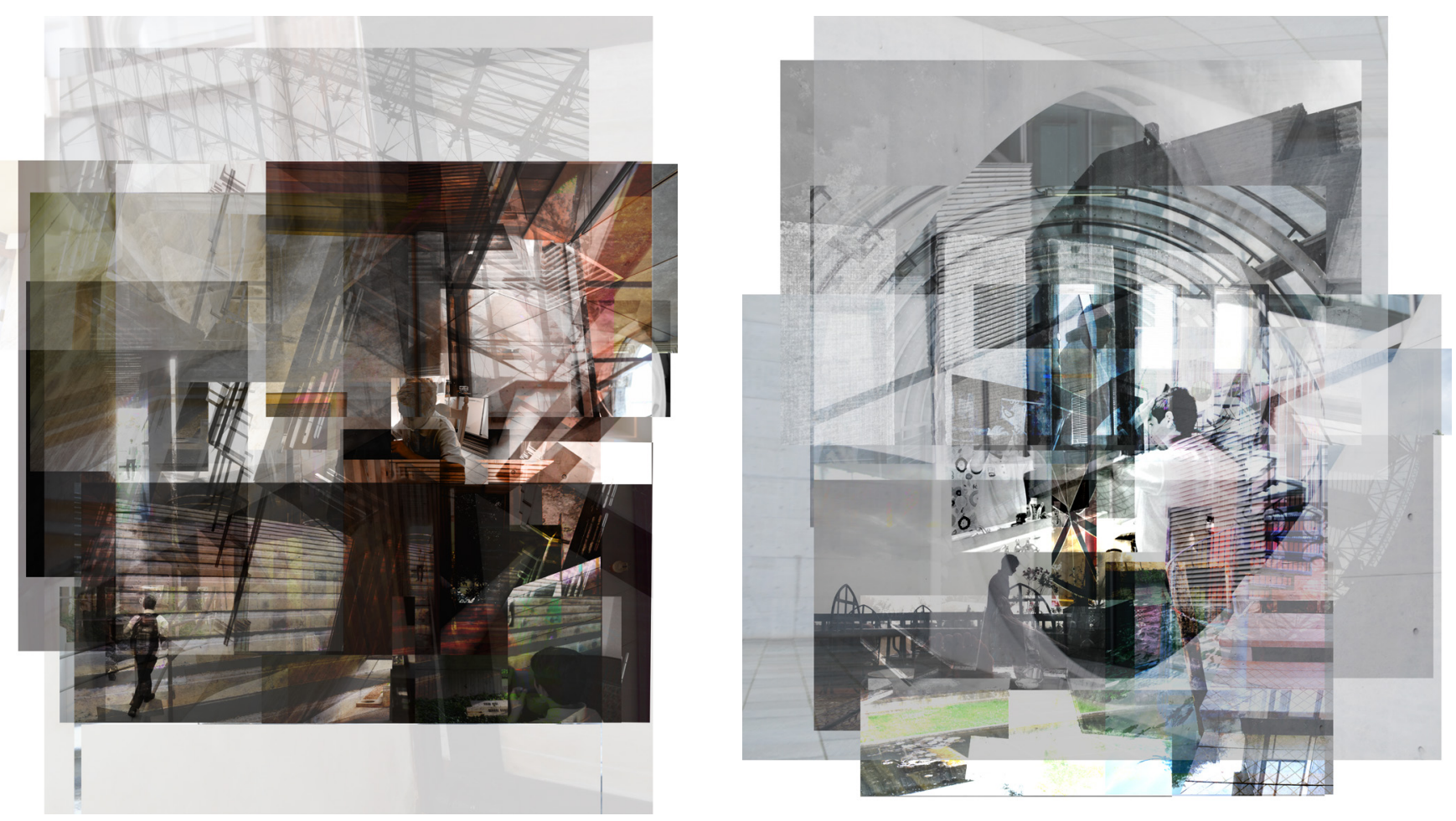

F.15 
Figure 15: Extracted Rituals

a. Communication; comprised of personal images from settings that suggest transmission and exchange of ideas/ information.

\section{b. Reception; comprised of personal} images from settings that suggest entry, procession and gathering.

c. Discipline; comprised of personal images from settings that suggest earth, shelter and concentration.

d. Cleansing; comprised of personal images from settings that suggest rain, water and purification.

(following page)

Figure 16: Ritual Acts Sequence
Conclusions: The relationship of the haptic to the visual was explored in Quotidian, which concluded that altering the typical visual routine (Attempt 1: Routine) and prompting a more haptic one (Attempt 2: Walking Backwards) turns the routine into a ritual. These findings demonstrate a relationship between the human body and surrounding environment. References made to changes in depth, edge conditions, environmental affordances and atmosphere from the transcriptions signal the user's multi-sensorial experience of space. These identified themes inform the design strategies of the final design project. (Refer to Appendix $A$ for full transcriptions and further analysis)

Habitual architectural experiences take place without concentration or direct focus: "As soon as we begin to find our bearings, the landscape vanishes at a stroke like the façade of a house as we enter it. It has not yet gained preponderance through a constant exploration that has become habit - once we begin to find our way about, the earliest picture can never be restored". ${ }^{14}$ An analysis of the habitual perceptions of the everyday environment was conducted in Quotidian. A wider attention to and understanding of the mundane is necessary to bridge the gap between the prevailing design model and the actual experience of the user (perceiver) within the built environment. Within this framework, architectural experience is understood as a series of separate events rather than a full, uninterrupted sequence..$^{15} \mathrm{An}$ understanding of how users perceive and interpret constructed landscapes is critical for designers as they approach new projects.

\subsection{Design Research Proposal}

When addressing the issue of habitual distraction, it is necessary to understand habitual acts. Habitual behaviour is a cycle of ordinary acts and repetitive behaviours that gives way to humble versions of formalized rituals. An exploration of an environment with heightened ritualistic components reveals the user's emotive connection to the environment being reinforced. Designing for ritua/ within the dwelling creates an accessible scale in the most familiar and negated environment and a suitable platform on which to conduct this design research. Authentic architectural experiences are encounters, confrontations and acts, not simply visual units. Ritual has been rendered a multi-sensorial act; therefore, an architecture of ritualistic acts is used to serve in the following exploration of imagery. The most familiar context, the dwelling, is used as a vehicle for exploring contemporary rituals through imagery and the schematic design of the project responds to four ritualistic spaces derived from Quotidian (Figure 15). 


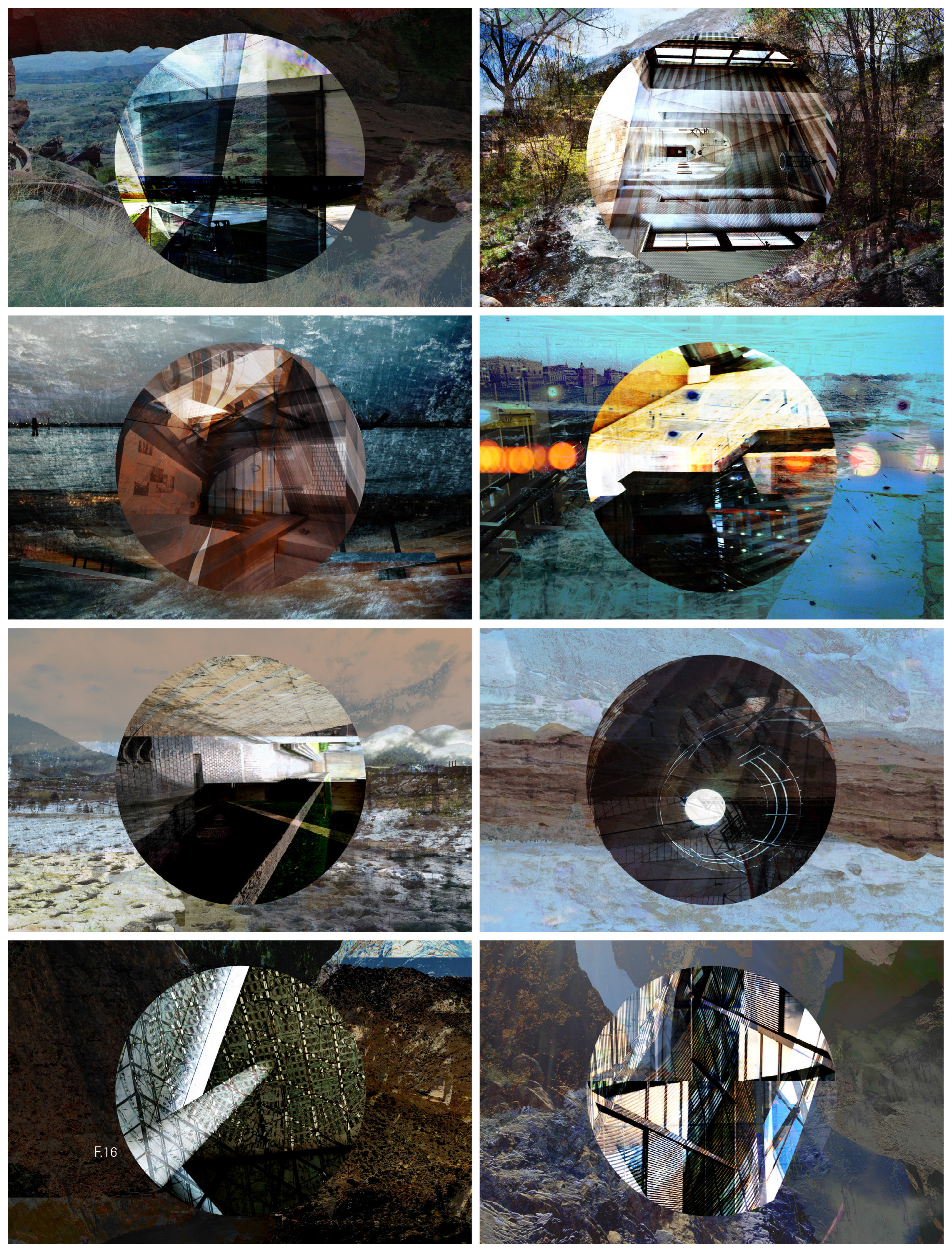




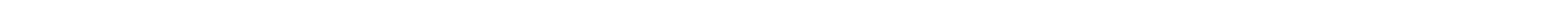



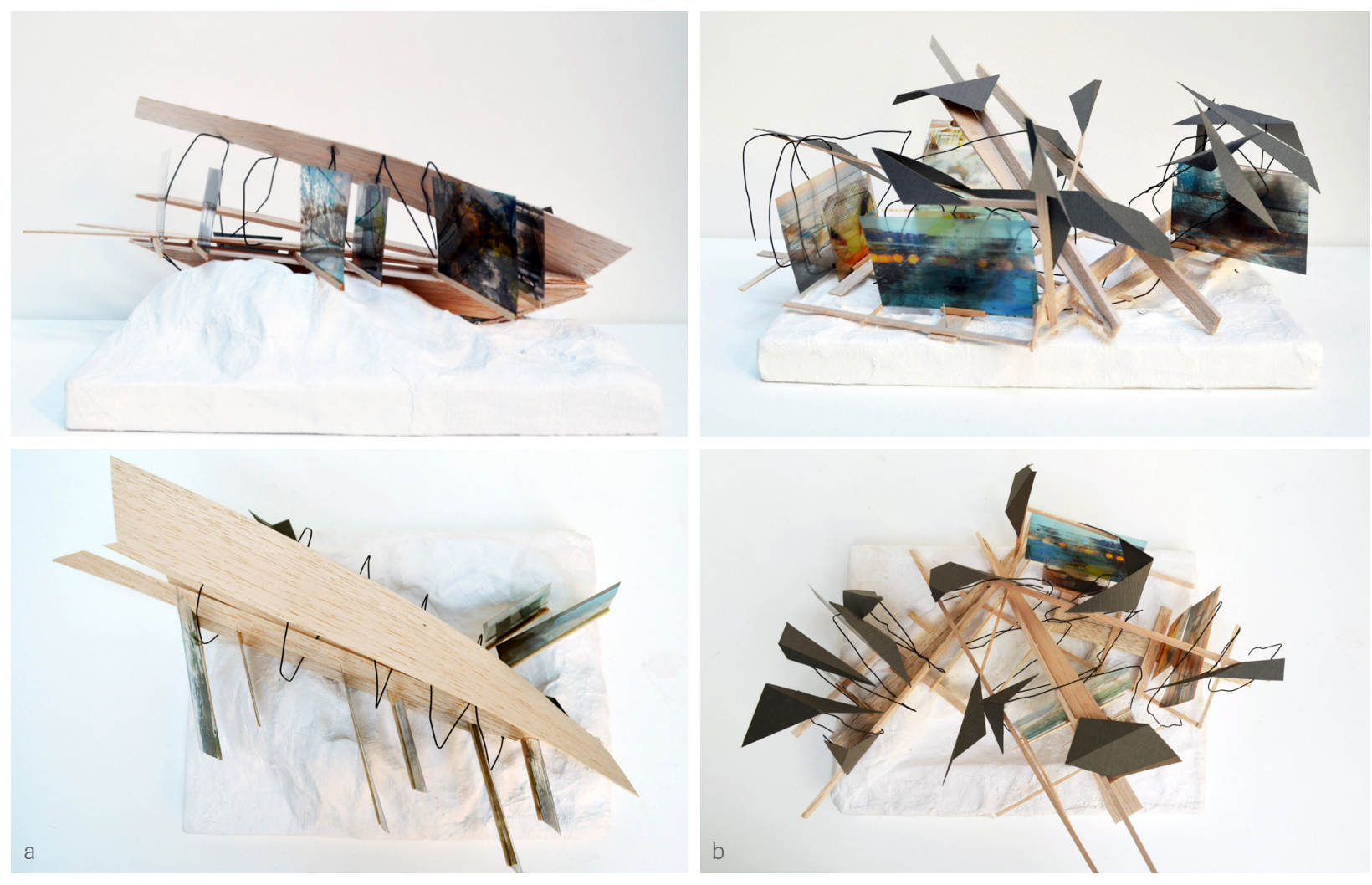

\subsubsection{Ritual Imagery}

The above illustrations consider the atmospheric qualities of space and represent the perceptual experience of the project. The emotive conditions of dwelling are idealized through imagery; the drawings are suggestive representations of space from the standpoint of the user. Revealing both new and imaginative spaces, the images set the tone for future to-be built spaces. Recombinatory imagery represents the acts of each everyday ritual. The illustration suggests the viewer's perceptions of the foregrounds and backgrounds of space (Figure 16). The environments created are obscure, abstract and representative of the multi-sensorial perception of the spatial experience.

The imagery from the environments of Figure 16 was manifested in four abstract models (Figure 17). These experimental models are volumetric constructions of movement, sequence and views that would confront the user as they move through each space of the dwelling. The proposed models are obscure; they abandon optical clarity and favour an architecture that idealizes the dwelling through multi-sensorial acts. The presented models use imagery from the preceding iterations (Figure 16), in both advancing and recessive processes, to develop and inform the sequence, movement and imagery of the dwelling. Furthermore, the fragmentation of the models supports the idea of a disjointed set of instances or experiences. The images intend to point beyond 

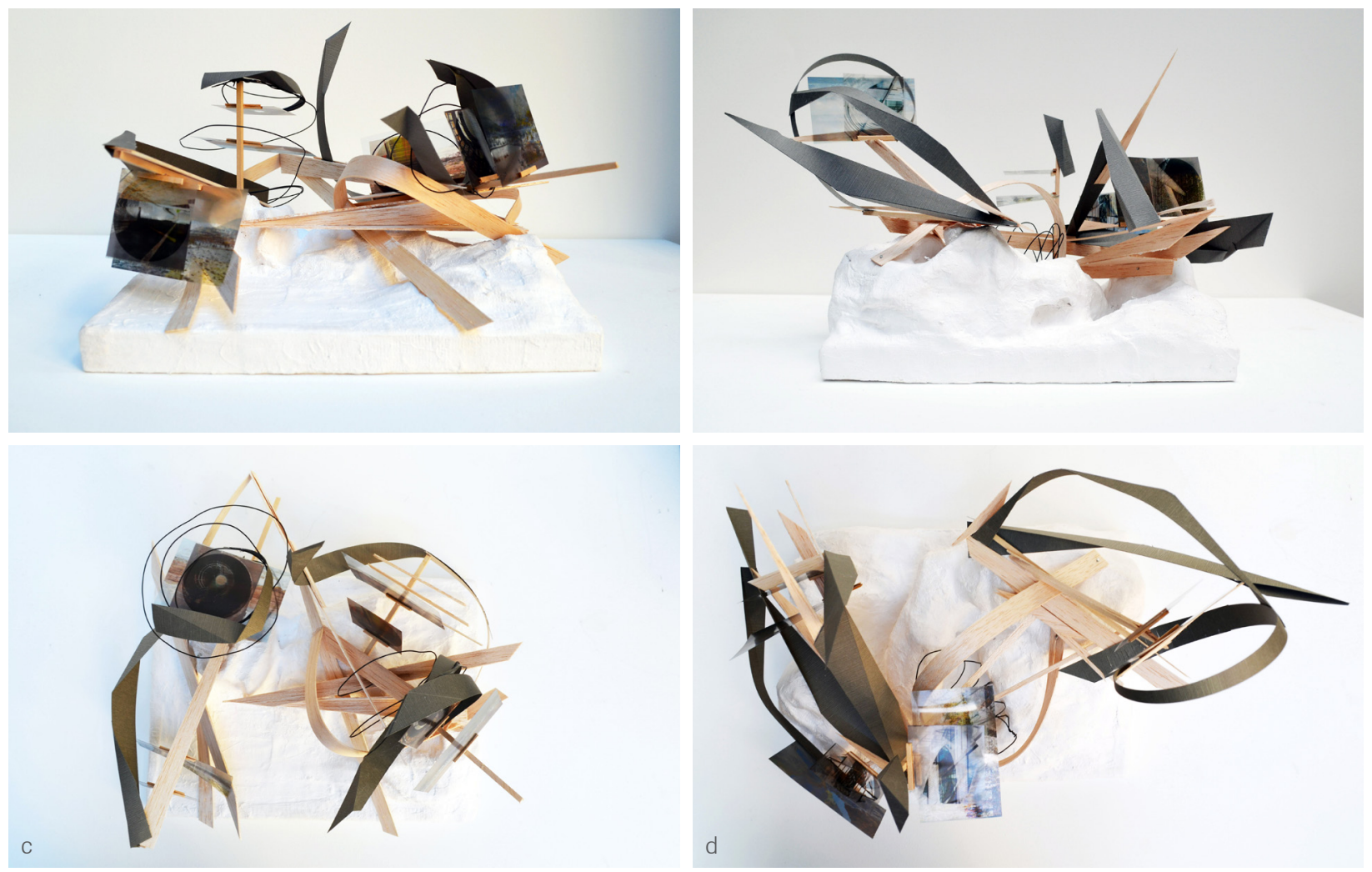

Figure 17: Study Models; Movement Representation

a. Communication; comprised of personal images from settings that suggest transmission and exchange of ideas/ information.

b. Reception; comprised of personal images from settings that suggest entry, procession and gathering.

c. Discipline; comprised of personal images from settings that suggest earth, shelter and concentration.

d. Cleansing; comprised of personal images from settings that suggest rain, water and purification. the optical; their subversion of recognizable spaces allows and supports the possibility of an experiential sequence. The dwelling is established through separate events in light of a formal structure. The graphic style of this design research uses images in both a literal and poetic sense to embody a discontinuous set of instances. The next phase of the design research continues to use fragmented spatial sequences to inform the dwelling's final composition. (Refer to Appendix B for supplementary illustrations of Quotidian) 


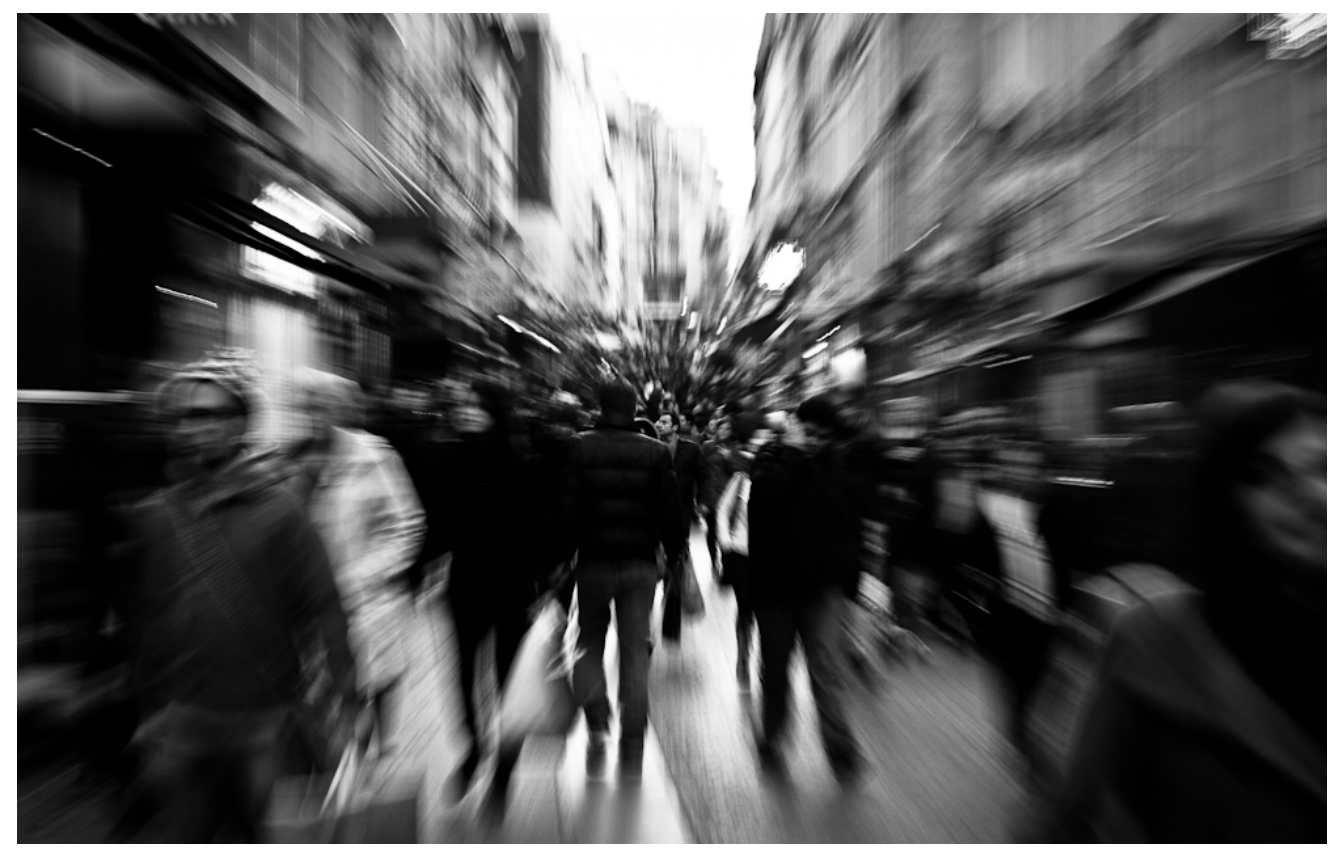

Figure 18: Agoraphobia, 2011

Franck Vervial 
Notes

1 Anthony Vidler, Warped Space: Art, Architecture, and Anxiety in Modern Culture. (Cambridge: MIT Press, 2000), 25.

2 Ibid., 28.

3 Ibid., 55.

4 Ibid., 62.

5 Walter Benjamin, The Work of Art in the Age of Mechanical Reproduction. trans. J. A. Underwood (London: Penguin, 2008), 33.

6 Ibid., 34-35.

7 Sven Arvidson, P. "A Lexicon of Attention: From Cognitive Science to Phenomenology." Phenomenology and the Cognitive Sciences 2 (2003): 99-132.

8 Bader, Aya Peri, "A Model for Everyday Experience of the Built Environment: The Embodied Perception of Architecture." The Journal of Architecture 20, no. 2 (2015): 244-67.

9 Sarah Robinson, Nesting: Body, Dwelling, Mind. (Richmond: William Stout Publishers, 2011), 116.

10 Ibid., 116.

11 Aya Peri Bader, "A Model for Everyday Experience of the Built Environment: The Embodied Perception of Architecture." The Journal of Architecture 20, no. 2 (2015): 244-67.

12 Michel de Certeau and Steven Rendall, The Practice of Everyday Life. (Berkeley: University of California Press, 1984), 482.

13 Henri Lefebvre, The Production of Space. (Oxford: Blackwell, 1991), 288.

14 Walter Benjamin, One-way Street, and Other Writings. (London: NLB, 1979), 78.

15 Steven Holl and Juhani Pallasmaa, and Alberto Pérez Gómez, Questions of Perception: Phenomenology of Architecture. (San Francisco: William Stout Publishers, 2006), 53. 


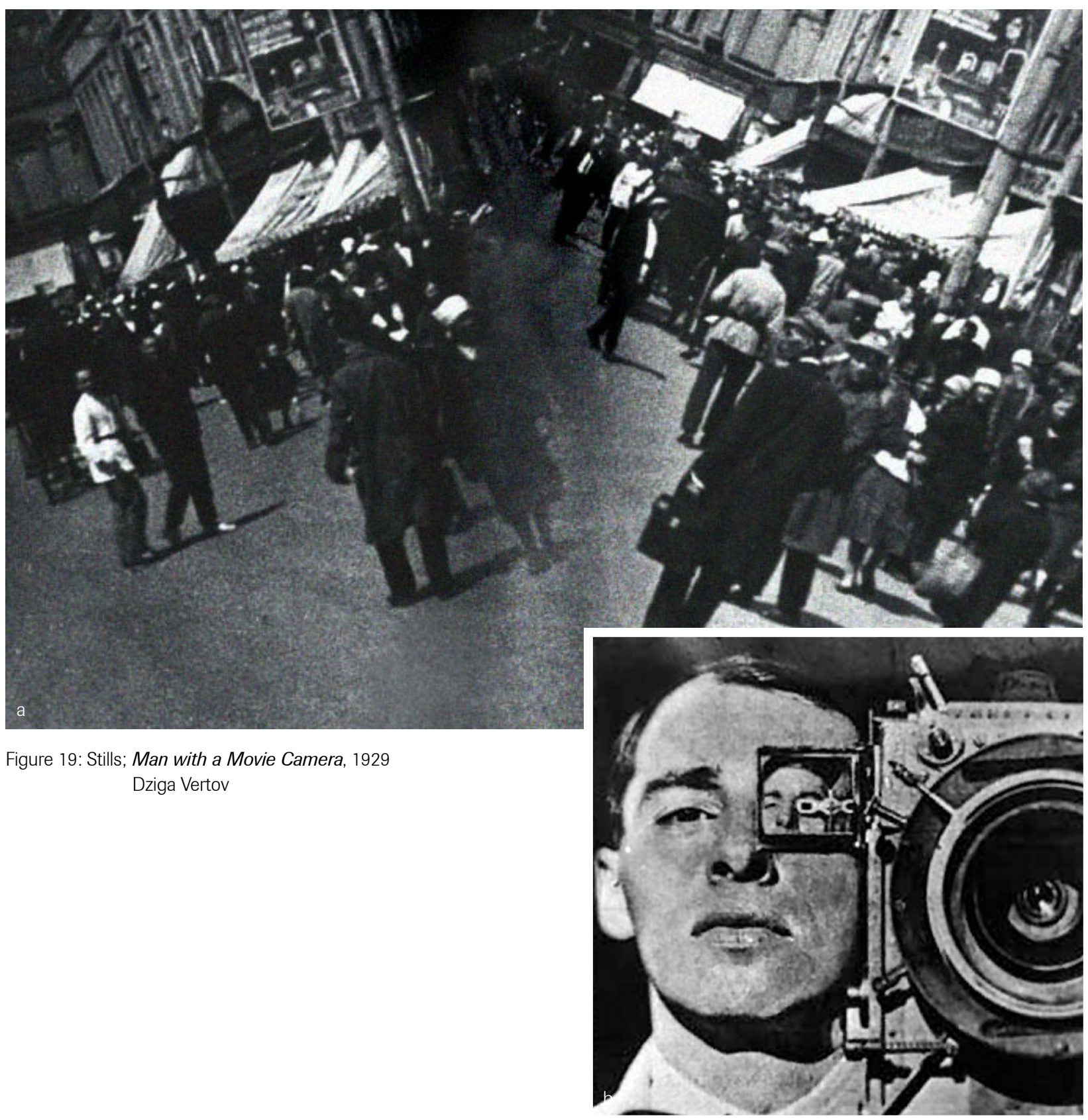




\section{3 | reel imagery}

\subsection{Cinema and the City}

Film has the ability to focus and deepen perceptions of everyday situations. As a visual medium, film focuses on realities that are otherwise overlooked in everyday life. Early $20^{\text {th }}$ century German art critic and New York Times correspondent Herman G. Scheffauer, suggests that film became humanity's sixth sense. For Scheffauer, as a tool for portraying the feeling of a room or a space, film could be used to transform reality:" "Cinematography renders perceptible through sight and sound individual beings we thought invisible, inaudible and divulges the reality of certain abstractions." Cinematography emerged as a means of documenting reality; for instance, the sounds and imagery of unvisited cities were distilled and understood by audiences. The cityscape was a primary subject of the avant-garde cinematography of the 1920s. The city was depicted as a montage of attractions, as demonstrated in Dziga Vertov's Man with a Movie Camera. Cinema rendered a social image of the city, and its representation of life influenced how audiences perceived the world. Vertov, a pioneer filmmaker and theorist, claimed that before the invention of cinema, people could not see social realities at all:

The evolution of the human capacity for understanding was brought by the art of film, opening a new chapter in the history of human culture. We were witnesses not only the development of new art but the development of a new sensibility, a new understanding, a new culture in its public... we have learned to see. $^{3}$

Cinematic representations of architecture were a means of distorting the user's ability to distinguish between the realities and imaginative components of the city. Cinema revealed the true political and social conditions of society, igniting the evolution of new human perceptual and cognitive abilities. Special effects rendered the bland metropolis magical while Surrealist cinema was characterized by its shocking imagery. Cinema made architecture pronounced and conspicuous to those normally in constant states of distraction:

The assertion of the shock effect of the film as that which allows the public, no longer distracted, to be put once more in the position of the critic. Thus the only way to render architecture critical again was to wrest it out of its uncritically observed context, its distracted state, and offer it to a now attentive public - that is, to make a film of the building. ${ }^{4}$ 


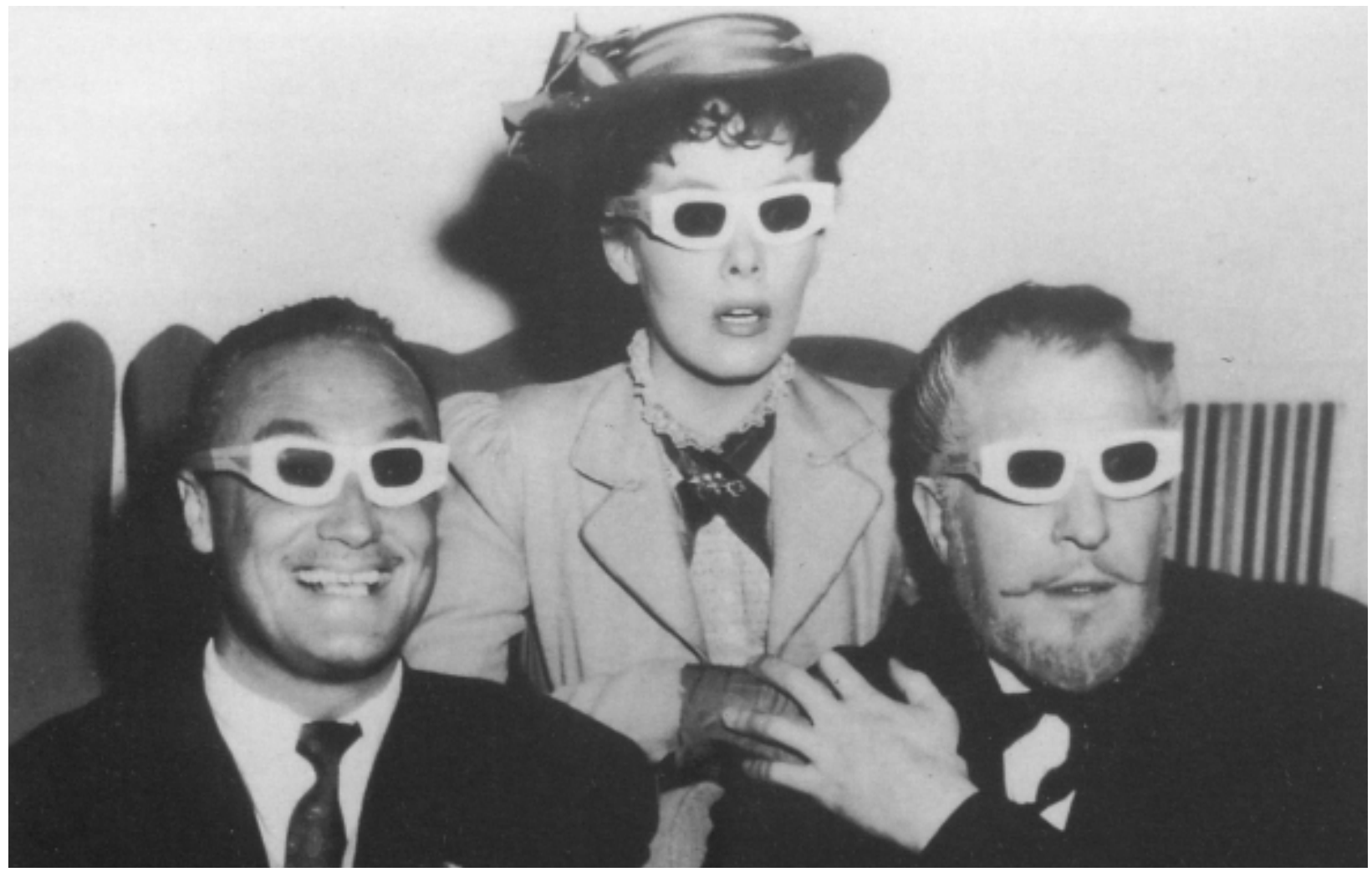

The camera effectively assisted in the rediscovery of the material world. In The Work of Art in the Age of Mechanical Reproduction, Benjamin argues that architecture and cinema while both superficially visual, are appropriated and apprehended by touch: "Cinema and architecture both required a kinesthetic inhabitation, the acquisition of a habitual mode of moving through space in order to understand it unconsciously." ${ }^{5}$ Watching a film is much like moving through a building; a sense of direction and attentiveness to signs, symbols and meanings is necessary to understand both the intention and function of place. ${ }^{6}$

Historically, film has been used to anticipate built forms of the city. It has been the envy of the static arts that have tried to imitate its effects and representations of movement. The age of mechanical reproduction changed the manner in which the individual contemplated imagery. Film's revelatory capacities extend beyond the power to dazzle the human eye, and it caused a fundamental shift in society's understanding of the physical world. Revealing new structural formations, the technical innovations of film expose truths and provide more complete representations of reality. Other arts lacked the technical innovations necessary to reveal these truths. As Benjamin asserts, "With the close-up, space expands; with slow-motion, movement is extended. . An unconsciously penetrated space is substituted for a space consciously explored by man ..."7 Like the microscope and the telescope, film is a significant visual technology. By abstracting, exaggerating and revealing details of reality, these technologies extend the perceptual and cognitive processes of their users.

Figure 20: Andre De Toth, Phyllis Kirk and Vincent Price watching House of Wax in 3D, 1953 


\subsection{Utopian Cinema}

Within modernism, architecture in cinema was no longer merely a background but a mechanism through which to communicate emotional experiences to an audience. More than contemporary art or literature, the film industry generated interest from the masses, encouraging participation by means of illusory presentations and suggestive speculations. ${ }^{8}$ Following the First World War, film became the new, mass medium for entertainment and communication. Avant-garde film attempted to portray the intersections and relationships between new, cultural structures and modern architecture:

\section{Neon signs flash, loudspeakers shriek, klaxons rattle, posters advertise, shop windows glitter: the simultaneity of the immeasurable events widens our concept of time and space, it enriches our lives. The constantly growing perfection of the graphic, the photograph and the cinematographic progress renders possible an even more precise reproduction of the real world. The visual image of the landscape of today is more multiform than ever. ${ }^{9}$}

Architectural imagery was designed and used to mirror and exaggerate the existing political and social realities of respective design periods. Cinema continually associates the dimensions of time with space. Film establishes the viewers' consciousness of the associations between the film's characters and imaginary places and makes these characters and places relative and believable. Jean Baudrillard's Simulacra and Simulation, considers the differences between the real and ree/ city. As Baudrillard points out, the development of the cinematic ree/ city prompted and influenced the evolution of the actual cityscape. An exploration of utopian, expressionist films of the modern and post-modern eras demonstrates architecture as a deliberate character in the cinematic city.
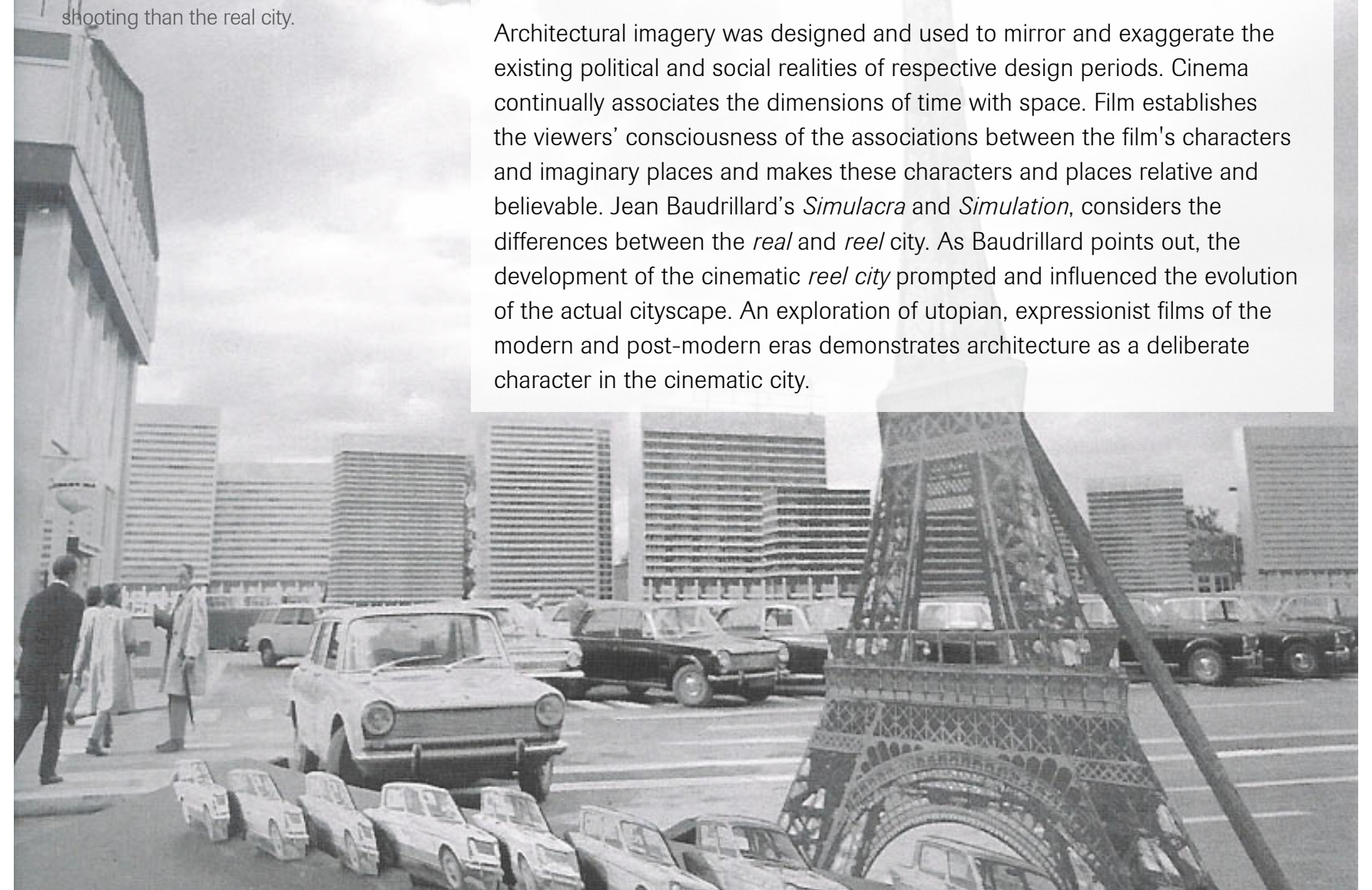


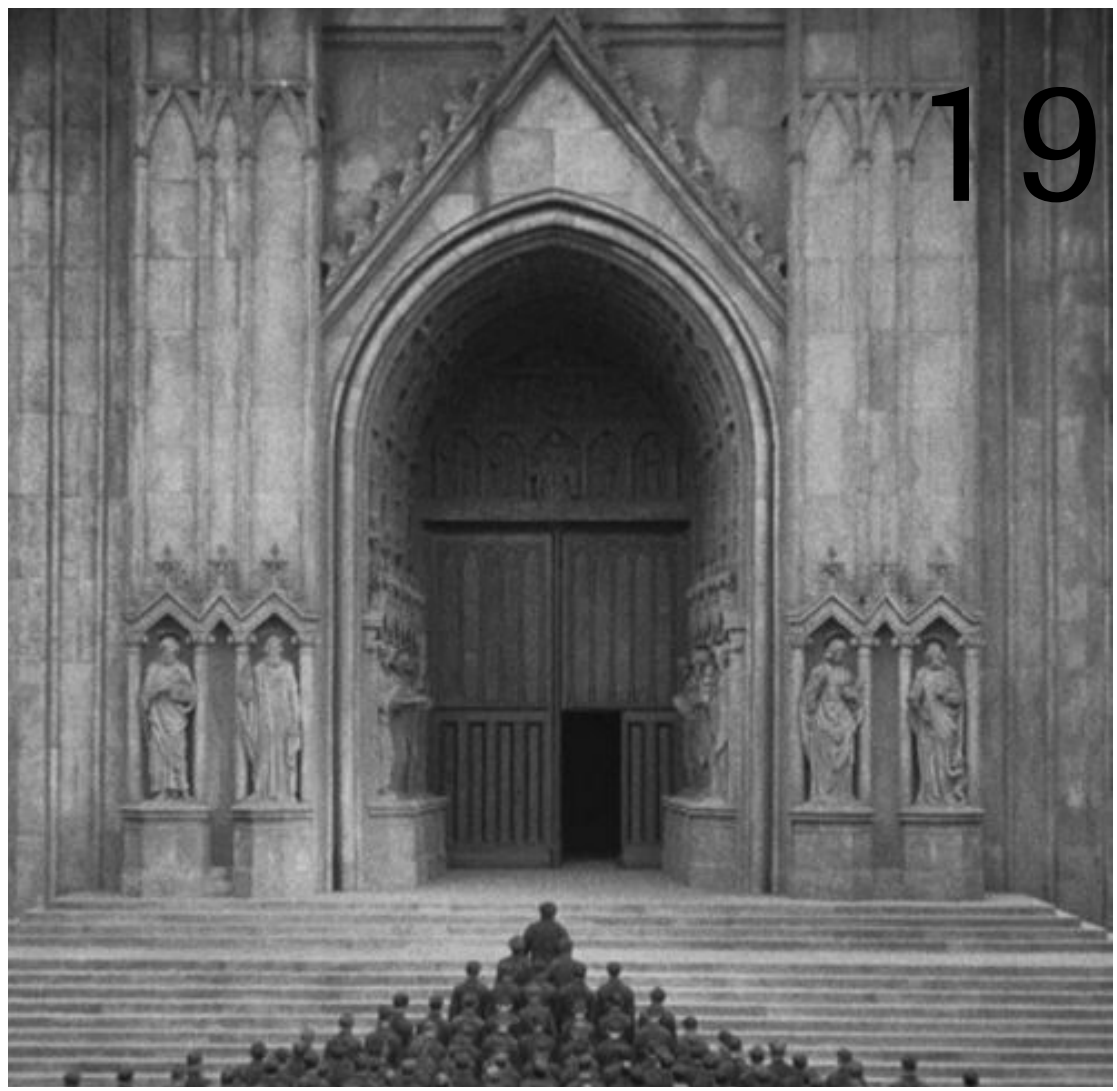

27 metropolis

fritz lang

The Expressionist film takes place within the futuristic society of 2026. Set within the "new machine-age,"10 the constructed sets were strongly informed by the art deco movement and address the modern era's emphasis on functionality. Although not explicitly identified with any particular place, Metropolis was organized around the struggle between capital and labour that dominated German cities at the end of the First World War. ${ }^{11}$ The city literally demonstrates the separation of between the upper and working classes: the wealthy live above ground and the working class reside and work on a subterranean level. The blue-collar workers of Metropolis are represented as prisoners of production. ${ }^{12}$

Both the city and technology are fetishized. Abstract, close-up shots in the opening scenes of the film make a
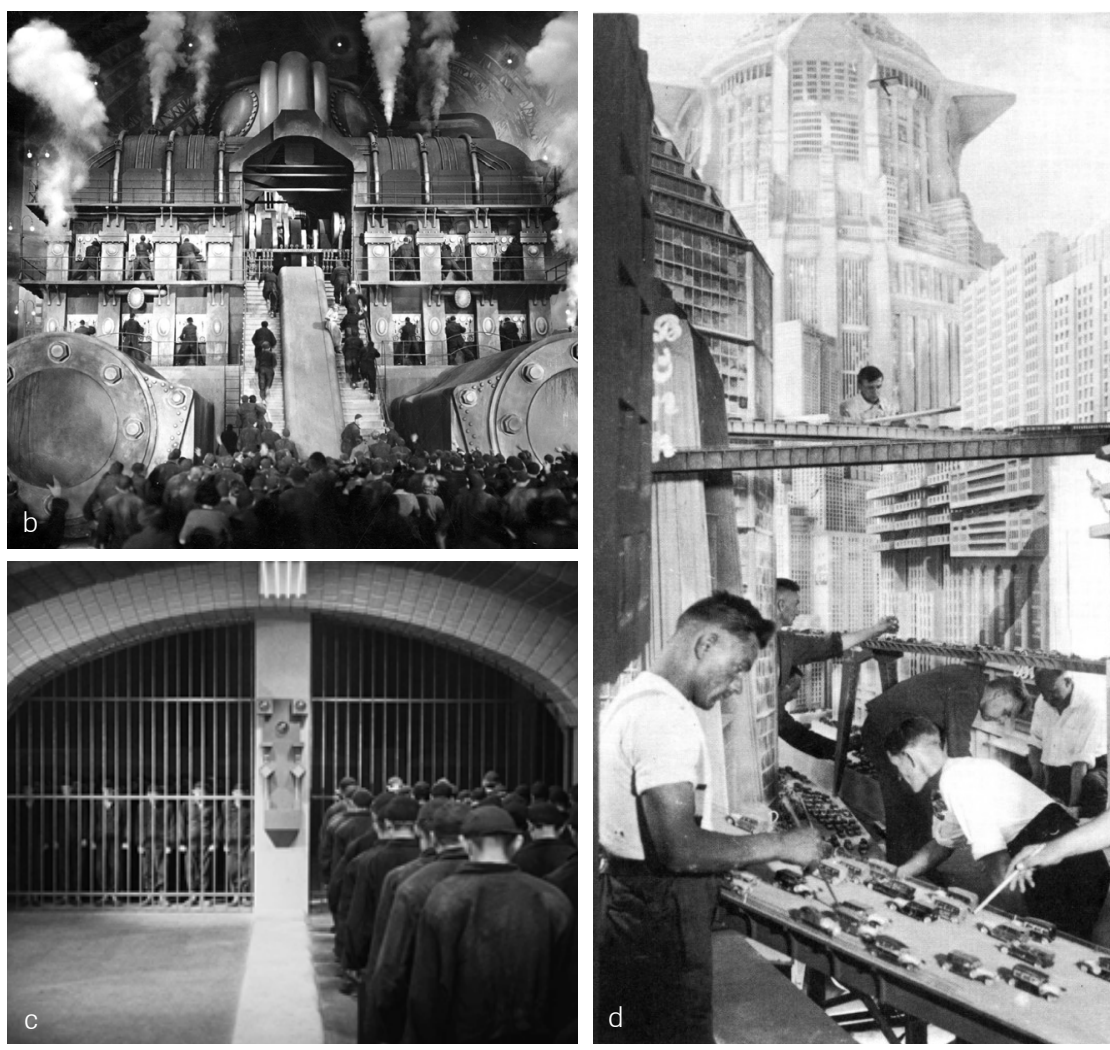
spectacle of the industrial machines. The film portrays the urban dweller's love-hate relationship with the big city as nightmarish and blames extreme industrial technology for the city's degradation into a modern, urban dystopia.

\section{Figure 22: Stills; Metropolis}

a. Constructed Sets; Gothic Cathedral

b. Opening Scene; The Heart Machine

c. Subterranean Workers

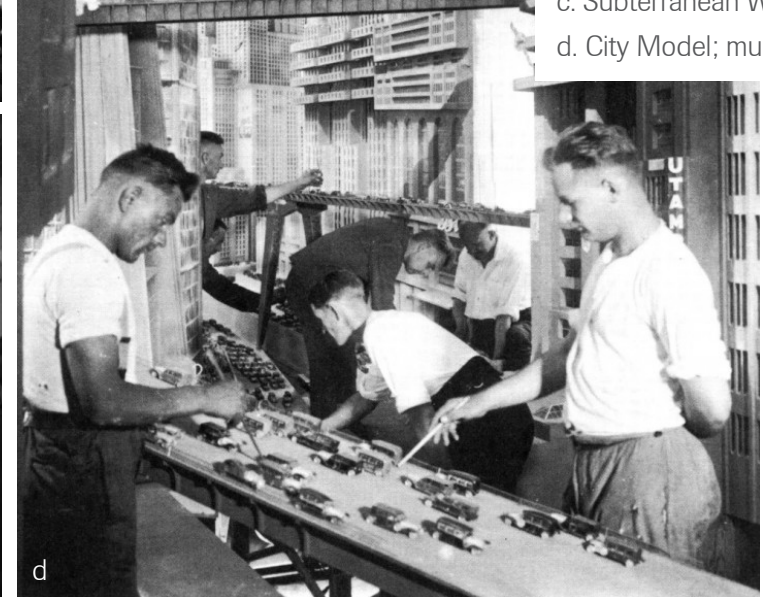




\section{8 mon oncle \\ jacques tati}

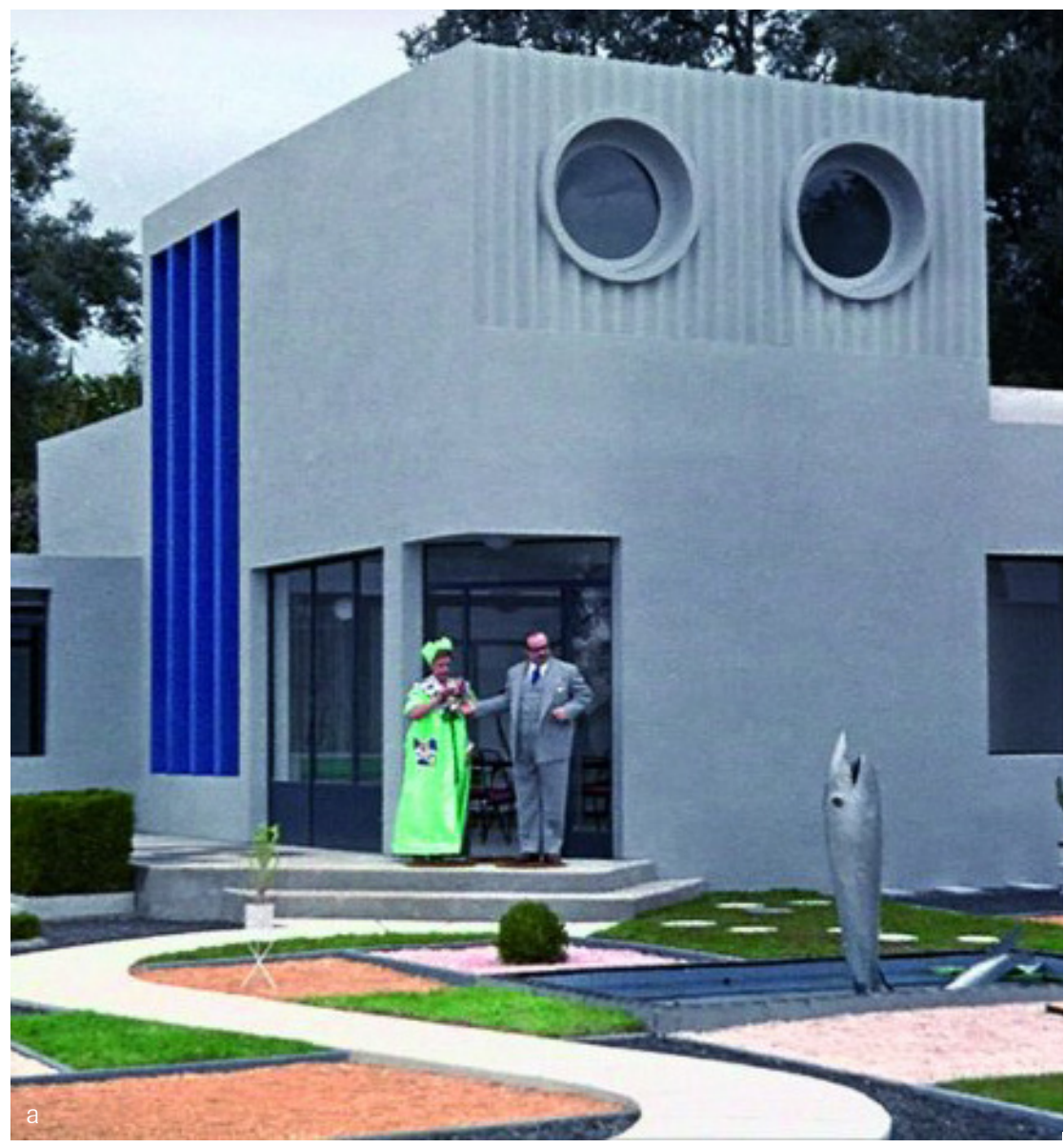

Mon Oncle follows Monsieur Hulot, Tati's reoccurring character in a series of 1950s and 60s films, through a criticism of modernism's post-war consumer culture. The narrative of the film is split between two architectural versions of Paris; new Paris, with its refined and impersonal facades, and old, crumbling Paris. Using tailored architecture, Tati addresses the blandness and uniformity of the Paris' post-war housing program.

Although superficially beautiful, Villa Arpel, set in the new Parisian suburbs, is an impersonal and dysfunctional environment. It is a contrast to Monsieur Hulot's neighbourhood within old Paris, which is a much more individualist and responsive atmosphere. ${ }^{13}$ The design and construction of Villa Arpel demonstrate Tati's suspicions of modern architecture. The house takes Le Corbusier's housing motto "a machine for living" 14 to ridiculous heights - the house is a gadget-filled symbol of the new world. Designed as a collage of images from new architecture review journals, the house is Tati's critique of modern architecture.
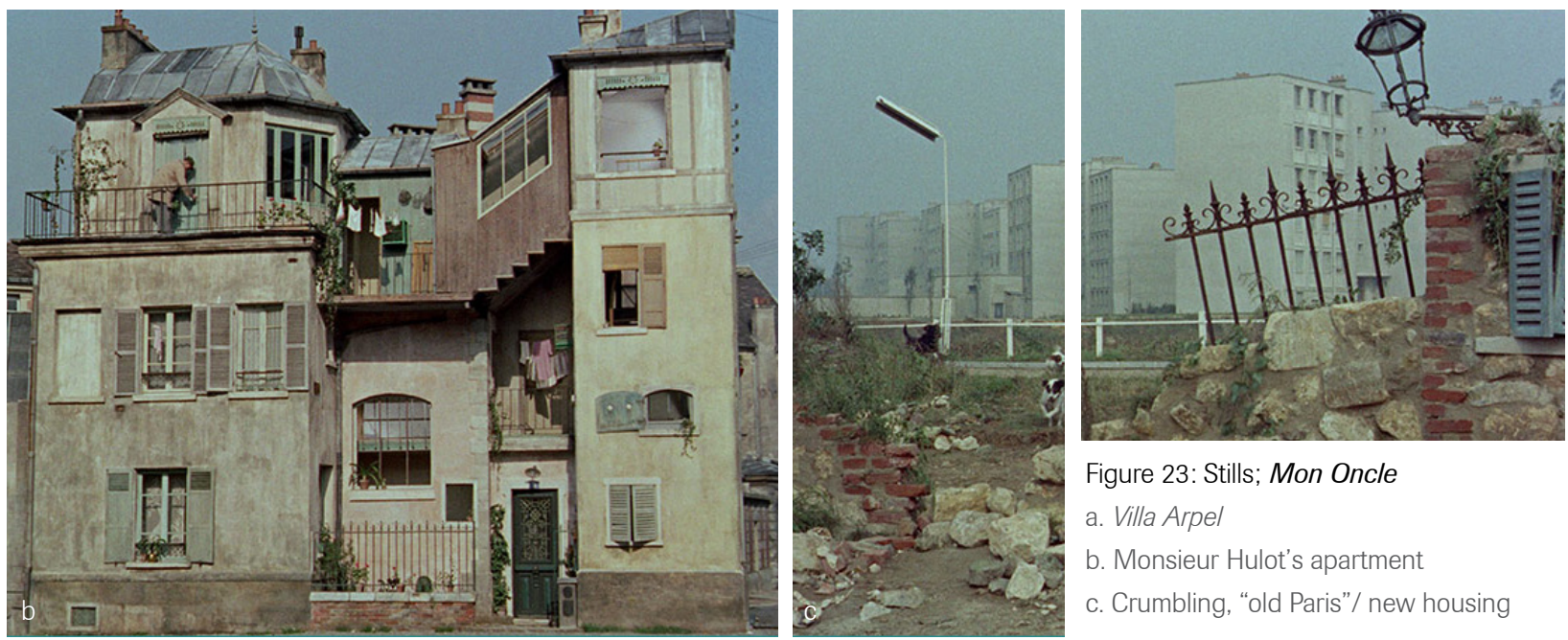

Figure 23: Stills; Mon Oncle

a. Villa Arpel

b. Monsieur Hulot's apartment

c. Crumbling, "old Paris"/ new housing 

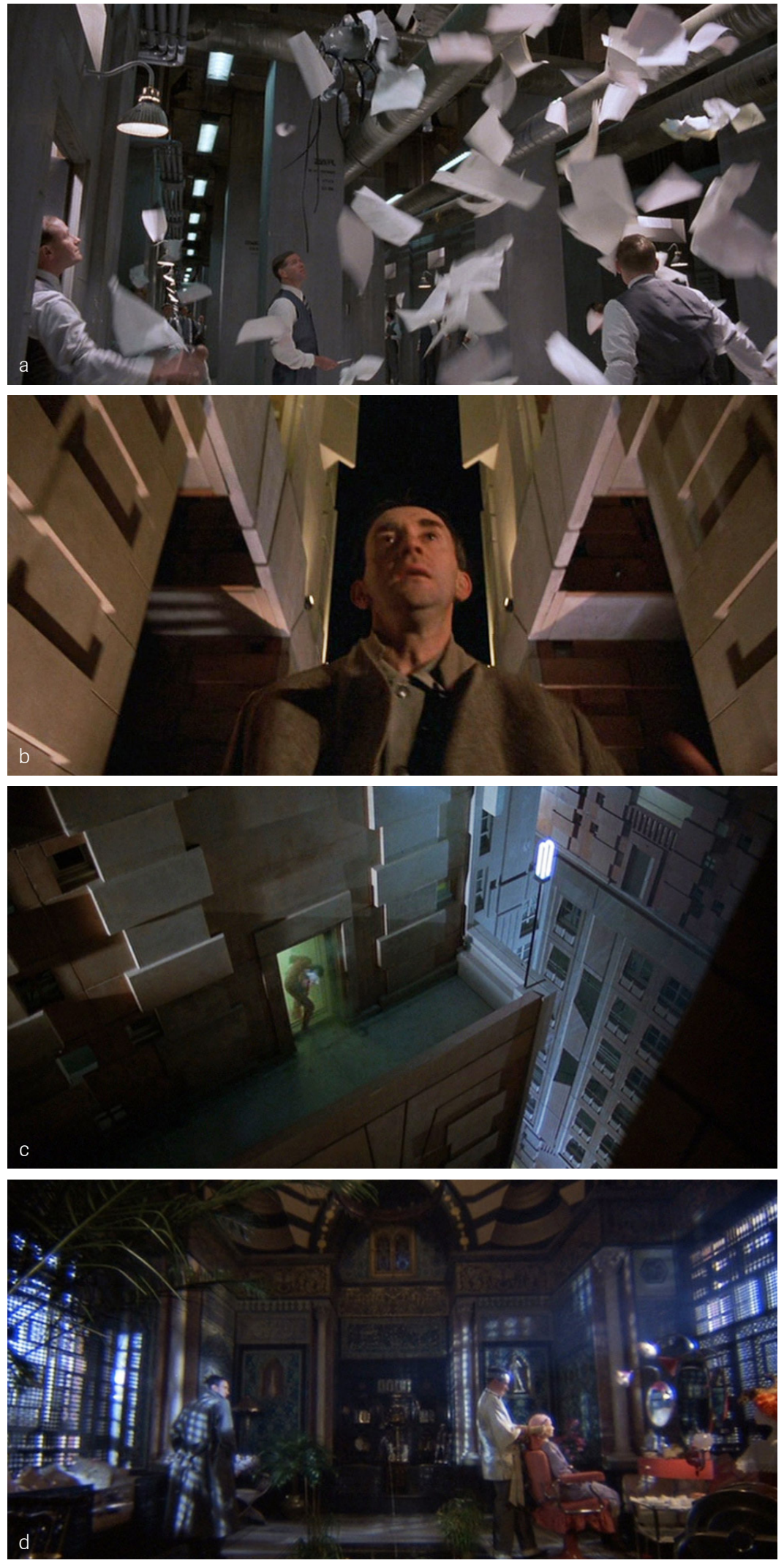

\section{5 brazil \\ terry gilliam}

Brazil depicts Gilliam's cynical view of the urban future. The film anticipates the grave downfall of postmodernism. The bright colour scheme and decadence of the film's aristocratic quarters dramatically contrast the monochromic palette of the working class' mediocre and dystopic world.

Sam Lowry's apartment complex is set within Les Espaces d'Abraxas and is so functional that it is inept for living. The use of the deteriorating Les Espaces d'Abraxas as a housing solution for the middle class exposes the futility of the postmodern era. ${ }^{17}$ The distorted neo-classical forms of Les Espaces d'Abraxas establish an environment that alienates and segregates its inhabitants. Furthermore, the rigidity of urban spaces impedes individuality and freedom. The harsh representation of the postmodern construction demonstrates the film maker's dissatisfaction with the newly developed, built environment.

The film was primarily shot in Europe but its retro and eccentric sets mask the film's location; Gilliam distorts the city leaving only slivers of familiarity. The lack of specificity in Brazil's time period or location suggests that this satiric society could be anywhere and a reality relatively soon.

Figure 25: Stills; Brazil

a. Sam's Workplace; Information Retrieval

b. Urban landscape of Brazil

c. Sam's Escape; Les Espaces d'Abraxas d. Ms. Ida Lowry's apartment 

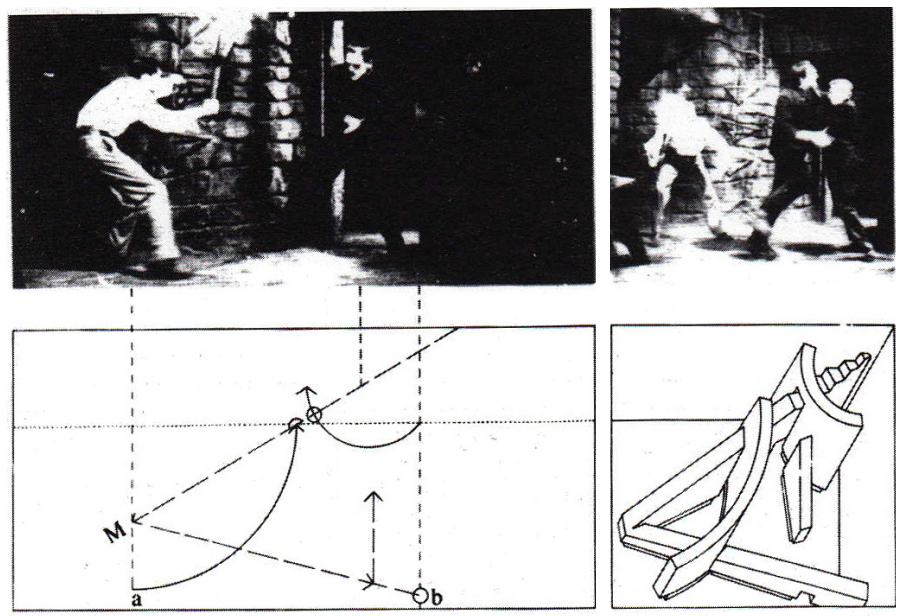
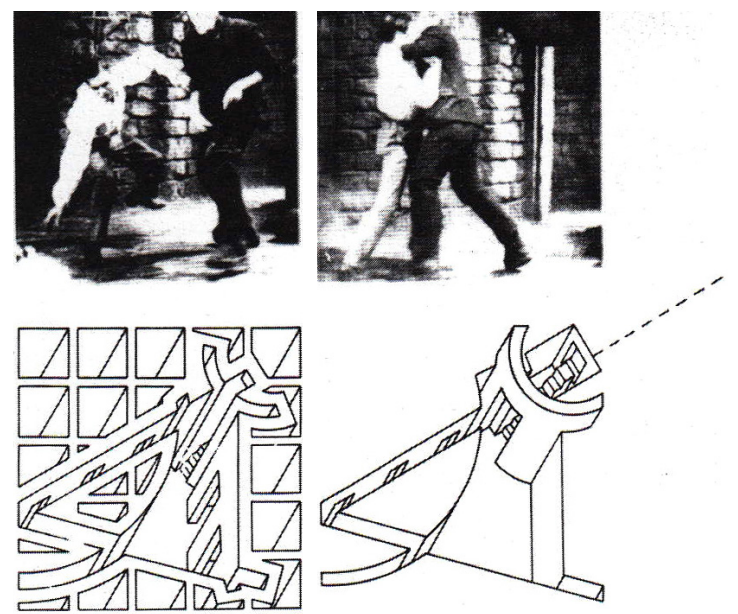

The cinematography of the films discussed above offers visual spectacles of supposedly utopian cities; as each narrative unfolds, the underlying dystopic character of each city is revealed. Lang, Tati and Gilliam use respective architectural styles to represent and exaggerate existing class systems and social conditions. Rather than known places, these utopias exist in Baudrillard's ree/space, the cinematic space. The spaces of the films are manifestations of Michel Foucault's mirror, a space that is both utopian and heterotopian. ${ }^{18}$ The intention of the ree/ space is to focus and reveal the conditions of reality. The revelatory components of film demonstrate cinema's ability to communicate both architecture and society to an audience. The communicative abilities of cinema have prompted this thesis research to consider taking the tools used to develop the ree/ city to create the real city. Instead of merely using film as a means of representing architecture, what would result from applying aspects of cinematography to the creation of architecture? Jean Nouvel considers this possibility:

Architecture exists, like cinema, in the dimension of time and movement. One conceives and reads a building in terms of sequences. To erect a building is to predict and seek effects of contrast and through which one passes... in the continuous shot/ sequence that the building is, the architect works with cuts and edits, framing and openings, screens and planes legible for obligatory points of passage. Architecture and film interface, increasingly . . the notion of journey is the new way of composing architecture. ${ }^{19}$

As an invaluable tool for modeling spatial experimentation, film is a critical medium for the both the exploration and representation of architectural space.
Figure 26: Manhattan Transcripts, 1981 Bernard Tschumi

The diagrams dictate the movement of a protagonist on an architectural set. The drawings are not fully developed projects; the Transcripts illustrates a series of discontinuous events. 


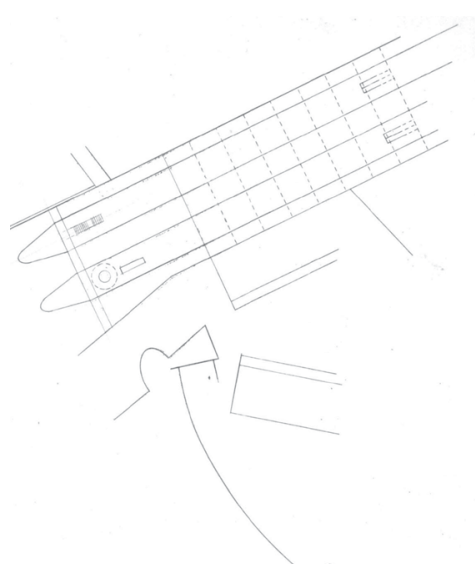

Figure 27: Porta Vittoria, 1986 Steven Holl

Partial view perspectives were drawn and later assembled into elements of the official plan. The design research is conducted through the planning of the phenomenological experience of space that later translates into a formal visual object or architectural form.

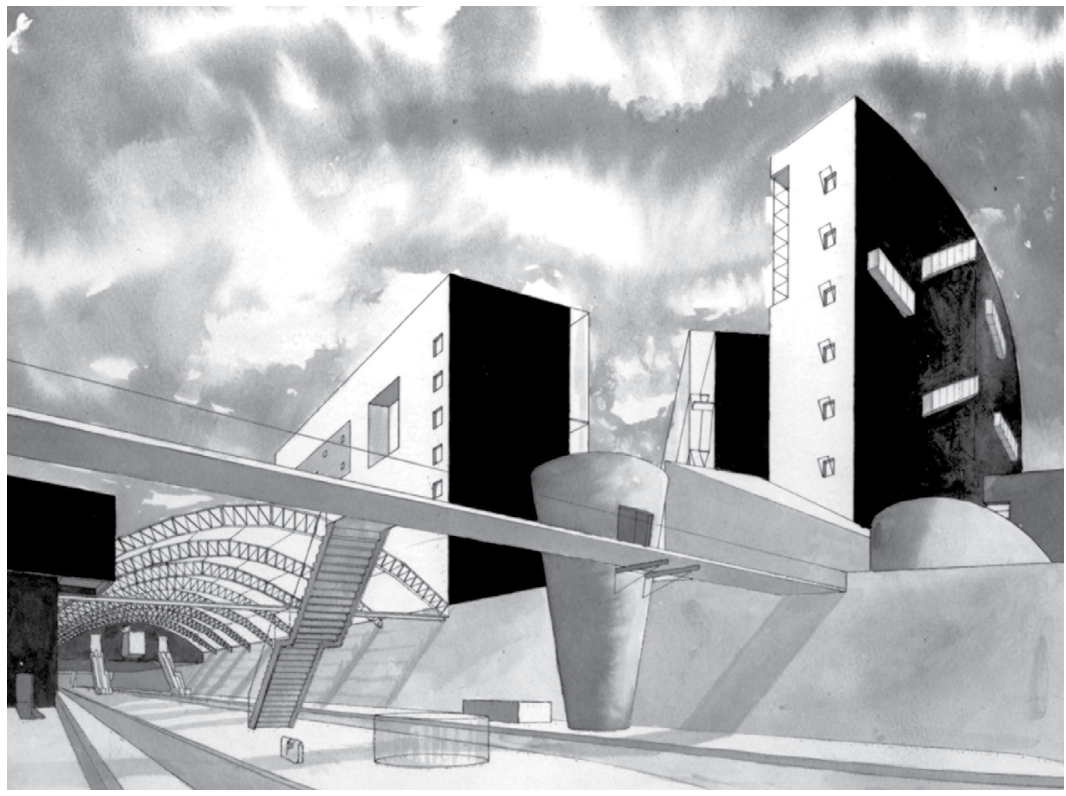

The fault in contemporary design remains in the creation of the image or a sequence of images rather than designing for the user's response; perception of space is often incidental in contemporary design. ${ }^{20}$ The experiments of Bernard Tschumi's Manhattan Transcripts and Steven Holl's Porta Vittoria project and the work of Elizabeth Diller and Ricardo Scofidio have all questioned the role of the spectator in the development of space. The value of the architectural experience emerges when the architectural phenomena are foregrounded rather than being the aftermath of constructed architectural objects. In pursuit of investigating the perceptual elements of architectural space, this thesis uses film as a design tool to explore the temporality of space from the standpoint of the spectator.

\subsection{A Day in the Life}

As a backdrop, architecture supports the conventions and activities of everyday life. Habitual use and incidental perception of the city render its material qualities indistinct. ${ }^{21}$ The purpose of this design research is to bring the city's architectural background into focus. The grids of cities are typically overlooked as users make their own paths and shortcuts, giving ritual significance to otherwise monotonous activity. ${ }^{22}$ The juxtapositions of everyday environments, through habitual use, become the hosts of these ritual significances. The next phase of the design project uses film and fragmented imagery to emulate the phenomenological textures of everyday landscapes. The constructed film, Quotidian Revisited, considers the peripheral areas of space, areas that are overlooked in the context of daily routine (Figure 28). 

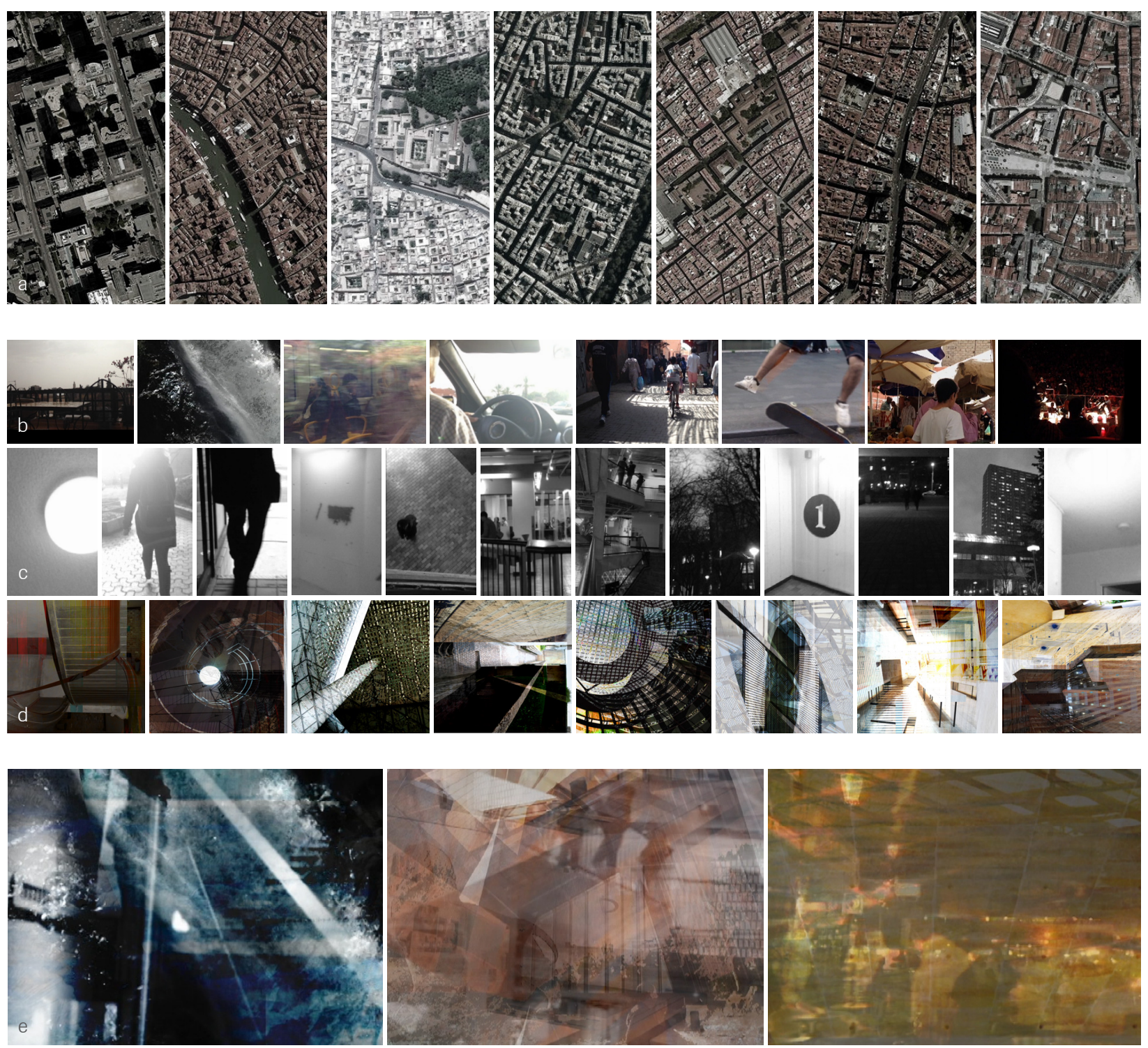

F.28 


\subsubsection{Thresholds of Juxtapositions}

The first layer of Quotidian Revisited (Figure 28b) is a series of films shot over a period of three years in various parts of the world. The films are categorized according to the criteria of each of Quotidian's rituals and edited into a sequence that mimics the actions and events of an average 12 hour day. The intent of this design research was to develop and distinguish the phenomenological textures of the architecture within the habitual schema of everyday life.

Figure 28: Layers of Quotidian Revisited

a. Films shot in: Toronto, Venice, Marrakesh, Paris, Barcelona, Madrid and Porto

\section{b. Stills; Environments for Acts}

The first grouping of clips is symbolic of the beginning of the architectural journey, that begins not by entering, but from within the space. As the film progresses, images of commuting, places of worship and the work environment unfold. The film's pace slows at the midpoint of the day, where a meal and the end of the work day are shown. A sequence of images and sounds concentrated from street musicians build up to an evening jazz concert. The film ends with a commute home.

\section{c. Stills; Threshold Documentation}

The scenes are cut to emphasize notable transitional points within the physical environment. At the midpoint of the film, the camera remains in a single position to document paths, intersections and revealed and concealed elements; images that only were prominent in the user's visual field as she stood in a stationary location. This layer is a composition of otherwise overlooked thresholds of the user's daily environment.

Notable physical traits include: enclosure/ openness, exposure/ concealment, borders/ limits, paths/ intersections, proximities/ distances and narrowness/ breadth.
d. Acts of Rituals
e. Stills; Morning, Midday, Evening
f. Film; Quotidian Revisited

The second layer of the film identifies significant moments of transition. From Henri Lefebvre's work, The Production of Space, emerges an exploration of the juxtapositions of everyday environments (Figure 28c). He explains that the thresholds of these juxtapositions are both transitional and significant. ${ }^{23}$ Here, a threshold should be understood as a link between the apparent reality of the present and the intangible experience of the past - a threshold signals what experience is to follow. This layer of the film is an attempt to recognize and document the user's experiences of thresholds throughout a single day. It is necessary to study and sequence these juxtapositions before generating an architecture.

\subsubsection{Quotidian Revisited}

Separated into three frames (morning, midday and evening), the film combines the layers already discussed with the ritual imagery from the previous design research (Figure 28d). The film's final composition is a chronological sequence of a single day but merges events into fragmented segments (Figure 28e). Film-making exposes the realities of space by manipulating the raw material of time. ${ }^{24}$ Quotidian Revisited was edited to annunciate the juxtapositions of a single day. The film is the sum of the phenomenological experiences of everyday life distilled into a single visual narrative. Film has the ability to intertwine various types of movement, time and space, and Quotidian Revisited explores textures of ordinary landscapes. Portraying ritual as integral to the human condition, as a performative action within space, the film is a useful exploration of the banalities of the contemporary environment; furthermore, it can be used to investigate the participatory role of vision in the creation of architecture.

This research gives way to the documentation of users making their own paths and shortcuts within architectural space. Fragmentation and intersection are the driving themes within the final section of this design project as they prompt a perceptible change in the atmosphere of space. The tempo, rhythm and atmospheres of film serve as the phenomenological texture around which the dwelling is developed. 
Notes

1 Anthony Vidler, Warped Space: Art, Architecture, and Anxiety in Modern Culture. (Cambridge: MIT Press, 2000), 102.

2 Malcolm Turvey, Doubting Vision: Film and the Revelationist Tradition. (Oxford: Oxford University Press, 2008), 7.

3 Ibid., 70.

4 Anthony Vidler, Warped Space: Art, Architecture, and Anxiety in Modern Culture. (Cambridge: MIT Press, 2000), 115.

5 Peter Wollen, Paris Hollywood: Writings on Film. (London: Verso, 2002), 200.

6 Ibid., 201.

7 Walter Benjamin, "The Work of Art in the Age of Mechanical Reproduction” 1935. Translated in Gerald Mast and Marshall Cohen, eds., Film Theory and Criticism: Introductory Readings, 3d ed. (New York: Oxford University Press, 1985), 689-690.

8 Walter Benjamin, The Work of Art in the Age of Mechanical Reproduction, trans J. A. Underwood. (London: Penguin, 2008), 23.

9 François Penz and Maureen Thomas, Cinema \& Architecture: Méliès, Mallet-Stevens, Multimedia. (London: British Film Institute, 1997), 35.

10 Andrew Milner, “Darker Cities." Darker Cities: Urban Dystopia and Science Fiction Cinema. Accessed April 29, 2016. http://ics.sagepub.com/content/7/3/259.abstract.

11 Ibid.

12 Barbara Caroline Mennel, Cities and Cinema. (London: Routledge, 2008), 143.

13 François Penz and Maureen Thomas, Cinema \& Architecture: Méliès, Mallet-Stevens, Multimedia. (London: British Film Institute, 1997), 62.

14 Le Corbusier and Frederick Etchells, Towards a New Architecture. (London: Architectural Press), 1946.

15 “Jacques Tati's Playtime: Modern Life Is Noisy." Spectacular Attractions. 2008. Accessed May 20, 2016. https://drnorth.wordpress.com/2008/11/12/jacques-tatis-playtimemodern-life-is-noisy/.

16 “Jonathan Rosenbaum." Jonathan Rosenbaum. Accessed May 20, 2016. http://www. jonathanrosenbaum.net/1973/05/tatis-democracy/.

17 Architecture in Movies - Brazil." Futuristic Architecture in Movies. 2011. Accessed May 06, 2016. https://futuristicarch.wordpress.com/2011/05/07/architecture-in-moviesbrazil/.

18 Michiel Dehaene, Lieven De Cauter, and Michael Foucault, Heterotopia and the City: Public Space in a Postcivil Society. Of Other Spaces. (London: Routledge, 2008).

19 Giuliana Bruno, Atlas of Emotion: Journeys in Art, Architecture, and Film. (London: Verso, 2002), 60.

20 Sean Lally and Jessica Young, Softspace: From a Representation of Form to a Simulation of Space. (Abingdon: Routledge, 2007). 
21 Guido Incerti, Daria Ricchi, and Deane Simpson, Diller Scofidio (Renfro), the Ciliary Function: Works and Projects, 1979-2007. (Milano: Skira, 2007), 11.

22 Michel de Certeau and Steven Rendall, The Practice of Everyday Life. (Berkeley: University of California Press, 1984).

23 Henri Lefebvre, The Production of Space. (Oxford: Blackwell, 1991).

24 Sean Cubitt, The Cinema Effect. (Cambridge: MIT Press, 2004). 


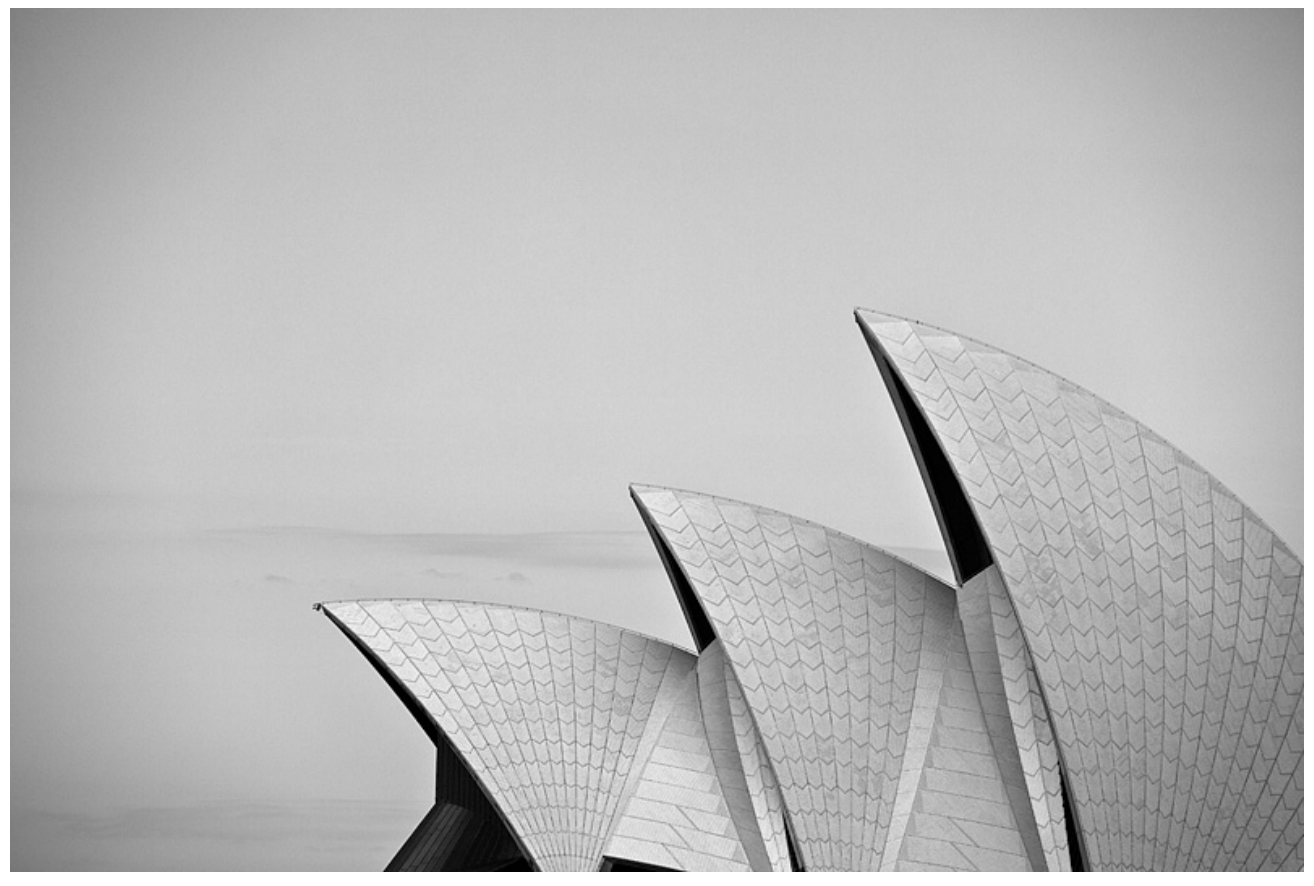

Figure 29: Sydney Opera House, 1973 Jørn Utzon 


\section{4 | image as communication}

\subsection{Pictorial Monuments}

The notion of architecture as image exists in both positive and negative contexts. Historically, iconographic programs linked to institutional or political systems (e.g. Nazi regime), religion (e.g. Catholicism, Islam) or cultural greatness (e.g. imperial Rome) have supported the cultivation of architectural narratives. In particular, imageability and spatial sequencing are integral to the production of narratives. Imageability relies on the user's cognitive tendencies to organize, simplify and store complex visual information. ${ }^{1}$ Monumental buildings, such as the Parthenon, rely on a user's interpretive processes of semiotics and embodied experience to convey narratives of social power. The Parthenon's pillars create rhythmic alterations of solid and void that characterizes a dramatic spatial sequencing. This sequencing results in a series of architectural climaxes. ${ }^{2}$ These monuments have a visual clarity, a concentrated unity and a sense of solidity that imply their permanence and weight. The large scale of monuments signifies their importance, durability and ongoing significance. These design features affect the user's interpretive processes and provide a context for constructing a narrative and establishing a personal relationship to the space. The features of monuments demonstrate the way in which architecture looks to political, social, economic or cultural authorities to define its structures.

Following the Second World War, a new monumentality emerged. No longer oriented towards the user on the ground, new monuments were based on pictorial stills, views and complexes from afar; less attention was paid to the embodied experience. The pictorial still is prevalent in Oscar Niemeyer's National Congress in Brasília and Minoru Yamasaki's former World Trade Centre in New York. These complexes were criticised for not playing an effective role in the user experience of space as they had little spatial and visual connection to surrounding streets. The monument was a legible tool that distinguished cities from each other. Human consciousness translated them into pictorial stills that could be committed to memory. Reproduction technologies facilitated the translation of monuments into pictorial stills and influenced the transformation of the western monument tradition. ${ }^{3}$ Image production has changed the communicative role of architecture; preceding technological media, buildings were the oldest forms of communication. Prior to print media, cathedrals were adorned with sculptures, frescoes and stained glass windows, mediums to convey biblical texts to the largely illiterate congregations. In Notre Dame de Paris, Victor Hugo states, "ceci tuera cela," which translates to "this will kill that." ${ }^{5}$ He believed that the development and mass production of pictures and diagrams was a death sentence to architecture. As a new way of transcribing human thought, image production was a more 


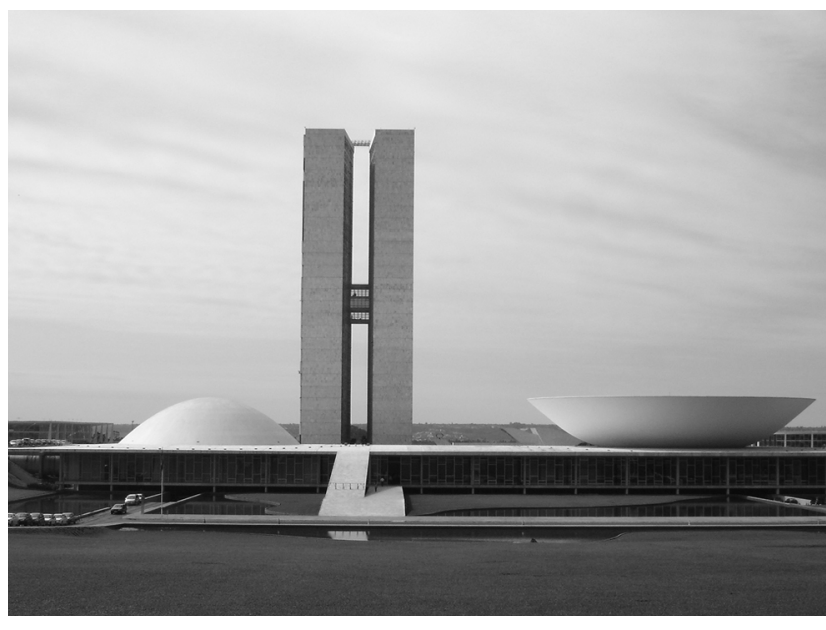

F.30

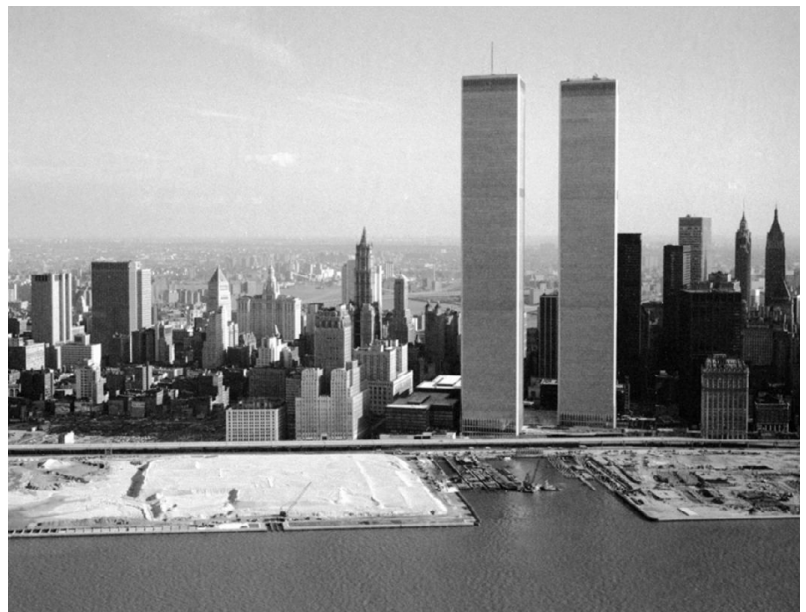

F.31 feasible and efficient form of communication. Hugo's prediction came to fruition: architecture lost its status as the focal point of cultural information to new media. ${ }^{6}$ The evolution of media technologies has created new means of monitoring, recording and analysing the visual world. Images are produced to distribute information, educate and entertain. Architecture becomes inauthentic when developed from a design model that foregrounds the pictorial still; it becomes one of many fleeting images in a society of information.

\section{2 Architecture as Spectacle}

Within contemporary society, limitless productions of transitory, memorable pictures exist as a superficial representation of culture. Juhani Pallasmaa defines architecture of image as the trademarking of a building for the purpose of creating seductive, memorable or formal configurations which deliberately focus the user's attention to an object in space. ${ }^{7}$ This type of design is commonly considered an architecture of spectacle and will be referred to as such going forward. The architecture of spectacle satisfies a small part of the visual field of attention; it occupies the first layer of focal attention.

\section{Figure 30: Brazilian National Congress, 1964 \\ Oscar Niemeyer}

Figure 31: World Trade Centre, 1966 Minoru Yamasaki 


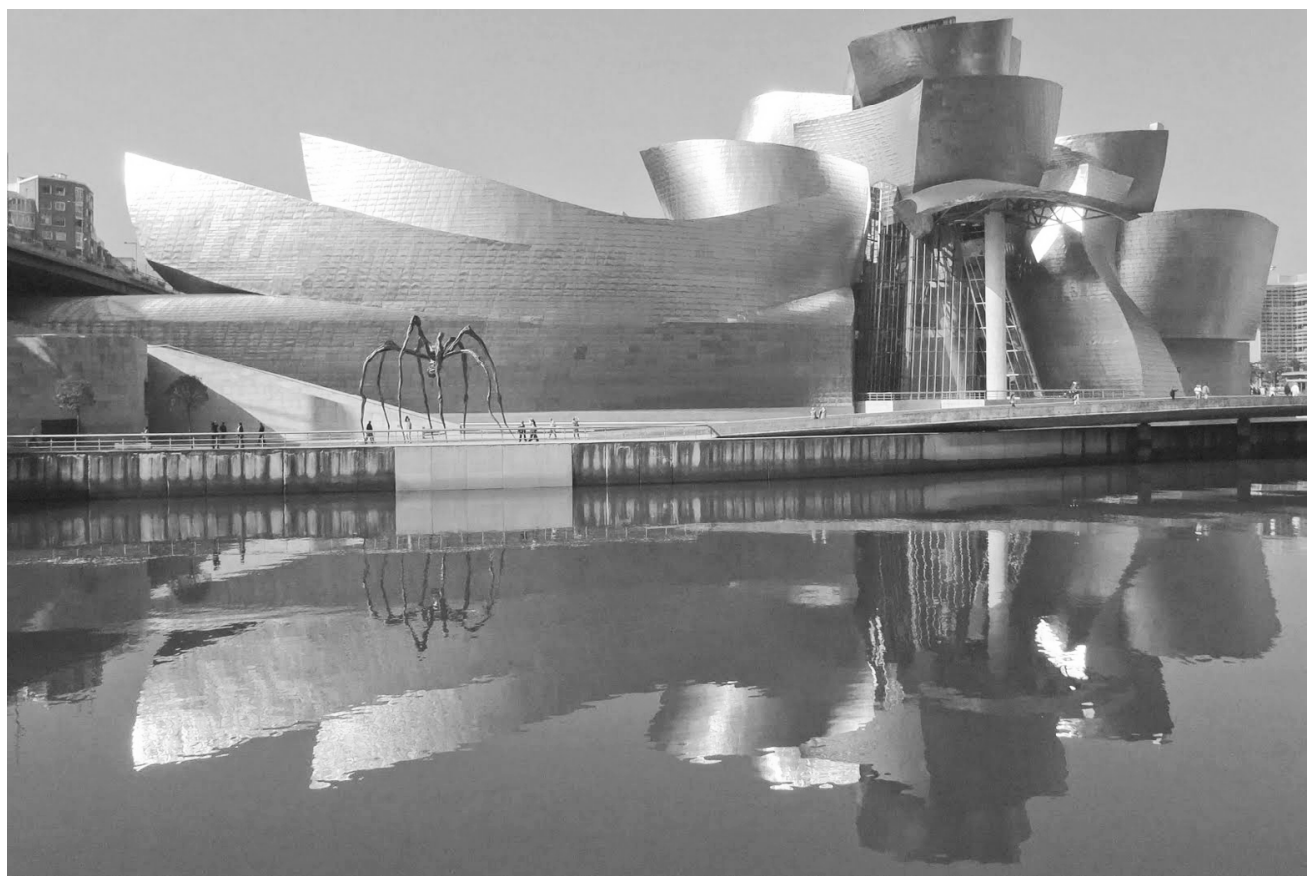

Figure 32: Guggenheim Museum, Bilbao, 1997

Frank Gehry
Modern society has evolved into a culture supported by excess. Mass production has enabled this new experience of living. Guy Debord's Society of Spectacle discusses how having was replaced by the appearance of having. Due to the globalization of images, architecture aggressively claims territory within the market economy and becomes a vehicle for capitalism. For Debord, this relationship between architecture and capitalism poses a problem for both the practice and critical reception of architecture. As architectural historian and critic Anthony Vidler states, Debord's Spectacle is "image accumulated to the point where it becomes capital." 8 The current focus on novelty and uniqueness within contemporary architecture limits the potential of the image as a communicative medium. The formal logic and programmatic elements of Frank Gehry's Guggenheim in Bilbao are negated in light of its touristic awe. Norman Foster questions moments in architectural design that are subject to the same spectacular effect as Bilbao's Guggenheim. There is a certain amount of self-indulgence in this freedom of expression, and it emphasizes that architecture has been transformed by capitalism into a marketing tool. No longer bound by historic ideals - Bilbao's Guggenheim is developed organically out of formal experimentation and material innovation - the project supports the consumer within the Society of Spectacle. 

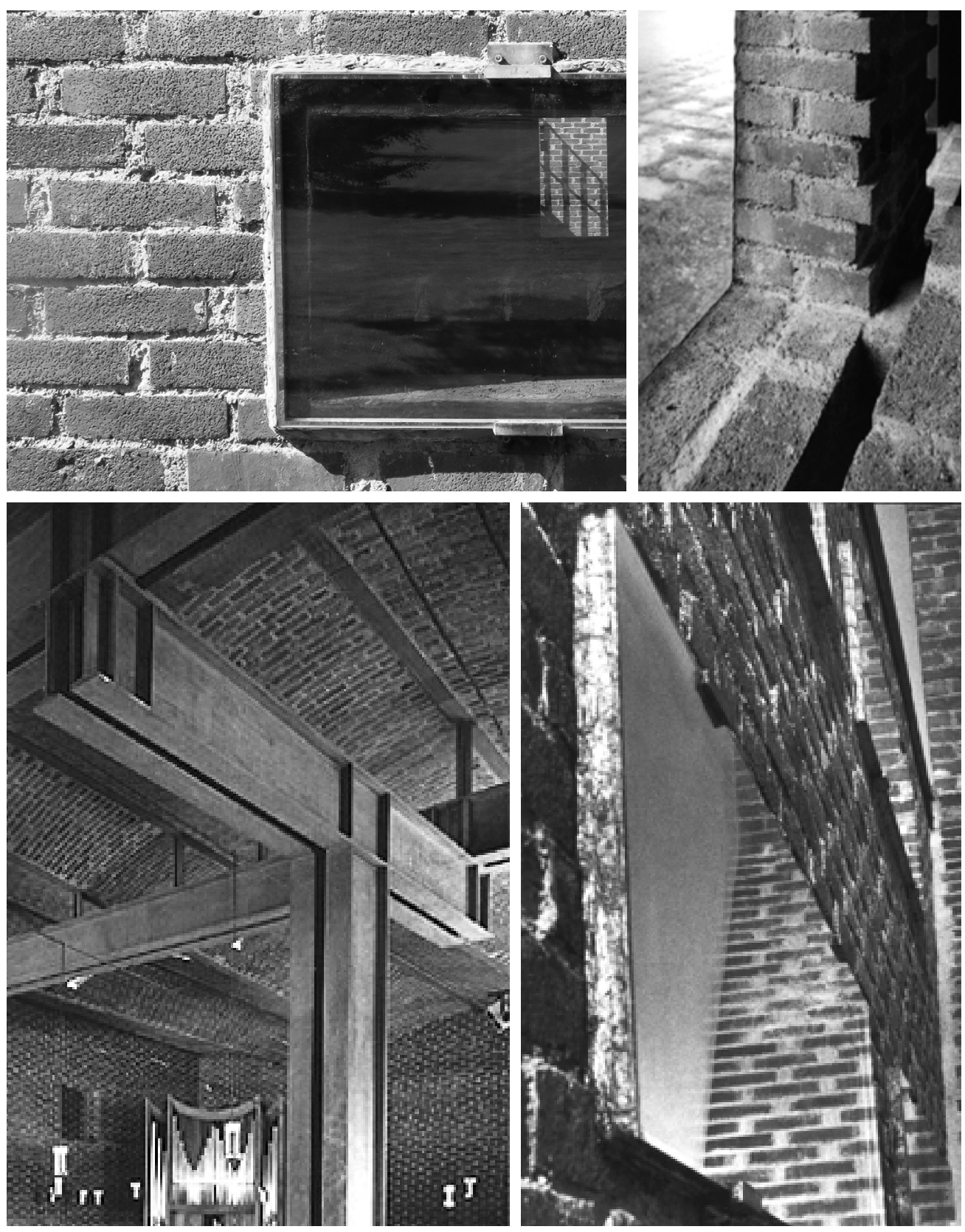

F.33 
Figure 33: St. Peter's Church, 1966 Sigurd Lewerentz

Some monuments that have little to do with the photograph or pictorial still, rather, express an overwhelming sensorial quality. Sigurd Lewerentz's St. Peter's Church is enveloped with a brick fabric; its openings and interior are complimented with the same texture. Neither iconographic nor fetishizing, the distinct contrast between the interior and exterior reinforces the intensely physical character of the building. Its singular use of material heightens the user's awareness of it. Structural expression is suppressed to emphasize the monotony of the material.
Historically, architecture has supplied the economy with its iconic associations. Postmodern architects Robert Venturi and Michael Graves provided consumer culture with designs that embrace the memorable picture above all else. The late-modern architecture of Richard Meier, Peter Eisenmann and Bernard Tschumi used design to deter viewers from the world of mindless consumer culture. Contrarily, within contemporary culture, there is a tendency to judge architecture as a technical achievement. Santiago Calatrava's structural engineering makes a spectacle of technology. This celebration of technical complexity is also apparent in the work of Jean Nouvel, Zaha Hadid and Daniel Libeskind. ${ }^{9}$

Architecture as an instrument for communication is the central theme of Dailbor Vesely's work Architecture in the Age of Divided Representation. For Vesely, architecture's role is to provide a setting for users to experience and participate in - its function is not fixed or absolute. ${ }^{10}$ Vesely equates contemporary design process with abstract geometrical definitions that are realized in a particular material to create a world of experience for the user. The current focus on producing novel, unique architecture that satisfies the aesthetic component of Vesely's first two criteria has stripped architecture of its ability to elicit an emotional response from its user. The architecture of spectacle emphasises formal expression above all else, and considers the user's experience of space secondary to the pictorial view that is created and distributed through media reproduction. The high-bandwidth of architectural pictures is a response to the public's capacity to absorb information. This increased rate of information distribution begs the question of whether it is the architect's responsibility to design the image in the first place. ${ }^{11}$ Society is continually inundated with information, which has led to a decrease in the user's attention to architecture and the meaning of architecture as a communicative representation of culture.

In a world increasingly veiled by representation, the role of the architect is to support human experience. The task of architecture is to enhance experience by designing for social and cultural interaction. ${ }^{12} \mathrm{~A}$ perceptual design model aims to counter the negative connotations of image within architecture. The role of the image has been reconsidered as a multi-sensorial device to express the perceptual qualities of space. A perceptual design model is focused on the user's peripheral awareness, as the periphery is where architectural elements are understood. This model foregrounds the user's emotive experience of architectural space. 

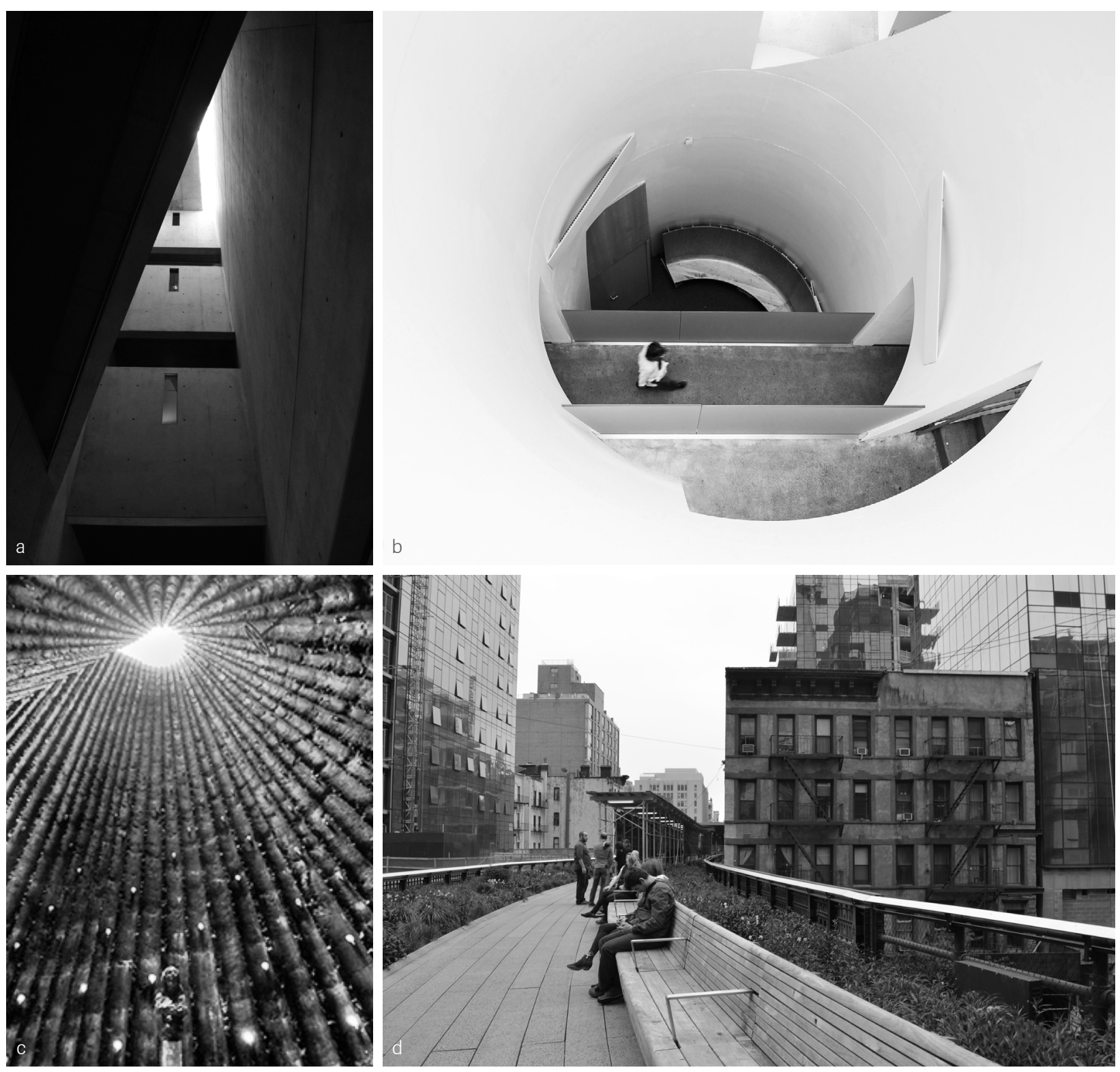

F.34 
Figure 34: Explored Precedents

a. Jewish Museum, 1999 Daniel Libeskind

The user's movement through the museum is not forced nor is it a stringent linear procession. The spaces are to be discovered by visitors through exploration. The artifacts within the exhibit become supporting characters; the spaces embody the poetic atmospheres of the Holocaust.

\section{b. Seona Reid Building, 2014 Steven Holl, Chris McVoy}

The voids cut through the building allow light into the interior spaces and visually link different levels. The central promenade interlaces disparate areas of program, prompting opportunity for social interaction. Several networks of stairs and ramps cut through the central promenade producing a variety of routes and pathways for users.

\section{c. Bruder Klaus Chapel, 2007} Peter Zumthor

The rich material palette and the everchanging atmosphere provide a space for contemplation and reflection.

d. High Line, 2014

James Corner Field Operations and Diller Scofidio + Renfro

The High Line uses individual instances, similar to improvised scenes, to represent a loose sequence of related events. The project lacks a definitive storyline as there are multiple points of entry into the 'scene'. The trajectories of space are based solely on the initiative of the users as there are a variety of destinations that lead from the project. The High Line mimics the sporadic narrative of everyday life and is a valuable alternative to organized leisure spaces within the contemporary urban environment.
Notes

1 Anthony Vidler, Architecture between Spectacle and Use (Williamstown: Sterling and Francine Clark Art Institute, 2008), 91.

2 Ibid., 91.

3 Ibid., 103.

4 Victor Hugo, Notre-Dame de Paris: Livre cinquième (Librairie Ollendorff, 1904), 133153.

5 “Google Translate," accessed May 08, 2016. https://translate.google.ca/?espv=2.

6 Juhani Pallasmaa, The Embodied Image: Imagination and Imagery in Architecture (Chichester: John Wiley \& Sons, 2011), 22.

7 Juhani Pallasmaa, The Architecture of Image: Existential Space in Cinema (Helsinki: Rakennustieto, 2001), 9.

8 Anthony Vidler, Architecture between Spectacle and Use (Williamstown: Sterling and Francine Clark Art Institute, 2008)

9 Juhani Pallasmaa, The Embodied Image: Imagination and Imagery in Architecture (Chichester: John Wiley \& Sons, 2011), 4.

10 Dalibor Vesely, Architecture in the Age of Divided Representation: The Question of Creativity in the Shadow of Production (Cambridge: MIT Press, 2004), 4.

11 Anthony Vidler, Architecture between Spectacle and Use (Williamstown,: Sterling and Francine Clark Art Institute, 2008), 175.

12 Juhani Pallasmaa, The Embodied Image: Imagination and Imagery in Architecture (Chichester: John Wiley \& Sons, 2011), 22. 

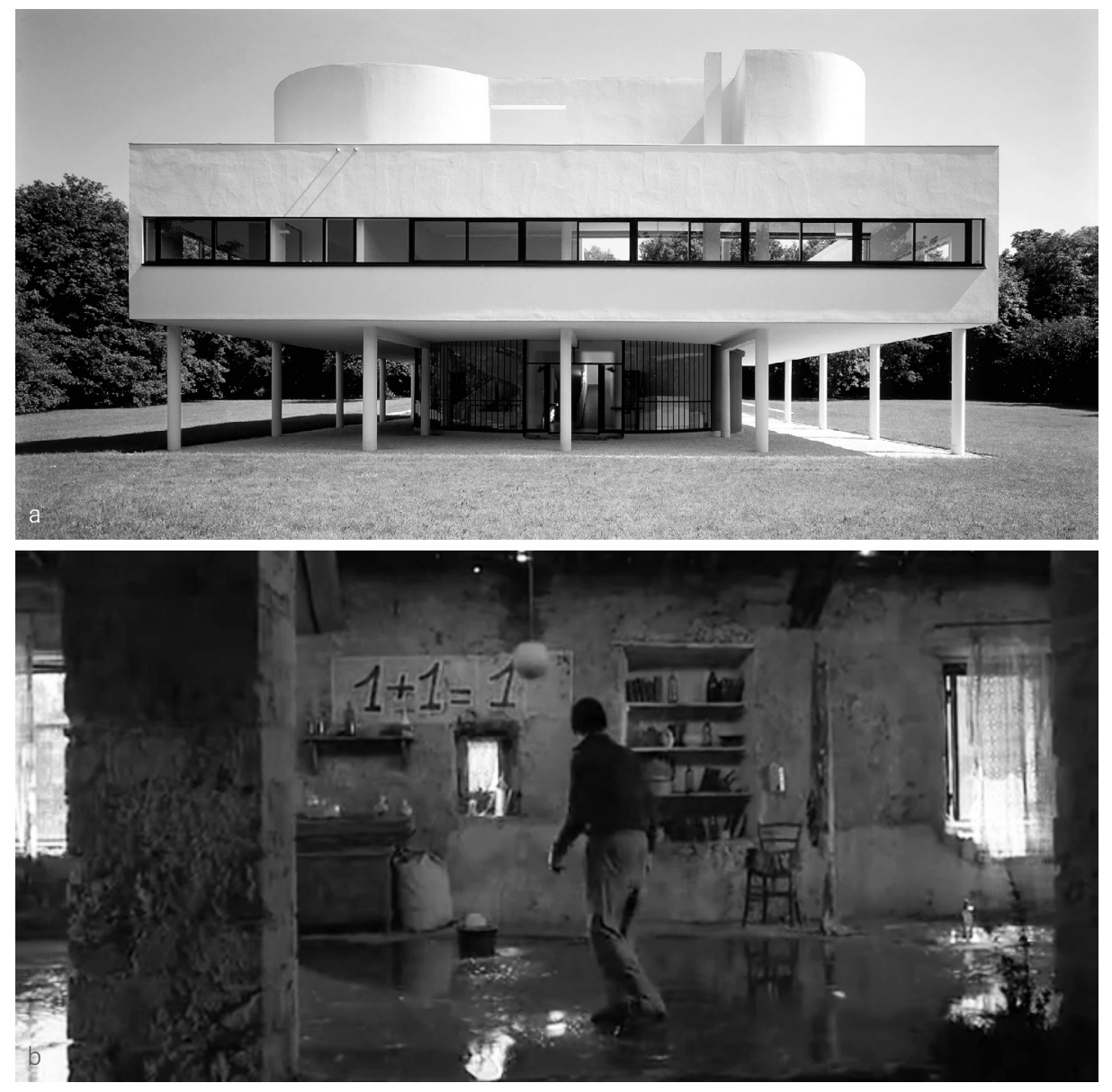

Figure 35: Images of Matter
a. Villa Savoye, 1929
Le Corbusier
b. Still; Nostalghia, 1983
Andrei Trakovsky 


\section{5 | mediums of imagery}

\subsection{Lived Imagery}

Rather than exist solely for visual sense, profound architectural space promises an environment for activity. The 'pictoral still' does not provoke multisensorial engagement within the built context. Modernist architecture was a quest of perfectly articulated forms and surfaces and Modern thinkers associated its flat, geometric character with timelessness. As Pallasmaa asserts, Le Corbusier's Villa Savoye encapsulates the ideals of Modernist architecture because of its perfect absoluteness. ' Le Corbusier aspired to Alberti's perfection of form, aiming to create a complete, autonomous space that required neither addition nor subtraction. Villa Savoye is both a celebration and a reaction to functionality of the new-machine age. Multi-sensorial images of architectural space are not pictorial stills - they are images with potential to activate multiple sense modalities. The user only sees a small fraction of the visual field at a time, and yet the viewer's perceptual system instantly synthesizes a setting to perceive and understand its tactile elements. The scene portraying Domenico's leaking roof in Andrei Trakovsky's 1983 film Nostalghia, sensitizes the film's audience to the vulnerability of the setting. The shot exemplifies Pallasmaa's "images of matter" 2 in that it allows audiences to interpret and contribute to its incompleteness. In order to recharge architectural images with emotive power it is necessary to reconnect them to the human mind. The act of inhabiting provokes dwellers to identify primal architectural images with the dwelling. ${ }^{3}$ The following passage by German poet Rainer Maria Rilke, exemplifies how users experience dwellings. Rather than a pictorial still, the poet describes his childhood home as an agglomeration of detached fragments of lived imagery:

Afterward I never again saw that remarkable house, which at my grandfather's death, passed into strange hands. As I recover it in recalling my child-wrought memories, it is no complete building: It is all broken up inside of me; here a room, there a room, and here a piece of hallway that does not connect these two rooms, but is preserved, as a fragment, by itself. In this way it is all dispersed within me... It is though the picture of this house had fallen into me from an infinite height and shattered against my very ground. ${ }^{4}$

As the above passage suggests, the mind idealizes dwellings over time. Perceptions of spaces undergo simplification, distortion, and elaboration as they are converted into memories. ${ }^{5}$ As such, memories are essentially imaginative reconstructions that inform understandings of space. 

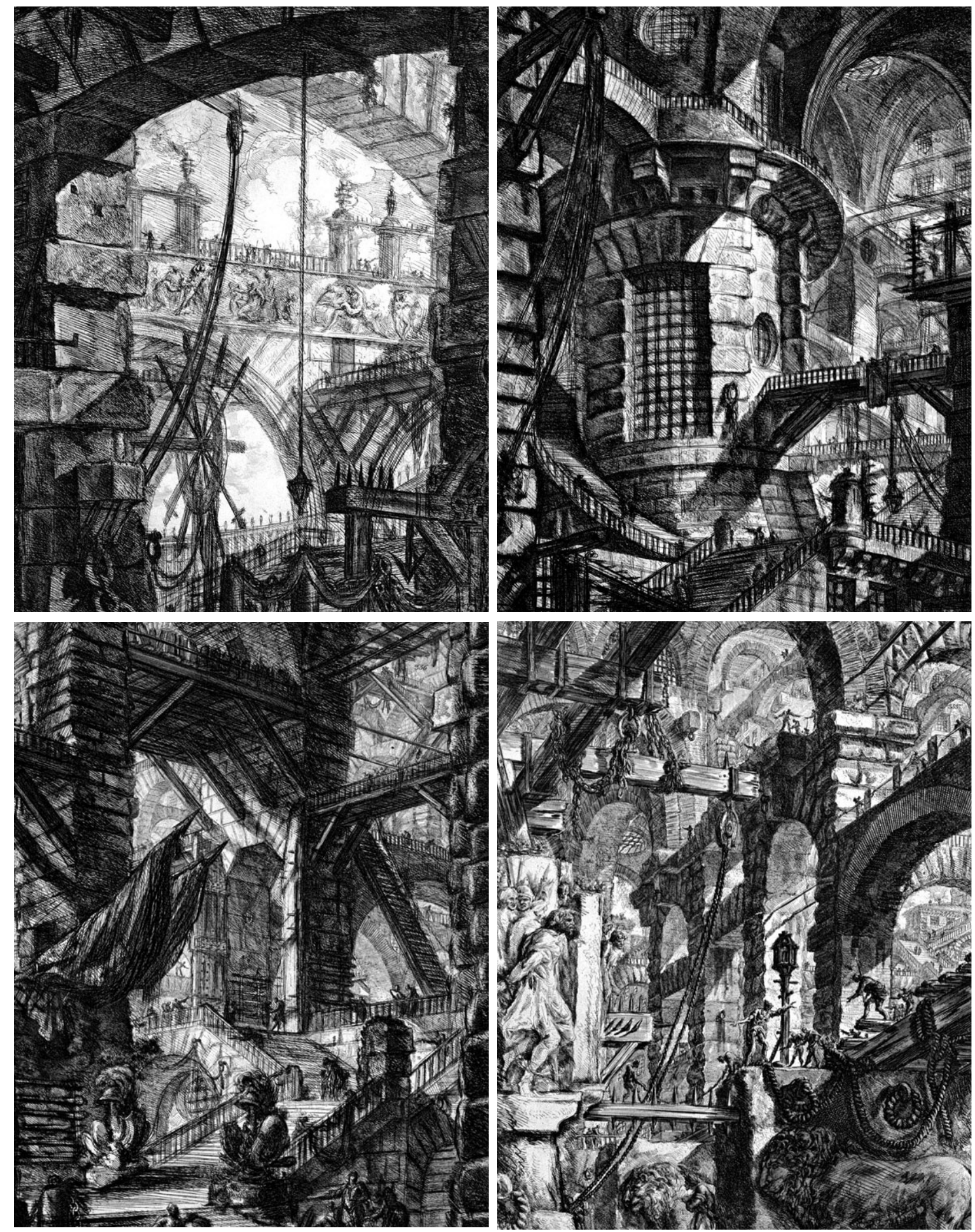


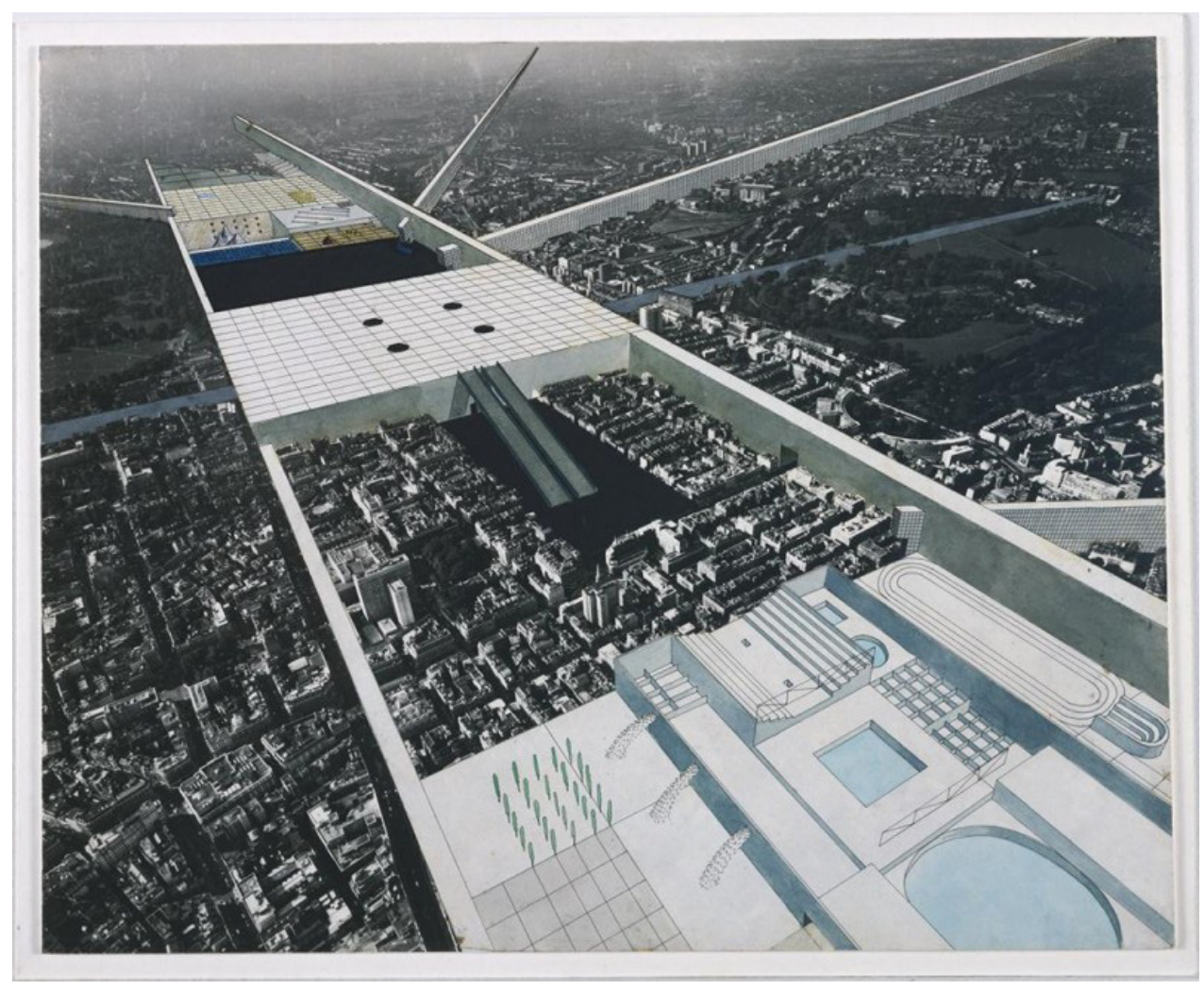

Figure 36: Carceri d'invezione, 1749 Giovanni Battista Piranesi

Figure 37: Exodus, or the Voluntary Prisoners of Architecture, 1972

Rem Koolhaas
Architecture has always fictionalized reality, romanticizing human dwelling spaces. This idealization is especially prevalent in fictional utopias or architectural projects that have yet to be built; recombinatory architectural representations are an effective medium to depict these projects. Created between 1745 and 1759, Giovanni Battista Piranesi's Carceri d' Invenzione are a series of imagined Roman, subterranean prisons. The drawings emphasize Piranesi's interpretation of the enormity and power of Roman architecture. The series' nightmarish character comments on the cruelty of the Roman Republic's judicial system under the reign of particular emperors. ${ }^{6}$ The project intentionally blends facts and fictions about the Roman prison system. Similarly, the drawings in Rem Koolhaas' thesis project, Exodus, or the Voluntary Prisoners of Architecture, remark on the Cold War in West Berlin. The drawings depict a prison at the scale of a metropolis and as a place in which people seek refuge voluntarily. The project proposes a long, walled city with vertical barriers cut through London's urban fabric. The storyboard and pictographic style points to Koolhaas' background in journalism and screenwriting. Both Piranesi's and Koolhaas' projects comment on the state of their respective societies and provide idealized images of culture. The scenes imply a multi-sensorial essence and strengthen the viewer's connection to the architect's imaginative world. 

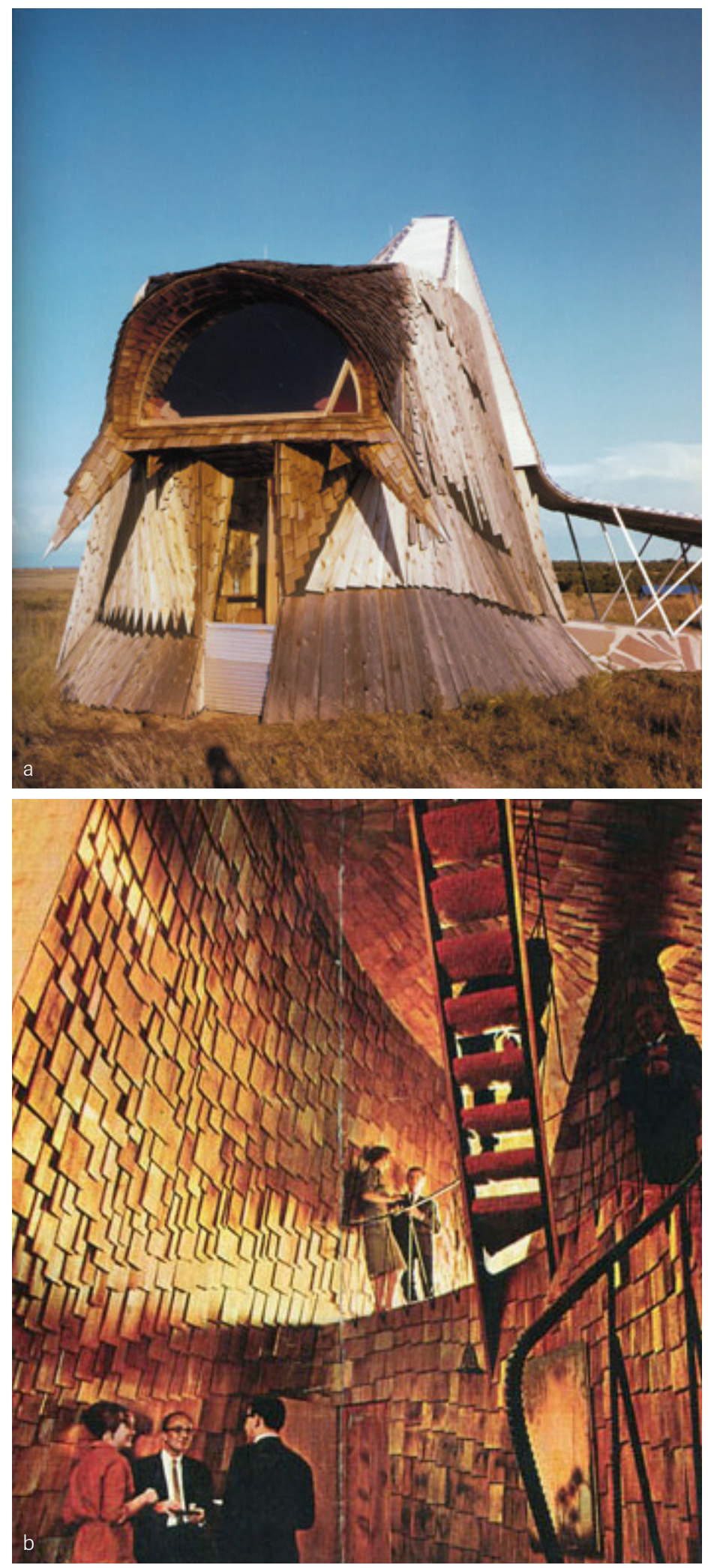

F.38 
Images provoke the human mind to recall life experiences, including the nuances of unique personal and cultural experiences. As Herb Greene states in Mind \& Image: An Essay on Art \& Architecture, "Images are a primary means of communicating the seemingly ineffable." Images allow the mind to recall multi-sensory data, including the shape, colour and texture of a space. A single image can alter previously established conceptions of and feelings about a space, object, or experience. As Greene asserts,

Sensory input is screened, dismantled, and reassembled, analyzed, interpreted and stored along a variety of channels belonging to different criteria of relevance. The particularization of experience in the process of memory formation is compensated to some extent by the multiplicity of abstracting hierarchies which participate in the process and by the retention of "picture-strips" - vivid fragments of emotive or symbolic significance. $^{8}$

Le Corbuiser's Notre Dame du Haut is an embodiment of these abstracted visual cues that speak to past European civilizations. The structure's massive thick walls, slits and small openings are synonymous with older European buildings and fortresses. Its monolithic slabs are similar to those of Carnac and Stonehenge and its white towers resemble Tunisian architecture. The roof is similar to a thatched farmhouse while its stained glass windows are reminiscent of gothic cathedrals. By using architectural elements associated with particular objects and time periods, Le Corbusier calls forth a multiplicity of stored experiences from his $20^{\text {th }}$ century views. ${ }^{9}$ The non-Euclidean shape of the roof contradicts familiar roof styles, encouraging users to question their assumptions regarding the function and style of roofs. By abstracting a roof, Le Corbusier reconstitutes its meaning. ${ }^{10}$ The roof becomes multi-layered symbol of the history of European culture.

In his Prairie House design, Herb Greene uses metaphorical imagery to poetically render several meanings simultaneously. Using a combination of sharp and pointed elements, the dwelling depicts a wounded creature. Greene merges suffering, an inextricable part of human life, with the dwelling, a space that is supposed to provide protection, shelter and comfort. ${ }^{11}$ The forms of the Prairie House attempt to convey creature, house, barn and temple all at once, in a single moment of perception. Prairie House dramatizes the cognitive process through which the mind determines the meaning of the object by drawing from a diversity of stored experiences. The dwelling is a many-membered matrix unified by components that are at once different from yet similar to one another. The value of imagery within architecture lies in its capacity to illuminate both the components and complexities of space. It is the user's interpretations of imagery that allow for an infinite variety of significance to be drawn from associative contexts. 

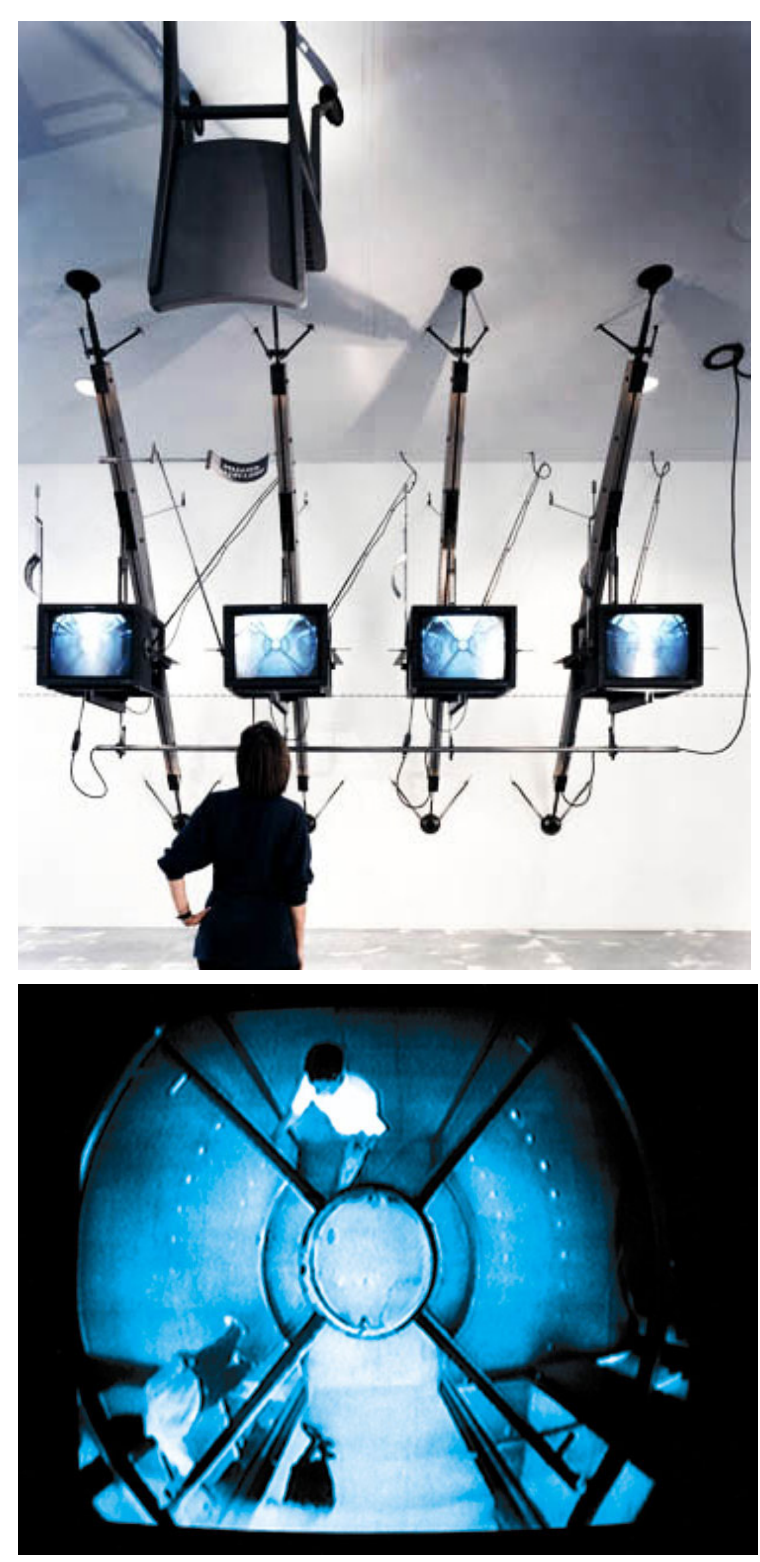

F.39 
Technological media is a staple that creates and contributes to the culture of society. All media are extensions of human senses which configure awareness and understanding of the world. In Understanding Media, Marshall McLuhan asserts that the medium by which information is transferred informs the content of the message. The state of society cannot be measured by the complexity of its machinery, but by the purpose for which the machinery is used and the efficiency of its use. ${ }^{12}$ In 1887, Eadweard Muybridge pioneered work in multi-picture projection. In his photographic studies of motion, a sequence of shots depicts a galloping racehorse. The work demonstrates the merging of the organic and the mechanical. ${ }^{13}$ By playing with speed and time, film manipulates ordinary sequences from reality into a new typology based on imaginative structure and configurations. ${ }^{14}$ Film transitions fragmented information into a narrative. The sequential arrangement generates a spirited space that is interpretable for its viewers. Film successfully transfers views from reality into another form when viewers accept the reality of the film subliminally and without critical awareness.

When conducting design research, some contemporary architects study space through film. Dziga Vertov understands film to be a prosthetic that provides psychoanalytic insight into architecture. ${ }^{15}$ Moving images and framing parallels architectural rendering and is arguably a more detailed, dynamic and exploratory means of designing. Architecture becomes a playful exercise in interpretation and imagination by enhancing the texture of the ordinary. ${ }^{16}$ Many experimental architectural projects use technology to extend human vision. John Hejduk's 1973 Wall House and Le Corbusier's 1930 Beistegui Penthouse were equipped with periscopes to explore electronic technology's ability to advance the functions of the window. ${ }^{17} \mathrm{~A}$ thoughtful architect is one who questions and magnifies contradictions of the current architectural environment. Sigfried Giedion, author of Space, Time and Architecture, discusses the value of images within an architectural context: "only film can make new architecture intelligible." 18 Images are no longer merely used to document buildings; they are used to investigate visual and spatial realities in the same manner that cinema has ambitiously tried to convey an experience to an audience. ${ }^{19}$

Diller, Scofidio + Renfo is a multifaceted studio that incorporates architecture and visual and performance arts. The studio combines disparate areas of the built environment by playing with media, physical barriers, perforating planes and altering routes of navigation. In the 1980s, Diller and Scofidio used film as a spatial investigation tool just as the VCR was transforming film distribution and exhibition style. ${ }^{20}$ The spatial narratives of Diller, Scofidio + Renfro are not fully developed stories; rather, they hint at recognizable genres of cinema. 


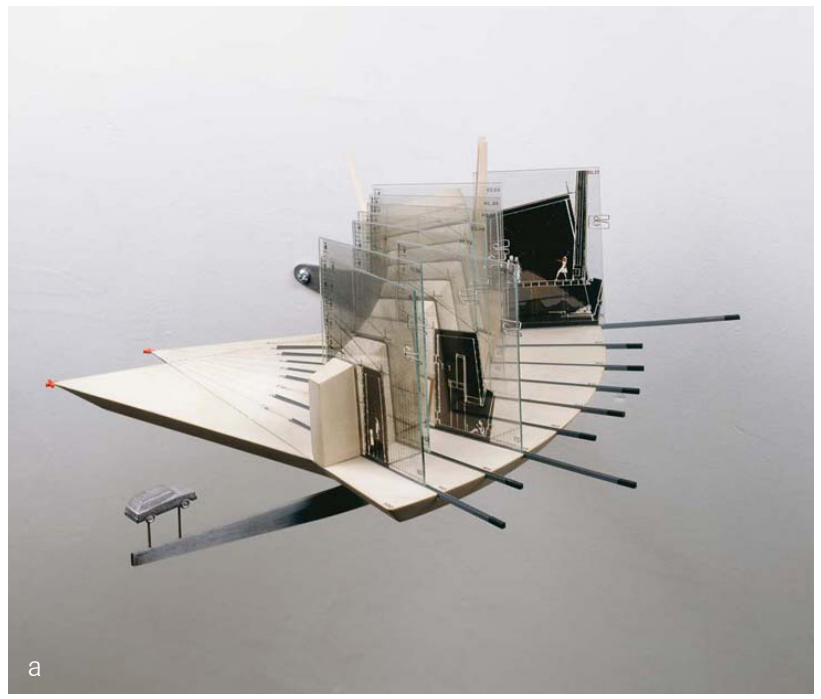

b

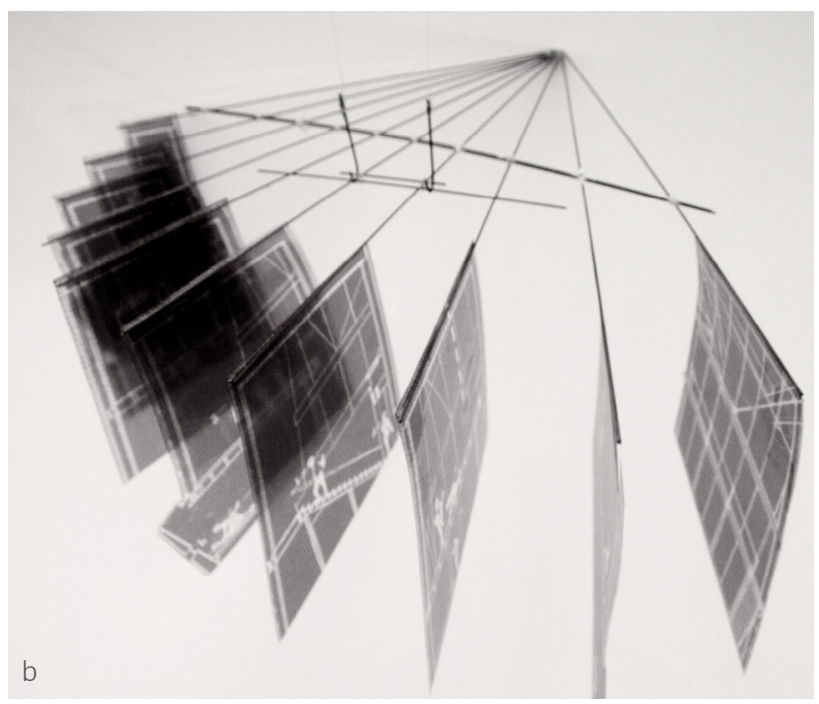

Diller and Scofidio's Slow House design, one of this design studio's early experiments of the dwelling, remarks on the spatial and cultural state of visual practice. As a response to technical culture, the Slow House bears an uncanny likeness to the automobile, the picture window and the television. The winding exterior shape suggests an organic form similar to the skeletal architectural designs of Santiago Calatrava. And yet, the interior does not imitate biomorphic precedents; rather, it has a direct, visual axis. As a critique of visual perspective, Slow House is fascinated with views. Its view of a shoreline inspired the remark, "vision is eroticized, the hostage of desiring eyes." ${ }^{21}$ The Slow House juxtaposes video image with sound to facilitate the discovery of the space before exposing the final view of the shoreline. Both freestanding and site-specific, the Slow House raises issues surrounding optical paranoia, commenting on the similarities between television and the picture window. Diller, Scofidio + Renfo is known for its ongoing exploration of the typical, Western lifestyle's dependence on machines, transportation and communication technologies. These explorations portray the architectural environment as an extension of the body. The investigative tools of Diller, Scofidio + Renfro have been extremely influential in this thesis' design research.

This thesis reconsiders the role of vision in both the development and representation of architectural space. It proposes film and multi-sensorial imagery as tools for establishing and enabling a perceptual design model. By foregrounding perception in its design model, an architecture that reconsiders image, peripheral vision and the pictorial plane illuminates the sensorial complexities of space.
Figure 40: Slow House, 1991

Diller + Scofidio

a. Constructed Slow House Model

b. Final Film Model 


\section{Notes}

1 Juhani Pallasmaa, The Embodied Image: Imagination and Imagery in Architecture (Chichester: John Wiley \& Sons, 2011), 42.

2 Ibid., 42

3 Gaston Bachelard, The Poetics of Space (New York: Viking Books, 1964), 129.

4 Rainer Maria Rilke, The Notebooks of Malte Laurids Brigge (New York: Norton, 1964).

5 Herb Greene, Mind \& Image: An Essay on Art \& Architecture (Lexington: University Press of Kentucky, 1976), 4.

6 Giovanni Battista Piranesi | the Round Tower, from 'Carceri d'invenzione' (imaginary Prisons) | the Met," The Met, accessed August 6, 2016, http://www.metmuseum. org/art/collection/search/337725.

7 Herb Greene, Mind \& Image: An Essay on Art \& Architecture (Lexington: University Press of Kentucky, 1976), 1.

8 Ibid., 3.

9 Ibid., 2.

10 Ibid., 5.

11 Ibid., 29

12 Marshall McLuhan, Understanding Media: The Extensions of Man (New York: McGraw-Hill, 1964), 24.

13 Ibid., 249.

14 Ibid., 13

15 Edward Dimendberg, Diller Scofidio + Renfro: Architecture After Images (Chicago: University of Chicago Press, 2013), 67.

16 Ibid., 201.

17 Ibid., 68.

18 S. Giedion, Building in France, Building in Iron, Building in Ferroconcrete (Santa Monica: Getty Center for the History of Art and the Humanities, 1995), 178.

19 Edward Dimendberg, Diller Scofidio + Renfro: Architecture After Images (Chicago: University of Chicago Press, 2013), 1.

20 Ibid., 4.

21 Ibid., 67.

22 Elizabeth Diller, Ricardo Scofidio, and Georges Teyssot. Flesh: Architectural Probes (New York: Princeton Architectural Press), 1994, 39. 


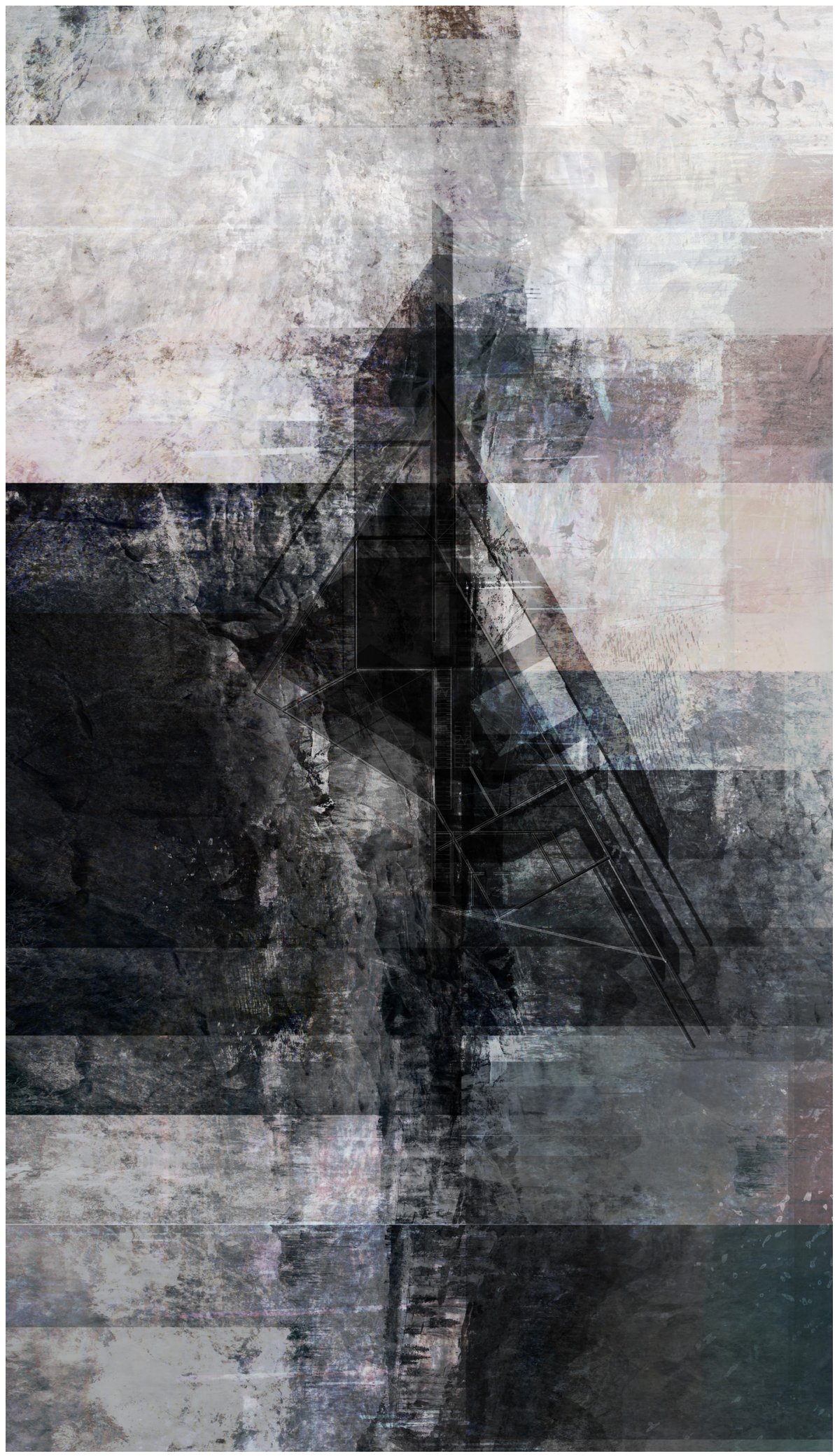

Figure 41: Experimental Drawing; House 1 


\section{6 | an architecture of imagery}

\subsection{A Perceptual Design Model}

Perception, as suggested by Maurice Merleau-Ponty, is not solely reliant on vision; rather, it is appropriated by the physical movements of the body within space. ${ }^{1}$ This design research investigates the intersections of the optical and tactile dimensions of space. Film and multi-sensorial imagery are used as tools to express the reality of the user experience by foregrounding the peripheral elements of consciousness. The previously discussed design research emulates the conditions of James Gibson's visual world; ${ }^{2}$ it idealizes the textures and atmospheric conditions of everyday landscapes.

This thesis explores the typical, negative notion of the pictoral still and advocates for the perceptual dimensions of imagery in both the exploration and final representation of architectural space. This design process suggests a reconsideration of how architecture is initially created and subsequently communicated. The role of the image is used as a multi-sensorial device to develop and represent the perceptual qualities of space.

The dwelling is utilized as a vehicle to explore a design model that caters to the peripheral zone of vision, and how a user understands and interacts with space. The intent of this project is to develop and distinguish the phenomenological textures of an architecture within the routines of everyday life. A perceptual design model facilitates contemporary design practice in a manner that counters the current ocularcentric culture. The following strategies and tactics of Figure 42 have guided the design research of this thesis in support of a perceptual design model. 

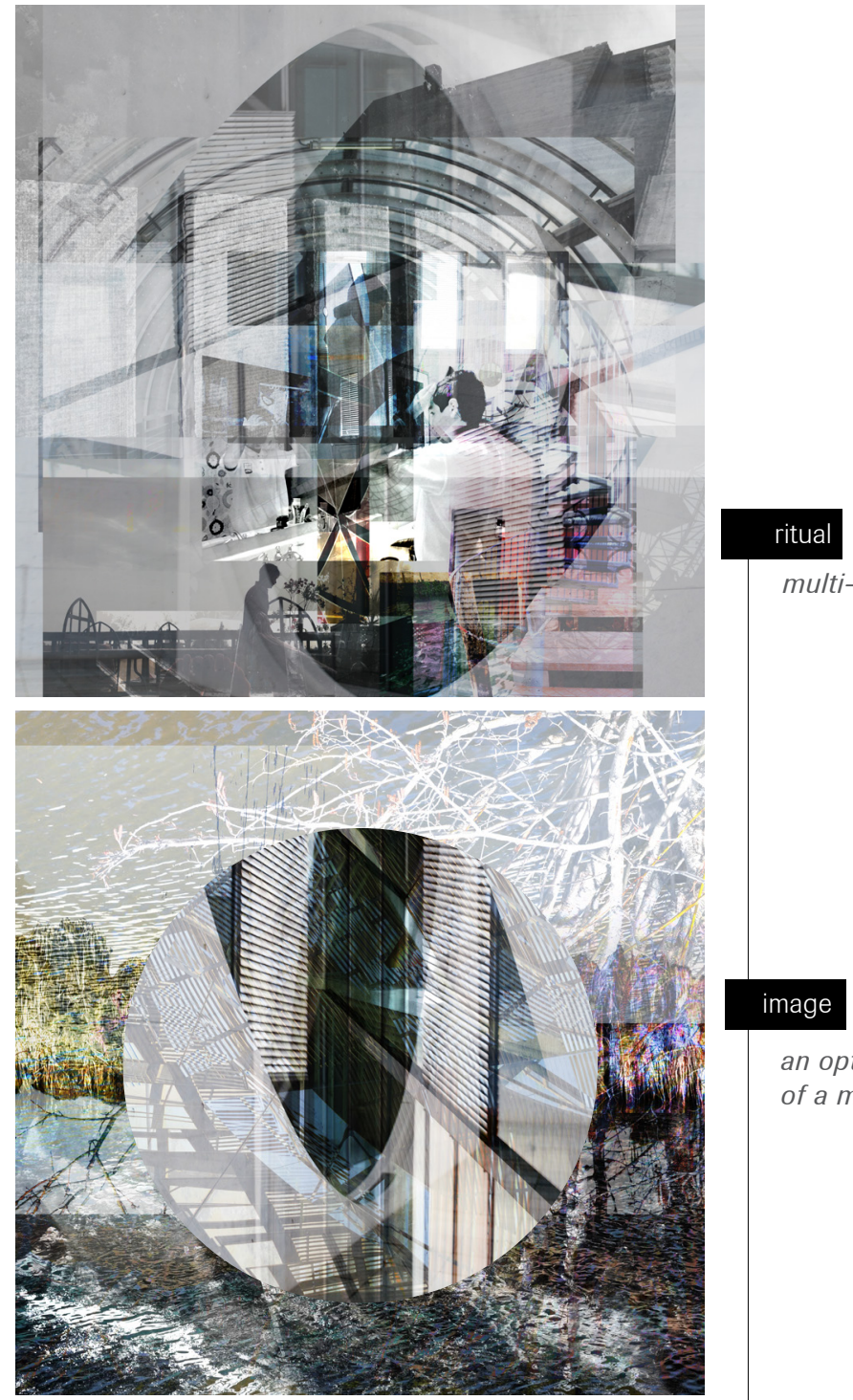

\section{image}

an optical, or other still, of a moment in time

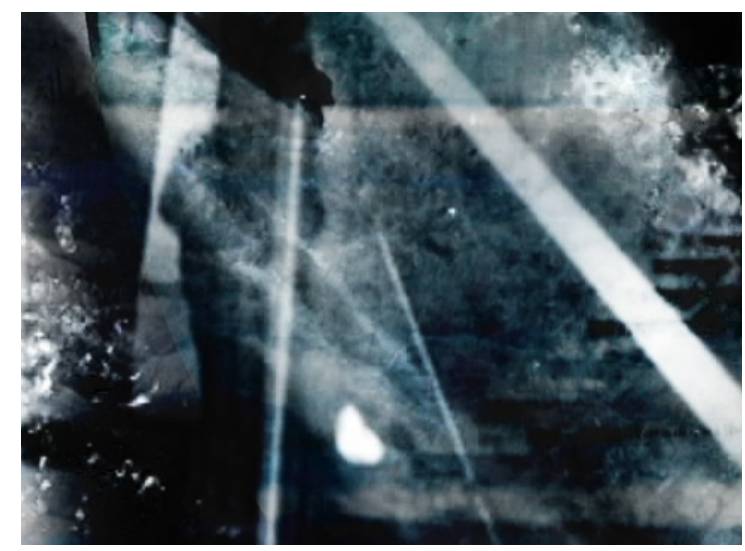

\section{imagery}

a perceptual composition; a system of

representational images 
Figure 42: Elements of Design Research Manipulating Perception

Exploring spectator's position; investigation of elements of foveal and peripheral vision.

_Cinemetrics; framing as a driver of design _Adapted film techniques; recombinatory imagery

\section{Deconstructing the Narrative}

Investigation of separate acts and events in height of a structured functional program.

_Emphasis of thresholds between areas of program; changes in scale of space/ orientation of user

_User connection to site; emphasis of views and transitions between interior and exterio space

Temporal Representation

Film as a tool to extend the role of vision; space is developed and articulated through imagery that is illustrative of foveal and peripheral vision.

_Use of imaginative (multi-sensorial) imagery; expressive of atmosphere

Film as a medium to articulate the textures and temporality of space

\section{Figure 43: Parti Models; House 1}

The parti models explore themes of intersection and fragmentation which were revealed in the design research of Quotidian.
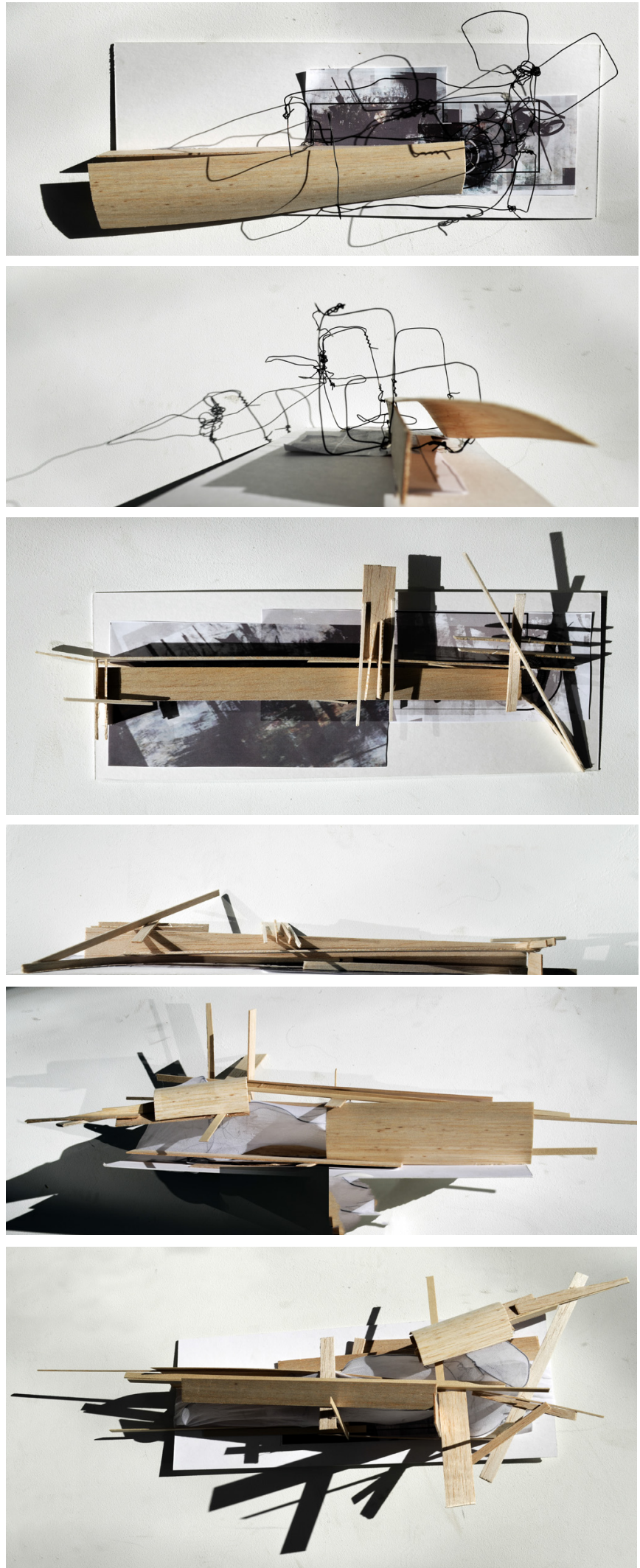


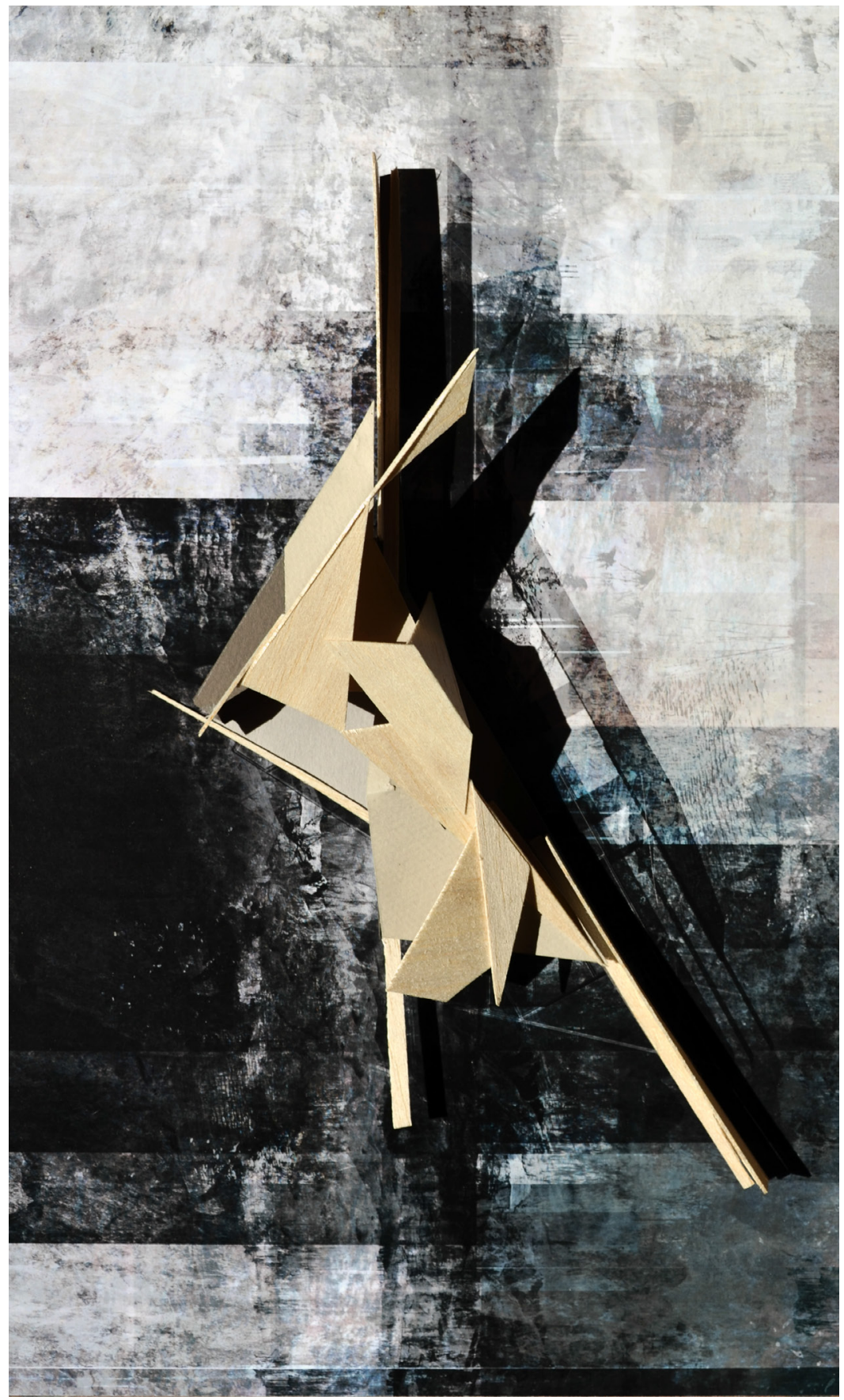

F.43 

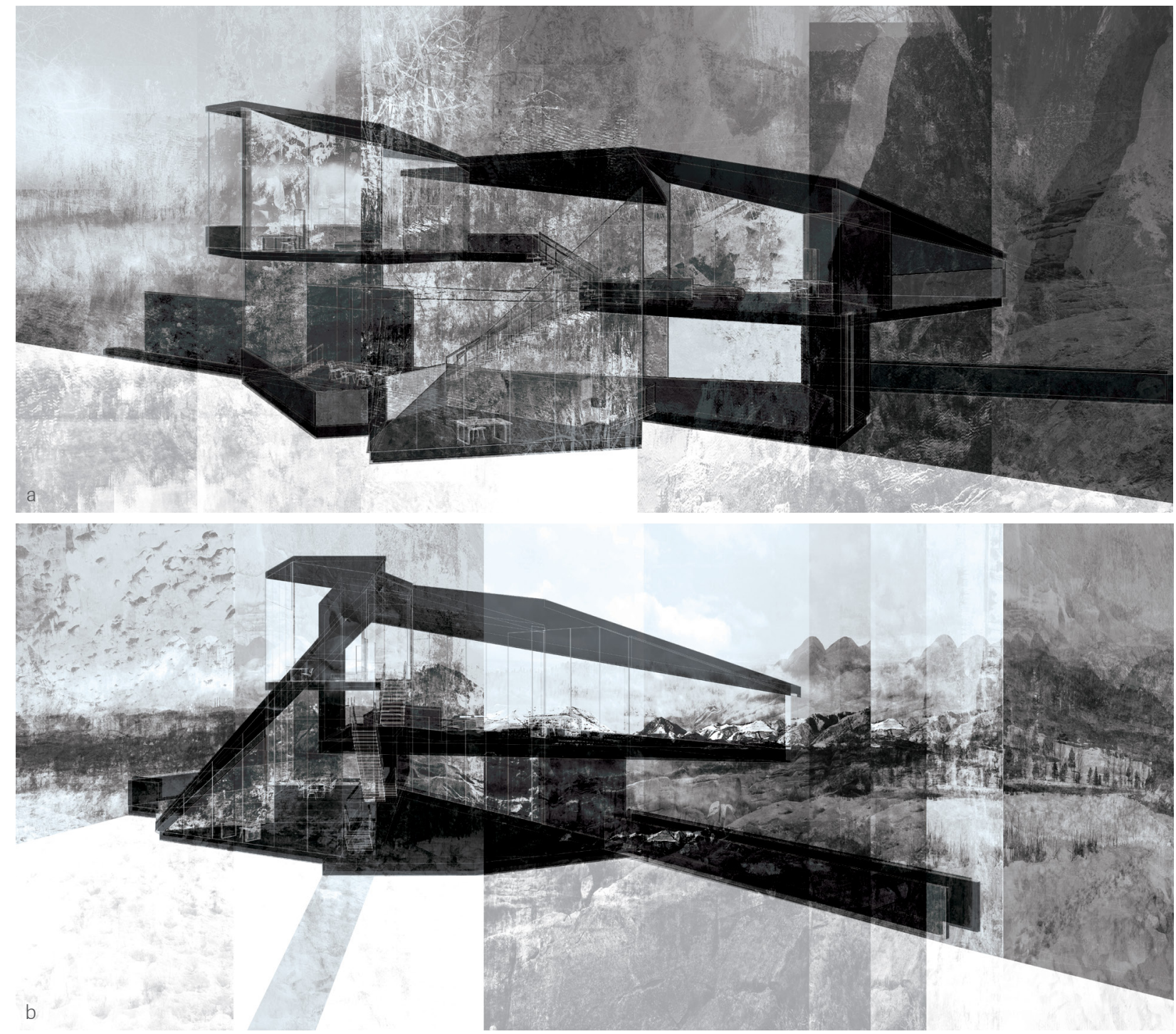

(continued)

Figure 43: Parti Models; House 1

Figure 44: Framed Landscapes Study

a. Longitudinal Section

b. Cross Section

The spaces of the dwelling are all physically and visually linked. The spaces overlap to create areas of interchangeable activity. Shared routes and spaces frame the landscape and distort the boundaries between the interior and exterior environment.

\subsection{House 1}

The first rendition of the dwelling presented in this thesis is situated in Idaho Springs, Colorado. The project site is on the shore of St. Mary's Lake, an eastern gateway to Glacier National Park. The reclusive site was chosen as it is the convergence point of prairie, mountain and forest ecosystems. This ideal landscape acts as the transient subject of the dweller's focal layer of attention. The picturesque views fall into the dweller's peripheral field of vision following the spectacle of its initial reveal. 

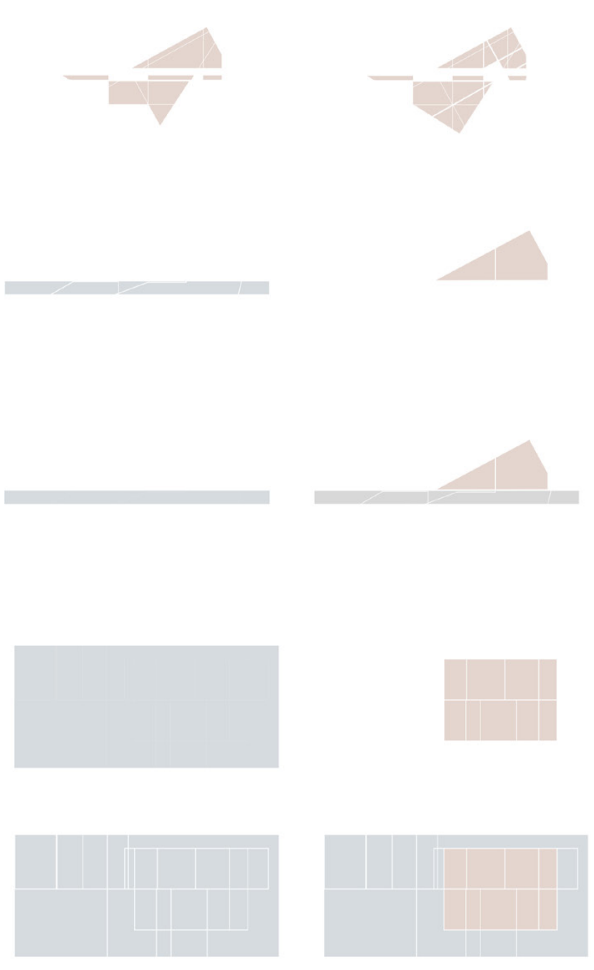

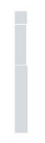

$$
1
$$
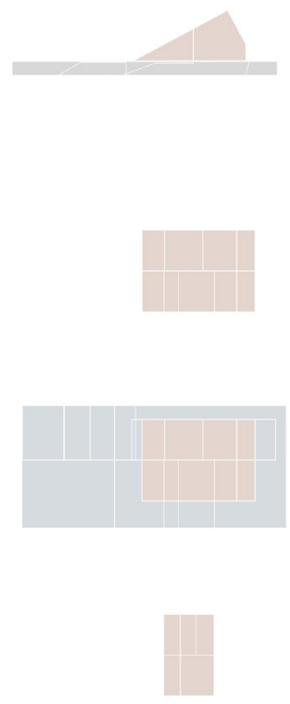
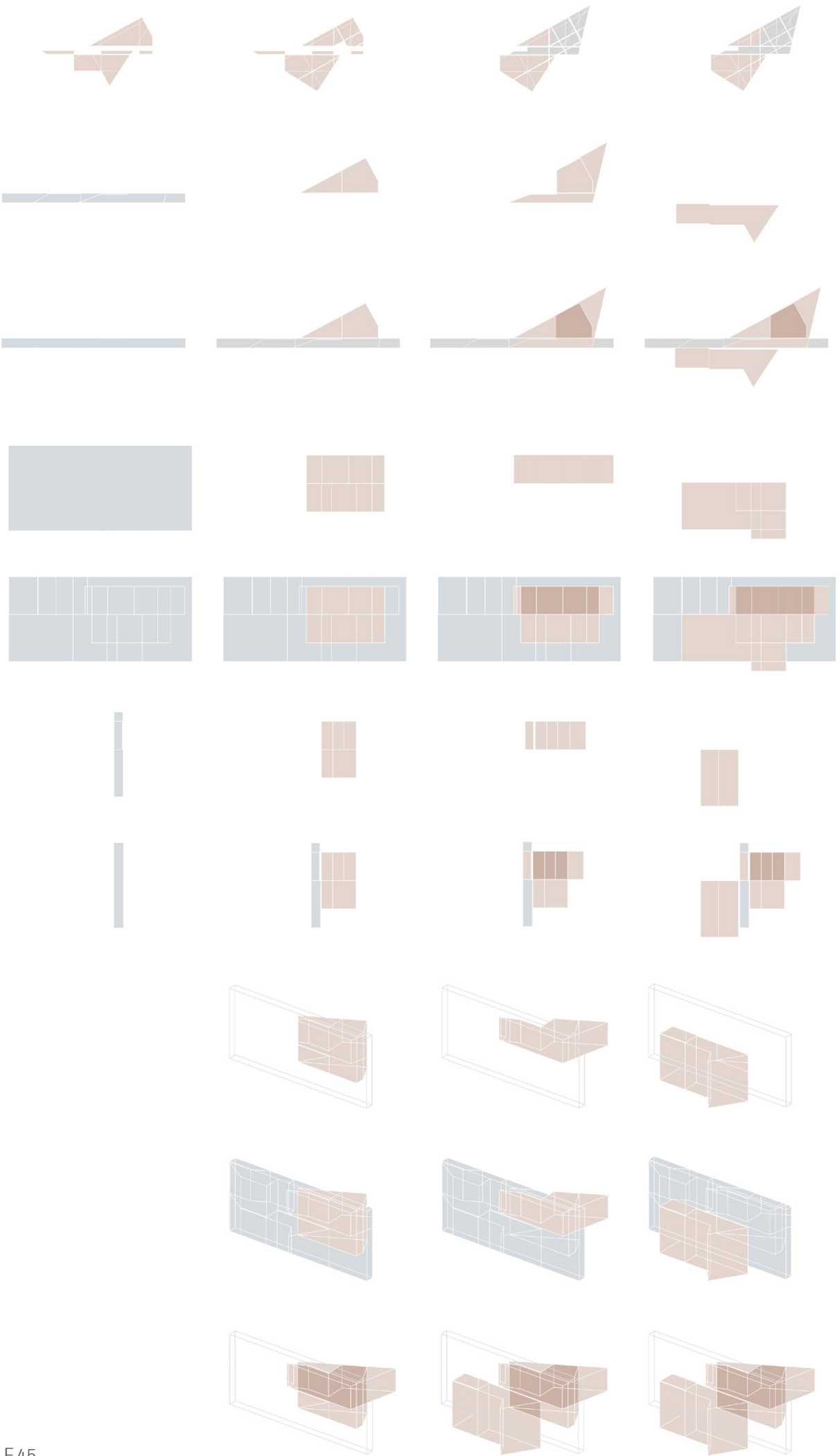

F.45
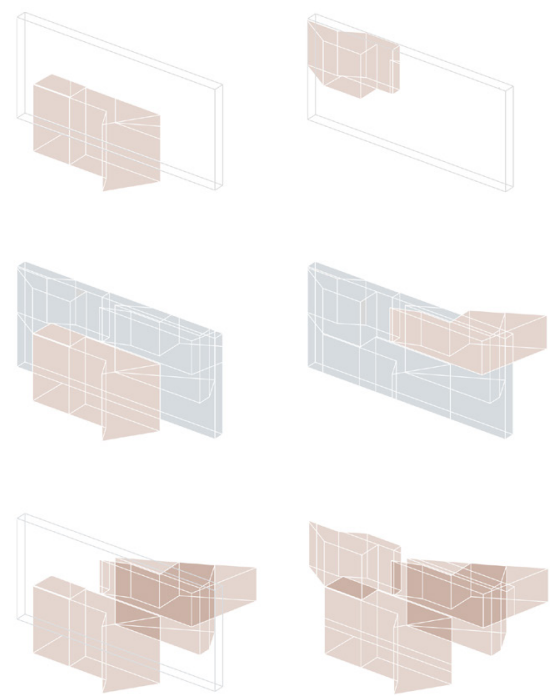
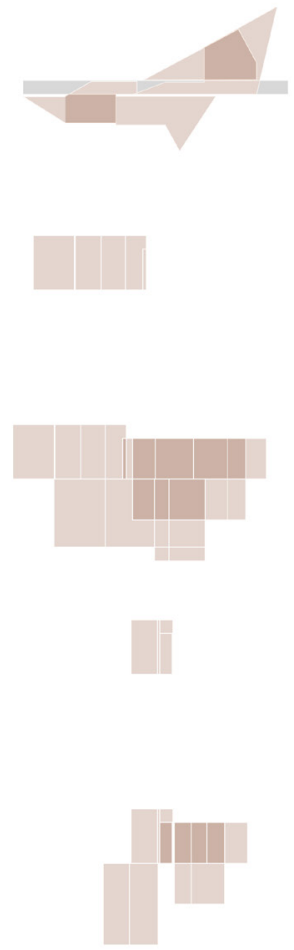


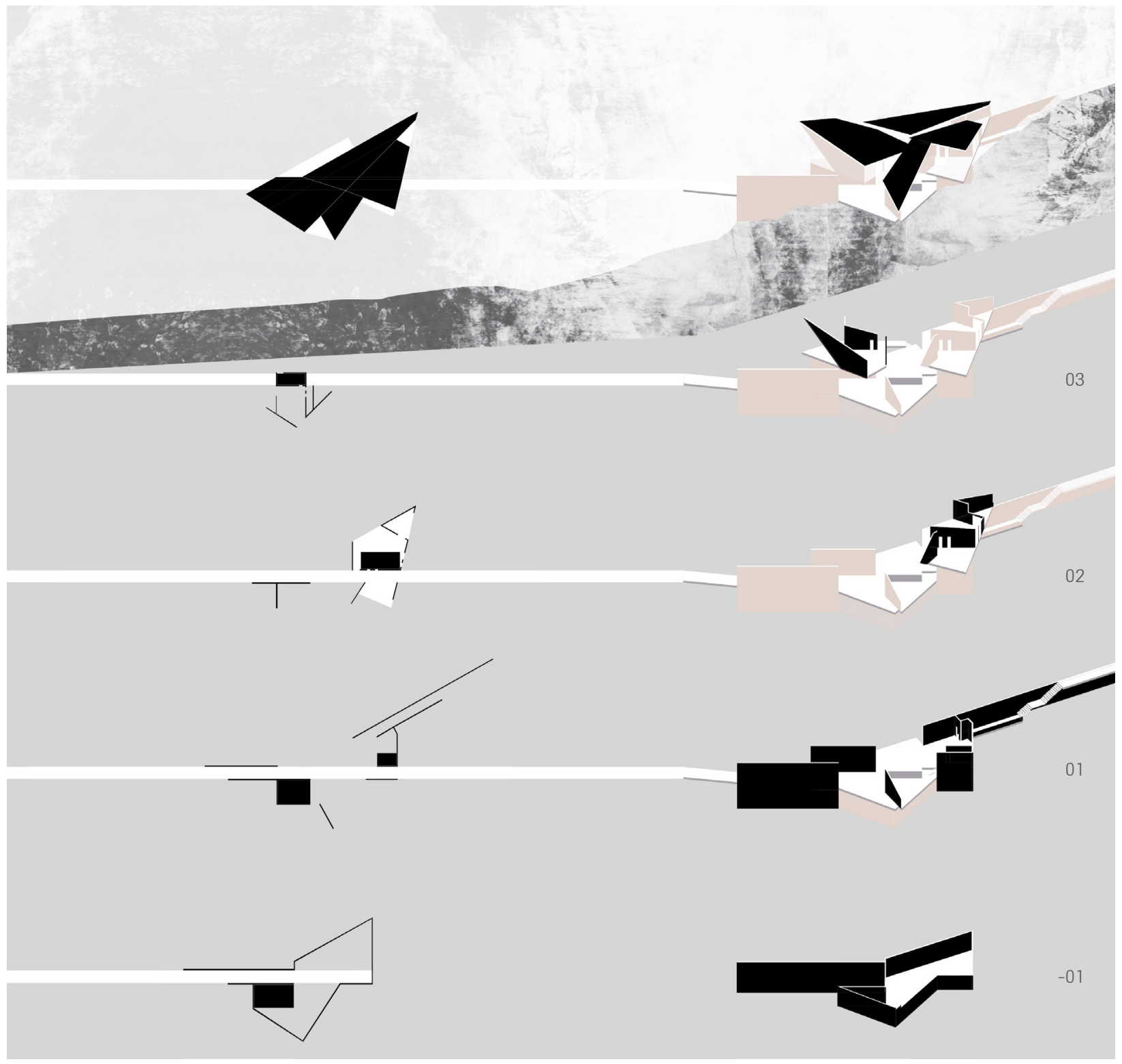

F.46

Figure 45: Layered Spaces Study

Figure 46: Axes Intersection Study

This diagram displays the relationship between solid and void elements within the dwelling. As an overall composition, in plan, the dwelling fits together clearly. Three-dimensionally, the intersections of volumes and changing orientations can be understood. The shifting planes of the dwelling alter the orientation of the user and create crossed viewports.
In House 1 (Figure 46), a single overriding plane is the unifying element from which all spaces are offset. The layering of spaces and the intersections of axes are explored in plan, section and three-dimensions (Figure 45). The darkened areas indicate the intersection of two different programs; these areas of overlap are where two types of space co-exist. The shared spaces indicate moments of transition that are further explored through film to inform the final design. 

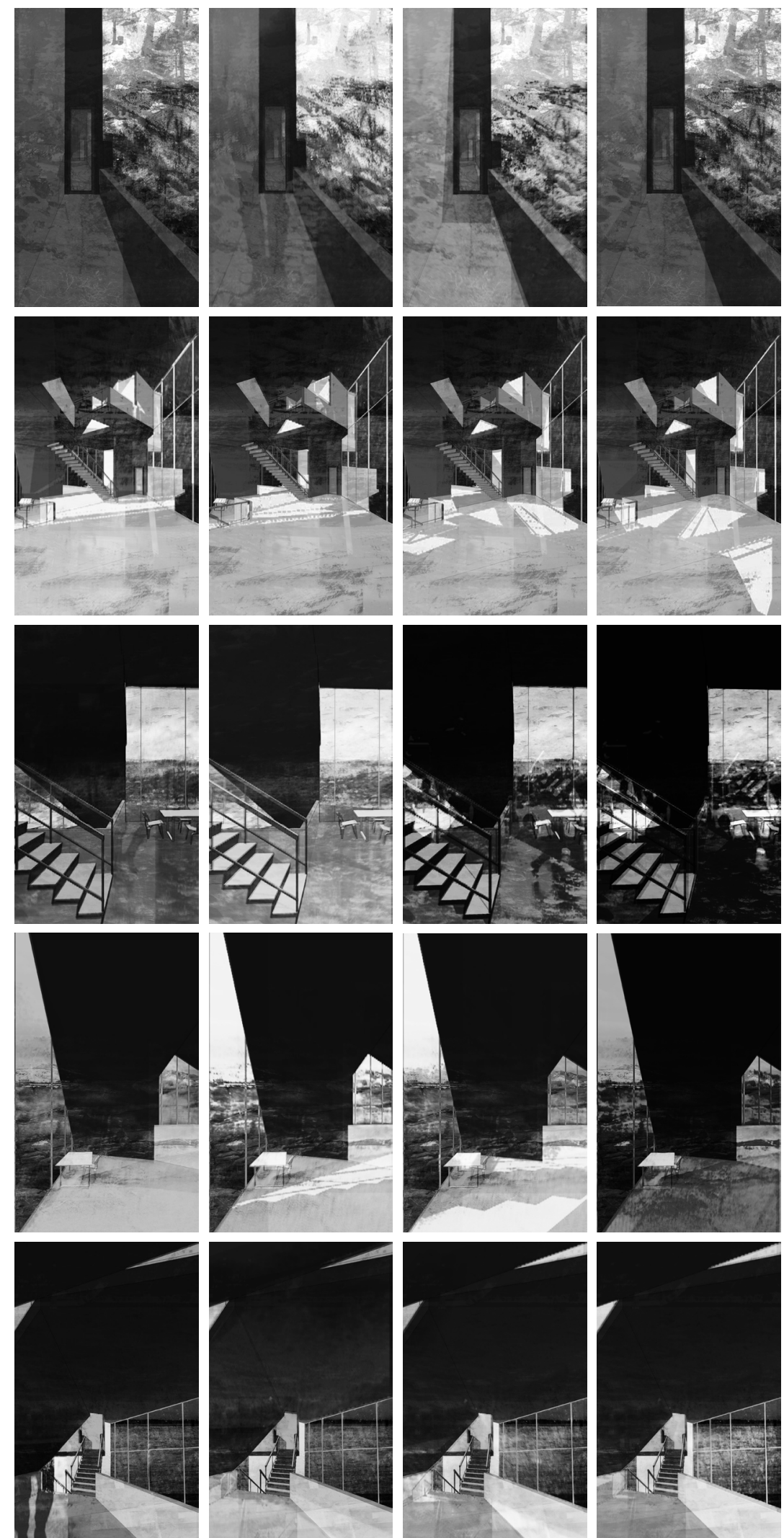


\subsubsection{Temporal Imagery}

Film is used to investigate areas of transition in House 1, to understand the spaces' temporal qualities. Figure 47 is a linear arrangement of film stills of selected transitional points within the dwelling studied over a single day. The films comprise three layers; the selected view, as a still image, is overlain with an animated, 12 hour sun path. The final layer is respective footage from the activities of routine from Quotidian Revisited. In contrast to Quotidian, this rendition of space is not in a documentary style; from stationary viewpoints, the film captures how the dwelling changes over the course of a single day (Figure 47). The spaces' relationships to each other are explored through a single lens from different locations within the dwelling

Figure 47: Framed Intersections; House 1
a. Stills
b. Film

Figure 48: Northern Exterior View
The views chosen illustrate the physical and visual connections within the dwelling. The aim of this exploration was to consider the temporal nature of the dwelling, as a whole, through its components. A single composition can make it possible to comprehend the atmospheric conditions and activities that took place in a space over the span of a day. The human eye cannot observe all the components of a given space at once. This composition affords the image a temporal dimension. The composition is multi-layered and distorts the boundaries severing foreground and background, imitating the techniques of Cubism. Whereas image is typically conceived twodimensionally, in these explorations, image is a multi-dimensional device used to investigate the experience of space around which the rest of the dwelling has been developed. As such, House 1 served as a vehicle to investigate and host the ritual activities that were explored in the earlier design research. Its idealistic context prompted an investigation into whether these strategies could be utilized in a more conventional setting. (Refer to Appendix $C$ for supplementary drawings of House 1)

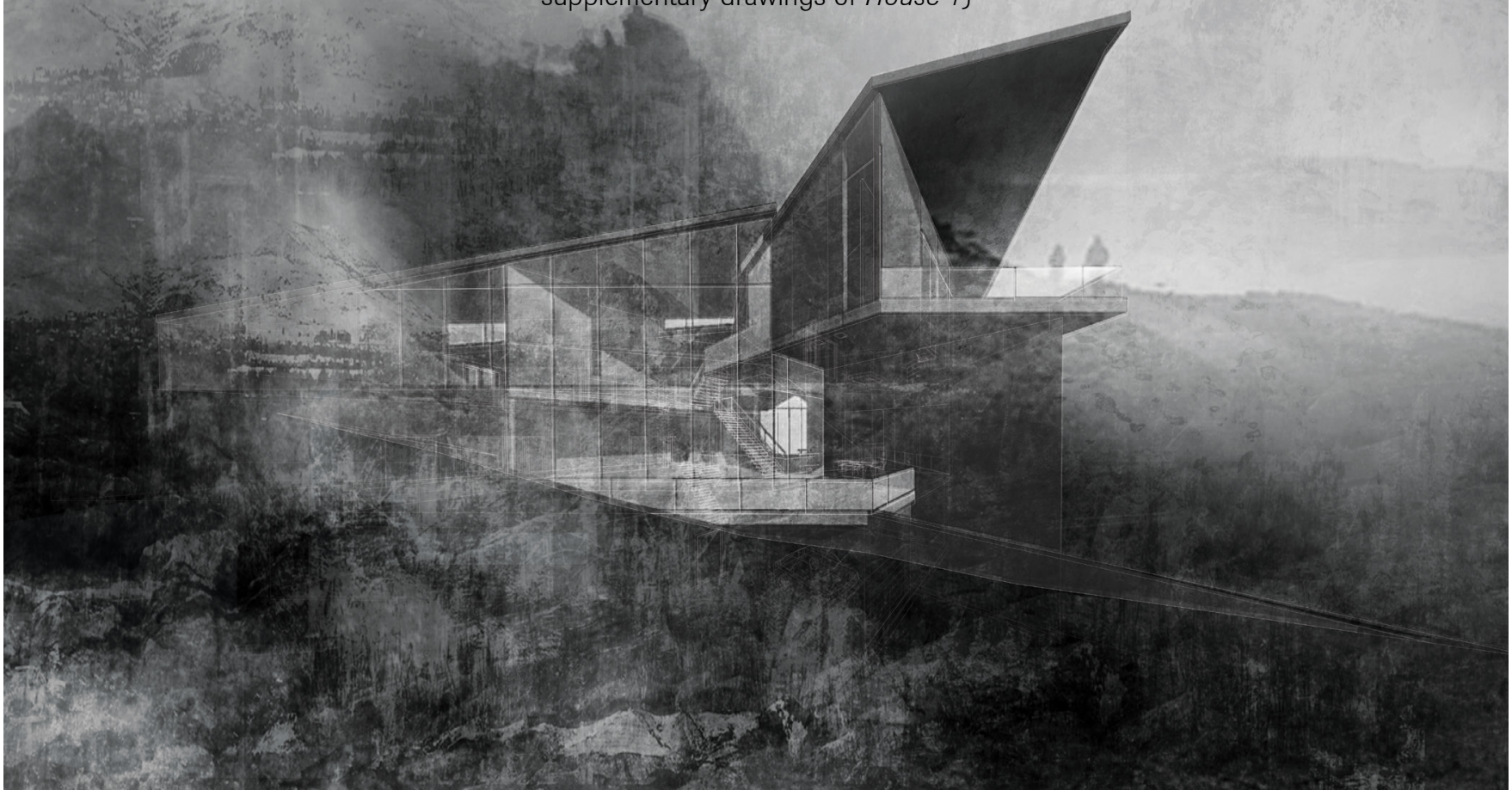


an architecture of imagery 

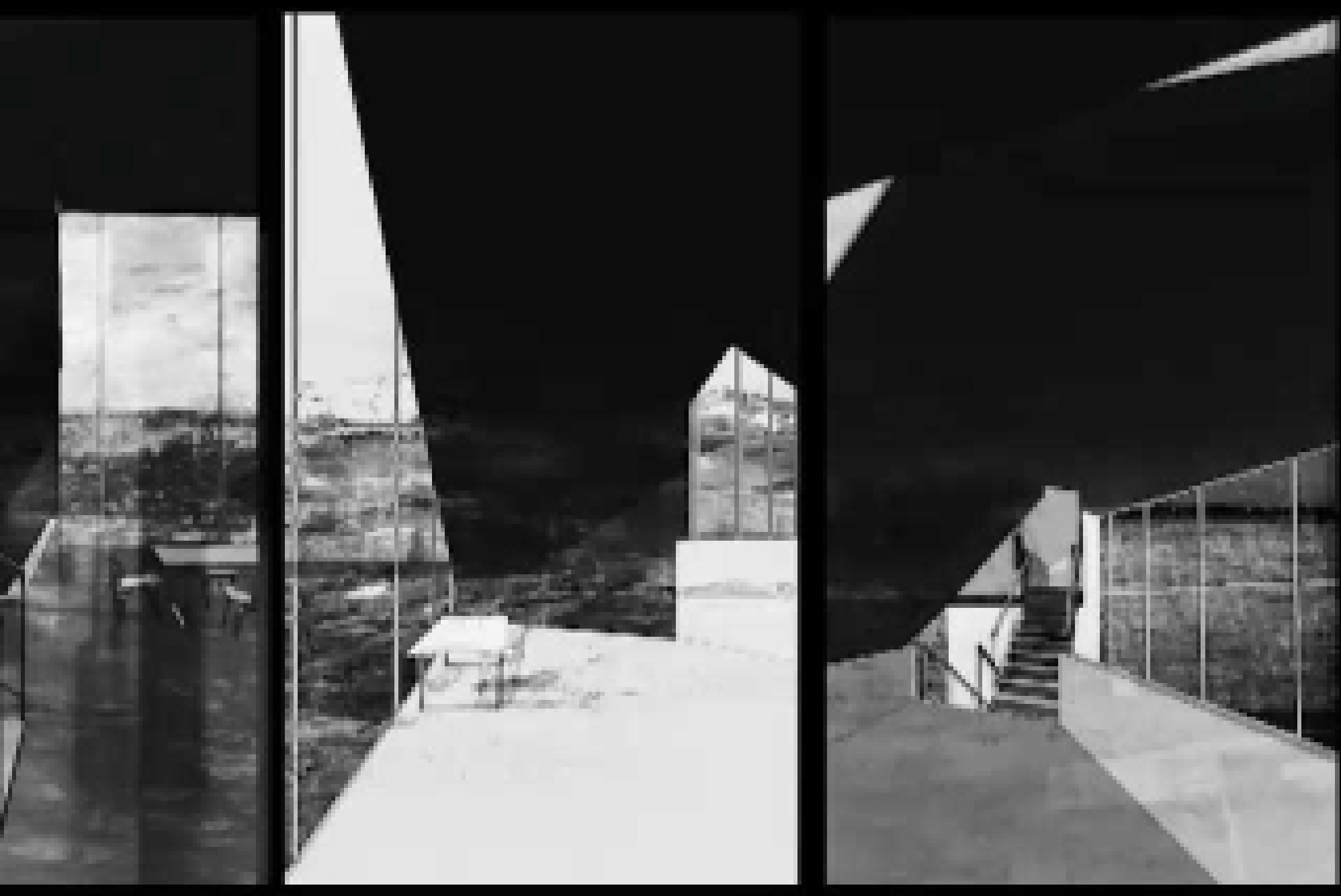


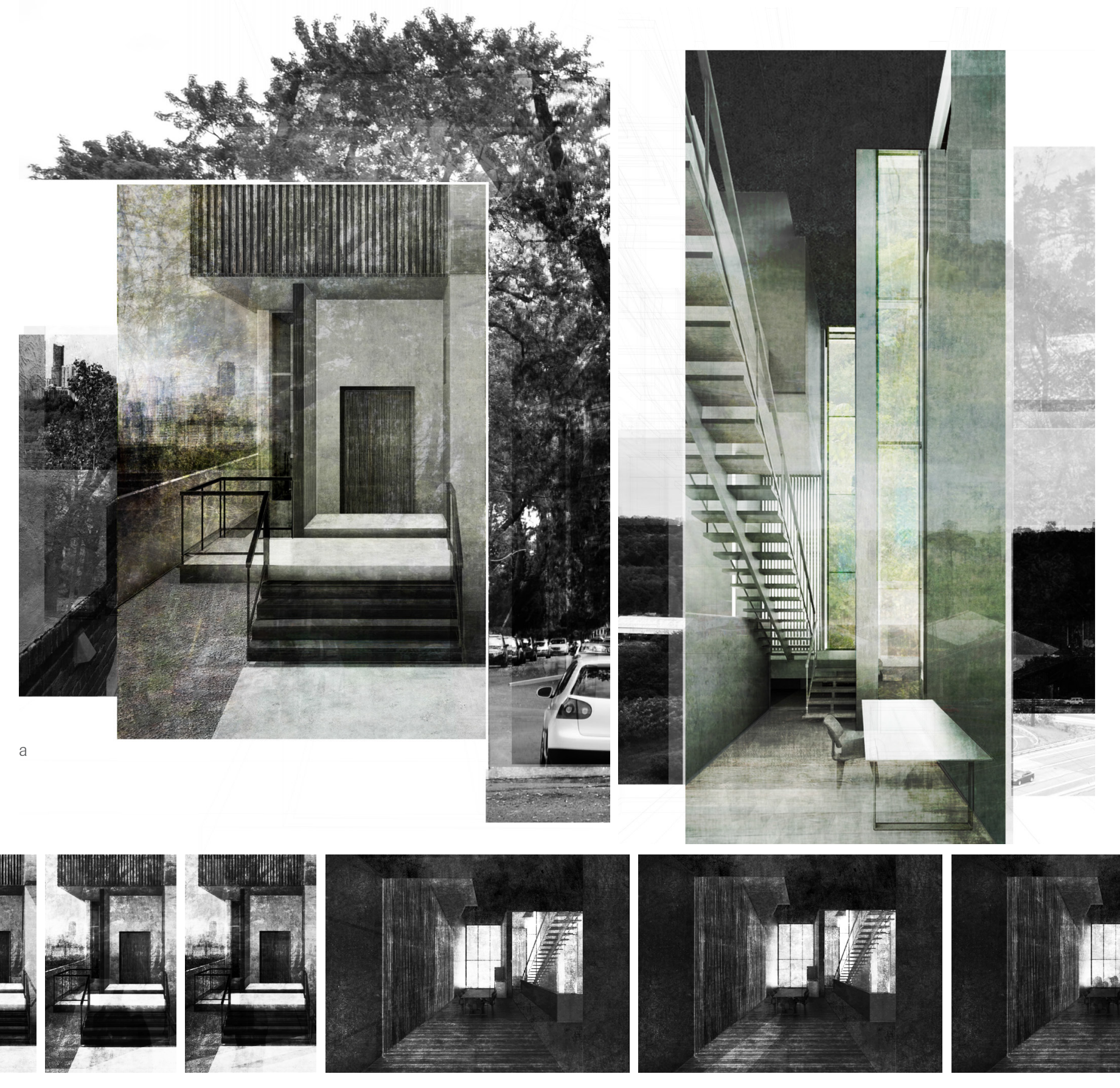

b 


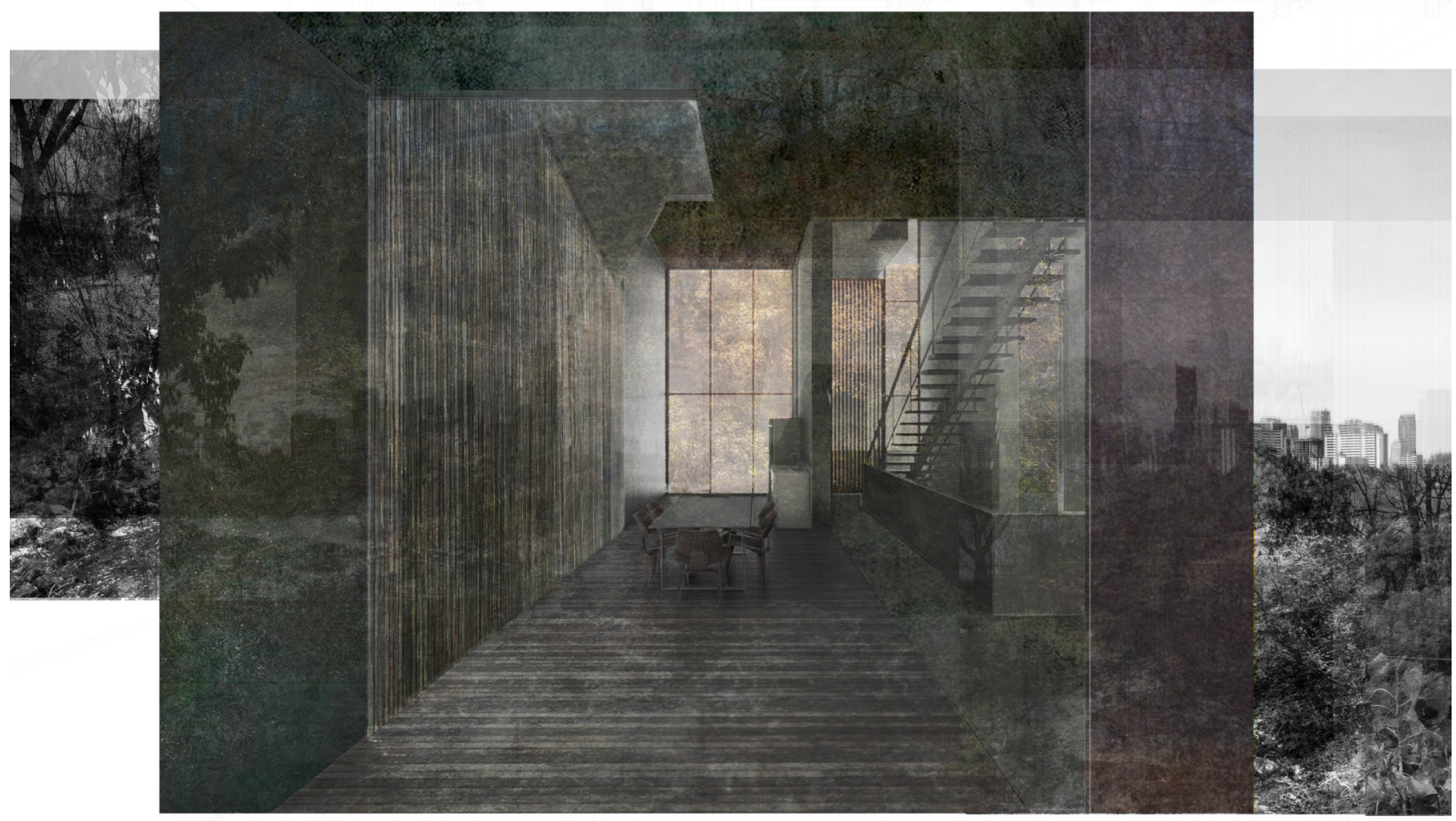

6.3 House 2

The scenes of House 1's threshold study (Figure 47) were reimagined and adjusted to fit a project site within a denser context. House 2's suburban context mirrors the repetitive conventions of the environment of Quotidian. The dwelling is wedged between two existing dwellings of a residential neighbourhood in Toronto. Its lot backs onto the Don River Valley. The dwelling was developed using the same principles and strategies explored in House 1. House 2 intends to represent space in a way that highlights peripheral vision. Adapting film techniques, Figure 48a represents House 2 through a series of long and short views; the work aims to represent the reality of material and human experience within the space. Within the final representations of House 2, colour elements of the drawings assume the focus of the camera. Monochromatic imagery extends out of the vanishing point of each space (Figure 49a). These murky illustrations represent the user's peripheral vision. The film's spectral figures portray the dweller performing acts of routine tasks (Figure 49b). By fading the dweller's actions, the distinction between foreground and background is rendered indistinct. The observer of the film views multiple perspectives simultaneously and can thus comprehend the relationship between the spaces throughout the course of a single day. 


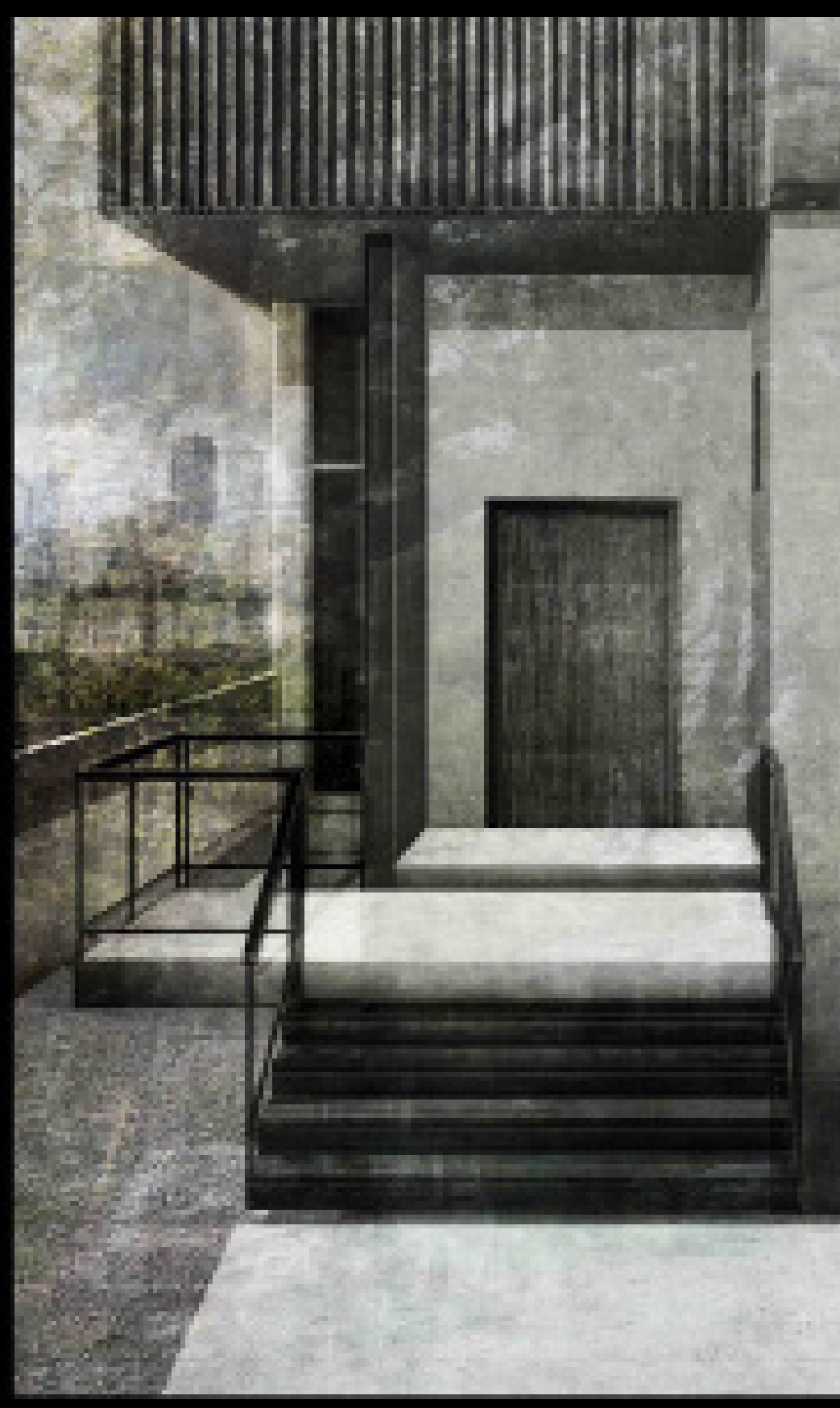




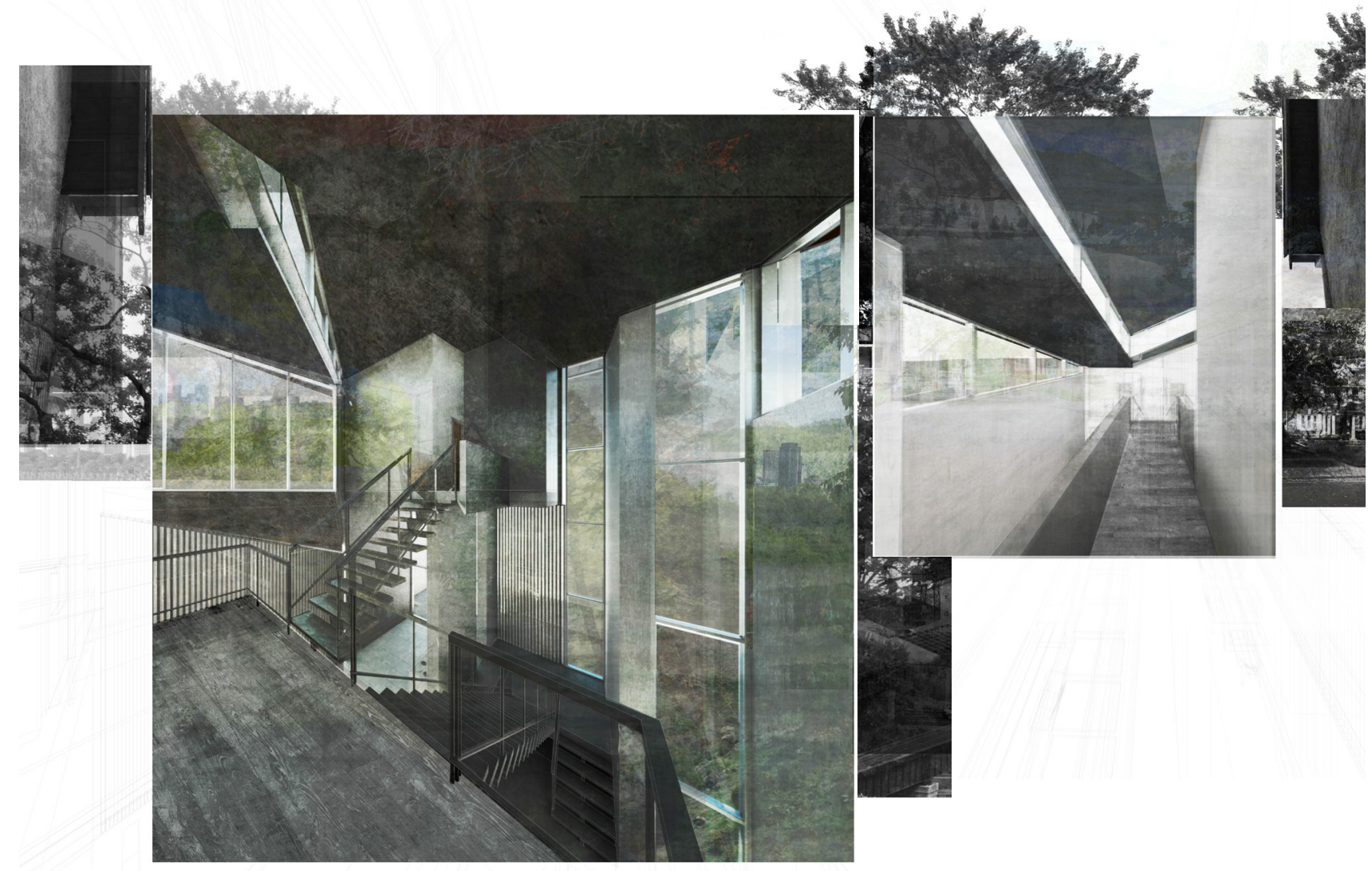

The proposed dwelling spaces are all physically and visually linked - they comprise a system that interconnects the phases of family life. As a web of routes, narratives and milieus, the dwelling presents the inhabitants with opportunities to create their own pathways through space. Loosely defined program boundaries and a series of transitional spaces make possible perceptible changes in the atmosphere of the space. Scale, material, planar and view shifts emphasize the ritualistic significance of the thresholds between disparate programs. These spaces are developed, explored and represented using adapted film techniques. The final filmic representation illuminates changes in material and life within the dwelling.

House 2 is clad in precast concrete. Left to weather, this material would
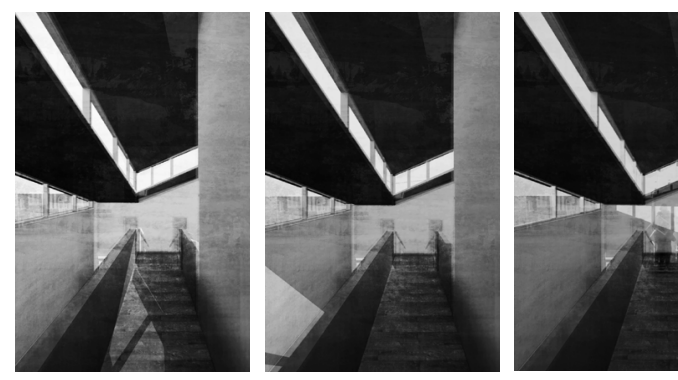
gradually blend into the lush terrain of the Don Valley River as an extension of the overgrown landscape. As shown in the figures above, silver fir wood screens on parts of the southern and eastern facades simultaneously welcome light and provide privacy for occupants. The slim, weathered wood mimics the site's existing vegetation. The views chosen (Figure 49a) distinguish spaces of intersection. These transitional spaces emphasize changes in program through shifts in scale, material and orientation of the user. 

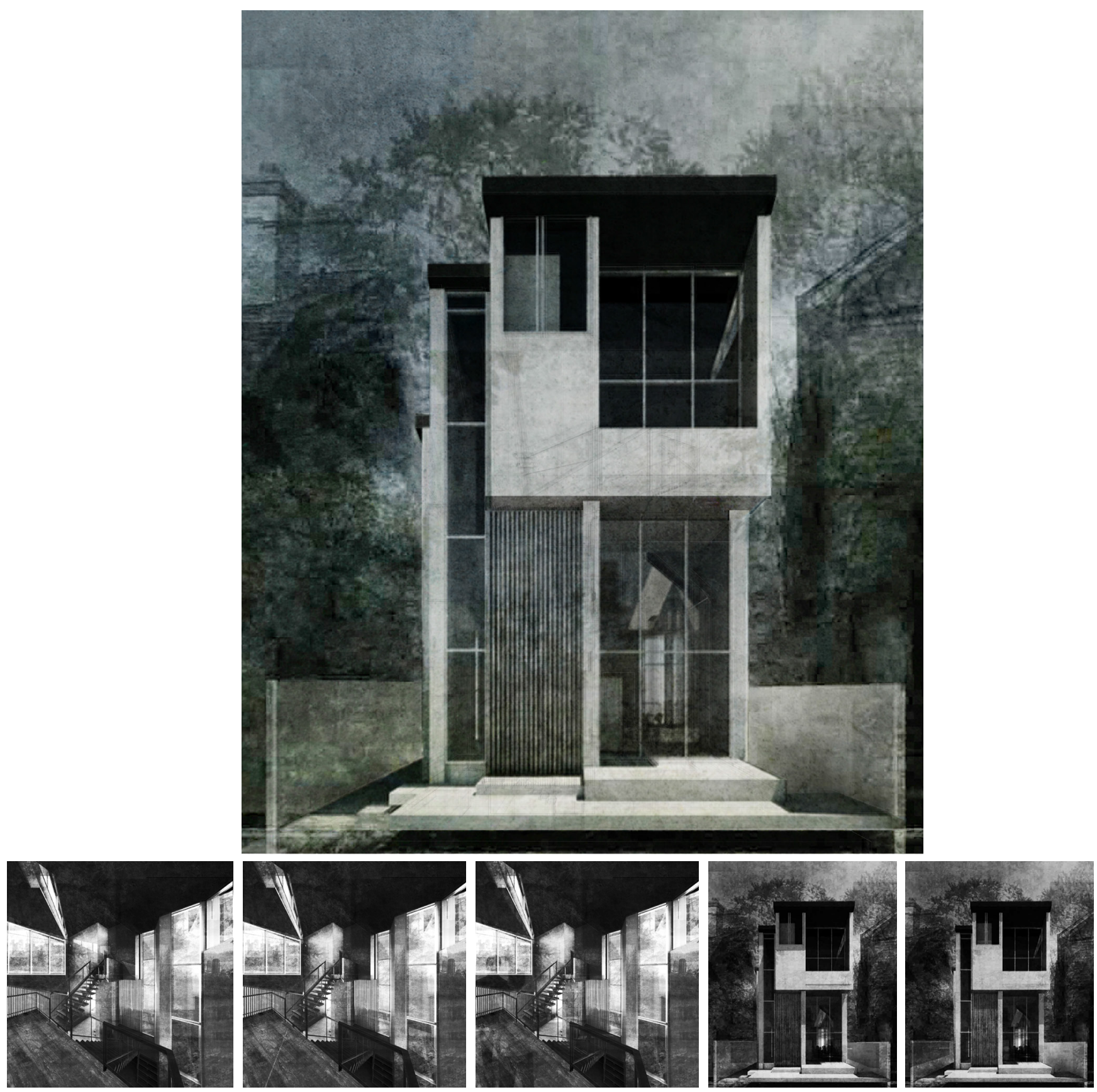

(continued)

Figure 49: Spatial Sequence; House 2

The models, drawings and films of this design

research are all similarly constructed through

the specific arrangement of fragmented spaces

into single compositions. These diagrams

illustrate the atmosphere of the dwelling. 


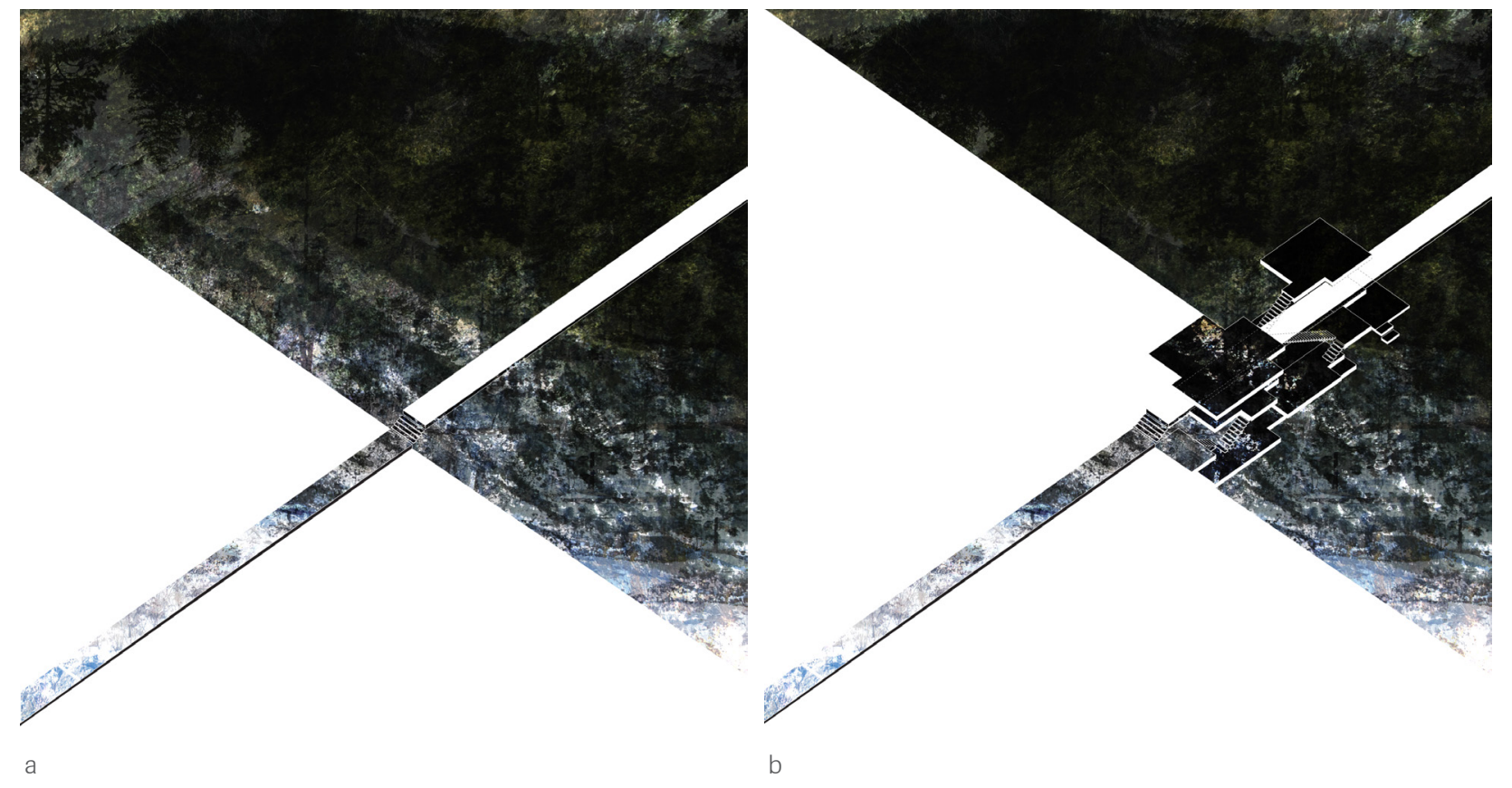

As with House 1, in House 2, a single plane divides public and private space (Figure 50). This voided plane is the main axis of circulation in the dwelling: it orients and visually interlocks all of the dwelling's spaces. The west façade overlooks the Don River Valley and features several apertures that frame Toronto's skyline. The uppermost level of the dwelling cantilevers out into the landscape, continuing the language of the main axis. House 2 evolved out of design research that focuses on the temporal qualities of interlaced spaces. Evading conventional form, House 2's roof is an arrangement of three, irregularly angled components that bridge the disparate areas of program beneath it. The roof's clerestories create a rhythmic play of light and shadow in the dwelling's interior spaces.

While House 2 was developed from the same scenes and formal strategies of House 1 , House 2 is meant to be internalized more than its predecessor. Tactility was emphasized and more thoroughly developed in the rendition of House 2 as this was found to prompt a perceptible change in the feel of space as the inhabitant moves through it. This was most accurately represented in the final filmic composition. This design experiment was done to consider the role of the observer, the dweller and vision within the creation and representation of architecture. (Refer to Appendix $D$ for supplementary drawings of House 2) 


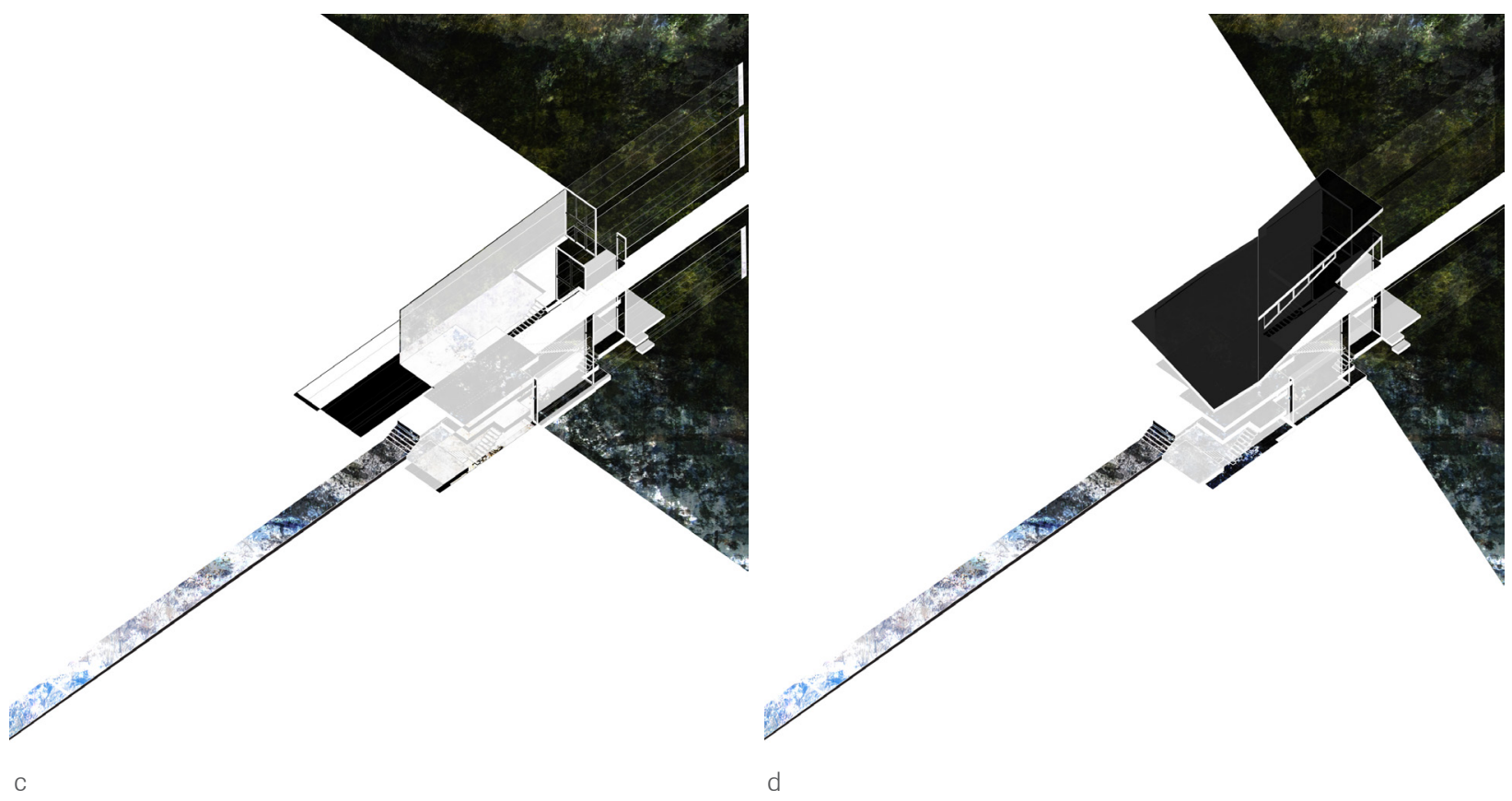

Figure 50: Void Axis Series; House 2

a. The central axis is carried through the dwelling and out into the landscape. It is a unifying element, from which all program extends and intersects.

b. The dwelling is relatively compact; the shifting floor plates allow for a perceptible change in the scale of space and create crossed viewports.

c. Toronto's skyline can be seen from multiple areas within the house.

d. The roof is broken into three separate components. Its planes intersect above the central axis as an array of clerestory windows that bridge disparate areas of space.
Notes

1 Maurice Merleau-Ponty and Colin Smith, and translated from the French by Colin Smith. Phenomenology of Perception. (London: Routledge \& Kegan Paul, 1962 (1981 printing), 1982), 162.

2 Edward T. Hall. The Hidden Dimension. (New York: Bantam Doubleday Dell Publishing Group, 1988), 92. 


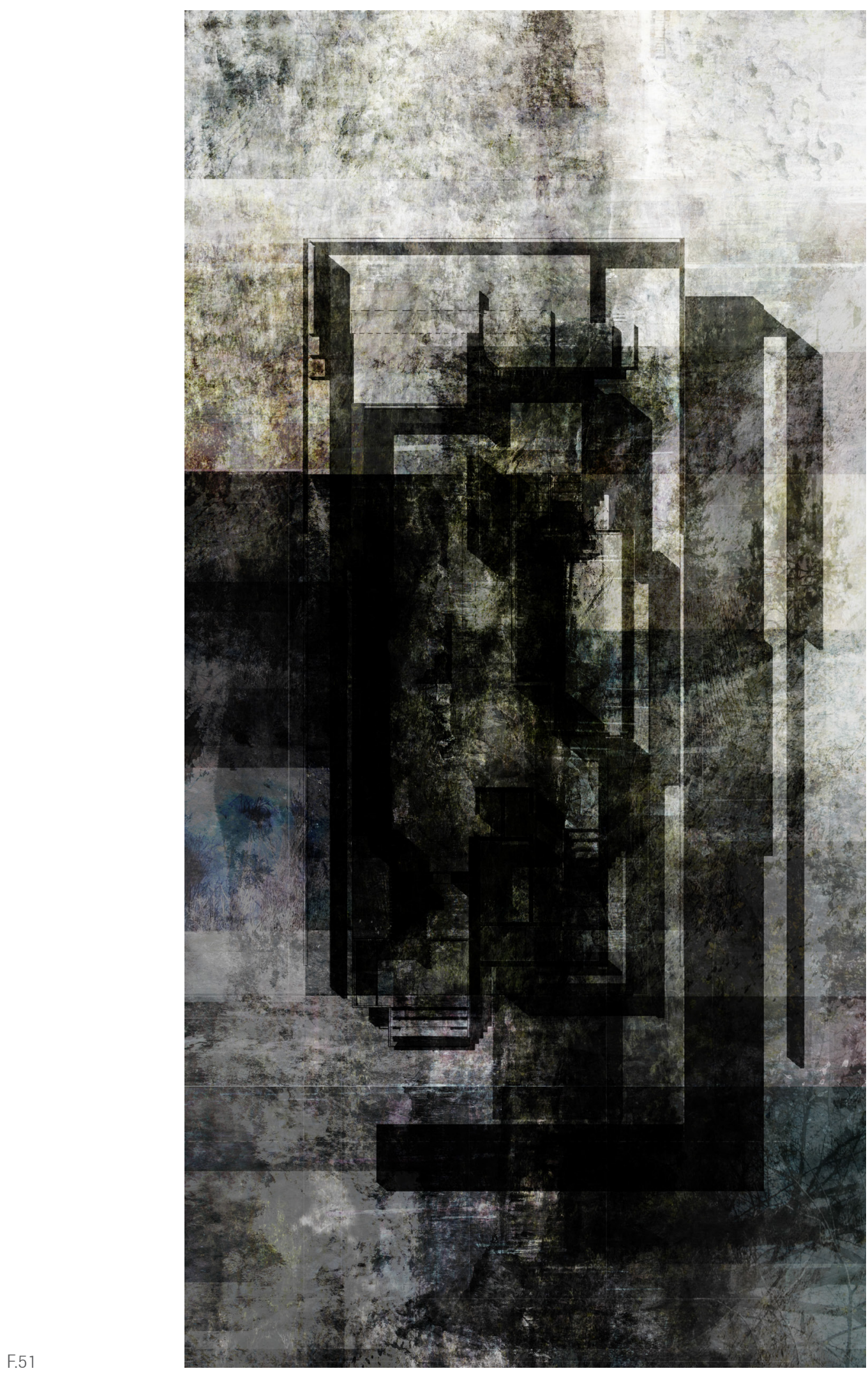




\subsection{Conclusions}

Ocularcentric culture characterizes contemporary life. Visual imagery is a prominent medium for depicting the world. Due to advancements in modes of representation, space can be viewed through a variety of interfaces. Interfaces make visual imagery accessible, subverting the physical or temporal boundaries associated with viewing objects in real life. Vision has become the most influential of the senses in the formation of judgement in that it is the most prevalent sense for perceiving space. The visual image is used to express ideas and can also serve political or commercial purposes.

Figure 51: Experimental Drawing; House 2
Within contemporary society, an accelerated form of communication exists that is supported by transient imagery. The notion of architecture as image is typically conceived as a seductive or memorable configuration that satisfies a small section of the visual field of attention. Images that attempt to market architecture cater primarily to the focal layer of attention; however, appealing to this focal layer is problematic as the focus of this layer is constantly shifting and re-adjusting to account for constant change in the surrounding environment. Therefore, an architecture developed for the focal layer of attention is transitorily experienced. The habitual activities of everyday life do not draw the dweller's attention to architectural objects - instead, the dweller primarily experiences the built context through the peripheral sphere of consciousness. This thesis explores, reinterprets and represents architectural spaces that are overlooked in the context of daily routine, spaces that exist within the sphere of peripheral attention.

This thesis proposes that studying built spaces through film enhances human perception of architecture. Film and contemporary media situate architectural imagery in temporal contexts so that it can be explored through a multisensorial and multi-dimensional 'lens'. Using film, this design research isolates and reconsiders the user experience of space by abstracting, reconfiguring and idealizing ordinary scenarios as a basis for creating architecture. This thesis deploys temporal imagery, peripheral vision and the pictorial plane to emulate the phenomenological textures of everyday landscapes.

The proposed design research in this thesis suggests that the development and communication of architecture's representative medium ought to be reconsidered. Architecture serves as a platform for engaging the intellectual and cultural curiosities of users. This thesis evaluates visual imagery's ability to inform and cultivate spaces that evoke human emotion. It proposes that the current model of architecture - which views architectural space as a formal object generated and described by lines, volumes and abstract geometries - be supplemented with a perceptual model. As the design research herein demonstrates, a perceptual design model considers how users sensorially engage with and participate in space. 

appendices 

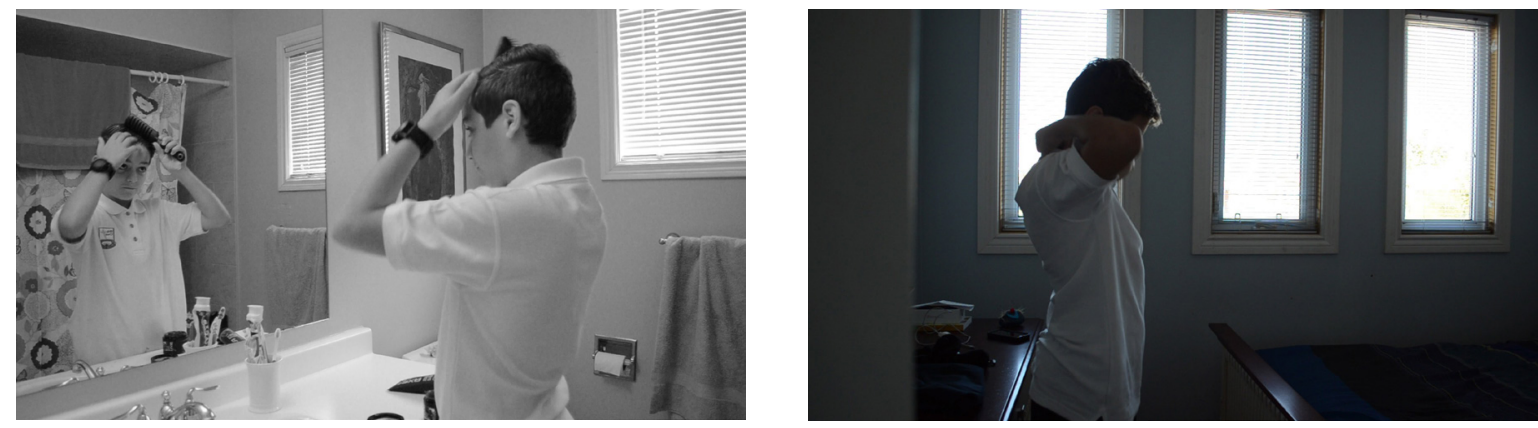

"My hair isn't good enough..."

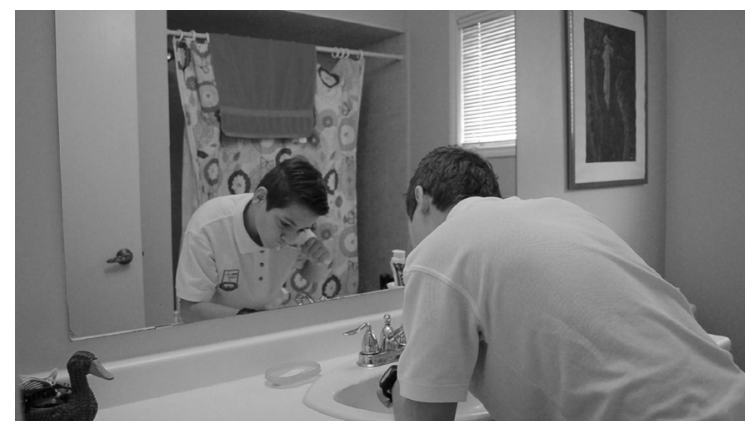

"I brush my teeth first because if my hands are wet I can't do my hair."

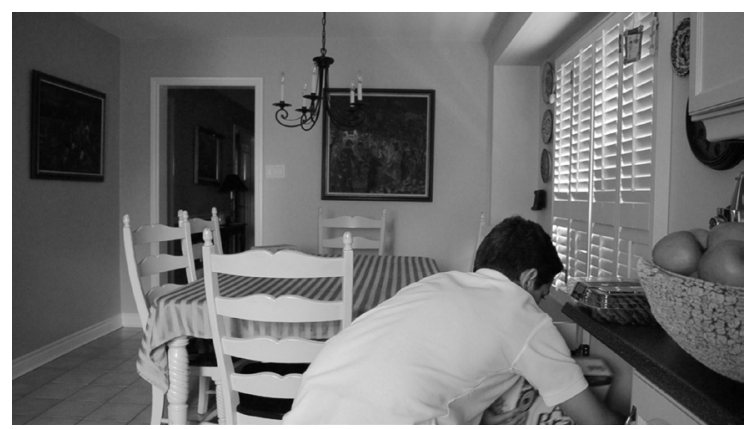

“Here, I was disappointed that there wasn't any good cereal, I forced myself to eat it."
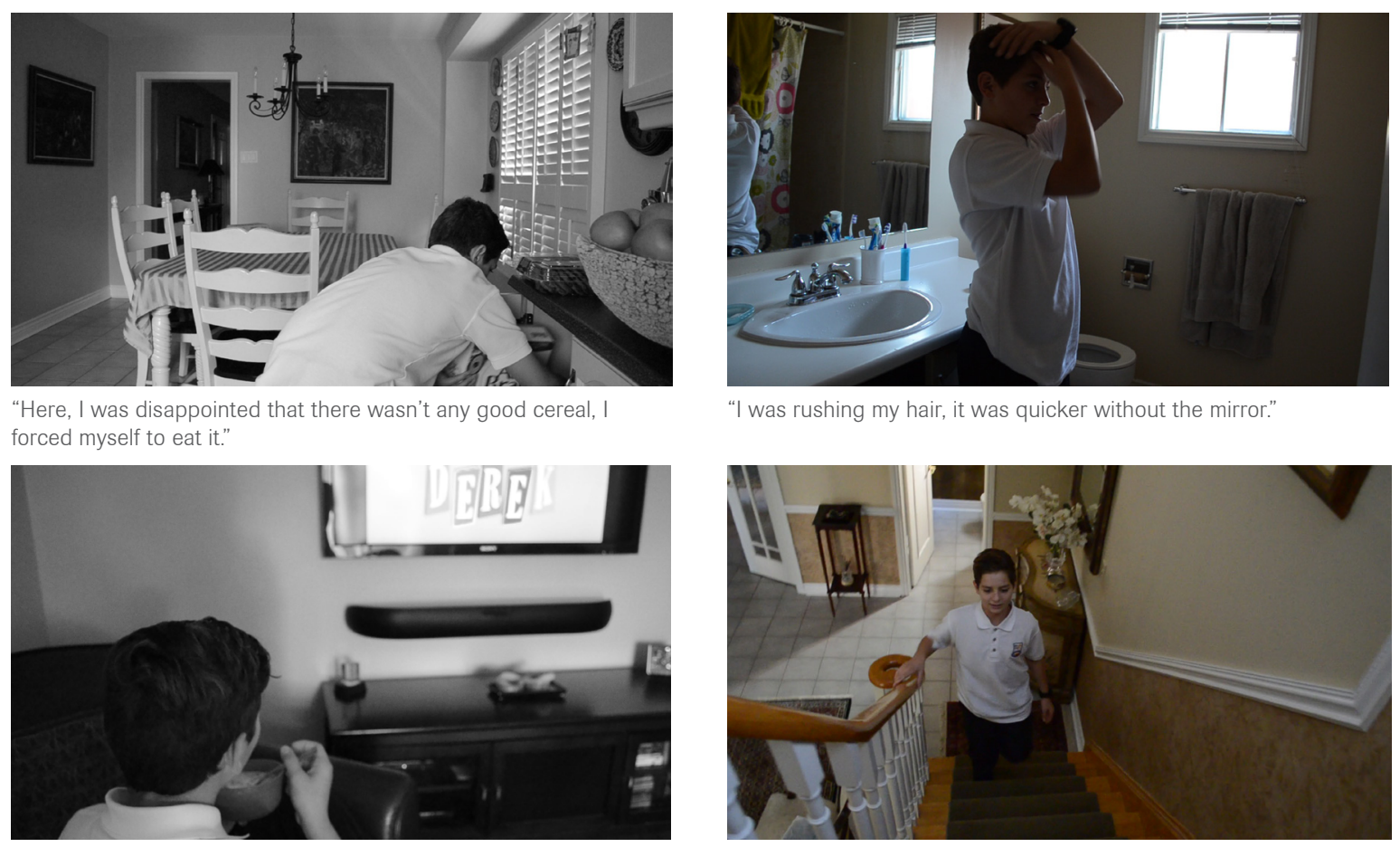

"I was rushing my hair, it was quicker without the mirror." usually I just check in the mirror."

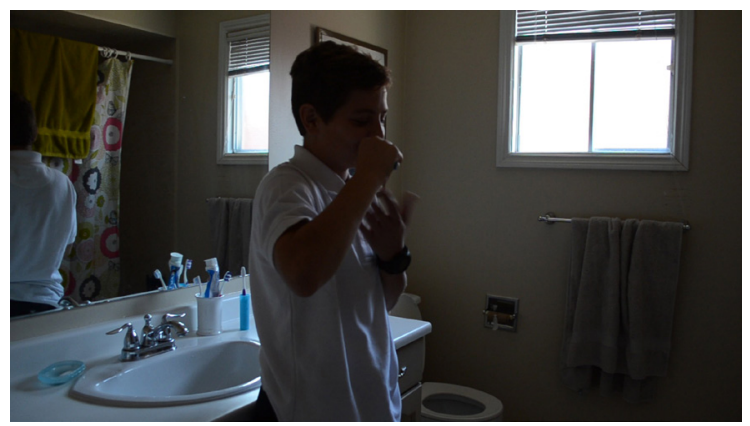

"I didn't turn on the light and I don't usually brush my teeth first..."

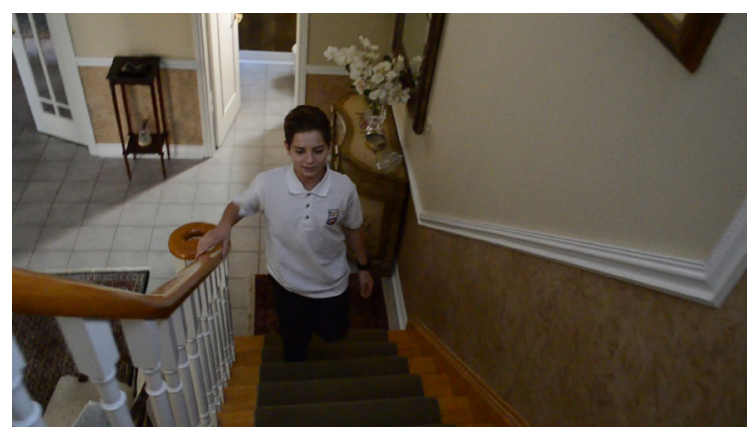

"I was excited that there was a new episode." F.52 


\section{appendix a}

film review + analysis | Quotidian

Quotidian explores the elements of daily architectural experiences with the perception of a user within a dwelling. This experiment identifies how a place becomes visible to a user by investigating the activities of routine tasks. This design research manipulates the imagery and narrative of routine to affect the Subject's awareness and perception of space. 
Attempt 1: Routine

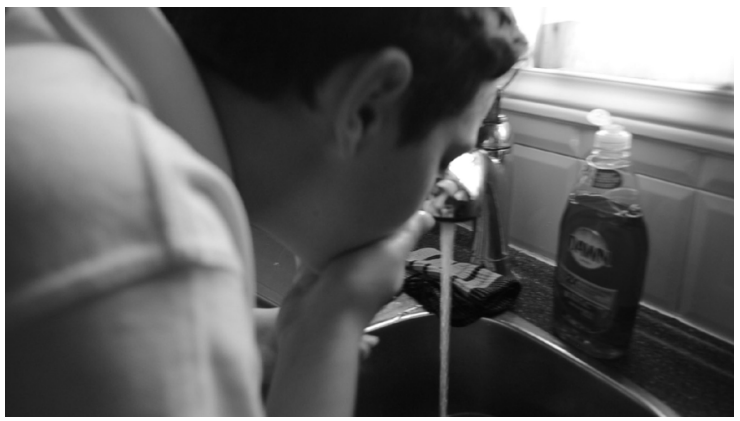

"I didn’t wash my bowl."

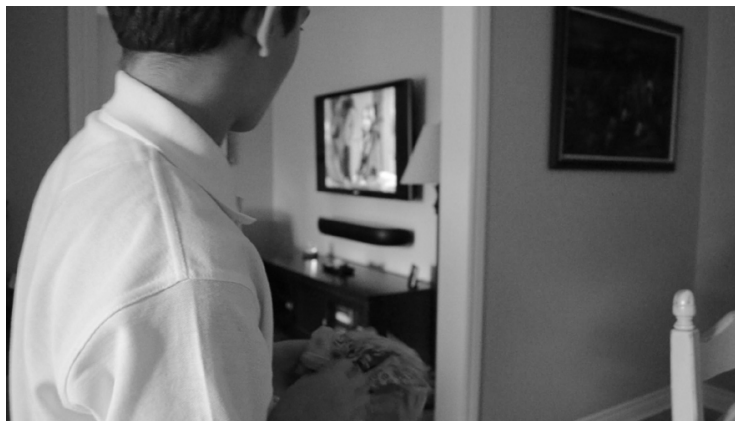

“Usually, I turn the TV off after I eat, I usually don't leave it on while I get ready"

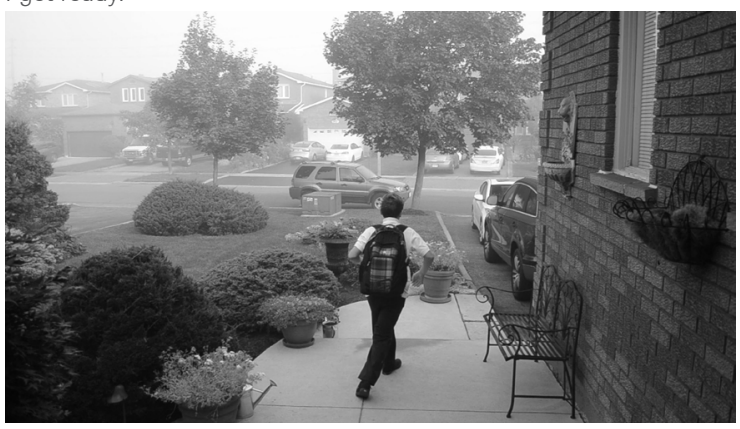

"I noticed it was foggy when I woke up this morning."
Attempt 2: "Backwards"
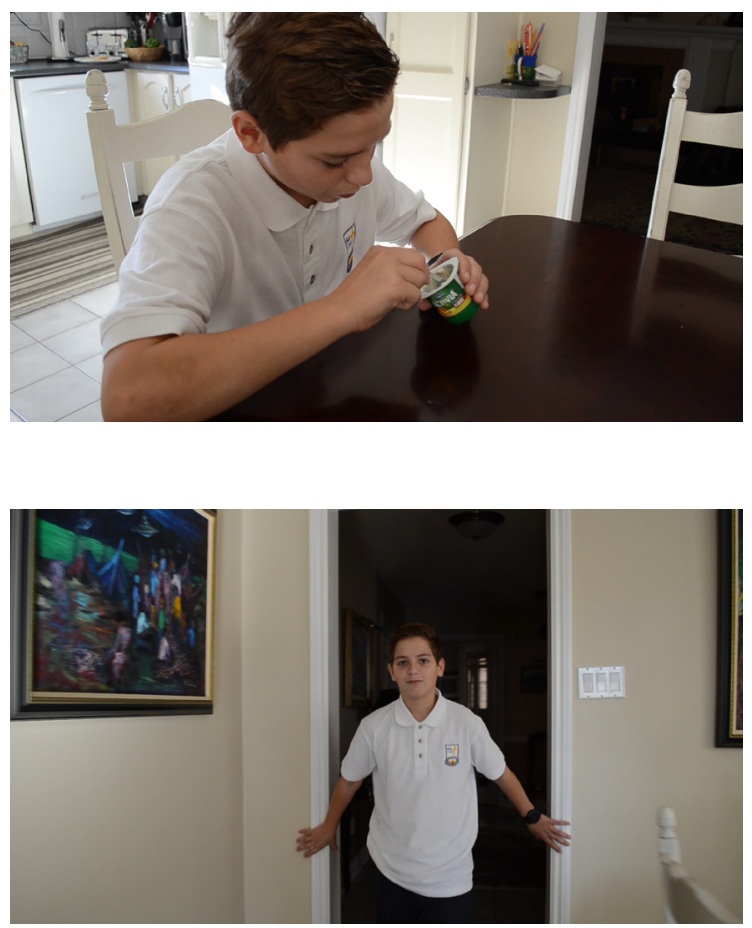

"See I kept touching everything."

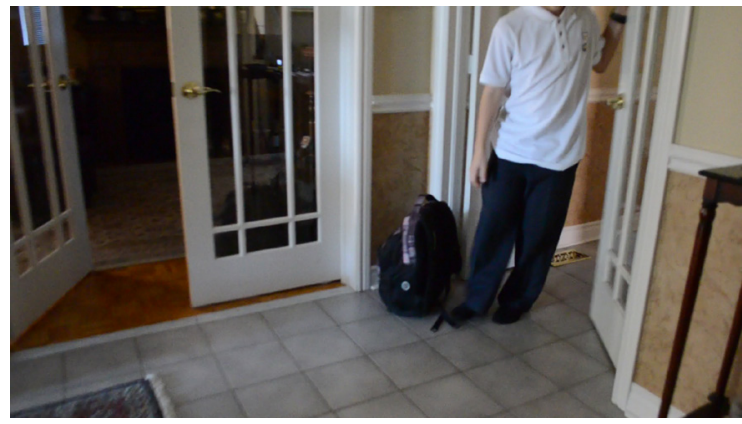

"I moved the door out of the way here, even though another door was already open."

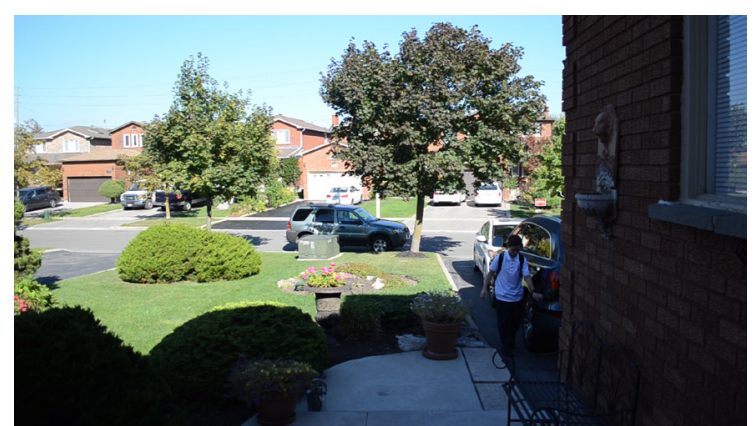

"That's the slim path, I move onto the grass here." 
Figure 52: Reviews of Lived Imagery

Subject

_15 year old male

Morning

_Waking up, preparing for school, leaving house

\section{Sequence of Events}

1. Bedroom (gets dressed, makes bed)

2. Bathroom (does hair, brushes teeth)

3. Goes Downstairs (Main Floor)

4. Kitchen (makes breakfast)

5. Family Room (watches TV)

6. Kitchen (makes lunch to take to school)

7. Basement (gets water bottle)

8. Dining Room (gets knapsack)

9. Kitchen (puts lunch in knapsack)

10. Front Entrance (brings knapsack/ gets shoes)

11. Bathroom (Mouth- wash, deodorant)

12. Goes Downstairs (Back to Main

Floor)

13. Office (says goodbye to father and sister)

14. Front Door (puts on shoes)

15. Walks down front porch (walks on

curb to the end of driveway)

16. Waits for Carpool

Time to complete

Attempt 1: 21 minutes

Attempt 2: 13 minutes

\section{Transcription Review}

Attempt 1: Subject is more animated in his description of the environment and creates an articulate description of events based on what he anticipates will happen. The transcription anticipates the mood and events of the day as a result of his routinely actions.

Attempt 2: The Subject recollects moments of his routine in a much more literal fashion, describing the physicality of his environment and how his body responds to it.

\section{Disrupted Narrative}

Sequence of tasks in Attempt 1 is completed more quickly and in a different sequential order than Attempt 2. Focus of attention changes (from routine to physical movement) and causes disruptions in the narrative. Subject notes the changes in sequence in the review of the film. (e.g. Subject states that he usually fixes his hair and then brushes his teeth. He cannot brush his teeth first, because with wet hands, he cannot fix his hair. During Attempt 2, Subject is disoriented and wrongly brushes his teeth first.)

\section{Representative Imagery}

Within Attempt 2, tasks are performed without distraction. Acts of routine are completed more efficiently without use of screens or mirrors. (e.g. Subject notes that he double-checks and physically adjusts his collar when getting dressed as his back is to the mirror.)

\section{Heightened Awareness}

In the transcription of Attempt 2, the Subject's focus of attention shifts to physical components of space. Subject notes all physical contact with surfaces, especially within transitional spaces (e.g. hallways, doorways, and stairs). Subject notes his anxiety and discomfort when moving up and down stairs. Subject states that he holds handrails and feels his way through the dwelling when changing rooms to reorient himself within the space. (e.g. Subject notes the narrow path between the car and curb. When walking backwards he actively moves onto the grass as is anxious of falling.) 


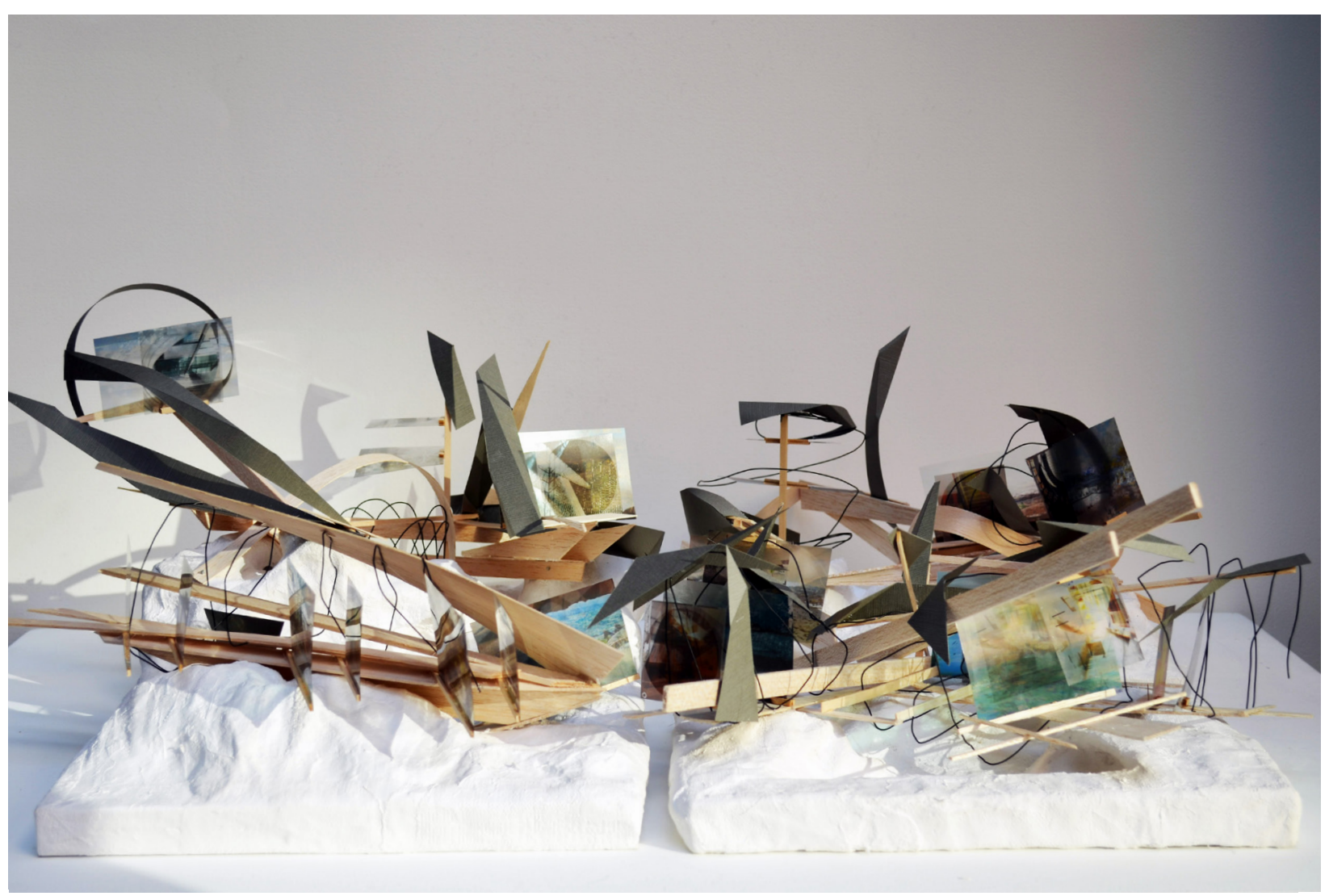




\section{appendix b}

ritual imagery | Quotidian
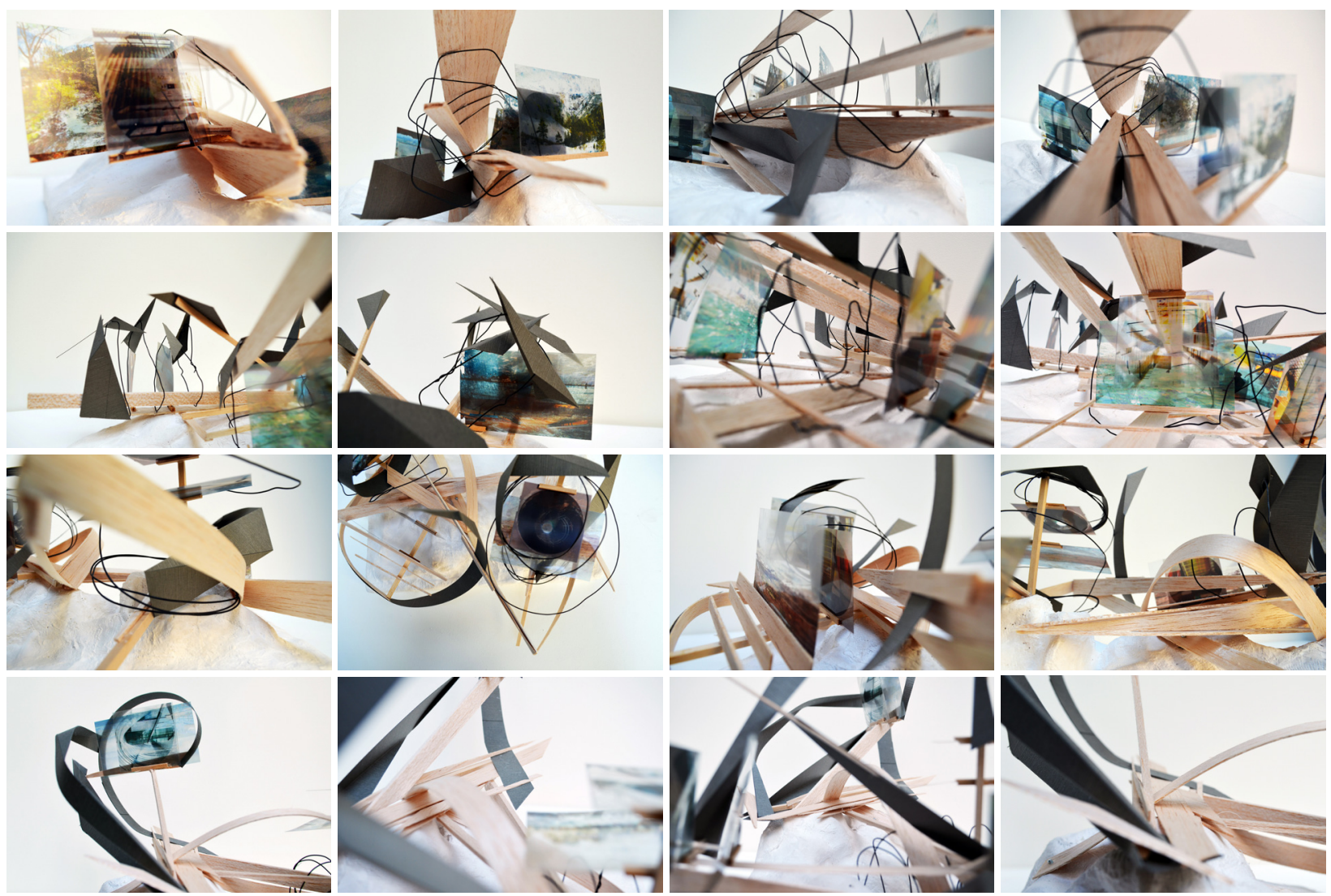

Figure 53: Study Models;

Movement Representation 

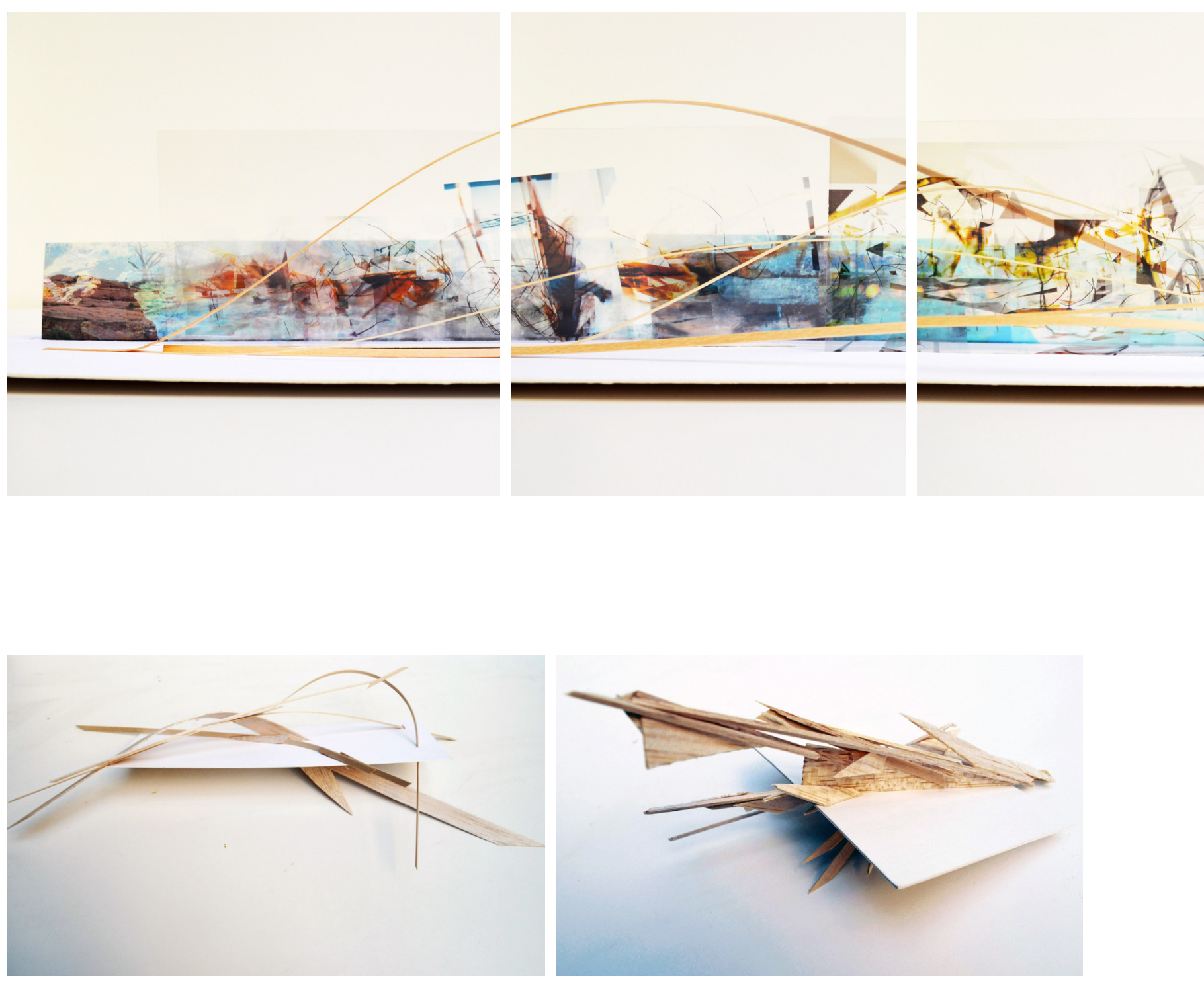

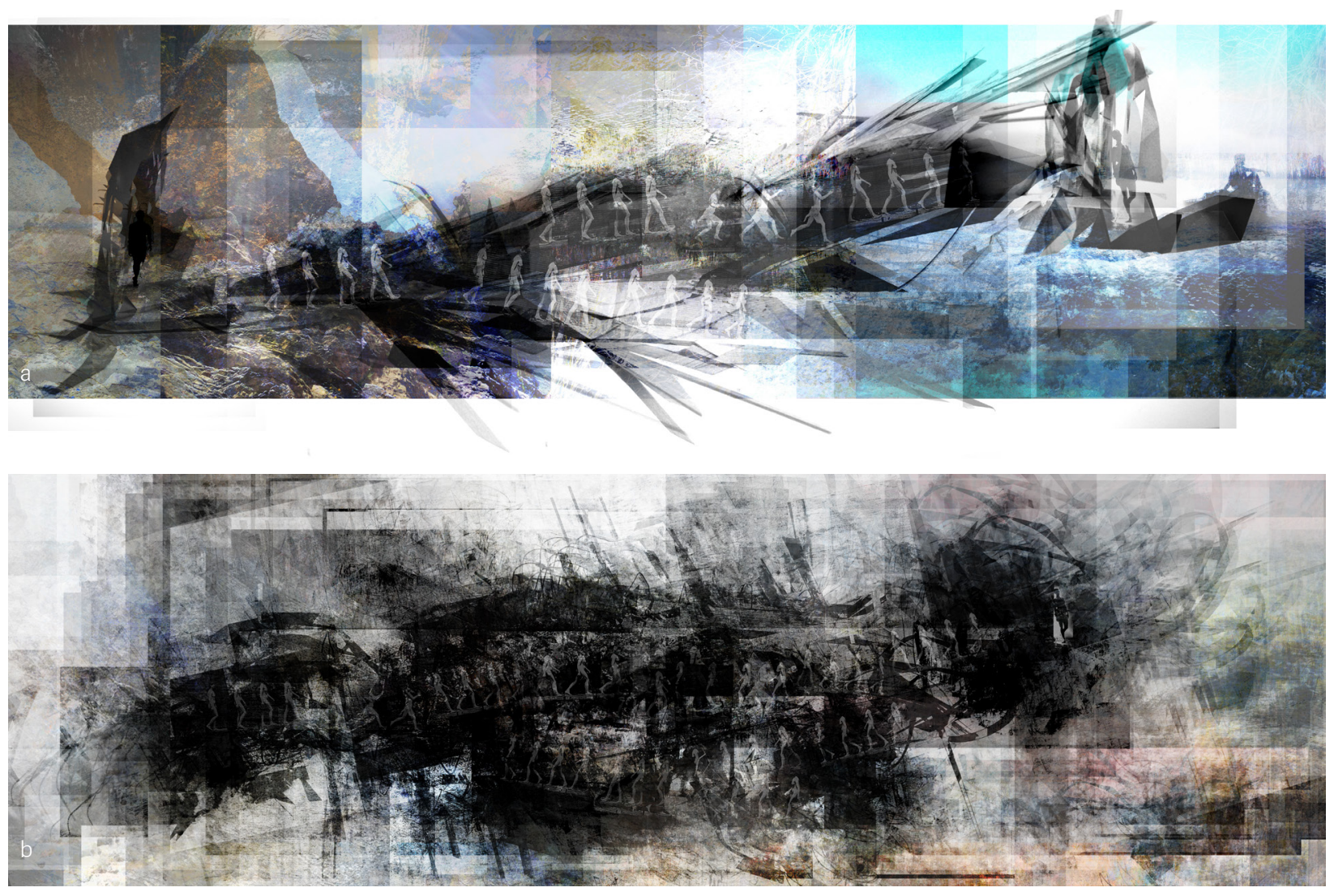

Figure 56: Experimental Drawings

a. Movement Iteration 1

b. Movement Iteration 2

c. Experiential Plan 


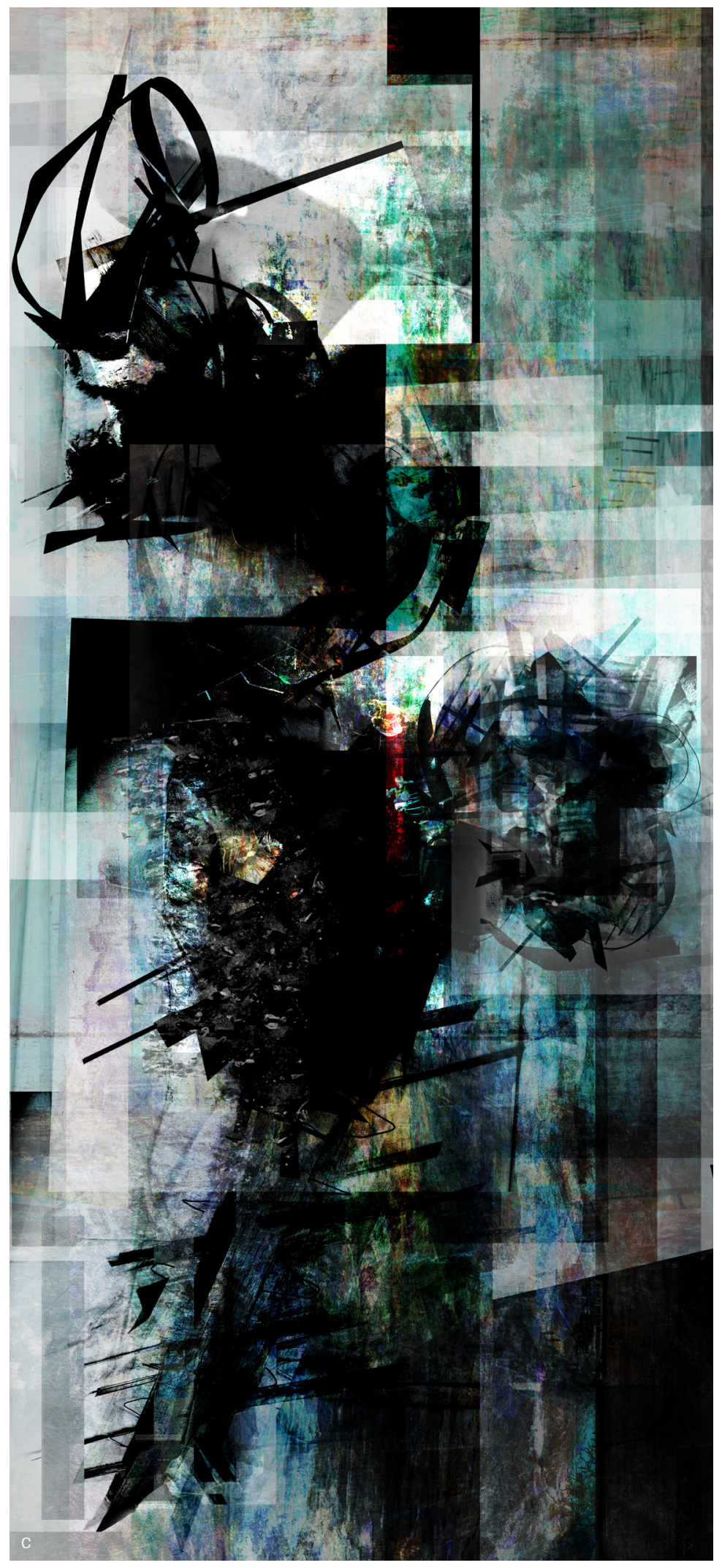



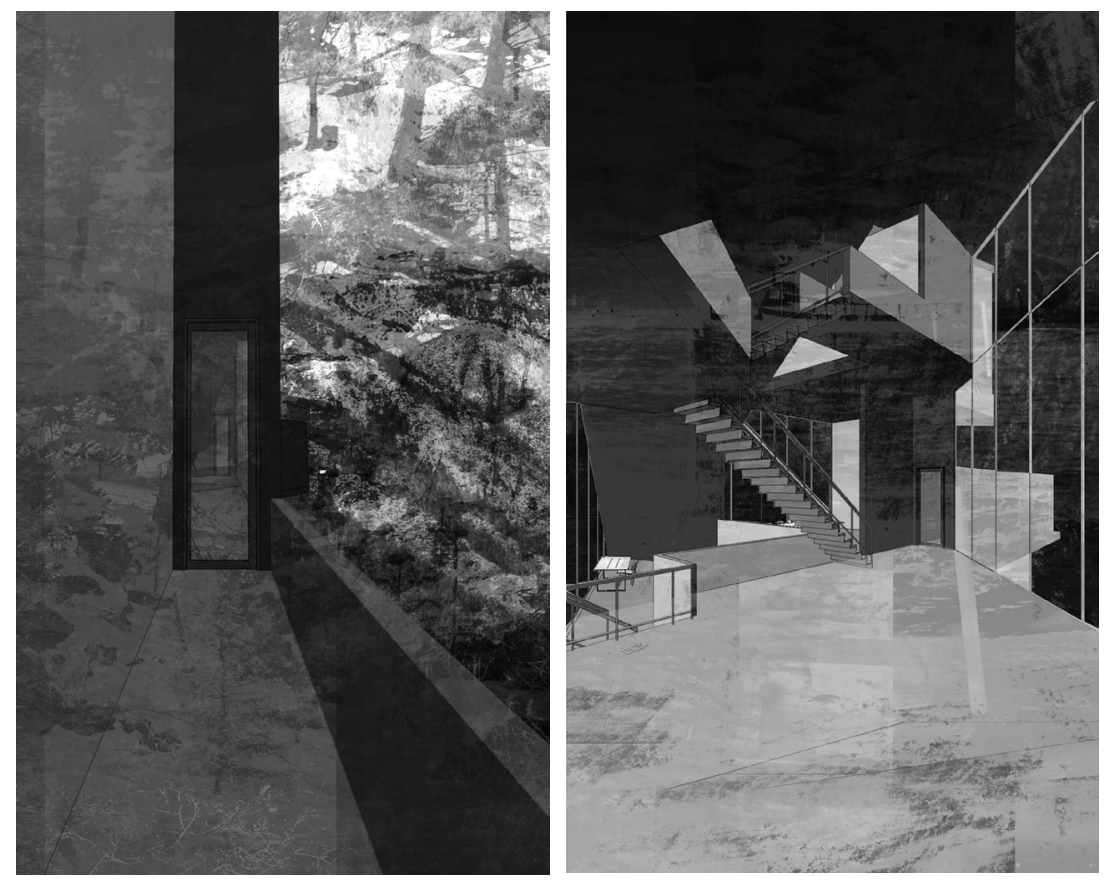


\section{appendix c}

schematic design | House 1
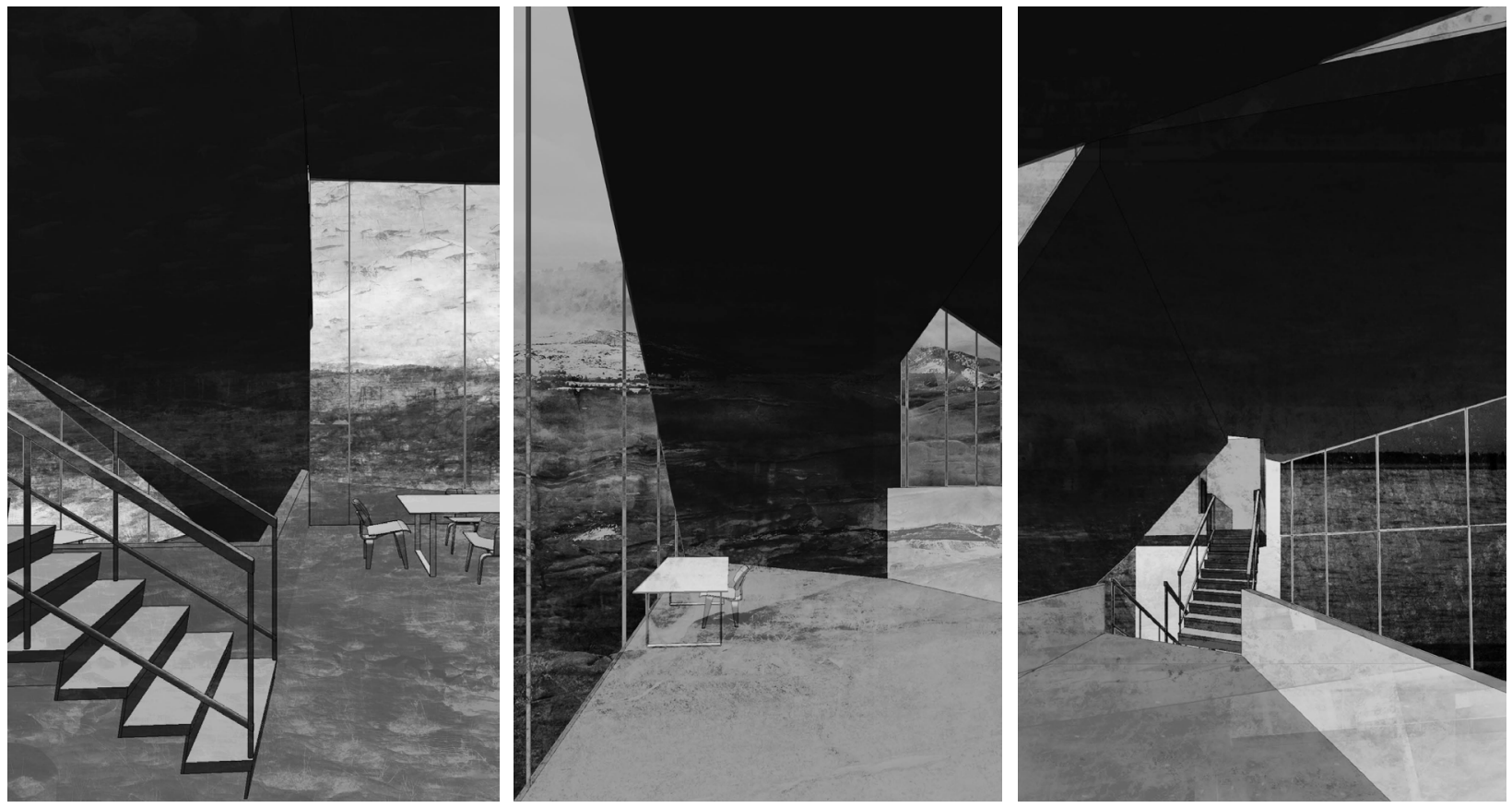

Figure 57: Scenes; Threshold Study 

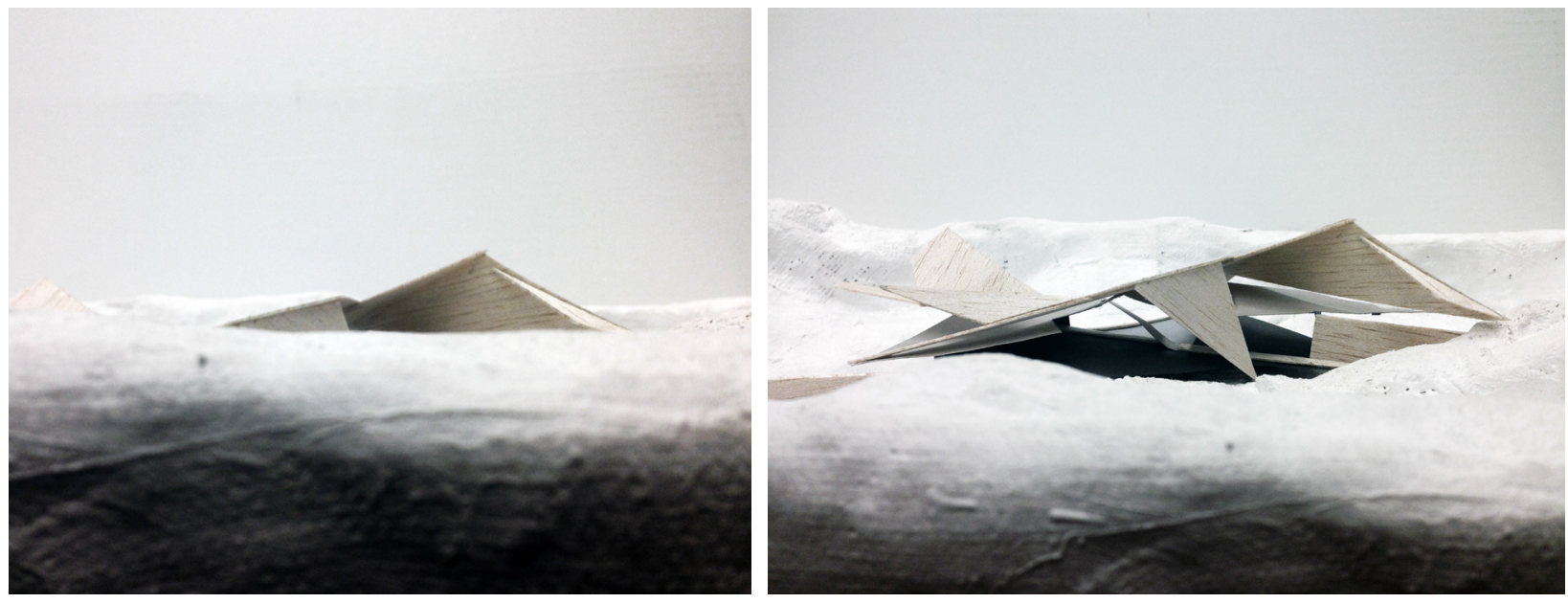

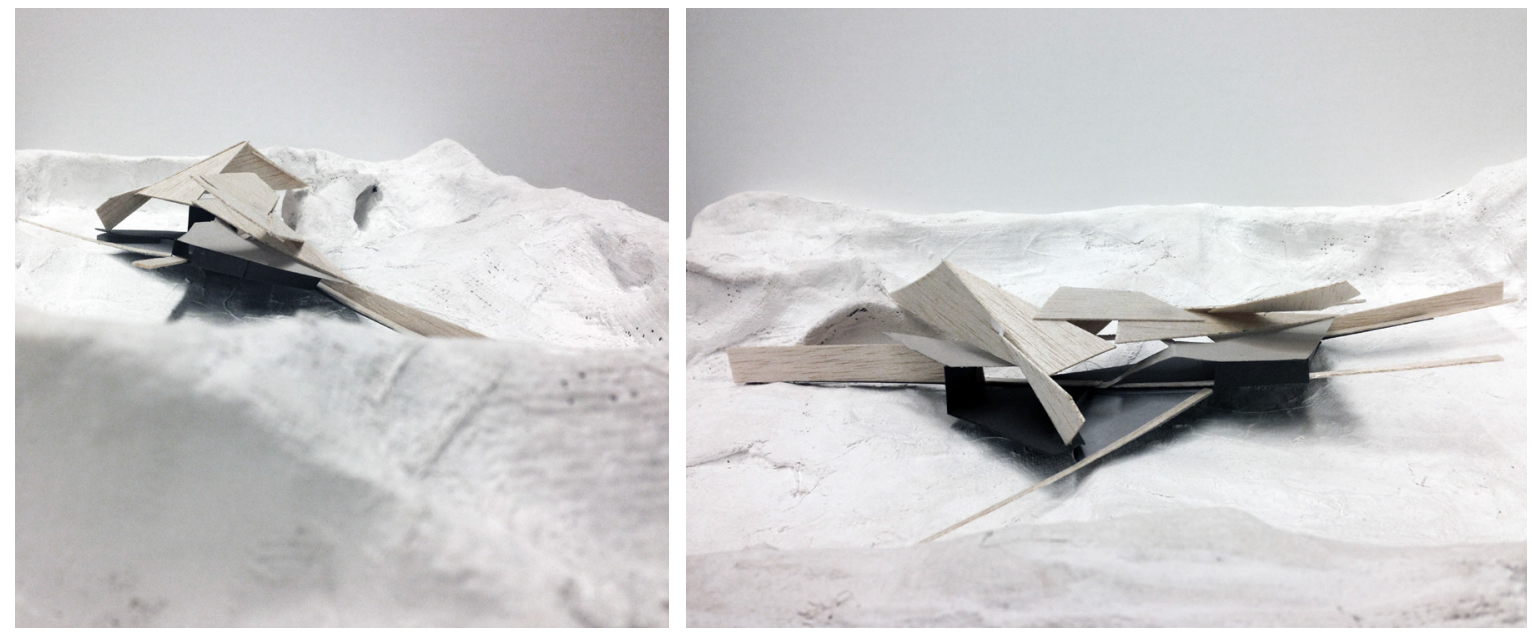

Figure 58: Parti Model; House 1 


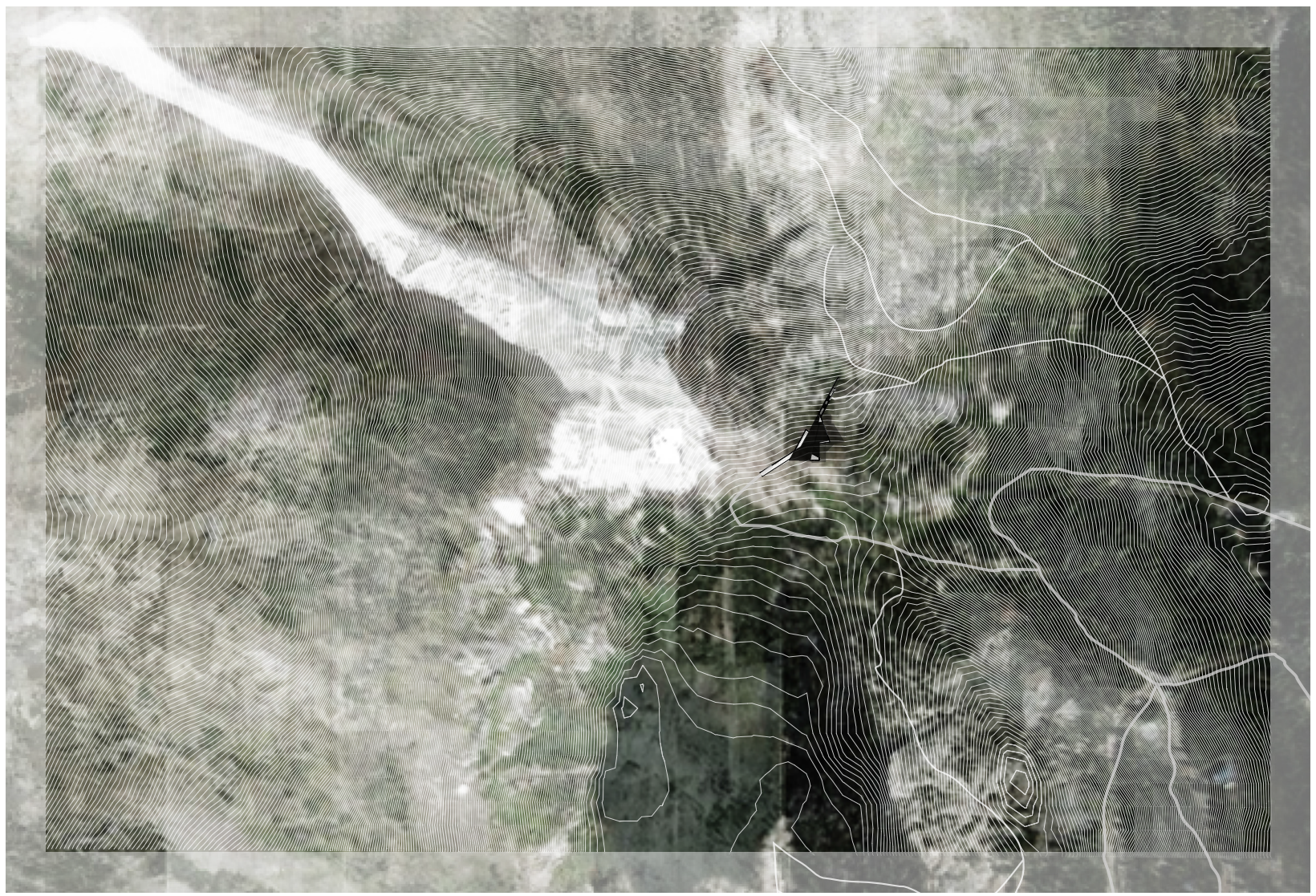

(1) $\overline{0}$ m

Figure 59: Project Context, Idaho Springs, Colorado

Figure 60: Eastern Exterior View

The dwelling is located off of an existing hiking trail on a mountainous terrain. 


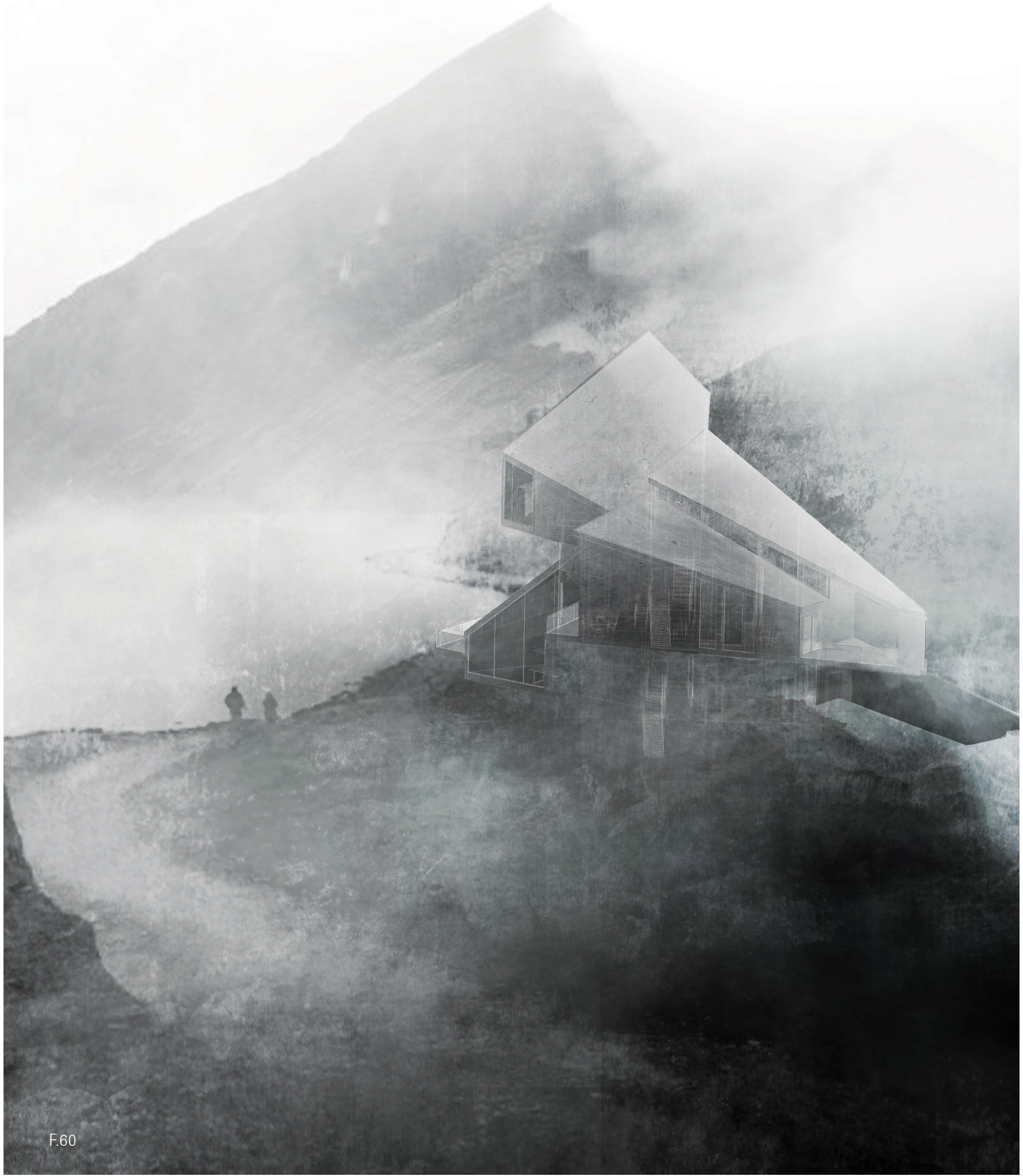



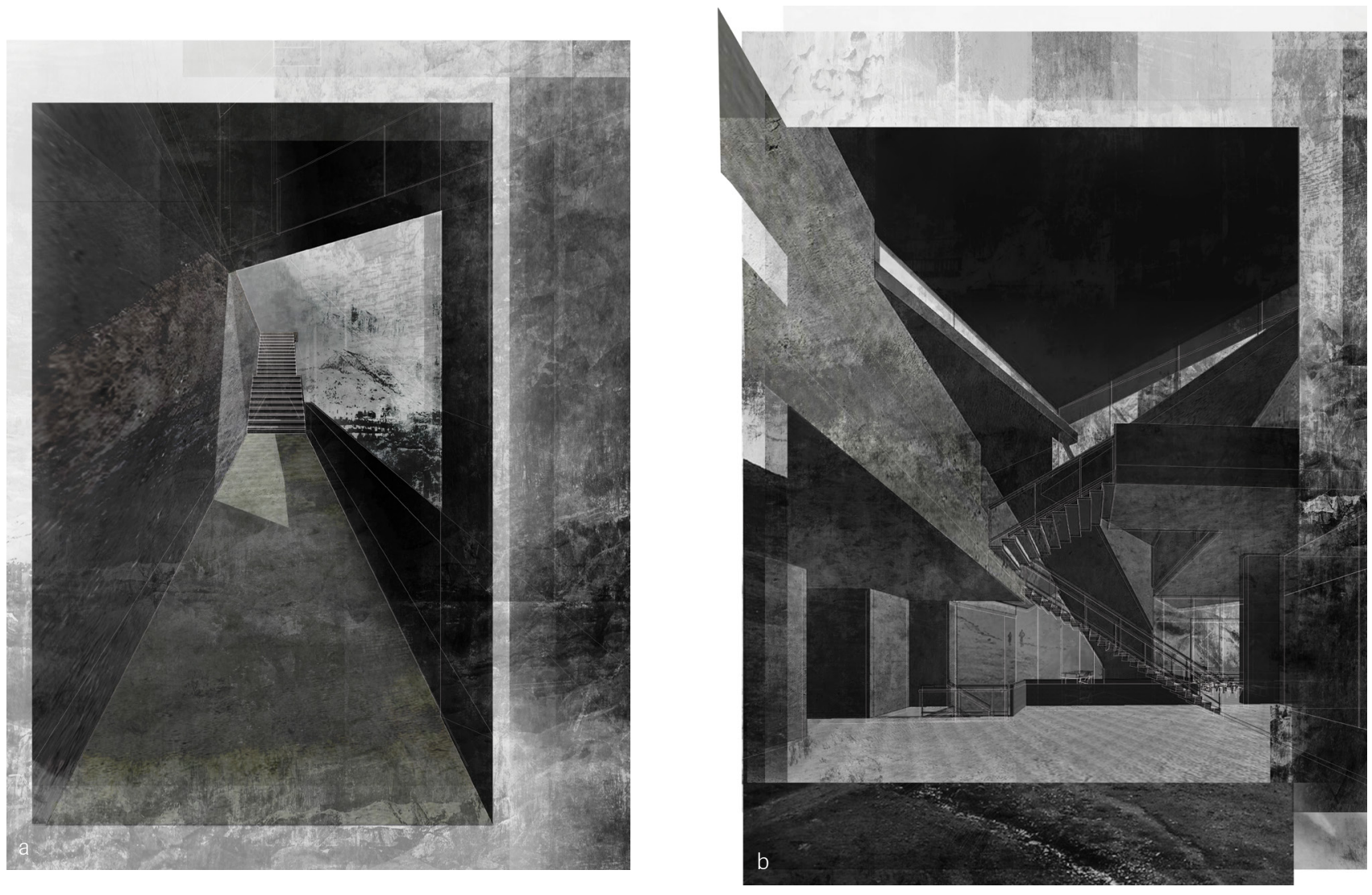

Figure 61: Level 01
a. Entrance
b. Interior

Two masonry walls support the narrow entrance that leads into a large, open living space with a view of the scenic landscape.

Figure 62: Axis Overview Study

$$
\begin{aligned}
& \text { a. Stills } \\
& \text { b. Film }
\end{aligned}
$$

The main axis is the central plane of circulation and works to orient and visually interlock all spaces of the house. This axis was developed through film to understand the spaces' temporal qualities. 

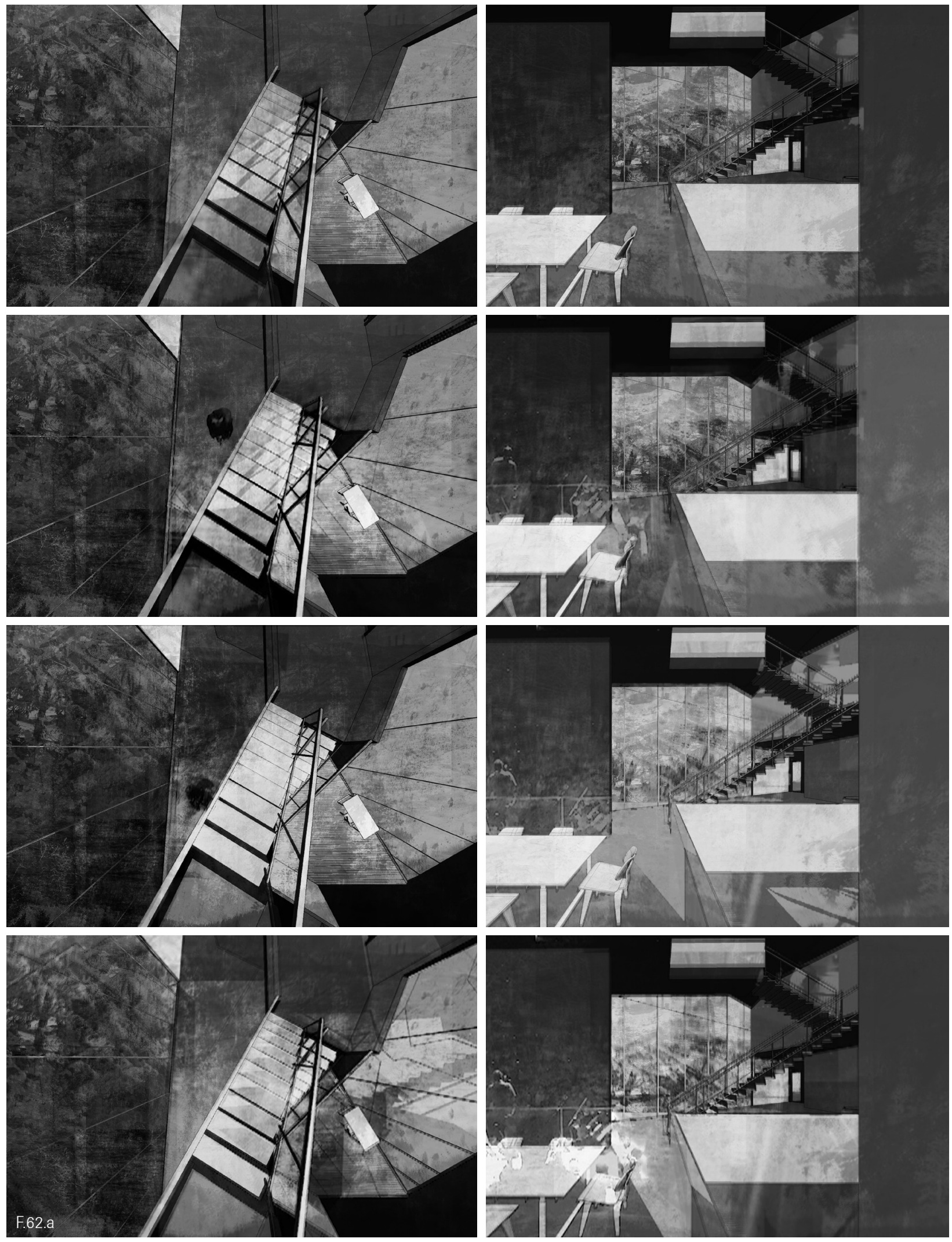


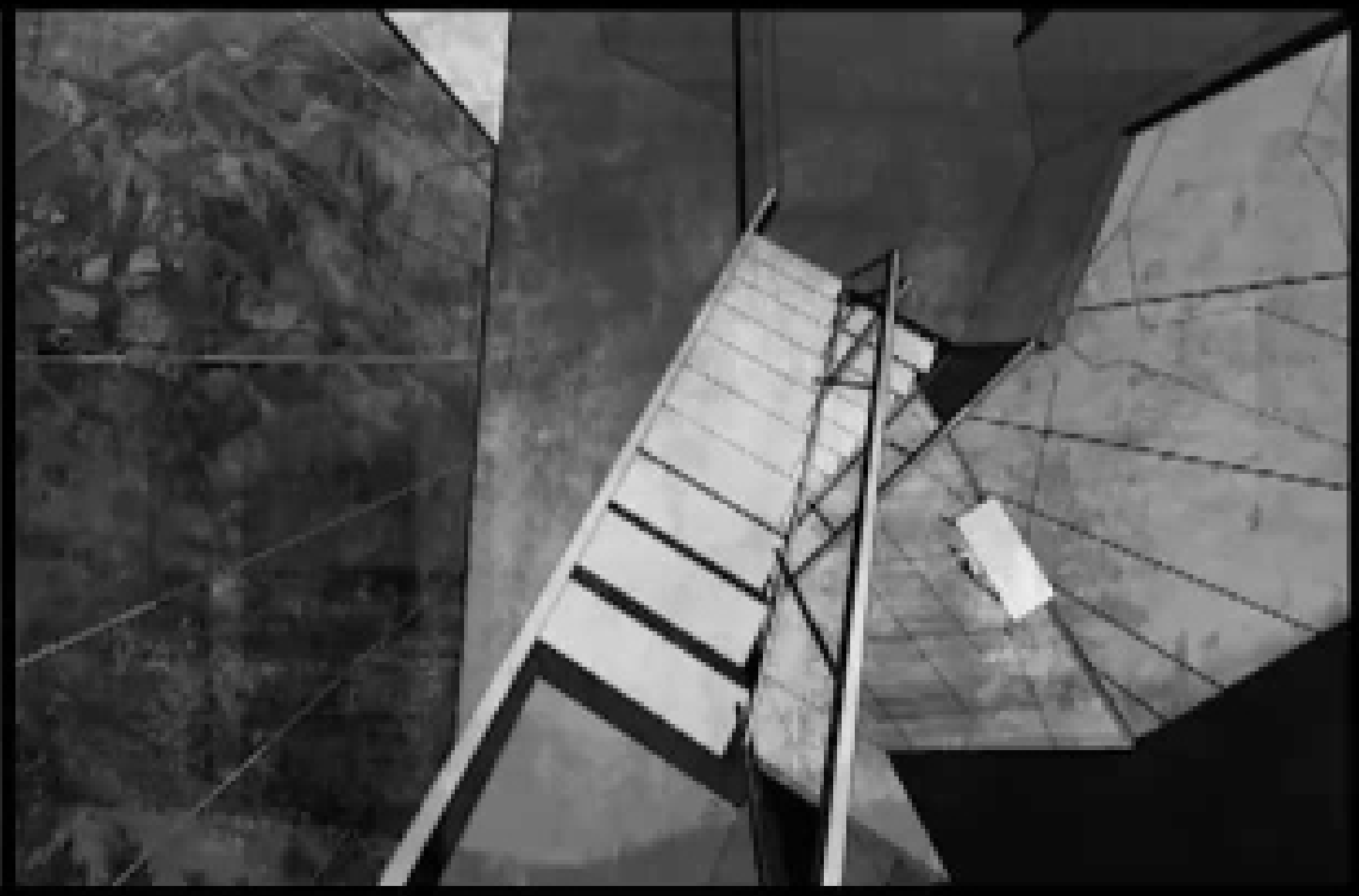




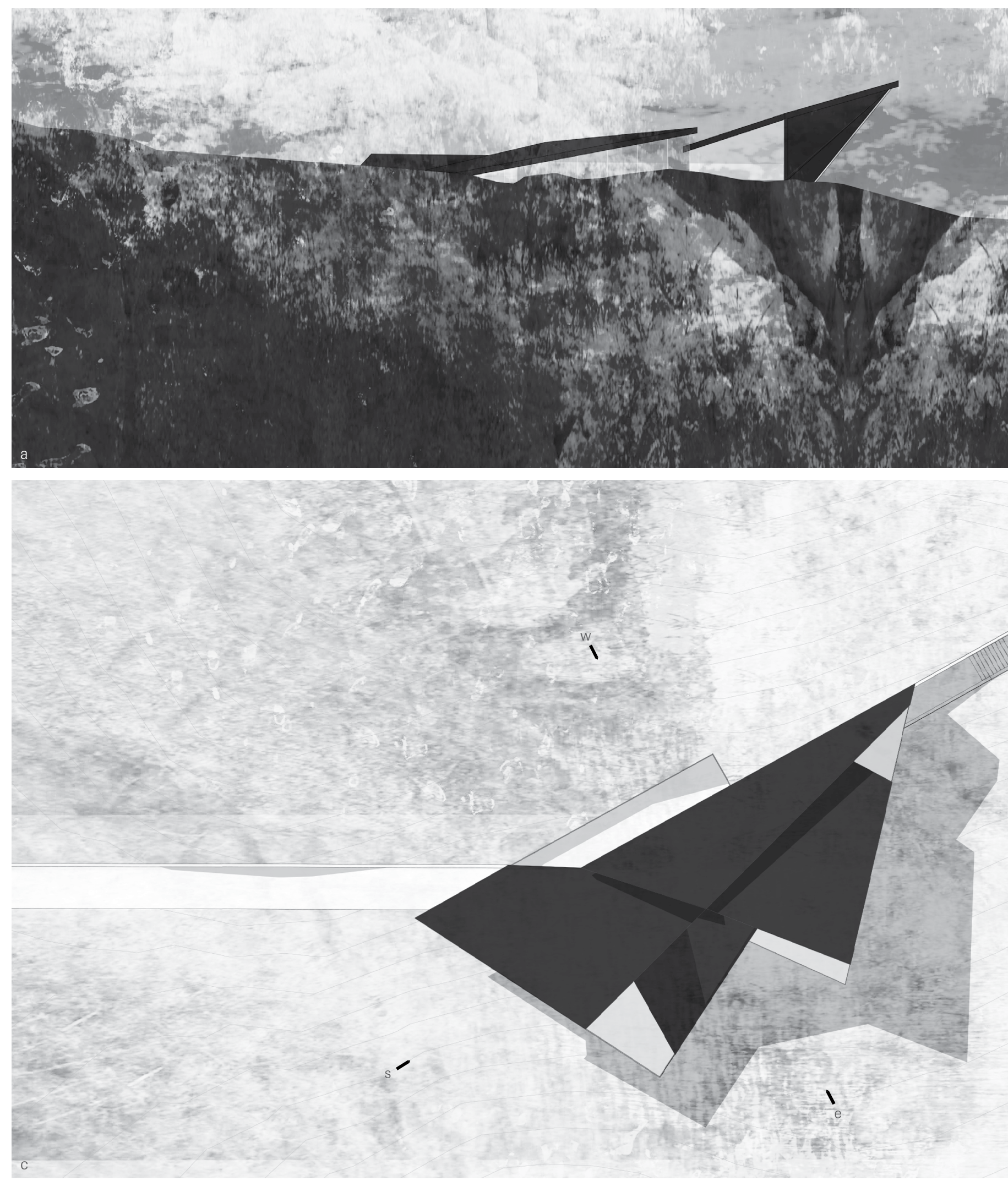




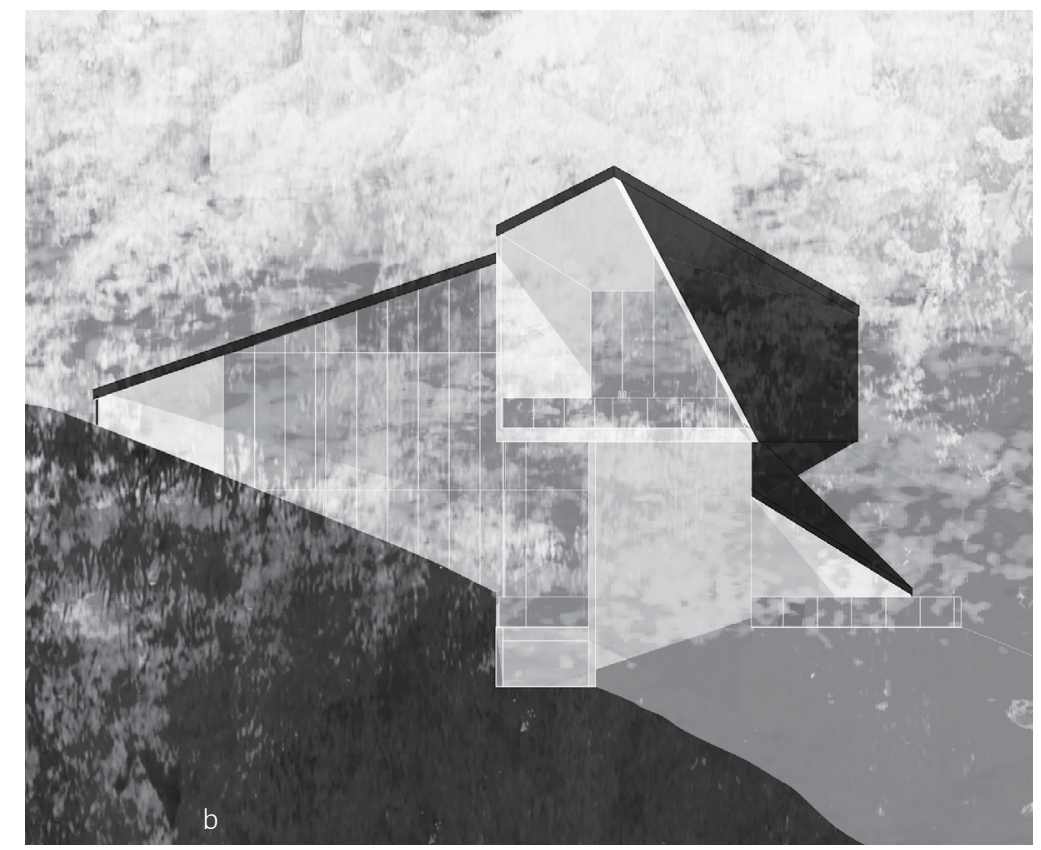

Figure 63: Orthographic Drawings; House 1

Mimicking the sharp and rugged landscape, elements of the dwelling poke out of the landscape; as such, the dwelling hints at but never reveals its full form. The drive is aligned with the dwelling's main axis.
a. West Elevation
b. South Elevation
c. Roof Plan

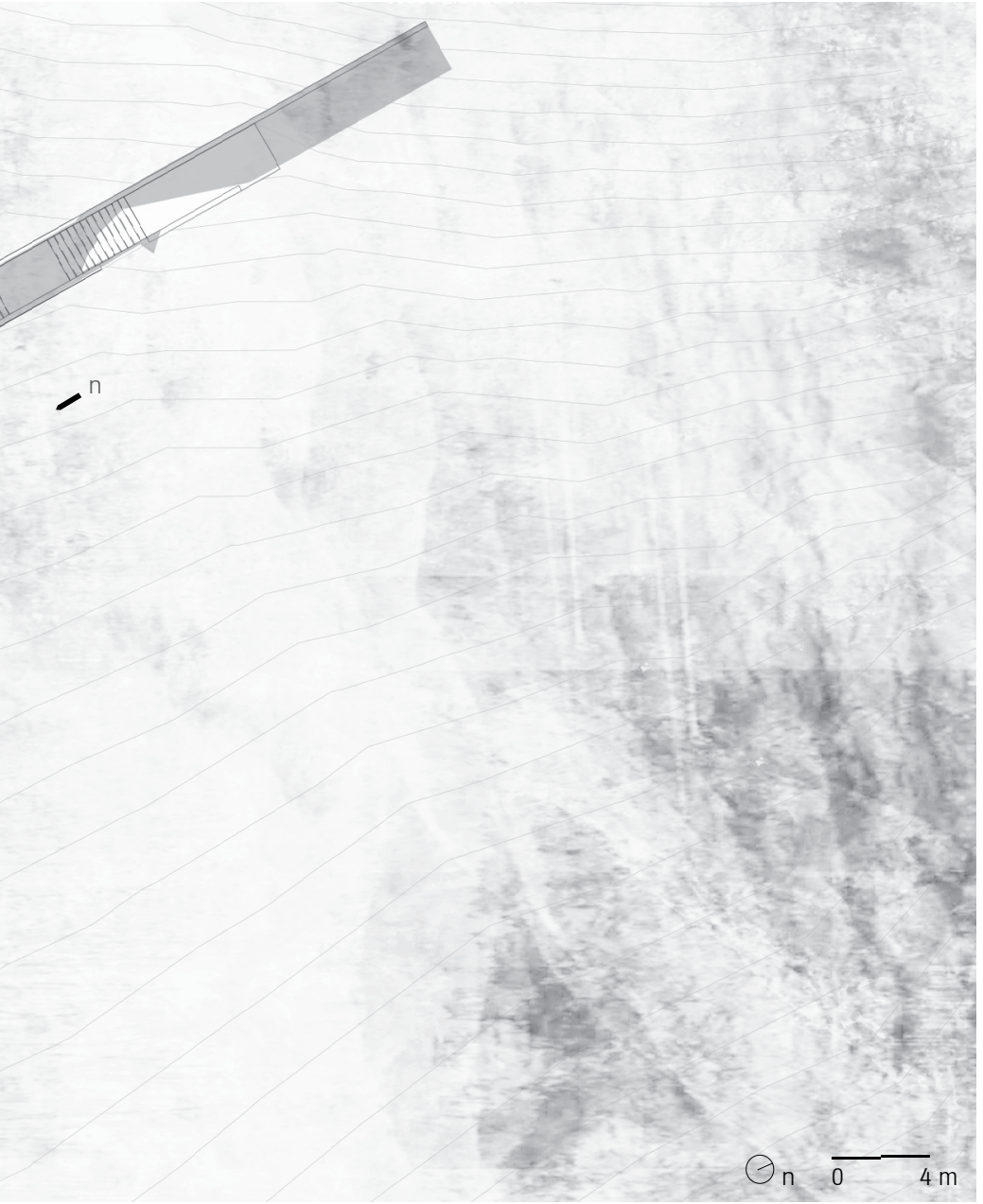



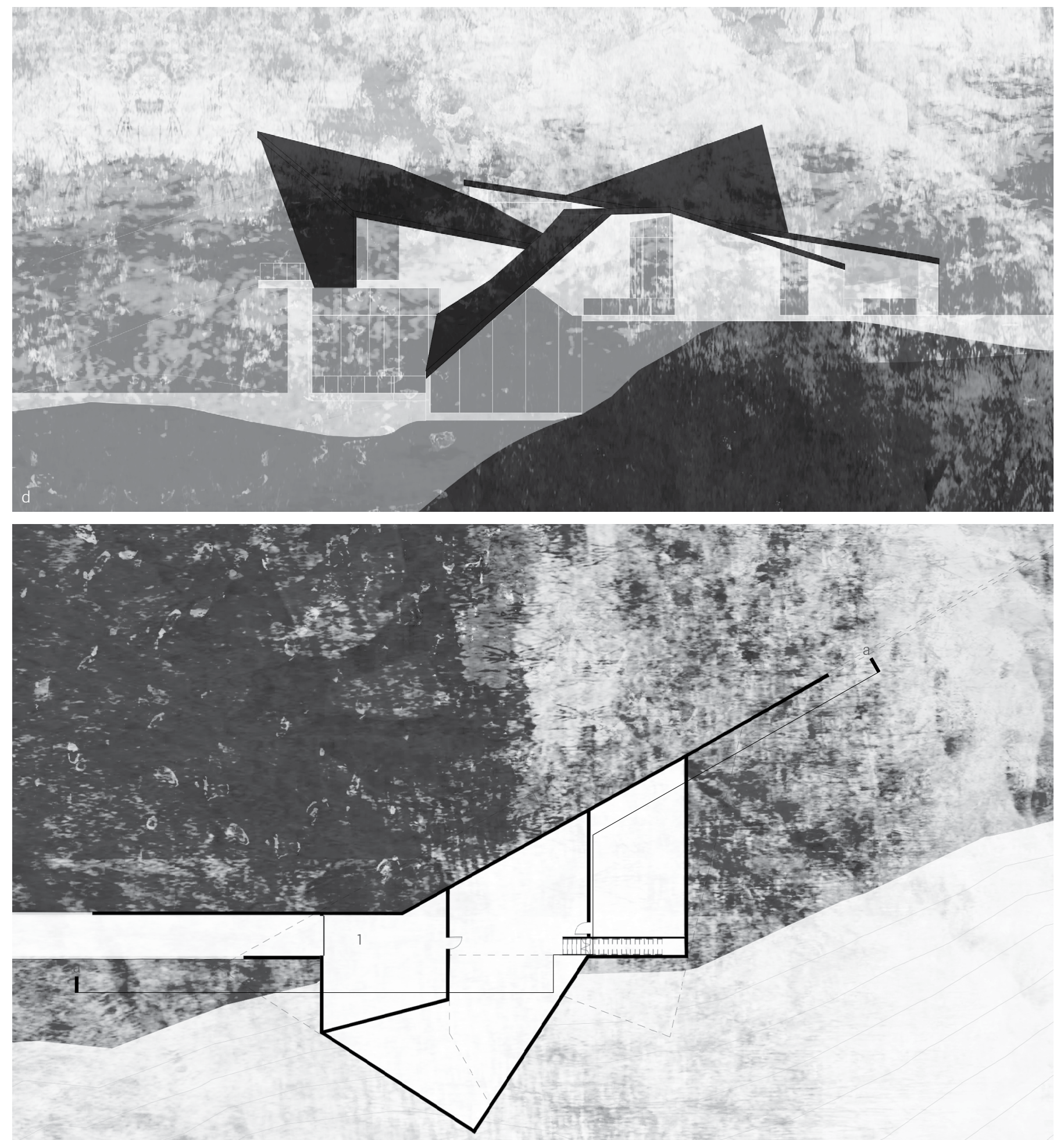


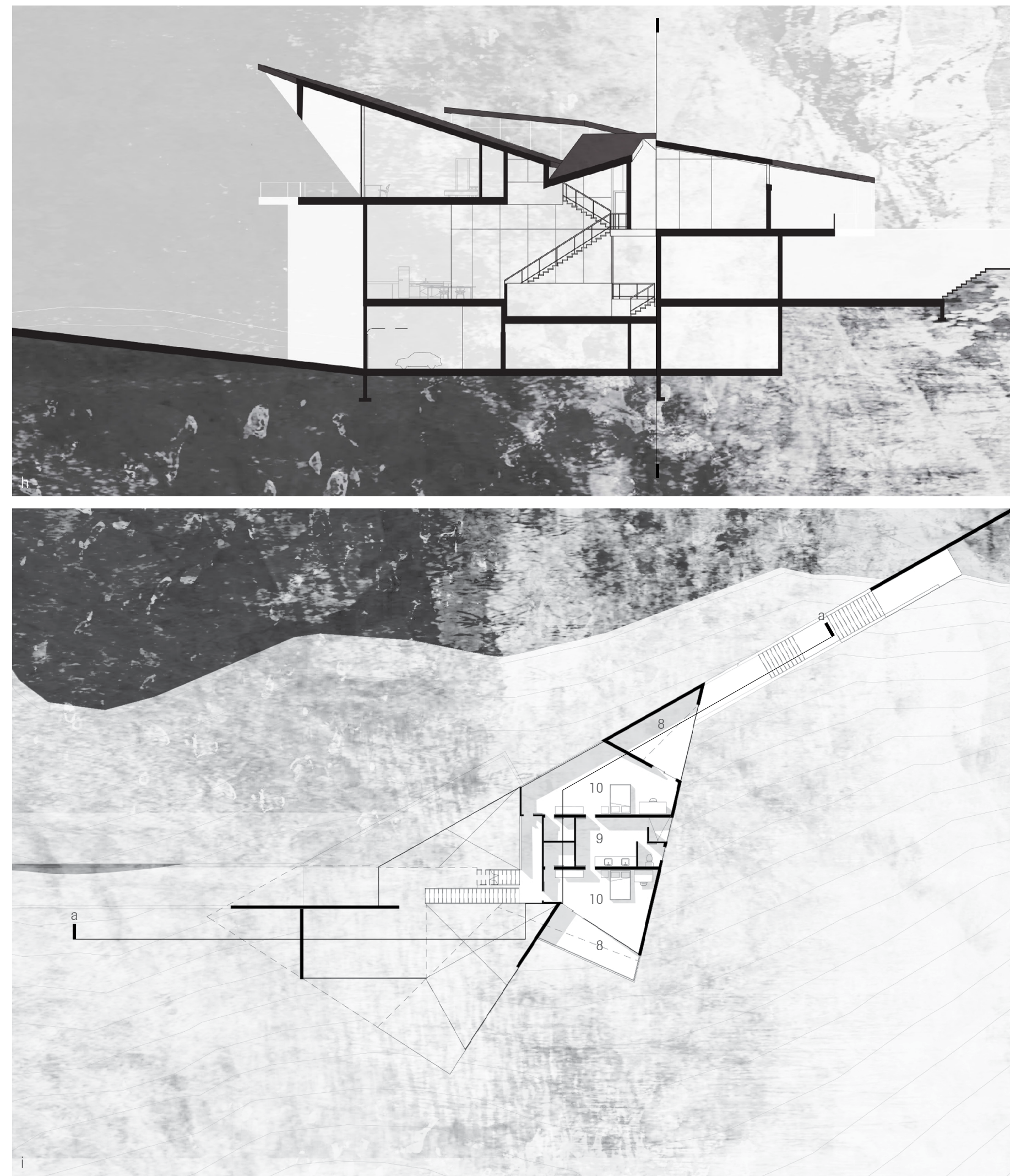


The common mezzanine space of the upper level looks down onto the living and studio areas below. The upper levels host sleeping areas, each with balconies oriented to different views in the landscape.

h. Section aa

i. Level 02

j. Level 03
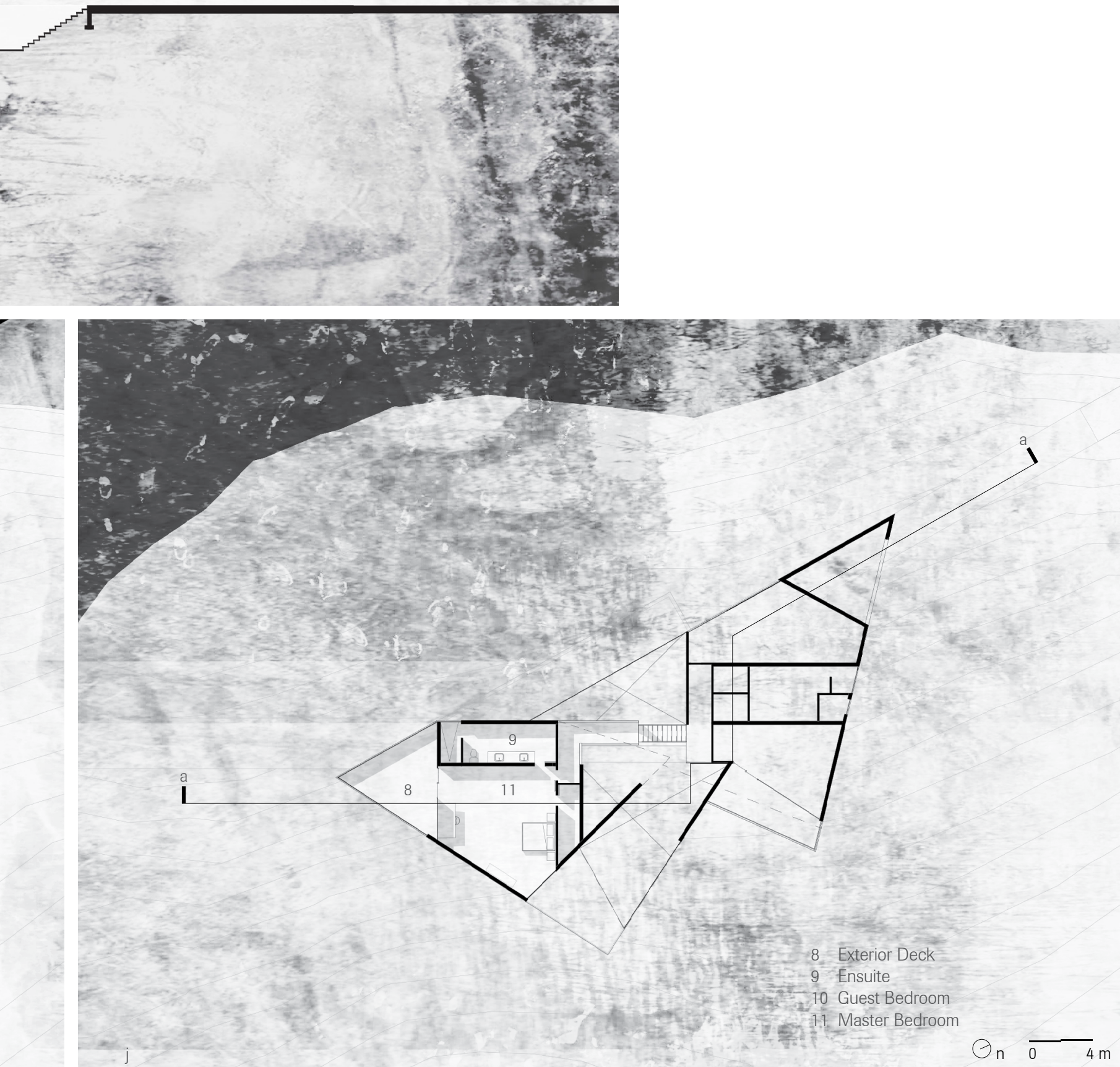


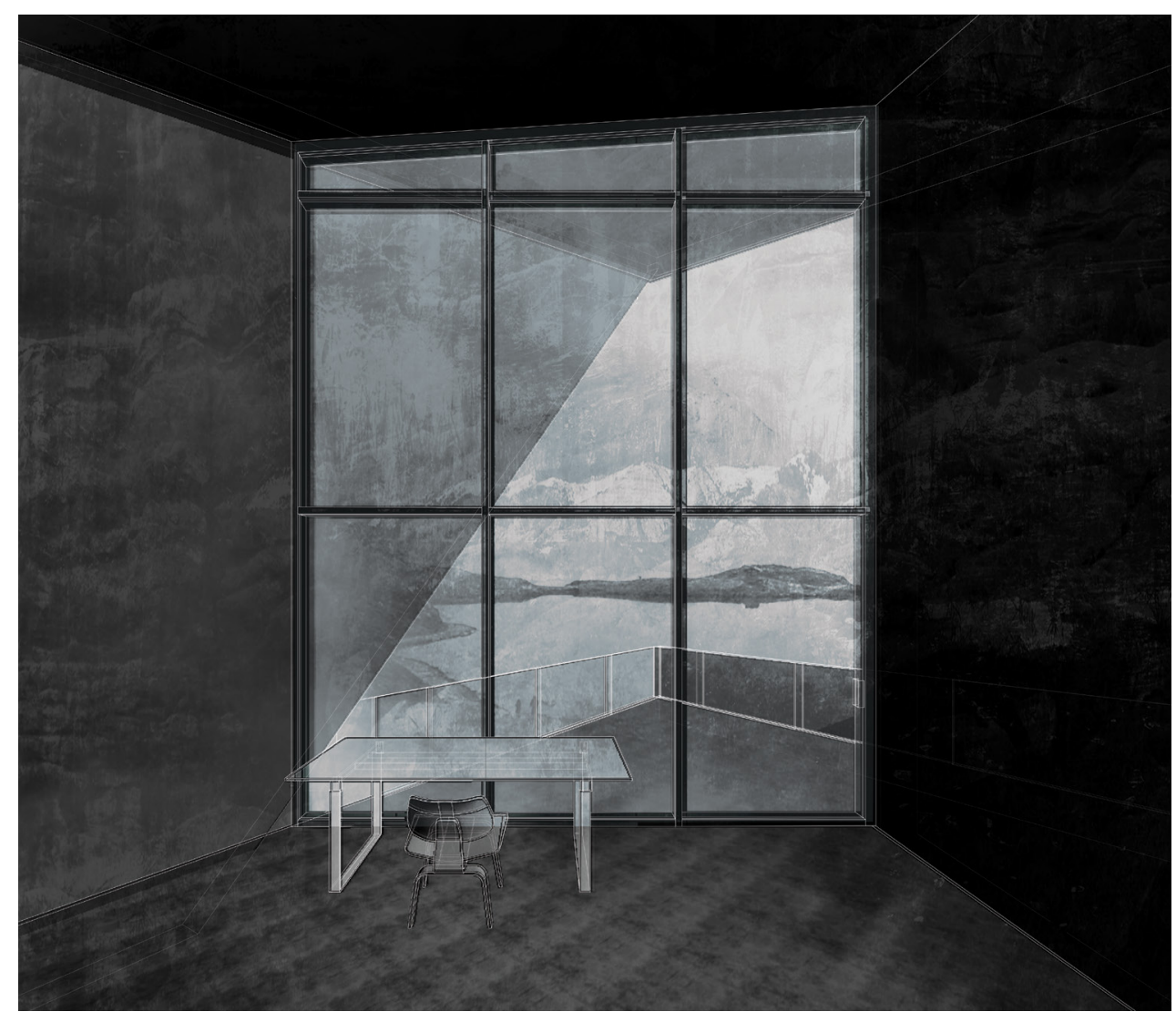

Figure 64: Level 03

The uppermost level cantilevers out into the landscape.

Figure 65: Western Exterior View 


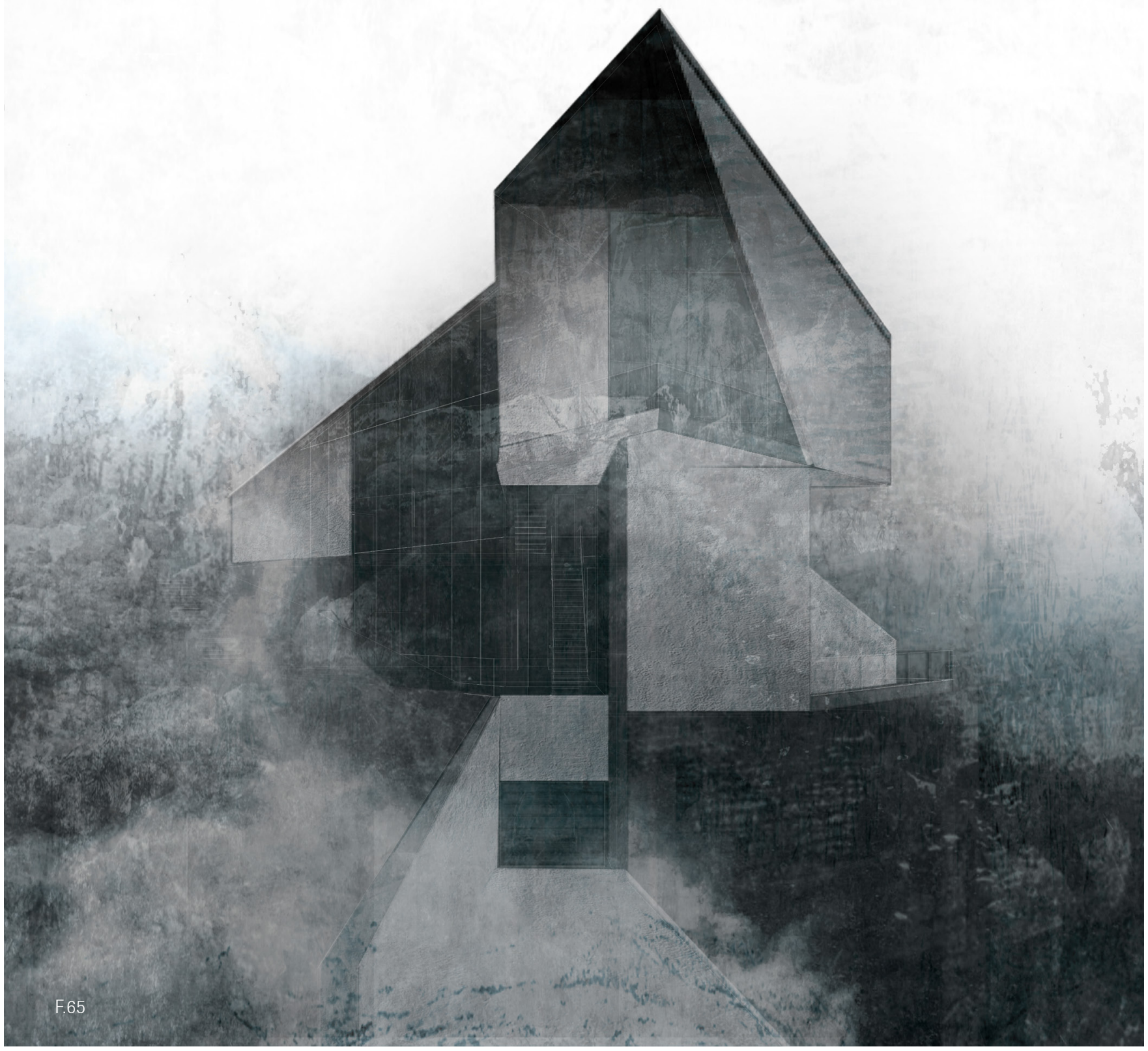



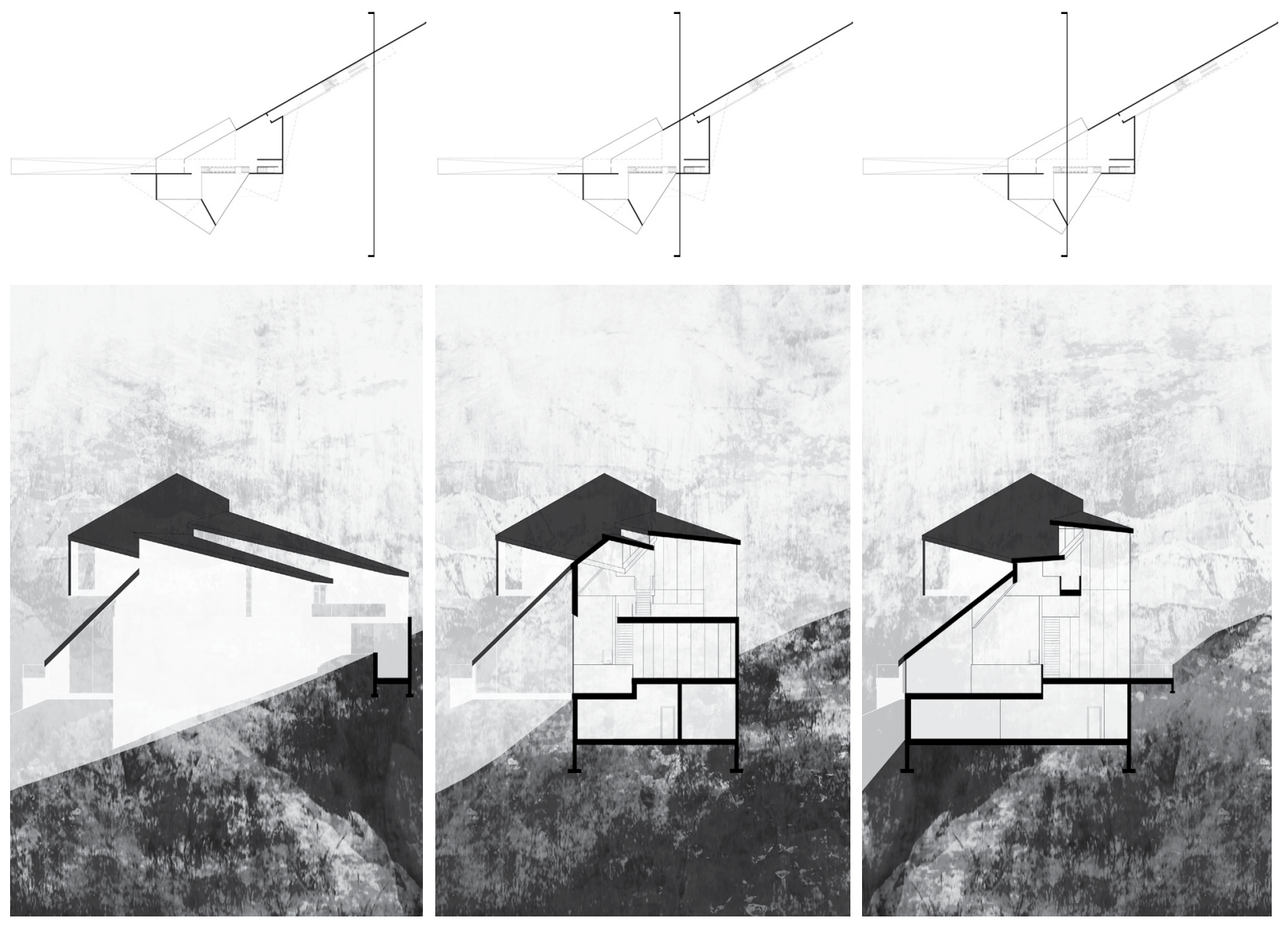

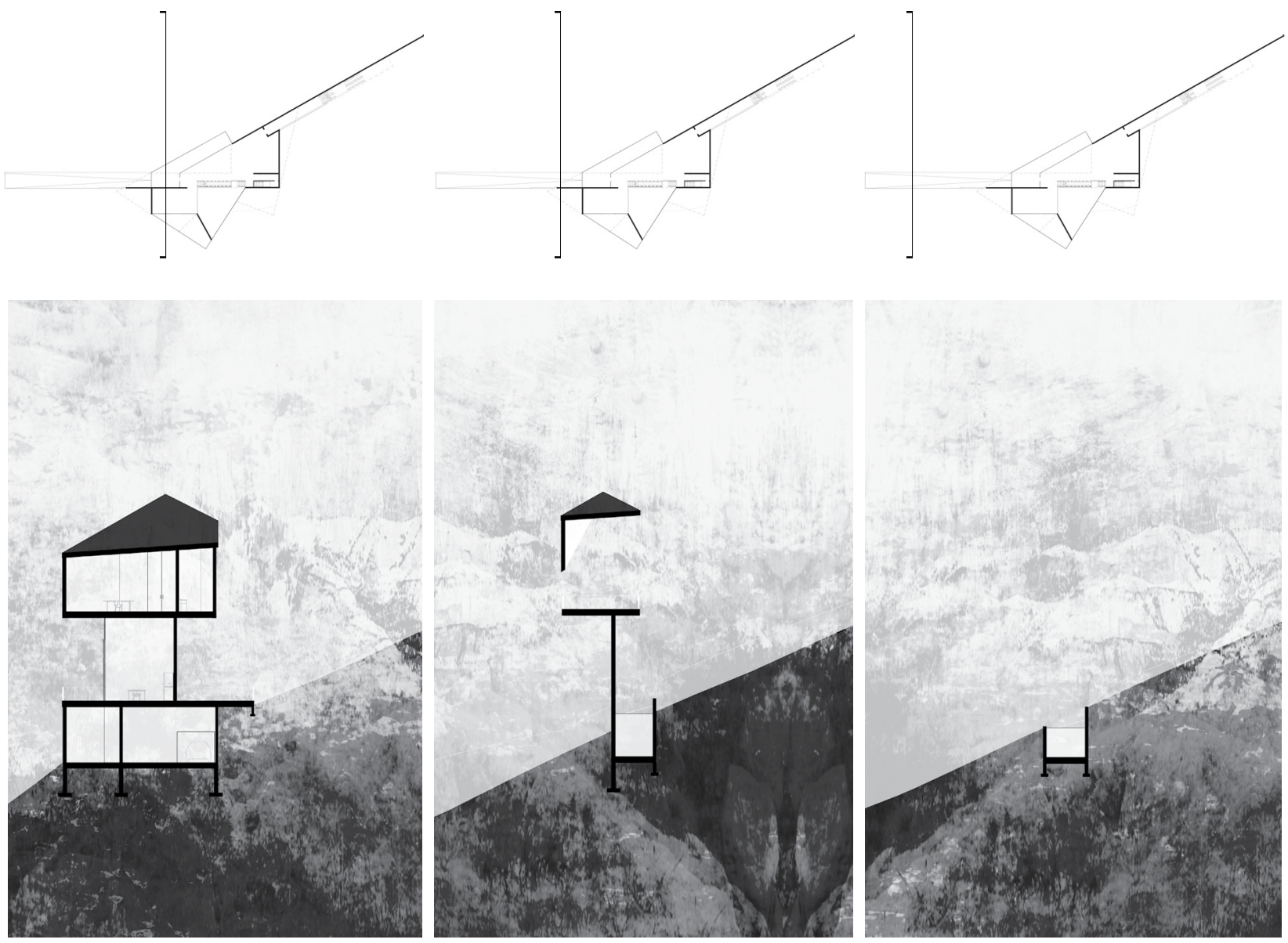

Figure 66: Cross Section Study

0 $6 \mathrm{~m}$

A series of sections were taken along the main axis to explore how the spaces change as the dweller moves through them. The dwelling is relatively compact as the shifting floor plates allow for a perceptible change in the scale of space. The roof is broken into 3 separate components; its planes link multiple elements of the program at once. All roof planes intersect above the central axis. This axis is carried through the dwelling and out into the landscape as a single unifying element from which all program extends and intersects. 


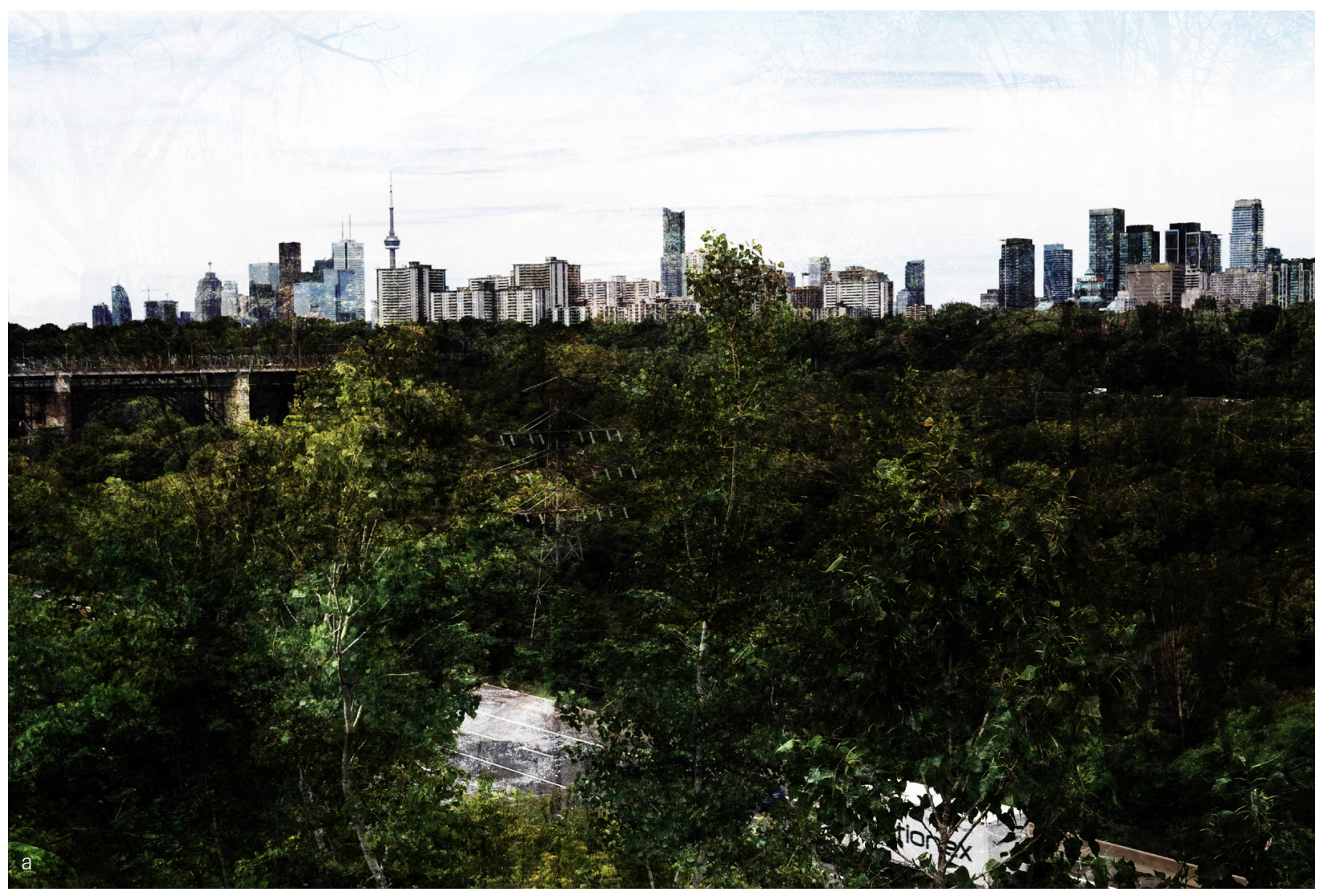




\section{appendix d}

schematic design | House 2

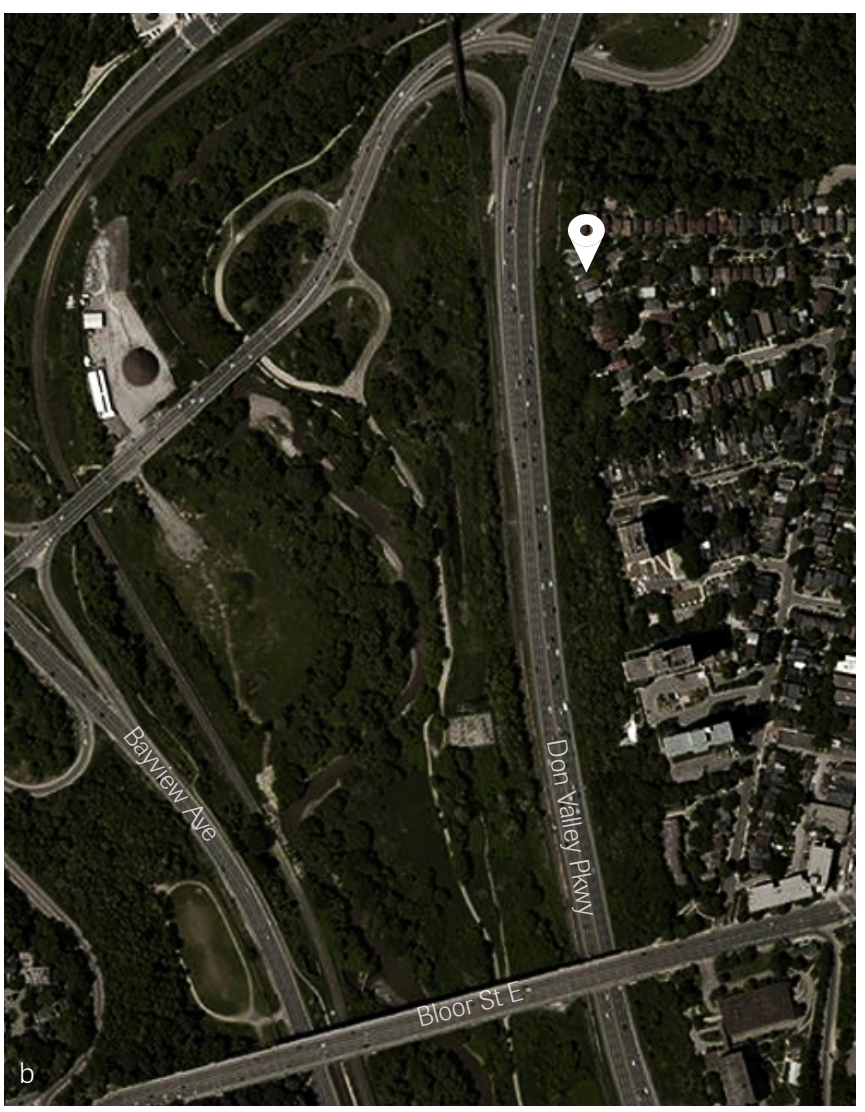

Figure 67: Project Context

a. View; House 2

b. Playter Estates, TO

c. Project Site

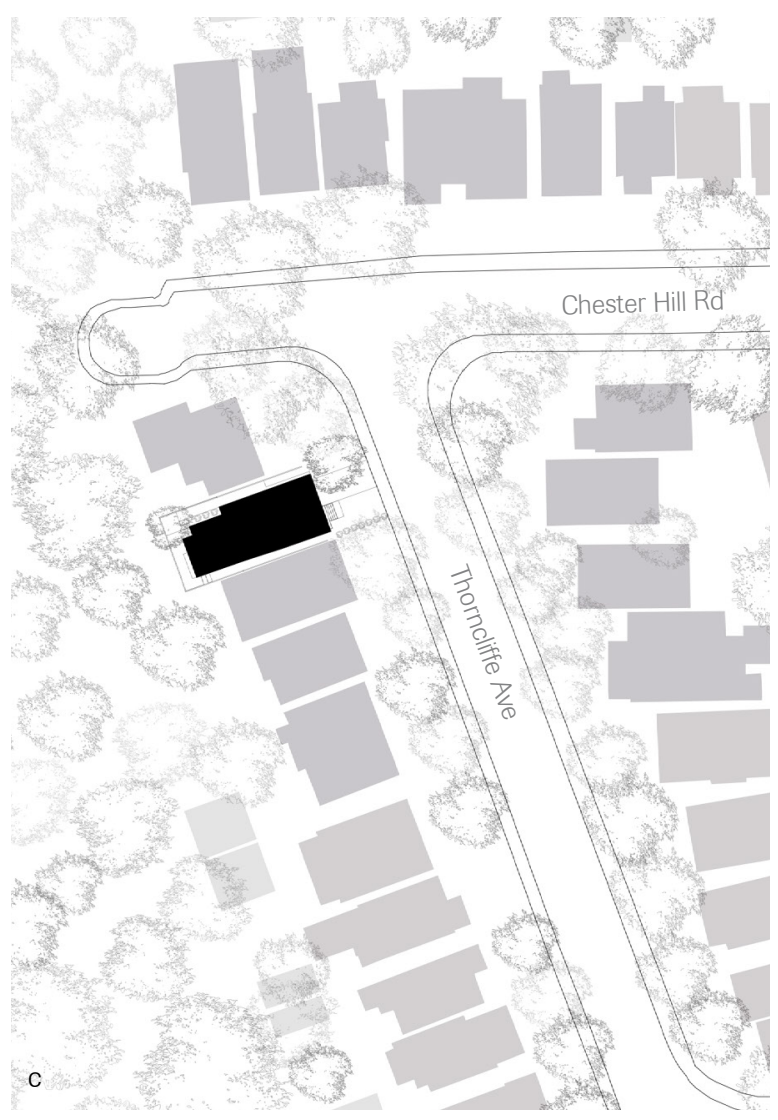

(1) $\mathrm{n} \overline{0}=20 \mathrm{~m}$ 
Figure 68: Voided Axis Study; House 2 This diagram illustrates House 2 in its suburban context, perched over the Don Valley, with its back framing Toronto's skyline. House 2 is more internalized by users than House 1; few interior walls exist, the spaces are visually connected and revolve around the voided axis that divides the house into public and private space. The overriding plane extends through the house as a point of orientation around which all program revolve. 


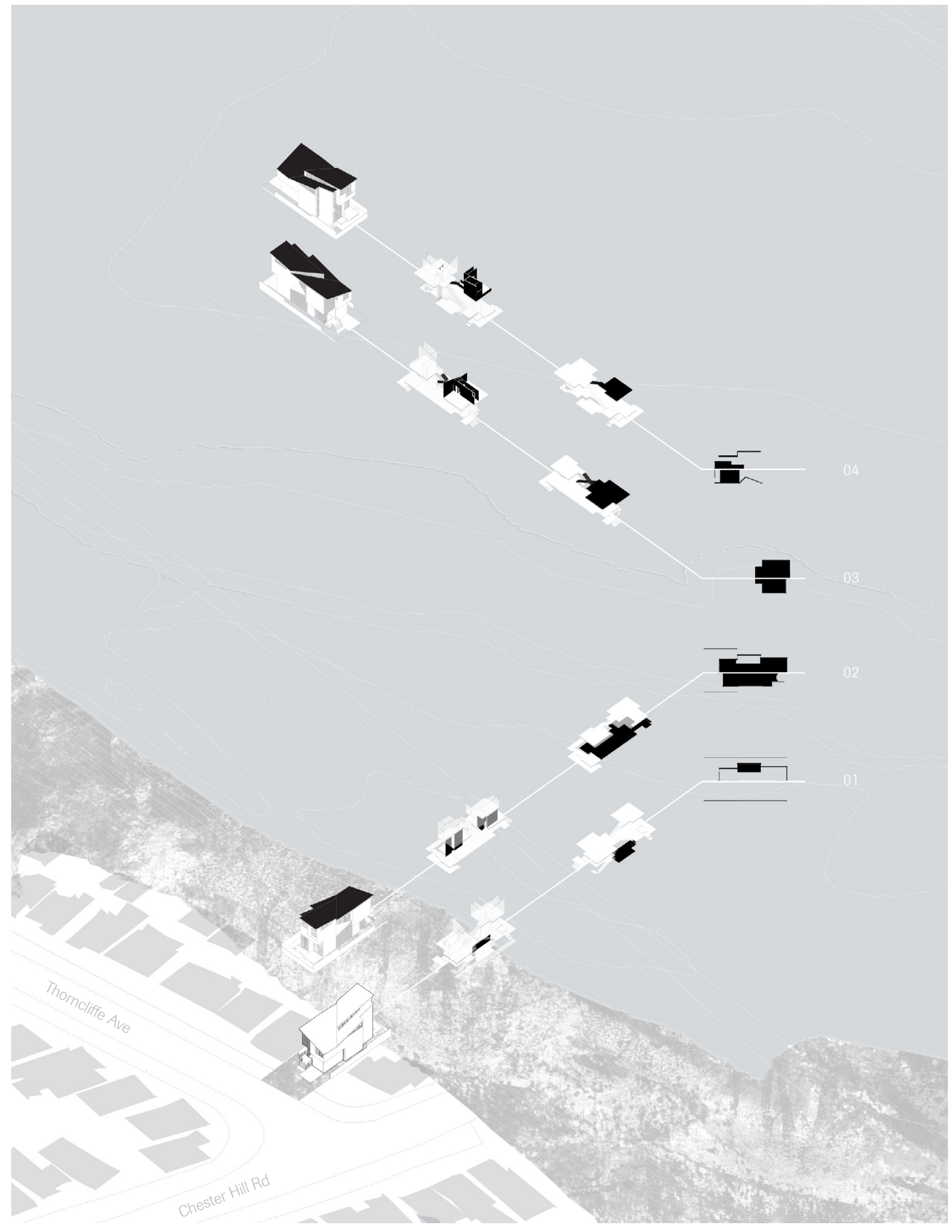



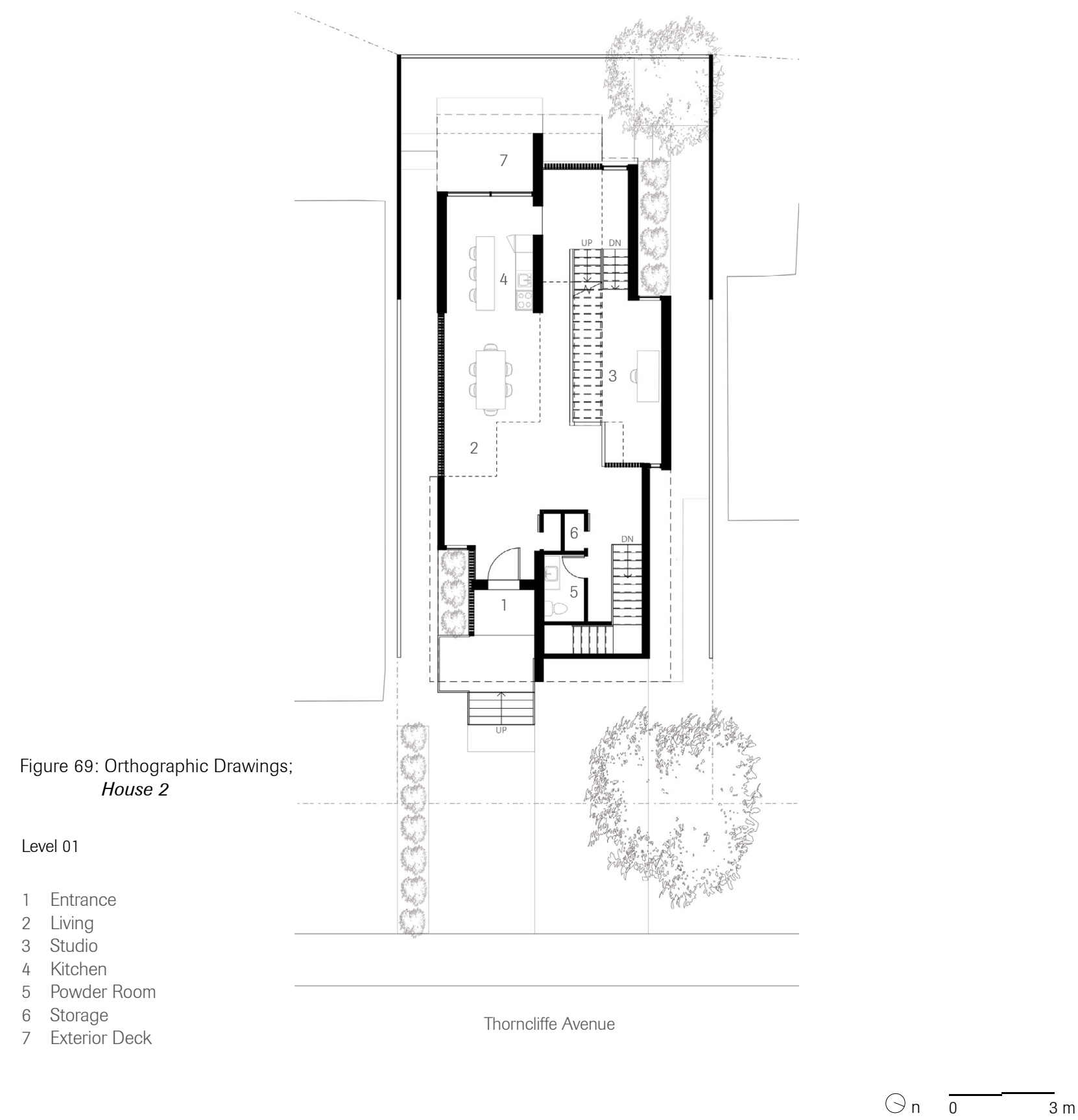


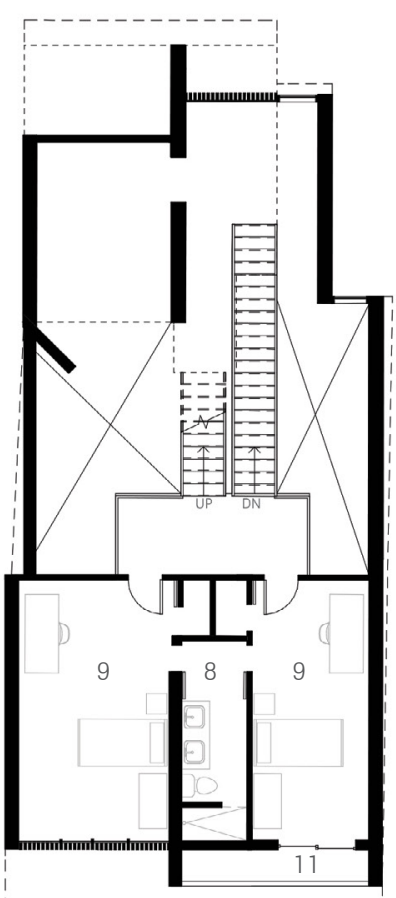

Level 02

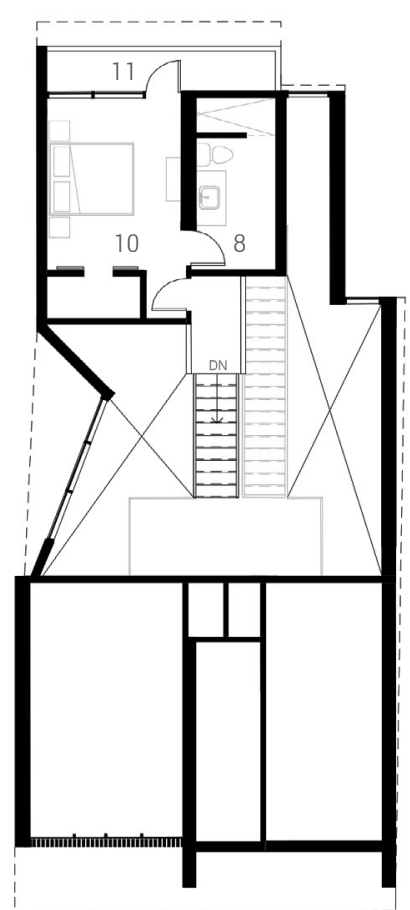

Level 03

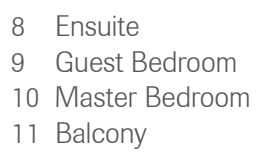

$\theta_{\mathrm{n}} \overline{0} \mathrm{~m}$ 


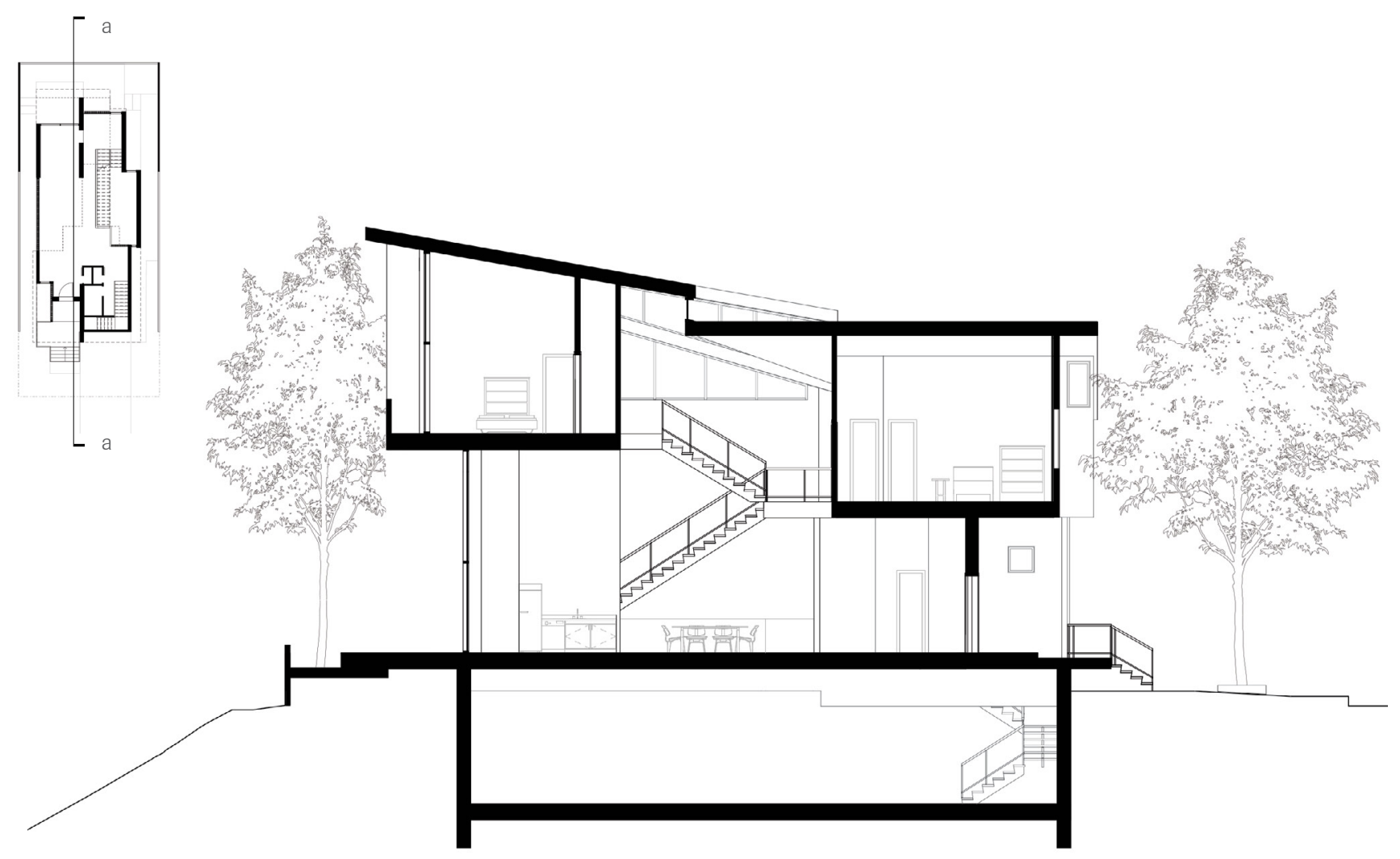

Section aa
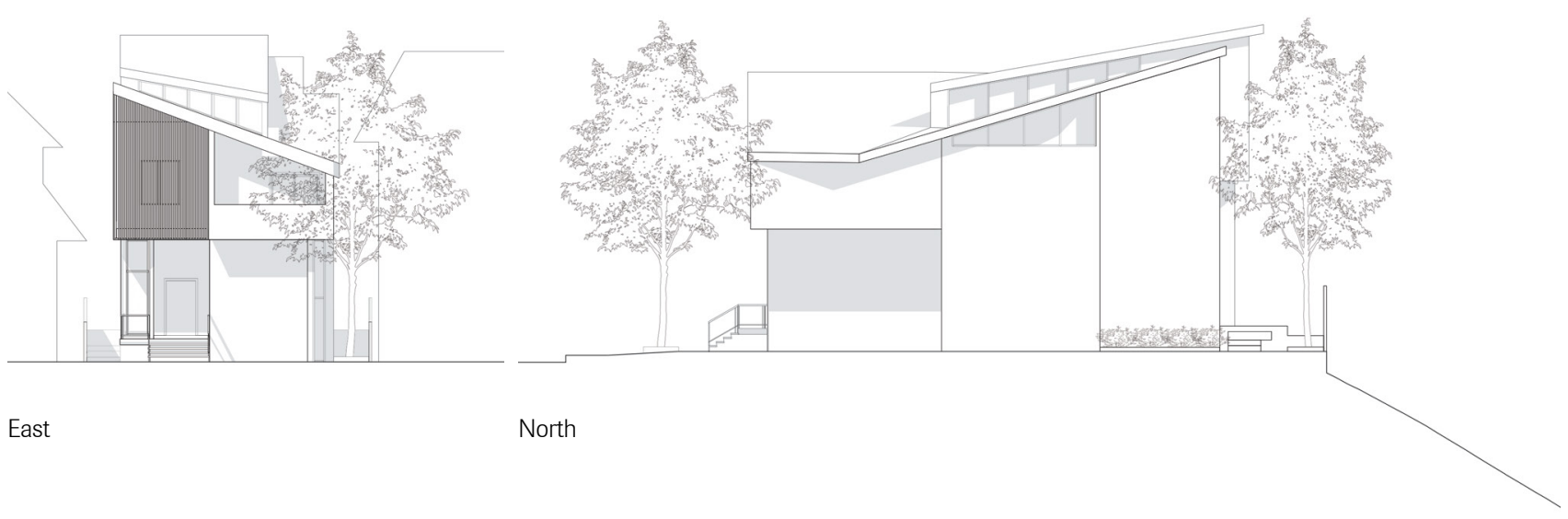

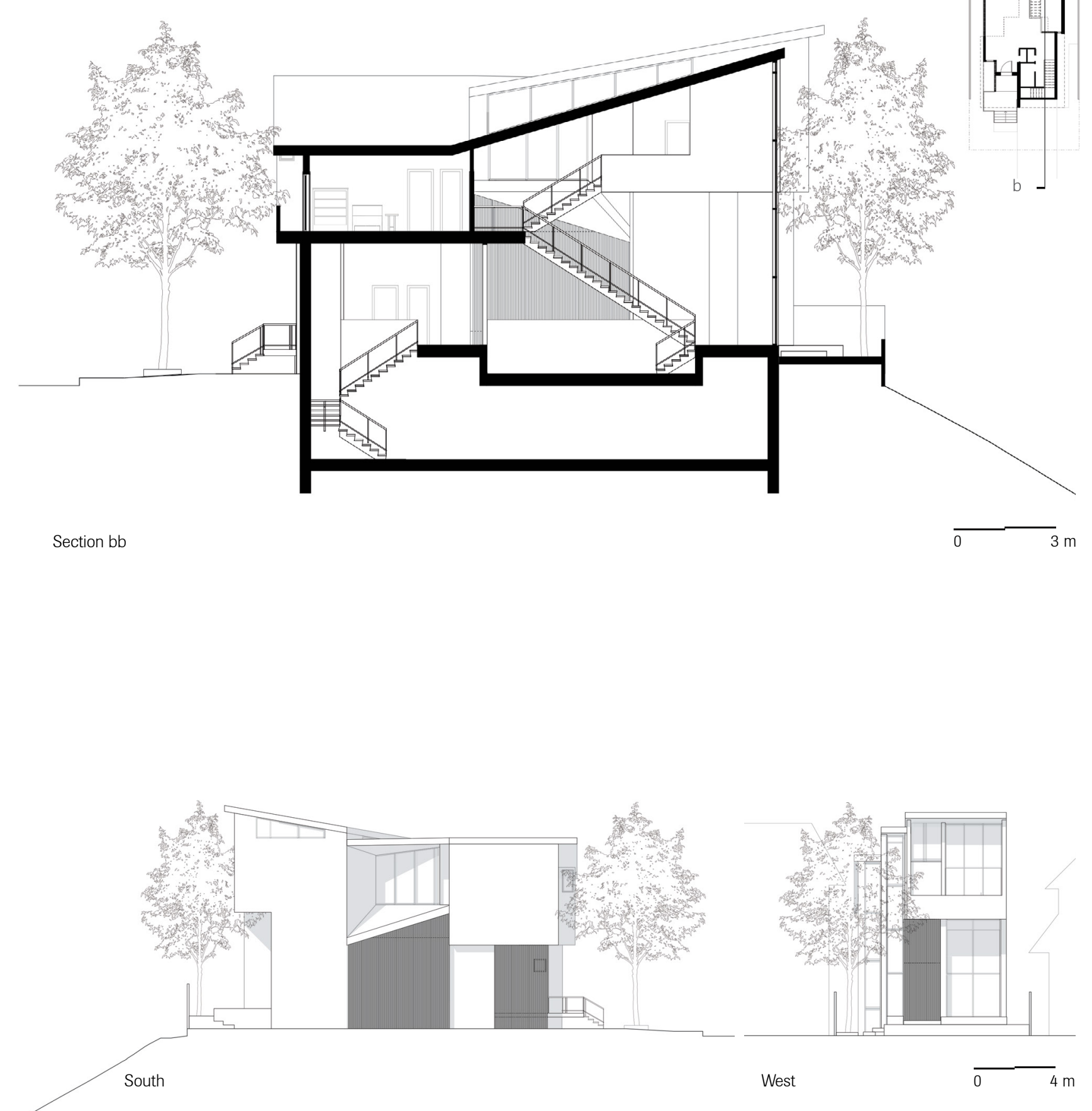


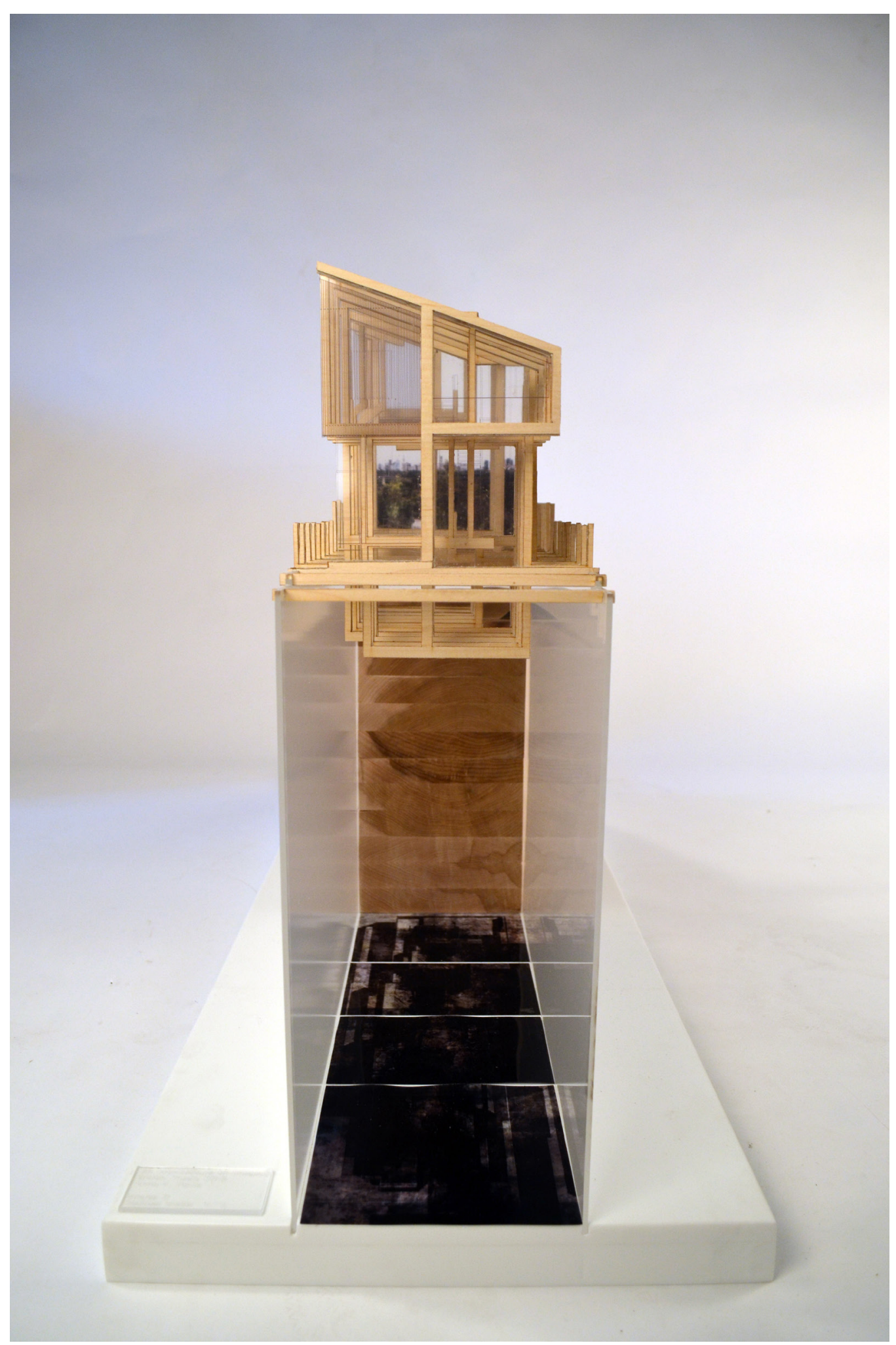



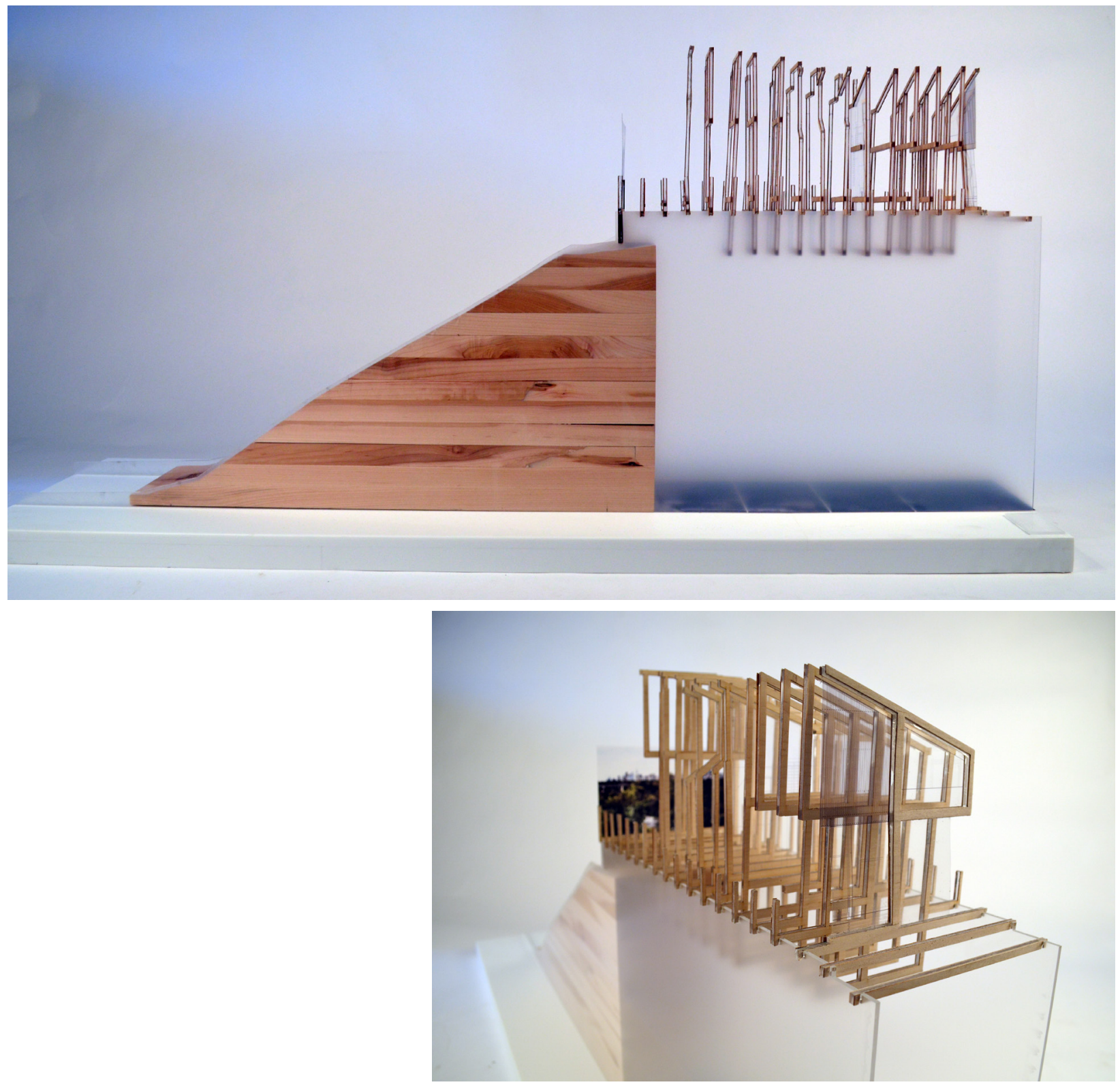

Figure 70: Planar Sections; Physical Model

A sequential arrangement of planes is used to represent the dwelling in its entirety. Several cross sections taken along the main axis distinguish changes of scale within the dwelling. The final section frames the view of Toronto's skyline. 


\section{Bibliography}

Arvidson, P. Sven. "A Lexicon of Attention: From Cognitive Science to Phenomenology." Phenomenology and the Cognitive Sciences 2 (2003): 99-132.

Bader, Aya Peri. "A Model for Everyday Experience of the Built Environment: The Embodied Perception of Architecture." The Journal of Architecture 20, no. 2 (2015): 244-67.

Bachelard, Gaston. The Poetics of Space. Translated by Maria Jolas. New York: Penguin, 1964

Benjamin, Walter. The Work of Art in the Age of Mechanical Reproduction. Translated by J. A. Underwood. London: Penguin, 2008.

Borsi, Franco. Architecture and Utopia. Paris: Hazan, 1997.

Bruno, Giuliana. Atlas of Emotion: Journeys in Art, Architecture, and Film. London: Verso, 2002.

Certeau, Michel de. The Practice of Everyday Life. Translated by Steven Rendall. Berkeley: University of California Press, 1984.

Corbusier, Le and Frederick Etchells, Towards a New Architecture. London: Architectural Press, 1946

Cubitt, Sean. The Cinema Effect. Cambridge: MIT Press, 2004.

Diller, Elizabeth, Ricardo Scofidio, and Georges Teyssot. Flesh: Architectural Probes. New York: Princeton Architectural Press, 1994.

Dimendberg, Edward. Diller Scofidio Renfro: Architecture after Images. Chicago: University of Chicago Press, 2013.

Gibson, James J. The Perception of the Visual World. Boston: Houghton Mifflin, 1950.

Giedion, Sigfried. Building in France, Building in Iron, Building in Ferroconcrete. Santa Monica: Getty Center for the History of Art and the Humanities, 1995.

Greene, Herb. Mind \& Image: An Essay on Art \& Architecture. Lexington: University Press of Kentucky, 1976.

Grütter, Jörg Kurt and Jorg Kurt Grutter. Architektur + Wahrnehmung = Architecture + Perception. Switzerland: Niggli Verlag, 2012.

Hall, Edward T. The Hidden Dimension. Garden City: Doubleday, 1966. 
Holl, Steven, Juhani Pallasmaa, and Alberto Pérez Gómez. Questions of Perception: Phenomenology of Architecture. San Francisco: William Stout Publishers, 2006.

Hugo, Victor. Notre-Dame de Paris: Livre cinquième. Librairie Ollendorff, 1904.

Incerti, Guido, Daria Ricchi, and Deane Simpson. Diller Scofidio (Renfro), the Ciliary Function: Works and Projects, 1979-2007. Milano: Skira, 2007.

Jay, Martin. Downcast Eyes: The Denigration of Vision in Twentieth-century French Thought. Berkeley: University of California Press, 1993.

Lally, Sean and Jessica Young. Softspace: From a Representation of Form to a Simulation of Space. Abingdon, Oxon: Routledge, 2007.

Lefebvre, Henri. The Production of Space. Oxford: Blackwell, 1991.

McLuhan, Marshall. Understanding Media: The Extensions of Man. New York: McGraw-Hill, 1964.

Mennel, Barbara Caroline. Cities and Cinema. London: Routledge, 2008.

Merleau-Ponty, M., James M Edie, and William Cobb. The Primacy of Perception: And Other Essays on Phenomenological Psychology, the Philosophy of Art, History, and Politics. 8th ed. Evanston: Northwestern University Press, 1964.

Milner, Andrew. "Darker Cities." Darker Cities: Urban Dystopia and Science Fiction Cinema. Accessed April 29, 2016. http://ics.sagepub.com/ content/7/3/259.abstract.

Pallasmaa, Juhani. The Architecture of Image: Existential Space in Cinema. Helsinki: Rakennustieto, 2001.

Pallasmaa, Juhani. The Embodied Image: Imagination and Imagery in Architecture. Chichester: John Wiley \& Sons, 2011.

Pallasmaa, Juhani. The Eyes of the Skin: Architecture and the Senses. Chichester: Wiley-Academy, 2005.

Penz, François, and Maureen Thomas. Cinema \& Architecture: Méliès, MalletStevens, Multimedia. London: British Film Institute, 1997.

Rilke, Rainer Maria. The Notebooks of Malte Laurids Brigge. New York: Norton, 1964.

Robinson, Sarah. Nesting: Body, Dwelling, Mind. Richmond: William Stout Publishers, 2011.

Schwarzer, Mitchell. Zoomscape: Architecture in Motion and Media. New York: Princeton Architectural Press, 2004. 
Tuan, Yi-fu. Space and Place: The Perspective of Experience. Minneapolis: University of Minnesota Press, 1977.

Turvey, Malcolm. Doubting Vision: Film and the Revelationist Tradition. Oxford: Oxford University Press, 2008.

Uffelen, Chris Van. Cinema Architecture. Salenstein: Braun, 2009.

Vesely, Dalibor. Architecture in the Age of Divided Representation: The Question of Creativity in the Shadow of Production. Cambridge: MIT Press, 2004.

Vidler, Anthony. Architecture between Spectacle and Use. Williamstown, MA: Sterling and Francine Clark Art Institute, 2008.

Vidler, Anthony. Warped Space: Art, Architecture, and Anxiety in Modern Culture. Cambridge: MIT Press, 2000.

Wollen, Peter. Paris Hollywood: Writings on Film. London: Verso, 2002.

\section{Works Considered}

Adler, Gerald, Timothy Brittain-Catlin, and Gordana Fontana-Giusti. Scale: Imagination, Perception, and Practice in Architecture. London: Routledge, 2012.

Elkins, James. How to Use Your Eyes. New York: Routledge, 2000.

Frascari, Marco, Jonathan Hale, and Bradley Starkey. From Mode/s to Drawings: Imagination and Representation in Architecture. London: Routledge, 2007.

Hamm, Victor M. "The Problem of Form in Nature and the Arts." The Journal of Aesthetics and Art Criticism 13, no. 2 (December 1954): 175.

McGrath, Brian, and Jean Gardner. Cinemetrics: Architectural Drawing Today. Chichester: Wiley-Academy, 2007.

Merleau-Ponty, Maurice. Phenomenology of Perception. Translated by Colin Smith. London: Routledge \& Kegan Paul, 1962 (1981 printing), 1982.

Norberg-Schulz, Christian. Existence, Space \& Architecture. New York: Praeger, 1971.

Ruskin, John, and Joan Evans. The Lamp of Beauty; Writings on Art. London: Phaidon Publishers, 1959.

Vidler, Anthony. The Architectural Uncanny: Essays in the Modern Unhomely. Cambridge: MIT Press, 1992. 

